\title{
Um método para a fusão automática de sentenças similares em português
}

\author{
Eloize Rossi Marques Seno
}


SERVIÇO DE PÓS-GRADUAÇÃO DO ICMC-USP

Data de Depósito:

Assinatura:

\title{
Um método para a fusão automática de sentenças similares em português
}

\author{
Eloize Rossi Marques Seno \\ Orientadora: Profa. Dra. Maria das Graças Volpe Nunes
}

Tese apresentada ao Instituto de Ciências Matemáticas e de Computação - ICMC-USP como parte dos requisitos para obtenção do título de Doutor em Ciências - Ciências de Computação e Matemática Computacional.

USP - São Carlos

Abril de 2010 
Aos meus pais Mário Ari e María Cecília

Ao men esposo Wesley 
"Nunca deixe que lhe digam que não vale a pena acreditar nos sonhos que se tem ou que os seus planos nunca vão dar certo ou que você nunca vai ser alguém. Tem gente que machuca os outros, tem gente que não sabe amar, mas eu sei que um dia a gente aprende. Se você quiser alguém em quem confiar, confia em si mesmo. Quem acredita sempre alcança."

Renato Russo. 


\section{AGRADECIMENTOS}

A Deus pela força e coragem para vencer cada obstáculo sem desistir ou desanimar.

Aos meus pais Mário Ari e Maria Cecília pelo amor incondicional e por terem suportado a minha ausência durante esses anos todos.

As minhas irmãs Ariele e Amanda, que não tenho palavras pra dizer o que representam pra mim.

Ao meu esposo Wesley, o grande amor da minha vida, pelo apoio, exemplo de vida e por ser tudo aquilo o que se espera de um grande companheiro.

Aos meus segundo pais José Roberto e Maria Cecília e a minha terceira irmã Larissa pelo carinho, amizade e apoio dispensados.

A Graça, minha orientadora, pelo profissionalismo, otimismo e paciência com que me orientou durante esses anos, e pela amizade.

Aos colegas do NILC pelos momentos de descontração, pelos cafés e bate-papos nada produtivos, pela amizade e pelas discussões científicas tão relevantes. Em especial a Ariane, Arnaldo, Carol, Claudinha, Erick, Magali e Thiago pelas contribuições tão valiosas para este trabalho.

A amiga e ex-orientadora Lúcia Rino, que foi uma das responsáveis por começar toda essa história. Obrigada pela amizade e respeito.

Ao CNPq pelo apoio financeiro e a USP e ao NILC pelas instalações.

A todos aqueles que cruzaram o meu caminho nesses quase cinco anos e que me incentivaram, me ajudaram ou que simplesmente me ouviram.

Muito obrigada! 


\section{ÍNDICE GERAL}

INTRODUÇÃO ........................................................................................ 1

1.1 Contexto e Motivação..................................................................................................1 1

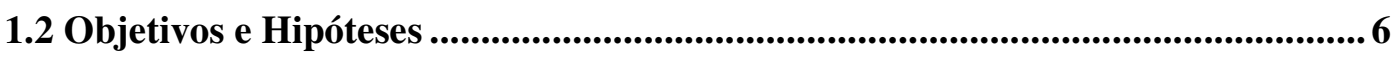

1.3 Organização do Texto ........................................................................................................8

MODELO BÁSICO DE FUSÃo AUTOMÁTICA E MÉTODOS DE AVALIAÇÃO

2.1 Arquitetura Básica de um Modelo de Fusão Sentencial ....................................... 10

2.2 Métodos de Avaliação ........................................................................................... 13

2.3 Considerações Finais...................................................................................................... 15

TRABALHOS RELACIONADOS ................................................................. 16

3.1 Modelos de Fusão Sentencial ............................................................................16

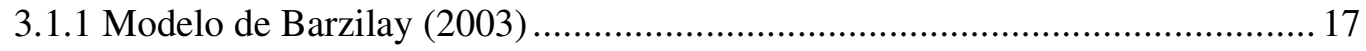

3.1.2 Modelo de Marsi \& Krahmer (2005) ........................................................ 26

3.1.3 Modelo de Fillipova \& Strube (2008) …..................................................... 28

3.2 Modelos de Geração de Paráfrases.....................................................................333

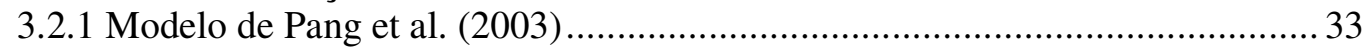

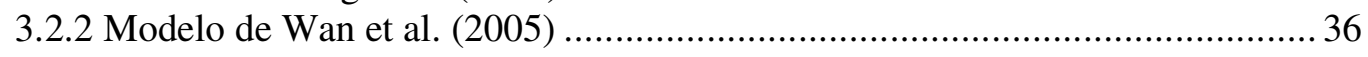

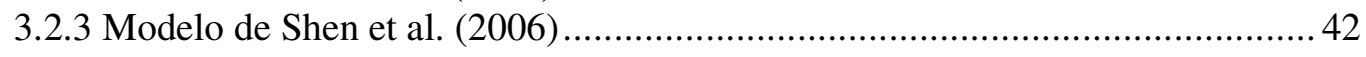

3.3 Considerações Finais............................................................................................ 45

CONSTRUÇÃO DO CORPUS DE TRABALHO ........................................... 47

4.1 SiSPI: Um Sistema para Identificação e Agrupamento de Sentenças Similares ................................................................................................................................. 49

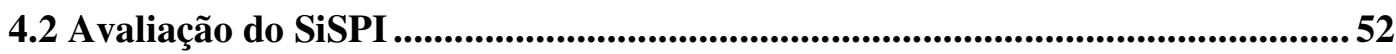

4.2.1 Corpus de Avaliação ............................................................................... 52

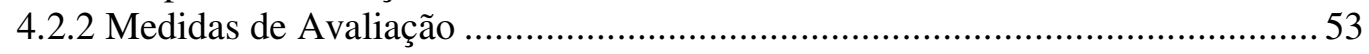

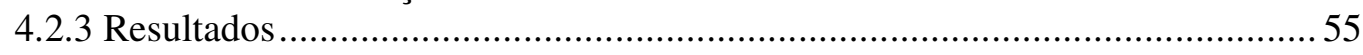

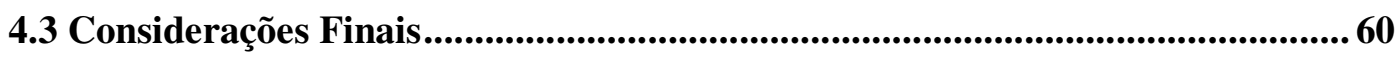

UM MÉTODO PARA A FUSÃO AUTOMÁTICA DE SENTENÇAS EM PORTUGUÊS.............................................................................................. 61

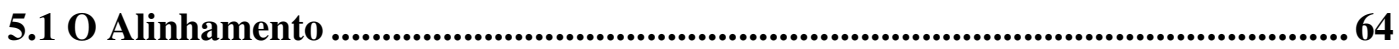

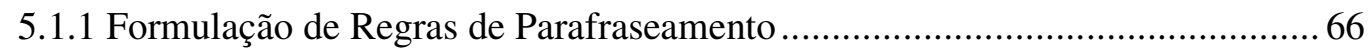


5.1.2 Estratégia de Alinhamento................................................................. 71

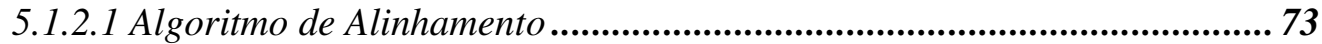

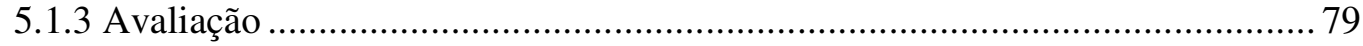

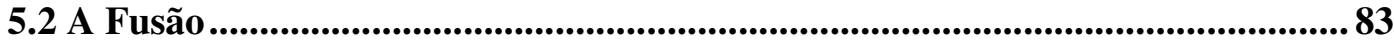

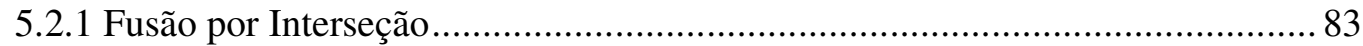

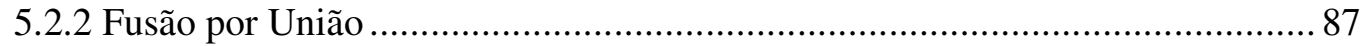

5.3 A Linearização ...................................................................................................................94

5.4 Considerações Finais...................................................................................................... 101

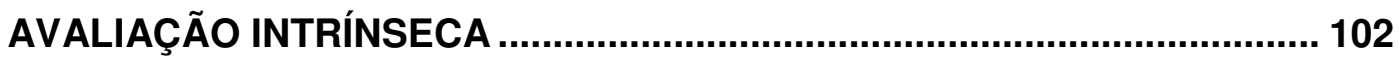

6.1 Sobre os Corpora de Avaliação ....................................................................... 102

6.2 Análise de Seleção de Conteúdo............................................................................ 104

6.2.1 Construção dos Corpora de Referência ...................................................... 105

6.2.2 Resultados da Análise de Seleção de Conteúdo na Fusão por Interseção ........ 107

6.2.3 Resultados da Análise de Seleção de Conteúdo na Fusão por União .............. 109

6.3 Análise de Gramaticalidade e Semanticidade ................................................ 112

6.3.1 Resultados da Análise de Gramaticalidade e Semanticidade na Fusão por

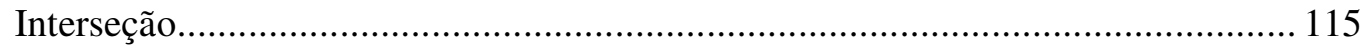

6.3.2 Resultados da Análise de Gramaticalidade e Semanticidade na Fusão por União

6.4 Análise de Representatividade................................................................................. 121

6.4.1 Resultados da Análise de Representatividade na Fusão por Interseção........... 123

6.4.2 Resultados da Análise de Representatividade na Fusão por União ................. 124

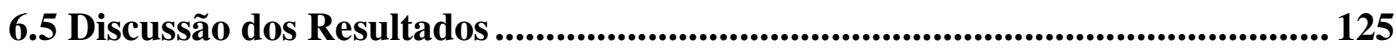

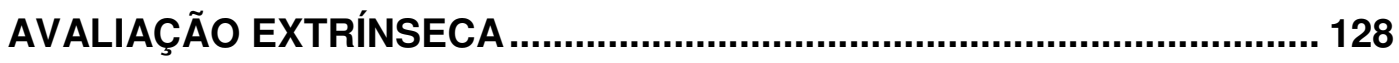

7.1 Metodologia de Avaliação ............................................................................ 130

7.2 Resultados da Avaliação Extrínseca ............................................................. 133

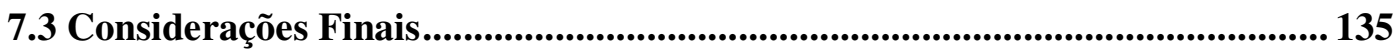

CONCLUSÕES ........................................................................................ 136

8.1 Principais Contribuições............................................................................................ 138

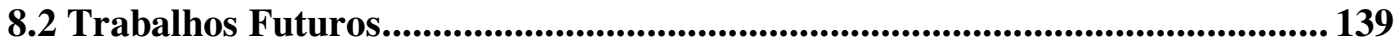

REFERÊNCIAS BIBLIOGRÁFICAS ...................................................... 142

APÊNDICE I - REGRAS DE PARAFRASEAMENTO ................................ 150 
ANEXO A - COLEÇÃO DE TEXTOS COMPARÁVEIS .............................. 152

ANEXO B - EXEMPLO DE ANÁLISE PRODUZIDA PELO PARSER

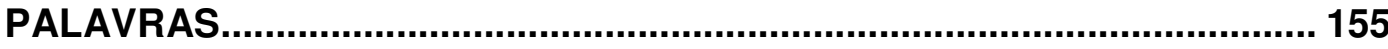




\section{ÍNDICE DE FIGURAS}

Figura 1: llustração do processo geral de fusão de sentenças proposto por Barzilay (2003)

Figura 2: Alinhamento de duas árvores de dependências sintáticas

(Barzilay \& Mckeown, 2005; pág. 308) 20

Figura 3: Árvore resultante da fusão das sentenças do Quadro 4 (Barzilay \& Mckeown, 2005; pág. 309) 22

Figura 4: Árvore resultante do processo de poda de subárvores irrelevantes (Barzilay \& Mckeown, 2005; pág. 311).............................. 23

Figura 5: Árvore de dependência sintática antes e após a transformação (Fillipova \& Strube, 2008; pág. 180).

Figura 6: Exemplo de alinhamento e fusão de árvores sintáticas (Pang et al., 2003; pág. 104) 34

Figura 7: Precisão média da relação verbo-argumento (Wan et al., 2005; pág. 93).

Figura 8: Cobertura média da relação verbo-argumento (Wan et al., 2005; pág. 94). 40

Figura 9: Precisão média dos argumentos adjacentes aos verbos (Wan et al., 2005; pág. 94)

Figura 10: Precisão média dos argumentos verbais de longa distância

(Wan et al., 2005; pág. 94). 41

Figura 11: Arquitetura do SiSPI 49

Figura 12: Principais etapas do método de fusão de sentenças 63

Figura 13: Árvores de dependências sintáticas .73

Figura 14: llustração das árvores de dependências sintáticas da Figura 13 após o alinhamento de informações comuns 79

Figura 15: Exemplo de poda de subárvores não intersectadas 85

Figura 16: Árvores 1 e 2 após a seleção de unidades lexicais na fusão por interseção 87

Figura 17: Exemplo de união de subárvores ............................................. 91

Figura 18: Árvore 2 após a união da subárvore da Árvore 1. 92

Figura 19: Árvores 1 e 2 após a seleção de unidades lexicais na fusão por união 
Figura 20: Exemplo de segmentos alinhados com características

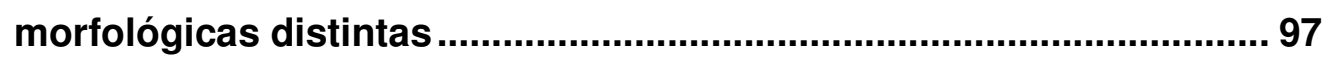

Figura 21: Árvore A1 da Figura 20 após o processo de fusão por interseção ........................................................................................... 98 


\section{ÍNDICE DE QUADROS}

Quadro 1: Exemplo de sumário multidocumento produzido pelo MEAD.... 3

Quadro 2: Exemplos de respostas candidatas a pergunta "O que provoca LER?".

Quadro 3: Exemplo de fusão por interseção e por união de informações 12 Quadro 4: Conjunto de sentenças comparáveis (Barzilay \& Mckeown, 2005; pág. 300) 19

Quadro 5: Exemplos de sentenças produzidas pelo modelo de Barzilay \& Mckeown(2005; pág. 313) 24

Quadro 6: Exemplos de fusão de sentenças (Marsi \& Krahmer, 2005; pág. 114) 27

Quadro 7: Exemplos de sentenças geradas pelo modelo de Wan et al. (2005) 38

Quadro 8: Exemplo de sentença que não pode ser produzida pelo método proposto por Marsi \& Krahmer (2005) ............................................... 46

Quadro 9: Algoritmo Single-pass ............................................................. 51

Quadro 10: Exemplo de sentenças similares e não similares...................... 53

Quadro 11: Exemplos bons de grupos de sentenças construídos pelo SiSPI 59

Quadro 12: Exemplos ruins de grupos de sentenças construídos pelo SiSPI. 59

Quadro 13: Sentenças similares 1 64

Quadro 14: Exemplos de paráfrases lexicais e sintáticas .......................... 67

Quadro 15: Exemplos de paráfrases atômicas........................................... 68

Quadro 16: Exemplos de paráfrases compostas ....................................... 68

Quadro 17: Exemplos de regras de parafraseamento ................................. 70

Quadro 18: Algoritmo de alinhamento de árvores de dependências sintáticas. 75

Quadro 19: Exemplos de alinhamentos identificados pela função

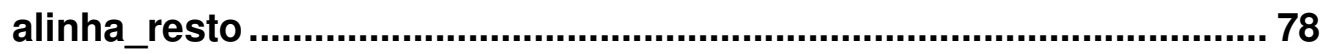

Quadro 20: Exemplos de alinhamento automático 82

Quadro 21: Algoritmo da função que poda subárvores não intersectadas 
Quadro 22: Exemplo de elementos sem interseção que são excluídos das sentenças. 86

Quadro 23: Algoritmo da função que une subárvores. 89

Quadro 24: Algoritmo da função que obtém subárvores para união 90

Quadro 25: Contra-exemplo de agregação de informações por meio do contexto dado pelo alinhamento ...................................................... 92

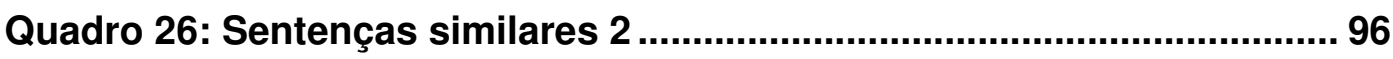

Quadro 27: Sentenças geradas a partir da árvore apresentada na Figura 21 100

Quadro 28: Sentenças geradas a partir da fusão por interserção e a partir da fusão por união 101

Quadro 29: Exemplo de fusões de sentenças produzidas manualmente 106

Quadro 30: Exemplo de sentença automática com redundância de informações, causadas por falha no processo de alinhamento ....... 111

Quadro 31: Exemplo de análise de gramaticalidade e semanticidade realizada por humanos ..................................................................... 114

Quadro 32: Exemplos de sentenças com erros geradas pelo ZíperInterseção 117

Quadro 33: Bons exemplos de sentenças geradas pelo Zíper-Interseção para o SubCorpus_SiSPI 117

Quadro 34: Bons exemplos de sentenças geradas pelo Zíper-Interseção para o SubCorpus_CSTNews. 118

Quadro 35: Bons exemplos de sentenças geradas pelo Zíper-União para o SubCorpus_SiSPI. 120

Quadro 36: Bons exemplos de sentenças geradas pelo Zíper-União para o SubCorpus_CSTNews 121

Quadro 37: Sentenças com erros produzidas pelo Zíper-Interseção e pelo Zíper-União, devido à erros do parser. 127

Quadro 38: Exemplo de sumário multidocumento produzido pelo método Geral de sumarização proposto por Jorge \& Pardo (2009) 130

Quadro 39: Sumário após a fusão por interseção de sentenças relacionadas por meio de Overlap..................................................... 132

Quadro 40: Sumário após a fusão por união de sentenças relacionadas por meio de Overlap 132 


\section{ÍNDICE DE TABELAS}

Tabela 1: Resultados da avaliação do modelo de Barzilay \& Mckeown (2005)

Tabela 2: Resultados da avaliação do modelo de Marsi \& Krahmer (2005)

Tabela 3: Resultados médios obtidos para legibilidade e informatividade

(Filippova \& Strube, 2008; pág. 183) 33

Tabela 4: Resultados da avaliação do modelo de Pang et al. (2003) .......... 36

Tabela 5: Resultados médios para gramaticalidade e fidelidade (Shen et al., 2006; pág. 752) 44

Tabela 6: Número de coleções de documentos do corpus comparável por cada domínio 48

Tabela 7: Resultados médios obtidos para os modelos TF-IDF e TF-ISF com centroides de tamanhos variados 56

Tabela 8: Resultados médios obtidos com cada medida de avaliação para diferentes limites de similaridade.

Tabela 9: Estatísticas sobre os grupos de sentenças identificados a partir do subcorpus de avaliação e a partir do corpus todo 58

Tabela 10: Resultados médios obtidos para Precisão, Cobertura e MedidaF no alinhamento de informações comuns

Tabela 11: Resultados médios obtidos para Precisão, Cobertura e MedidaF no alinhamento de sinônimos, cognatos e paráfrases.

Tabela 12: Concordância média obtida em termos de Precisão, Cobertura e Medida-F na construção dos corpora de referência 106

Tabela 13: Resultados da análise de seleção de conteúdo obtidos na fusão por interseção com o SubCorpus_SiSPI 107

Tabela 14: Resultados da análise de seleção de conteúdo obtidos na fusão por interseção com o SubCorpus_CSTNews.............................. 109

Tabela 15: Resultados da análise de seleção de conteúdo obtidos na fusão por união com o SubCorpus_SiSPI 110

Tabela 16: Resultados da análise de seleção de conteúdo obtidos na fusão por união com o SubCorpus_CSTNews 
Tabela 17: Concordância obtida em termos da medida Kappa na análise de gramaticalidade e semanticidade ............................................... 113

Tabela 18: Concordância obtida em termos da medida Kappa na análise de gramaticalidade e semanticidade, considerando apenas duas classes de sentenças

Tabela 19: Resultados da análise de gramaticalidade e semanticidade obtidos na fusão por interseção com o SubCorpus_SiSPI 115

Tabela 20: Resultados da análise de gramaticalidade e semanticidade obtidos na fusão por interseção com o SubCorpus_CSTNews......... 116

Tabela 21: Resultados da análise de gramaticalidade e semanticidade obtidos na fusão por união com o SubCorpus_SiSPI ........................ 119

Tabela 22: Resultados da análise de gramaticalidade e semanticidade obtidos na fusão por união com SubCorpus_CSTNews ................... 119

Tabela 23: Concordância obtida em termos da medida Kappa na análise de representatividade 122

Tabela 24: Concordância obtida em termos da medida Kappa na análise de representatividade, considerando apenas duas classes de sentenças. 123

Tabela 25: Resultados da análise de representatividade obtidos na fusão por interseção com o SubCorpus_SiSPI........................................... 124

Tabela 26: Resultados da análise de representatividade obtidos na fusão por interseção com o SubCorpus_CSTNews ..................................... 124

Tabela 27: Resultados da análise de representatividade obtidos na fusão por união com o SubCorpus_SiSPI................................................ 125

Tabela 28: Resultados da análise de representatividade obtidos na fusão por união com o SubCorpus_CSTNews............................................ 125

Tabela 29: Resultados médios obtidos para Precisão, Cobertura e MedidaF antes e depois da fusão por interseção e por união de sentenças relacionadas por meio de Overlap..................................................... 134 


\section{RESUMO}

Nos últimos anos, há um crescente interesse por aplicações do Processamento de Língua Natural (PLN) que processam uma coleção de textos sobre um mesmo assunto e produzem um novo texto de saída, quer seja um sumário ou uma resposta para uma dada pergunta. Para se produzir textos com qualidade, essas aplicações precisam lidar adequadamente com vários fenômenos, tais como a redundância, a contradição e a complementaridade de informações. Nesse contexto, um processo que permita a identificação de informações comuns em um conjunto de sentenças relacionadas, e gere uma nova sentença a partir da fusão de informações das sentenças de entrada, sem redundâncias e sem contradições, é de grande relevância para as aplicações que processam múltiplos textos. A fusão automática de sentenças é um tema de pesquisa relativamente recente na literatura de PLN e para a língua portuguesa, em particular, não se tem conhecimento de trabalhos dessa natureza. Neste trabalho propõe-se um método inédito para a fusão de sentenças similares em português, baseado em uma abordagem simbólica e independente de domínio, e produz-se o Zíper, um sistema de fusão sentencial que implementa o método proposto. O Zíper é o primeiro sistema a contemplar a geração de sentenças que expressam todas as informações das sentenças de entrada, ou seja, que representam a união do conjunto. Além disso, ele permite a geração de sentenças que expressam apenas as informações redundantes do conjunto (consideradas mais importantes), isto é, que representam a interseção das sentenças de entrada. O sistema foi avaliado intrinsecamente e os resultados obtidos mostram que, de modo geral, as sentenças produzidas são bem formadas e preservam a mensagem original do conjunto (isto é, a mensagem toda, na fusão por união e apenas a mensagem principal, na fusão por interseção). Zíper também foi avaliado extrinsecamente no contexto de um sumarizador multidocumento do português. Os resultados alcançados sugerem que o método proposto contribui para melhorar a qualidade dos sumários, reduzindo a redundância de informações, que frequentemente provoca a perda de coesão e de coerência. 


\begin{abstract}
In recent years, there is increasing interest in applications of Natural Language Processing (NLP) that process a collection of texts on the same subject and generate a new output text, for instance, a summary or an answer to a given question. In order to generate quality texts, these applications need to cope with various phenomena such as information redundancy, contradiction and complementarity. In this context, a process that is able to identify common information in a set of related sentences and generate a new sentence by merging information from the input sentences, without redundancies and contradictions, is of great relevance for applications that process multiple texts. Automatic sentence fusion is a relatively new research topic in NLP literature and for Portuguese, in particular, we are not aware of any such work. This work proposes a new method for fusing similar sentences in Portuguese, based on a symbolic and domainindependent approach, and produces Zíper, a sentence fusion system that implements the proposed method. Zíper is the first such system to generate sentences that express all the information from input sentences, i.e., the union of the input set. Moreover, it allows generating sentences that express only the redundant information of the set (considered more important), i.e., the intersection of the input sentences. The system was evaluated intrinsically and the results show that, in general, the generated sentences are well formed and preserve the original message of the set (i.e. the entire message in the fusion by union, and only the main message in the fusion by intersection). Zíper was also evaluated extrinsically in the context of a Portuguese multi-document summarizer. The results suggest that it can improve the quality of summaries by reducing redundancy, which often causes loss of cohesion and coherence.
\end{abstract}




\section{Capítulo 1}

\section{Introdução}

Este capítulo tem como propósito apresentar o contexto onde surge o problema de pesquisa, discutir a relevância de investigá-lo e a contribuição em resolvê-lo, bem como explicitar os objetivos gerais e específicos da tese.

\subsection{Contexto e Motivação}

Tradicionalmente, a Geração de Língua Natural (GLN) consiste na produção automática de textos em linguagem humana, a partir de uma representação não linguística da informação subjacente (abordagem conhecida por concept-to-text generation, em inglês) (Reiter \& Dale, 2000). Sistemas de GLN baseiam-se em algum tipo de conhecimento sobre o domínio da aplicação e sobre a língua-alvo para produzir resumos, fazer perguntas, gerar relatórios, entre outros. Entretanto, o uso de conhecimento especializado sobre o domínio para a interpretação de dados não linguísticos é um fator limitante na construção de sistemas escaláveis e robustos. Diante disso, e da grande oferta de conteúdo linguístico em meio digital, nos últimos anos há um crescente interesse por aplicações de Processamento de Língua Natural (PLN) que produzem textos a partir de representação linguística, ao invés da representação abstrata do significado. Mais especificamente, essas aplicações baseiam-se em um processo de geração de textos a partir de textos (text-to-text generation, no inglês). Essa abordagem é mais barata do que a abordagem tradicional, pois não requer conhecimento especializado do domínio (Barzilay, 2003).

A geração de textos a partir de textos consiste em produzir, dado um ou mais textos de entrada, um novo texto, satisfazendo certas restrições como tamanho ou estilo. Em outras palavras, essa abordagem faz reuso do(s) texto(s) de entrada para gerar a 
saída pretendida. Alguns exemplos de aplicações que geram textos a partir de textos são os sistemas de sumarização, que produzem sumários a partir de um texto ou de uma coleção de textos sobre um mesmo assunto, os sistemas de perguntas e respostas, que buscam responder perguntas por meio de consultas a uma coleção de textos, os sistemas de simplificação textual, que produzem uma versão simplificada de um dado texto, entre outras.

A produção de um texto a partir de um ou mais textos é um processo não trivial que em geral requer a interpretação do(s) texto(s) de partida. Como essa é uma tarefa muito complexa, que exige o uso de conhecimento linguístico profundo (por exemplo, informações semânticas e discursivas) e, em muitos casos, o uso intensivo de inferência lógica, muitas propostas baseiam-se apenas em métodos superficiais, isto é, estatísticos ou empíricos. Esses métodos são de mais simples aplicação e não usam conhecimento linguístico profundo. Tais métodos são ditos "cegos", pois não fazem interpretação de textos. É o caso dos métodos de sumarização extrativos, que utilizam informações superficiais (por exemplo, frequência, posição, etc.) para identificar as sentenças (ou parágrafos) mais importantes de um ou mais textos e extraí-las para compor o sumário (vide, por exemplo, Radev et al., 2004).

Embora métodos superficiais sejam mais baratos do que métodos profundos, eles apresentam várias limitações, principalmente, para lidar com aplicações que processam múltiplos textos de entrada, como a sumarização multidocumento e os sistemas de perguntas e respostas. Com frequência esses textos contêm muitas informações redundantes, complementares e até contraditórias, impondo vários desafios para os métodos que não fazem o entendimento dos textos. Na sumarização multidocumento, por exemplo, um dos maiores desafios consiste em produzir sumários sem redundâncias e sem contradições de informações (Barzilay \& Mckeown, 2005). A incapacidade dos métodos superficiais de lidar com a variabilidade de verbalizações usadas para expressar um mesmo conceito frequentemente resulta em sumários não coerentes ou não coesos. Um exemplo de sumário multidocumento produzido por um método superficial é apresentado no Quadro 1. Esse sumário foi construído a partir de quatro textos relacionados à explosão de uma bomba em um mercado de Moscou (extraídos do corpus de trabalho (Capítulo 4) e apresentados no Anexo 2) pelo sistema MEAD ${ }^{1}$ (Radev et al., 2004), um sumarizador multidocumento multilíngue bastante popular na

\footnotetext{
${ }^{1}$ Disponível para download em: http://www.clsp.jhu.edu/ws2001/groups/asmd (último acesso: 06/04/2010).
} 
literatura ${ }^{2}$. Como se pode notar há algumas informações contraditórias (sublinhadas), relacionadas ao número de mortos e feridos na explosão, e várias informações repetitivas (em negrito) que prejudicam a coesão e a coerência, comprometendo a qualidade do sumário.

Quadro 1: Exemplo de sumário multidocumento produzido pelo MEAD.

Dez pessoas morreram, duas delas criancas, e outras 39 ficaram feridas nesta segunda-feira em uma explosão de uma bomba no mercado de Cherkizov, um dos maiores de Moscou, em um ataque que as autoridades dizem acreditar ser um acerto de contas.

O mais sangrento aconteceu em 19 de março de 1999, quando terroristas detonaram uma bomba no mercado Central de Vladikavkaz, capital da república russa da Ossótia do Norte, vizinha da Tchetchênia.

A bomba, com uma carga entre $1 \mathrm{~kg}$ e $1,5 \mathrm{~kg}$ de dinamite, explodiu às $10 \mathrm{h40}$ (3h40 de Brasília) e destruiu mais de 200 metros quadrados de construções leves em Evrazia, um dos setores no qual é dividido o mercado de Cherkizov, no nordeste de Moscou. Inicialmente, a polícia divulgou a versão de que foi um acidente causado pela explosão de um bujão de gás. No entanto, pouco depois, o primeiro vice-prefeito de Moscou, Vladimir Resin, descartou essa hipótese.

A explosão, supostamente causada por vazamento de um botijão o de gás, foi registrada por volta das $10 \mathrm{~h} 40$ (3h40 de Brasília) no setor denominado Evrazia do mercado Cherkizov, um dos maiores shoppings da capital da Rússia. Cerca de dezenas de carros de bombeiros e mais de uma dezena de ambulâncias foram enviadas ao local, que foi isolado pela polícia.

MOSCOU Rússia - Uma explosão causou nesta segunda-feira a morte de dez pessoas e deixou cerca de 30 feridas no mercado Cherkizov de Moscou.

MOSCOU Rússia - Nove pessoas morreram, sendo três crianças, e outras 25 ficaram feridas nesta segunda-feira em uma explosão registrada em um mercado moscovita, informou a Polícia de Moscou.

A explosão, cujas causas ainda são desconhecidas, aconteceu às $10 \mathrm{~h} 40$ (3h40 em Brasília) no mercado Cherkizov, localizado no nordeste da capital russa.

A redundância, a contradição e a complementaridade impõem desafios também para os sistemas que buscam respostas para perguntas (Dalmas \& Webber, 2007). Várias respostas possíveis para uma mesma pergunta podem ser encontradas em textos distintos e de formas muito diferentes. Em muitos casos, elas são complementares, ou seja, cada uma apresenta também informações adicionais não encontradas nas outras respostas. Além disso, frequentemente a resposta está disseminada em várias sentenças como ocorre com perguntas do tipo definição (por exemplo, "O que é Inteligência Artificial?"), causa (por exemplo, “O que provoca o infarto do miocárdio?”), etc. Por exemplo, considere que as sentenças [1], [2] e [3] do Quadro 2 estão entre as três

\footnotetext{
${ }^{2}$ Para mais detalhes sobre o método de sumarização do MEAD, vide Radev et al. (2004).
} 
respostas mais prováveis de uma lista de candidatas a responder a pergunta " $O$ que provoca LER?". A seleção de apenas uma delas não seria suficiente para fornecer uma resposta completa descrevendo todas as possíveis causas da LER, já que elas são complementares e nenhuma delas contém todo o conteúdo expresso também nas demais candidatas. Por outro lado, ao apresentar todas as respostas, a redundância e as contradições (caso houvesse) deveriam ser tratadas. Idealmente, a resposta em potencial deveria agregar todas as informações apresentadas na lista de candidatas, sem repetições e sem contradições. Entretanto, métodos superficiais em geral não permitem agregar informações de várias respostas em uma única resposta. Devido a isso, a maioria das propostas encontradas na literatura se limita apenas a responder perguntas factuais (por exemplo, "Em que ano nasceu Nelson Mandela?") com respostas curtas, mais facilmente resolvidas pelos métodos superficiais (vide, por exemplo, Branco et al., 2008 e Costa \& Cabral, 2008).

\section{Quadro 2: Exemplos de respostas candidatas a pergunta "O que provoca LER?"}

[1] A LER é geralmente causada por movimentos repetidos e contínuos com consequente sobrecarga do sistema músculo-esquelético.

[2] Movimentos repetitivos, má postura e stress podem provocar o aparecimento da LER.

[3] A LER é comumente provocada pelo trabalho na empresa, falta de flexibilidade de tempo e ritmo, exigência de produtividade, mobiliários e equipamentos inadequados.

Com o avanço significativo do PLN nas últimas décadas e a disponibilidade de recursos e de ferramentas linguísticas para várias línguas, tais como corpora, thesaurus, parsers, modelos de língua, entre outros, vários métodos vêm sendo propostos nos últimos anos com o intuito de agregar, automaticamente, um conjunto de informações em uma única sentença, sem repetições. Mais especificamente, esses métodos se baseiam em um processo de fusão de sentenças (ou fusão sentencial) que, dado um conjunto de sentenças, produz uma nova sentença que combina as informações das sentenças de entrada. Por se tratar de um processo de geração baseado em representação linguística (ou seja, sentenças em língua natural), a fusão de sentenças não requer conhecimento formalizado sobre o domínio. O conhecimento linguístico necessário para gerar a nova sentença pode ser extraído diretamente do conjunto de entrada e a partir de corpora. 
Daumé III \& Marcu (2004) argumentam, entretanto, que a fusão de sentenças não relacionadas é uma tarefa mal definida. Experimentos realizados pelos autores mostraram que não há concordância entre humanos quando se trata de fusão de sentenças com pouca ou nenhuma similaridade semântica, ainda que as sentenças pertençam a um mesmo texto. Por outro lado, Barzilay \& Mckeown (2005) relatam uma concordância bastante satisfatória na fusão de sentenças altamente similares do inglês (vide Seção 3.1.1). Assume-se, então, que a fusão sentencial só faz sentido quando realizada entre sentenças semanticamente similares.

Como se trata de um processo de geração de língua natural, métodos de fusão sentencial permitem expressar na sentença de saída somente o conteúdo necessário para atender aos objetivos específicos da aplicação. O método proposto em Barzilay \& Mckeown (2005), por exemplo, que é utilizado por um sumarizador multidocumento para o inglês, preserva somente o conteúdo redundante das sentenças de entrada, ou seja, a interseção do conjunto. Informações que não se repetem no conjunto são consideradas irrelevantes. Na proposta de Fillipova \& Strube (2008), também voltada para a sumarização multidocumento, somente o conteúdo mais relevante é preservado, o qual é determinado com base em estatísticas derivadas a partir de corpus. Contudo, em alguns cenários, o grau de informatividade das sentenças geradas pode depender das necessidades de cada usuário. Por exemplo, usuários de um sistema de perguntas e respostas ora podem desejar respostas mais curtas, ou seja, que preservam somente as informações mais importantes, ora podem desejar respostas mais completas, com preservação total das informações de entrada, isto é, que representam a união do conjunto. É válido dizer que a maioria das propostas existentes não permite essa flexibilidade de escolha, quer seja pelo usuário, quer seja pela própria aplicação.

Métodos de fusão sentencial têm sido propostos para várias línguas, como o inglês, o alemão e o holandês. Para a língua portuguesa, no entanto, não se tem conhecimento de outros trabalhos dessa natureza (nem mesmo em Portugal). Vale ressaltar, aqui, que as pesquisas com abordagens profundas são ainda pouco exploradas no Brasil. No que se refere às aplicações que processam múltiplas entradas, mais especificamente, pode-se citar o trabalho de Jorge \& Pardo (2009; 2010), que propõe um sumarizador multidocumento baseado no modelo CST - Cross-document Structure Theory (Radev, 2000). Esse é o segundo sumarizador multidocumento desenvolvido para o português, sendo o primeiro uma extensão do GistSumm (Pardo et al., 2003; Pardo, 2005), um sumarizador monodocumento baseado em métodos superficiais. Em 
relação às pesquisas com métodos de perguntas e respostas, não se tem conhecimento de nenhum trabalho específico para o português do Brasil. Para o português europeu, por outro lado, já existem algumas pesquisas na área (vide, por exemplo, Branco et al., 2008 e Costa \& Cabral, 2008).

Nesse contexto, diante da escassez de pesquisas para o português, principalmente relacionadas ao desenvolvimento de aplicações que processam múltiplos textos, e de recursos e ferramentas que permitam lidar adequadamente com os diversos fenômenos existentes em múltiplos textos relacionados a um mesmo assunto (conforme citados anteriormente), neste trabalho pesquisam-se métodos para a fusão automática de sentenças similares e produz-se o primeiro sistema de fusão sentencial para o português, denominado Zíper. A concepção do Zíper consiste em uma das principais contribuições deste trabalho, criando oportunidades para o avanço das pesquisas em várias áreas do PLN envolvendo o português, ainda muito incipientes no Brasil (e também em Portugal), principalmente no que se refere às abordagens profundas.

Na subseção a seguir apresentam-se os objetivos e as hipóteses desta tese.

\subsection{Objetivos e Hipóteses}

Tendo em vista o cenário apresentado anteriormente, este trabalho tem como objetivo principal o desenvolvimento de um método para a fusão automática de sentenças similares em português, que seja independente de domínio e que possa servir a qualquer aplicação do português em que esse processo se faz necessário. Para atender a este último requisito, o método deve ser flexível o bastante de modo a permitir que o grau de informatividade das sentenças a serem geradas seja definido pela própria aplicação, de acordo com o que for mais adequado ao seu propósito. Mais especificamente, o método de fusão deve possibilitar tanto a geração de sentenças que preservam todo o conteúdo das sentenças de entrada, isto é, a união do conjunto, quanto a geração de sentenças que preservam somente o conteúdo mais relevante, por exemplo, a interseção do conjunto.

A hipótese deste trabalho é que, com o uso de recursos e ferramentas linguísticas existentes para o português, tais como parsers, thesaurus, corpora, modelos de língua, entre outros, é possível desenvolver um método de fusão de sentenças similares em português, que produza sentenças com qualidade satisfatória, ou seja, sentenças 
gramaticais e que preservam a mensagem original do conjunto (somente a mensagem principal ou a mensagem toda, dependendo do grau de informatividade desejado), sem redundâncias.

Com o intuito de alcançar os objetivos gerais e específicos mencionados anteriormente e comprovar a hipótese da tese, foram traçados diversos objetivos intermediários, a saber:

a) A investigação dos principais métodos de geração de sentenças baseados em representação linguística existentes para outras línguas, com ênfase especial nos métodos de fusão de informações.

b) A construção de um corpus de sentenças similares em português que pudesse subsidiar o desenvolvimento, a avaliação e a validação do método de fusão sentencial. Para tanto, desenvolver um protótipo que permita a identificação automática de sentenças similares em textos do português.

c) A definição, a implementação e a avaliação de um método que permita a identificação de conceitos redundantes (por exemplo, sinônimos e paráfrases) em um conjunto de sentenças similares em português. Esse processo é de fundamental importância para a fusão automática de sentenças.

d) A definição, a implementação e a avaliação de um método de fusão de sentenças em português, que receba como entrada duas ou mais sentenças similares e gere como saída uma nova sentença, que agrega informações das sentenças de entrada, de acordo com os requisitos da aplicação.

e) A validação do método de fusão sentencial no contexto de uma aplicação em que a fusão se faz adequada, como a sumarização multidocumento. 


\subsection{Organização do Texto}

O restante desta tese está organizado da seguinte maneira:

O Capítulo 2 apresenta as principais etapas que compõem um modelo de fusão de sentenças, destacando brevemente os aspectos principais que diferenciam as abordagens existentes (por exemplo, o tipo de entrada, o tipo de saída, as ferramentas e os recursos linguísticos usados), bem como os métodos de avaliação empregados.

O Capítulo 3 apresenta uma contextualização da área de fusão de sentenças, descrevendo de forma detalhada as principais propostas da literatura e os resultados alcançados por cada uma delas. Como a fusão trata da geração de sentenças a partir de sentenças, a descrição também se estende a outros trabalhos de geração sentencial a partir de representação linguística (sentenças). Em particular, apresentam-se alguns métodos de geração de paráfrases, já que os principais procedimentos envolvidos nesse processo também se aplicam a fusão.

O Capítulo 4 apresenta a construção do corpus de trabalho, descrevendo a ferramenta computacional construída para a identificação de sentenças similares em textos em português, assim como a metodologia de avaliação da ferramenta e os resultados obtidos.

O Capítulo 5 trata do desenvolvimento do método de fusão sentencial para o português, apresentando: i) a construção e a avaliação de um método para a identificação automática de conceitos comuns (redundantes) entre sentenças similares, ii) a geração de sentenças que capturam todo o conteúdo das sentenças de entrada e iii) a geração de sentenças que capturam somente o conteúdo mais relevante daquelas sentenças.

O Capítulo 6, por sua vez, apresenta algumas avaliações intrínsecas do método de fusão proposto, descrevendo a metodologia de avaliação e os resultados alcançados.

A validação do método proposto (isto é, avaliação extrínseca) é o tema do Capítulo 7, no qual são descritos alguns experimentos realizados no contexto de sumarização multidocumento.

Por fim, o Capítulo 8 apresenta as conclusões do trabalho, bem como as principais contribuições e algumas possibilidades de trabalhos futuros. 


\section{Modelo Básico de Fusão Automática e Métodos de Avaliação}

A fusão de sentenças é uma tarefa variante da geração de texto a partir de texto (text-to-text generation, no inglês), que consiste em produzir, dado um conjunto de sentenças relacionadas de entrada, uma nova sentença. Ao contrário das abordagens de geração tradicionais, que produzem textos (ou sentenças) a partir de uma representação semântica elaborada (concept-to-text generation, no inglês) sobre um determinado domínio (por exemplo, Radev \& Mckeown, 1998), as abordagens de geração de sentenças a partir de sentenças produzem sentenças por meio da combinação de informações expressas no conjunto de entrada, satisfazendo determinadas restrições (por exemplo, eliminando informações irrelevantes e redundantes).

Por se tratar de um processo de geração de língua natural, um sistema de fusão sentencial precisa tomar decisões em vários níveis de representação textual, desde o planejamento de conteúdo até a realização superficial (Reiter \& Dale, 2000). Grosso modo, o planejamento de conteúdo envolve a seleção dos conceitos a serem veiculados na sentença de saída e a escolha das unidades lexicais apropriadas para expressar cada conceito. A realização superficial é responsável por mapear a estrutura abstrata da sentença obtida a partir do planejamento de conteúdo em sentenças propriamente ditas, selecionando as estruturas morfológicas e sintáticas apropriadamente. Em outras palavras, o planejamento de conteúdo determina o que se deve dizer na sentença a ser produzida, e a realização superficial determina como se deve dizer.

Enquanto nos sistemas de geração tradicionais a seleção de conteúdo é determinada com base em restrições pragmáticas do domínio em específico, e a escolha lexical requer o uso de um dicionário de domínio para o mapeamento dos conceitos em unidades linguísticas apropriadas, nos sistemas que geram sentenças a partir de 
sentenças o conhecimento é extraído das próprias sentenças de entrada e obtido de corpora ou de thesaurus. Essa abordagem é mais barata e não requer uma representação conceitual e semântica formalizada do domínio, nem o uso de léxicos especializados.

Este capítulo tem como objetivo apresentar os processos envolvidos em um sistema de fusão sentencial, mostrando brevemente os principais aspectos que diferenciam os trabalhos da literatura (descritos em mais detalhes no Capítulo 3), e os métodos de avaliação desses sistemas. A arquitetura básica de um sistema de fusão de sentenças é o tema da Seção 2.1, enquanto que a avaliação é o tópico da Seção 2.2.

\subsection{Arquitetura Básica de um Modelo de Fusão Sentencial}

O primeiro modelo de fusão automática de sentenças foi desenvolvido por Barzilay (2003) para o inglês (Capítulo 3). Sua metodologia de desenvolvimento e a arquitetura composta por três etapas de processamento em pipeline formam a base da maioria dos trabalhos desenvolvidos na área e inclusive do método proposto nesta tese (vide Capítulo 5). Conforme ilustrado na Figura 1, a primeira etapa do processo de fusão de sentenças é a identificação de informações comuns, que tem por objetivo identificar os conceitos equivalentes entre as sentenças de entrada como os sinônimos e as paráfrases. A segunda etapa, a fusão propriamente dita, consiste no planejamento de conteúdo da nova sentença a ser gerada. Esse processo envolve a seleção dos conceitos a serem comunicados, bem como das unidades lexicais mais adequadas para expressar cada conceito. A última etapa, por sua vez, é a linearização, que consiste na realização superficial da sentença obtida na etapa anterior. A linearização envolve a determinação dos aspectos morfológicos e sintáticos de cada constituinte da sentença e a organização desses constituintes.

Os métodos propostos na literatura (por exemplo, Pang et al., 2003; Barzilay \& Mckeown, 2005; Marsi \& Krahmer, 2005; Shen et al., 2006 e Fillipova \& Strube 2008) variam de acordo com três aspectos principais: o tipo das sentenças de entrada, os recursos linguístico-computacionais utilizados (por exemplo, parsers, thesauri, dicionários de paráfrases, modelos de língua, entre outros) e a estratégia de fusão adotada, que remete ao grau de informatividade das sentenças de saída. 


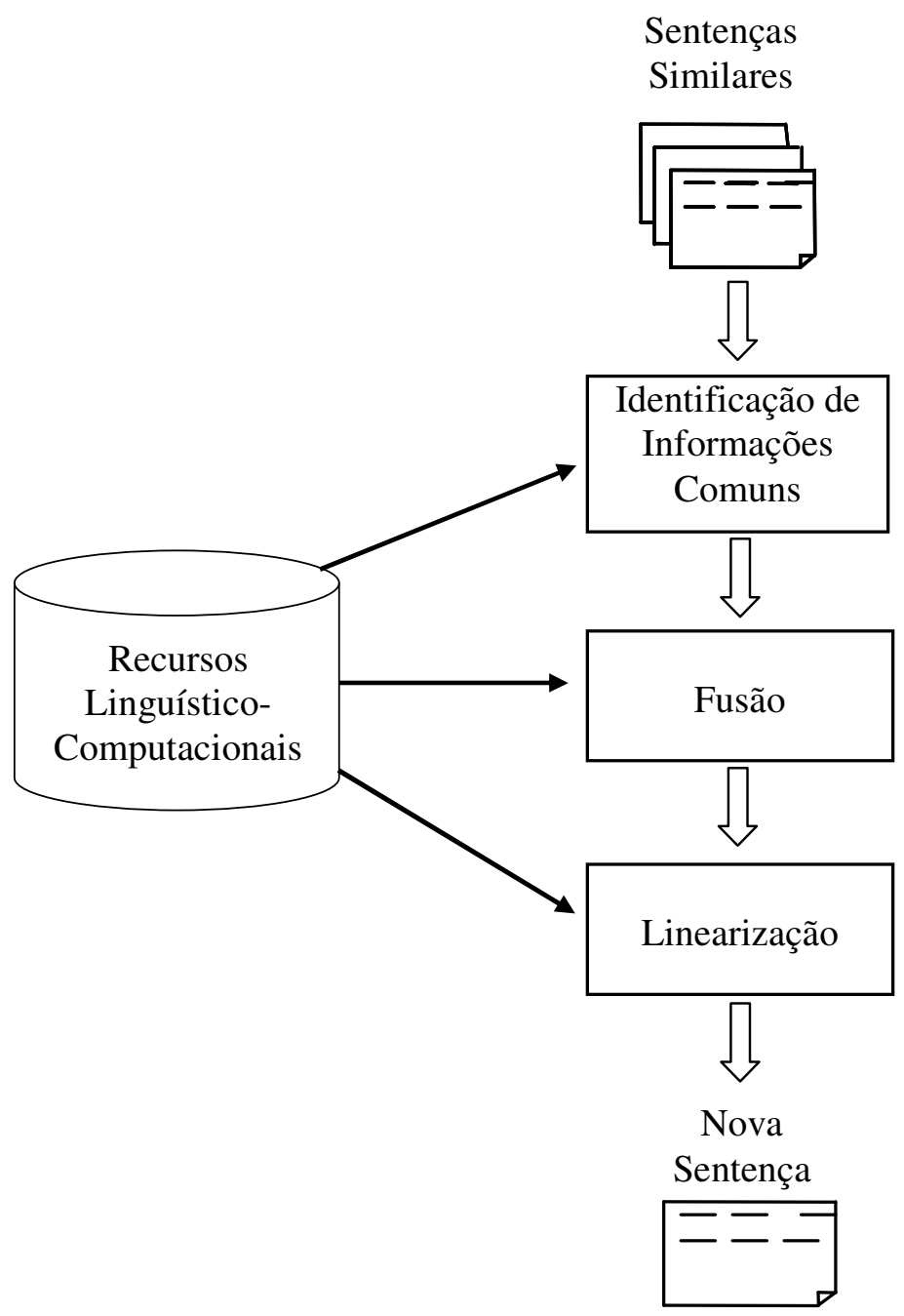

Figura 1: Ilustração do processo geral de fusão de sentenças proposto por Barzilay (2003)

No que se refere às sentenças de entrada, essas podem ser basicamente de dois tipos: comparáveis monolíngues ou paralelas monolíngues (Shen et al., 2006). As sentenças comparáveis se referem a um mesmo fato ou evento, porém são obtidas de fontes de informação diferentes (por exemplo, sentenças sobre um mesmo fato publicadas por diferentes agências de notícias). As sentenças paralelas são traduções distintas de uma mesma sentença, em uma língua qualquer, para uma mesma língua alvo.

O tipo da entrada pode influenciar na escolha dos recursos linguísticocomputacionais. Por exemplo, as abordagens que lidam com sentenças comparáveis geralmente fazem uso de um parser de dependências, de um thesaurus e em alguns casos de um léxico de paráfrases, pois as estruturas sintáticas dessas sentenças nem 
sempre são similares e em muitos casos há pouca semelhança lexical, apesar da alta similaridade semântica entre elas. Em contrapartida, alguns métodos que tratam sentenças paralelas utilizam apenas um parser de constituintes (isto é, sem fazer uso das relações de dependências sintáticas) e não utilizam qualquer informação sobre paráfrases, já que essas sentenças, em geral, são bastante similares lexicamente e sintaticamente (vide, por exemplo, Pang et al., 2003).

Com relação à estratégia de fusão, que determina o grau de informatividade das sentenças a serem produzidas, têm-se basicamente duas formas possíveis: i) por interseção ou ii) por união (ou agregação) de informações (Marsi \& Krahmer, 2005). A fusão por interseção consiste em combinar na sentença de saída as informações comuns que se repetem nas sentenças de entrada. Assim, as informações que ocorrem em somente uma das sentenças do conjunto e que, portanto, não têm qualquer interseção com outras sentenças, são eliminadas. Já a fusão por união preserva todas as informações das sentenças de entrada na sentença de saída, eliminando a redundância. $O$ Quadro 3 apresenta um exemplo de interseção e um de união de um conjunto de três sentenças comparáveis extraídas do corpus de trabalho descrito no Capítulo 4. Como se podem notar, na interseção apenas as informações que ocorreram em mais de uma sentença (em negrito) são preservadas. Ao contrário da interseção, na união todas as informações apresentadas no conjunto de sentenças são mantidas.

Quadro 3: Exemplo de fusão por interseção e por união de informações

[1] O Airbus A320, voo JJ3054, partiu de Porto Alegre, às 17 h16 da terça-feira e chegou a São Paulo às $18 \mathrm{~h} 45$.

[2] A aeronave da TAM Airbus A320, voo JJ3054, partiu de Porto Alegre, às 17 h16 com destino a Congonhas.

[3] Um Airbus A320 com capacidade para 170 passageiros partiu de Porto Alegre (RS) às 17 h16 com destino a Congonhas.

Interseção: O Airbus A320, voo JJ3054, partiu de Porto Alegre, às 17h16 com destino a Congonhas.

União: A aeronave da TAM Airbus A320, voo JJ3054, com capacidade para 170 passageiros, partiu de Porto Alegre (RS), às $17 \mathrm{~h} 16$ da terça-feira com destino a Congonhas e chegou a São Paulo às 18h45.

De acordo com Krahmer et al. (2008), a escolha por uma ou outra estratégia de fusão depende do tipo da aplicação e do grau de informatividade necessários aos usuários. Experimentos realizados por esses autores com usuários de um sistema de Perguntas e Respostas do domínio médico mostraram que a fusão por união é mais 
adequada nesse tipo de aplicação, pois há uma preferência maior dos usuários por respostas mais longas e completas. Por outro lado, a interseção de informações é de grande interesse na Sumarização Automática, especialmente na sumarização multidocumento, em que a redundância de informações é um problema (principalmente para os métodos extrativos), pois remete a um processo de síntese de sentenças com a preservação de conteúdo mais frequente, considerado mais relevante (Barzilay \& Mckeown, 2005). No entanto, pode haver cenários em que ora um tipo ora outro tipo de fusão seja mais desejável. Sistemas de fusão deveriam, assim, ser independentes de aplicação, possibilitando a opção por um tipo ou outro de acordo com as necessidades da aplicação ou do grupo de usuários.

\subsection{Métodos de Avaliação}

Como a fusão de sentenças é uma tarefa intermediária, podendo ser utilizada em outras aplicações, há duas maneiras possíveis de se avaliar as sentenças resultantes desse processo, a saber: (a) avaliação intrínseca (ou, simplesmente, avaliação), na qual as sentenças resultantes são avaliadas sem se considerar a tarefa em que serão aplicadas, e (b) avaliação extrínseca, também denominada validação, na qual os resultados são avaliados em termos de sua contribuição para o desempenho global de uma aplicação que os utiliza, por exemplo, a sumarização multidocumento (Sparck-Jones \& Galliers, 1998). Nesse último caso, o sistema de fusão deve ser incorporado a um sistema no contexto do qual esse processo se faz necessário e os resultados obtidos devem ser comparados com os resultados alcançados antes da inclusão do sistema de fusão. Em ambos os casos, a avaliação pode precisar da ajuda de um humano para determinar a qualidade dos resultados produzidos. De fato, na maioria dos trabalhos encontrados na literatura a avaliação é realizada de forma manual (por exemplo, Barzilay \& Mckeown, 2005; Marsi \& Krahmer, 2005; Shen et al., 2006 e Fillipova \& Strube 2008).

As sentenças produzidas pelos sistemas de fusão são avaliadas intrinsecamente de três maneiras, a saber: i) em termos de gramaticalidade, ii) em termos de semanticidade e iii) em termos do conteúdo apresentado. A análise de gramaticalidade visa medir a qualidade das sentenças em função dos problemas gramaticais apresentados, enquanto que a análise de semanticidade tem por objetivo avaliar se o significado da sentença produzida automaticamente (daqui em diante sentença 
automática) é coerente com o significado das sentenças de entrada, ou se houve distorção do significado. A análise de conteúdo, por sua vez, visa medir o grau de informatividade das sentenças automáticas. Entretanto, por se tratar de uma área de pesquisa muito recente, não há um critério bem definido para a avaliação de cada quesito, que seja comum a todos os trabalhos. Em geral, a gramaticalidade e a semanticidade são julgadas por humanos, que atribuem uma nota para cada sentença de acordo com critérios pré-estabelecidos (por exemplo, Marsi \& Krahmer, 2005 e Fillipova \& Strube, 2008). Esses critérios podem variar de um trabalho para outro, conforme será apresentado no Capítulo 3.

Na avaliação de conteúdo, cada sentença automática é comparada com uma sentença de referência produzida por um humano para um mesmo conjunto de sentenças similares. Essa comparação tem por objetivo avaliar o quanto do conteúdo das sentenças de referência foi preservado nas sentenças automáticas. Para tal, as sentenças automáticas e de referências são segmentadas em nível de informações (conceitos) e, para cada informação expressa em uma sentença automática (denotada por $A$ ), o avaliador humano verifica se o seu significado foi preservado também na sentença de referência (denotada por $R$ ). O desempenho dos sistemas é calculado usando as medidas tradicionais de Precisão, Cobertura e Medida-F. A Precisão, nesse caso, representa o número de informações de $A$ preservadas em $R$ (denotado por $|A \cap R|$ ) sobre o total de informações de $A$ (denotado por $|A|$ ) (Fórmula 1). A Cobertura corresponde ao total de informações de $A$ reproduzidas em $R$ sobre o total de informações de $R$ (denotado por $|R|$ ) (Fórmula 2). A Medida-F, por sua vez, representa a média harmônica entre a Precisão e a Cobertura (Fórmula 3).

$$
\text { Precisão }=\frac{|A \cap R|}{|A|}
$$

$$
\text { Cobertura }=\frac{|A \cap R|}{|R|}
$$

$$
\text { Medida-F }=\frac{2 * \text { Precisão } * \text { Cobertura }}{\text { Precisão }+ \text { Cobertura }}
$$


Com relação ao baseline de comparação dos métodos de fusão, geralmente é utilizada uma versão simplificada do algoritmo de fusão, por exemplo, que não faz uso de relações de dependência (vide, por exemplo, Shen et al., 2006). Em alguns casos, uma sentença do próprio conjunto de entrada é usada como base de comparação. Barzilay \& Mckeown (2005), por exemplo, usam a menor sentença do conjunto de entrada para avaliar seu modelo de fusão por interseção. No caso da fusão por união, a maior sentença do conjunto pode ser usada como parâmetro, ou outra sentença qualquer selecionada aleatoriamente (vide, por exemplo, Fillipova \& Strube, 2008).

No que diz respeito à avaliação extrínseca, não foram encontrados trabalhos reportando esse tipo de avaliação.

O método de fusão apresentado nesta tese foi avaliado tanto de forma intrínseca como de forma extrínseca. $\mathrm{Na}$ avaliação intrínseca, as sentenças produzidas foram analisadas em termos de conteúdo, de gramaticalidade, de semanticidade e de representatividade. Esta última teve por objetivo verificar o quão bem cada sentença representa o conjunto a partir do qual foi gerada. A avaliação intrínseca será abordada no Capítulo 6. $\mathrm{Na}$ avaliação extrínseca, o método foi aplicado no contexto de um sistema de sumarização multidocumento do português. Essa avaliação será descrita no Capítulo 7.

\subsection{Considerações Finais}

Este capítulo apresentou os processos básicos envolvidos em um sistema de fusão sentencial, bem como os principais aspectos que diferenciam os métodos propostos na literatura, por exemplo, o tipo de entrada, os recursos utilizados em cada processo e a estratégia de fusão adotada. Além disso, foram apresentados os principais métodos de avaliação desses sistemas. A descrição detalhada de como cada processo é abordado na literatura, bem como os resultados obtidos, é apresentada no Capítulo 3. 


\section{Capítulo 3}

\section{Trabalhos Relacionados}

Este capítulo descreve os métodos empregados na literatura, bem como as metodologias de avaliação e os resultados alcançados até o momento. É dado especial enfoque ao trabalho de Barzilay (2003), por ter servido de base para este e para vários outros trabalhos da área.

Dado que a fusão sentencial trata de um processo de geração de sentenças a partir de sentenças, a descrição se estende também a outros trabalhos de geração sentencial baseada em representação linguística (sentenças), pois, de modo geral, os

principais conceitos e procedimentos envolvidos nesse processo também se aplicam a fusão. Mais especificamente, são apresentados alguns trabalhos que visam à geração de sentenças parafrásticas, ou seja, que parafraseiam as sentenças de entrada. Grosso modo, a principal diferença entre esses trabalhos está na saída produzida. Enquanto na fusão as sentenças produzidas devem representar somente as informações mais importantes das sentenças de entrada (no caso da interseção), ou todas as informações expressas naquelas sentenças (no caso da união), na geração de paráfrases as sentenças produzidas não representam necessariamente a interseção ou a união das sentenças de entrada. O objetivo, nesse caso, consiste apenas em parafrasear as sentenças originais, sem se preocupar com quais informações serão preservadas.

Os métodos de fusão de sentenças e de geração de paráfrases são apresentados nas Seções 3.1 e 3.2, respectivamente. Em seguida, a Seção 3.3 apresenta algumas considerações finais.

\subsection{Modelos de Fusão Sentencial}




\subsubsection{Modelo de Barzilay (2003)}

O modelo de fusão de sentenças proposto por Barzilay (2003) atua como um processo intermediário no sumarizador multidocumentos MultiGen (Barzilay \& Mckeown, 2005), que opera na web como parte do Newsblaster ${ }^{3}$, um framework de sumarização. O MultiGen recebe como entrada um conjunto de textos jornalísticos (em inglês) sobre um mesmo assunto (isto é, textos comparáveis monolíngues), obtido de várias agências de notícias da web pelo Newsblaster, e produz um sumário que resume as informações principais do conjunto. Como esses textos geralmente contêm muitas informações similares expressas de formas diferentes, o sistema de fusão age sintetizando as informações redundantes em uma única sentença. Mais especificamente, o sistema recebe como entrada um conjunto de sentenças similares candidatas a um sumário, e produz como saída uma nova sentença que representa a interseção das sentenças do conjunto.

A primeira etapa do processo de fusão de sentenças, a identificação de informações comuns, consiste no alinhamento de palavras e de segmentos multipalavras (como os sintagmas) que expressam conceitos similares entre duas sentenças. $\mathrm{O}$ alinhamento é realizado entre pares de árvores de dependências sintáticas e é construído recursivamente, partindo dos nós terminais em direção às raízes, processo comumente conhecido como bottom-up.

Dadas duas árvores de dependências sintáticas $T$ e $T^{\prime}$, o algoritmo calcula a similaridade entre cada nó $v$ de $T$ e cada nó $v^{\prime}$ de $T$. A similaridade entre $v$ e $v^{\prime}$ é definida pela função $\operatorname{Sim}\left(v, v^{\prime}\right)$ apresentada na Fórmula 4. Os três termos da função correspondem às três formas possíveis de alinhamento entre dois nós, a saber: Sim_subárvore $\left(v, v^{\prime}\right)$ representa o alinhamento entre os nós $v$ e $v^{\prime} ; \max _{i}={ }_{1}, \ldots,{ }_{n} S\left(v_{i}, v^{\prime}\right)$ representa o alinhamento entre qualquer nó $v_{i}$ filho de $v$ e o nó $v^{\prime}$; e $\max _{j}={ }_{1}, \ldots, m S\left(v, v_{j}{ }^{\prime}\right)$ representa o alinhamento entre qualquer nó $v_{j}$ filho de $v^{\prime}$ e o nó $v$. A função Sim_subárvore $\left(v, v^{\prime}\right)$, por sua vez, calcula a similaridade entre as subárvores que têm $v$ e $v$ ' como raiz e é dada pela Fórmula 5.

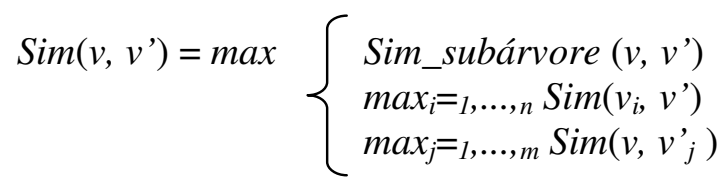

\footnotetext{
${ }^{3}$ www.newsblaster.com
} 


$$
\begin{aligned}
& \operatorname{Sim\_ subárvore}\left(v, v^{\prime}\right)=\operatorname{Sim\_ nós}\left(v, v^{\prime}\right)+ \\
& \underset{p \in P\left(v, v^{\prime}\right)}{\operatorname{Max}}\left(\sum_{(i, j) \in p} \operatorname{Sim\_ dep}\left(\left(v_{i}, v\right),\left(v_{j}, v^{\prime}\right)\right)+\operatorname{Sim}\left(v_{i}, v_{j}\right)\right)
\end{aligned}
$$

$\operatorname{Sim\_ nós}\left(v, v^{\prime}\right)$ representa a similaridade entre as palavras associadas aos nós $v \mathrm{e}$ $v^{\prime}$. Essa função recebe valor $1 \mathrm{em}$ casos de palavras idênticas ou sinônimas, um valor 0,5 em caso de paráfrases e um pênalti de $-0,1$ em caso de palavras não relacionadas. A similaridade lexical é obtida por meio de consultas a uma base de sinônimos, a Wordnet do inglês (Miller et al., 1993), e a uma lista de paráfrases, construída automaticamente a partir de um corpus comparável de notícias. Essa lista contém pares de paráfrases em nível de palavras (por exemplo, auto e automobile) e em nível de sintagma (por exemplo, mission-control office e control centers). Durante o alinhamento, o algoritmo verifica, para cada par de palavras não idênticas, se há uma relação de sinonímia na Wordnet. Caso não haja uma relação entre elas, o algoritmo, então, verifica se elas são paráfrases.

$P\left(v, v^{\prime}\right)$, por sua vez, é um conjunto que contêm todas as combinações possíveis entre os $n$ filhos de $v$ e os $m$ filhos de $v^{\prime}$. A maximização (Fórmula 5) representa o melhor alinhamento possível entre dois nós descendentes de $v$ e $v^{\prime}$.

Por fim, $\operatorname{Sim} \_d e p\left(\left(v_{i}, v\right),\left(v_{j}, v^{\prime}\right)\right)$ é uma função que calcula a similaridade das relações de dependência sintática que ligam os nós $v_{i}$ e $v$ em uma árvore $T$ e os nós $v_{j} \mathrm{e}$ $v^{\prime}$ em uma árvore $T$. Essa função pode assumir três valores distintos: 0,03, quando ambas as relações indicam uma dependência entre sujeito e verbo ou entre verbo e objeto; 0,02 para outros casos de relações equivalentes e 0 , quando não há equivalência.

Para facilitar o alinhamento, as palavras são reduzidas a sua forma canônica e as auxiliares (por exemplo, did) são eliminadas. As características morfossintáticas de cada palavra são armazenadas, de modo a permitir a recuperação de palavras auxiliares na fase de linearização. $\mathrm{O}$ alinhamento é do tipo um-para-um, ou seja, cada nó de uma árvore é alinhado com no máximo um nó da outra. Diferentemente do alinhamento lexical realizado em outras tarefas do PLN, por exemplo, na Tradução Automática, pode haver casos de subárvores para as quais não existem alinhamentos. A Figura 2 ilustra o alinhamento de duas árvores de dependências sintáticas (Árvores 1 e 2 ), correspondentes às sentenças comparáveis [1] e [2] do conjunto apresentado no Quadro 
4, respectivamente (Barzilay \& Mckeown, 2005; pág. 308). As setas indicam as dependências entre cada nó terminal e seu nó pai. Por exemplo, o nó terminal IDF spokeswoman (Árvore 1) é dependente do nó não terminal confirm e representa uma relação de dependência entre sujeito e verbo ${ }^{4}$. Na Árvore 3, resultante do alinhamento das duas árvores, as caixas retangulares e as setas não tracejadas representam os nós alinhados, enquanto que os círculos e as setas tracejadas indicam os nós sem alinhamento.

Quadro 4: Conjunto de sentenças comparáveis (Barzilay \& Mckeown, 2005; pág. 300)

[1] The IDF spokeswoman did not confirm this, but said the Palestinians fired an antitank missile at a bulldozer.

[2] The clash erupted when Palestinian militants fired machine guns and antitank missiles at a bulldozer that was building an embankment in the area to better protect Israeli forces.

[3] The army expressed "regret at the loss of innocent lives" but a senior commander said troops had shot in self-defense after being fired at while using bulldozers to build a new embankment at an army base in the area.

\footnotetext{
${ }^{4}$ As relações de dependências sintáticas e as informações de $P O S$ foram omitidas na figura original apresentada em Barzilay \& Mckeown (2005, pág. 308) e por essa razão não são mostradas aqui.
} 


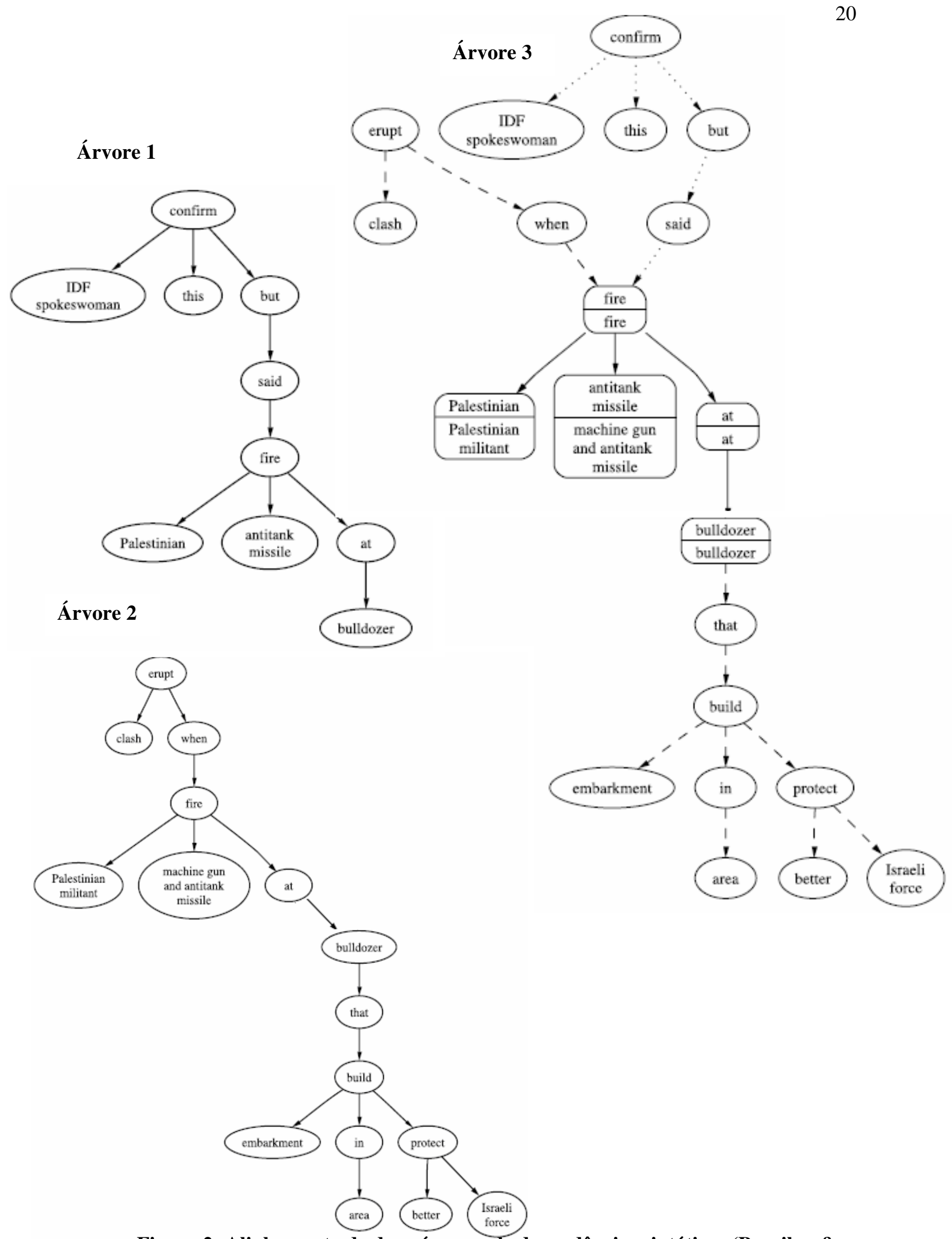

Figura 2: Alinhamento de duas árvores de dependências sintáticas (Barzilay \& Mckeown, 2005; pág. 308) 
O processo de alinhamento é aplicado a todas as combinações de pares de sentenças do conjunto de entrada. Finalizado esse processo, a próxima etapa é a fusão de informações comuns, que consiste basicamente em combinar as subárvores com interseções. A fusão é realizada em três passos: (i) seleção da árvore base, a partir da qual iniciará a fusão de informações, (ii) inclusão de verbalizações alternativas e (iii) poda de subárvores irrelevantes. A seleção da árvore base baseia-se no grau de similaridade de cada sentença, dado pelo número médio de alinhamentos da sentença em relação a todas as sentenças do conjunto. Posteriormente, a árvore base é complementada com verbalizações alternativas presentes em outras árvores que têm interseção com ela. Em outras palavras, para cada nó da árvore base são armazenadas todas as alternativas possíveis (se existir) dos nós de outras árvores que se alinham a um determinado nó. Além disso, são adicionadas também as subárvores de outras sentenças cujas raízes alinham com algum nó da árvore base. A Figura 3 ilustra a árvore resultante da fusão das três sentenças do Quadro 4, com as verbalizações alternativas de cada nó (Barzilay \& Mckeown, 2005; pág. 309). As caixas retangulares representam as interseções identificadas durante o alinhamento; as setas tracejadas representam os nós não alinhados e as setas pontilhadas indicam as subárvores com interseção somente na raiz.

Por fim, as subárvores que não têm qualquer interseção com a árvore base são removidas. Entretanto, para prevenir que a sentença resultante seja agramatical ou semanticamente incorreta, somente os constituintes sintáticos autocontidos são removidos. Tais constituintes incluem as orações relativas, uma oração em uma coordenação e alguns elementos de uma oração como advérbios e preposições. A Figura 4 apresenta a árvore ilustrada na Figura 3 após o processo de remoção de subárvores não intersectadas (Barzilay \& Mckeown, 2005; pág. 311). 


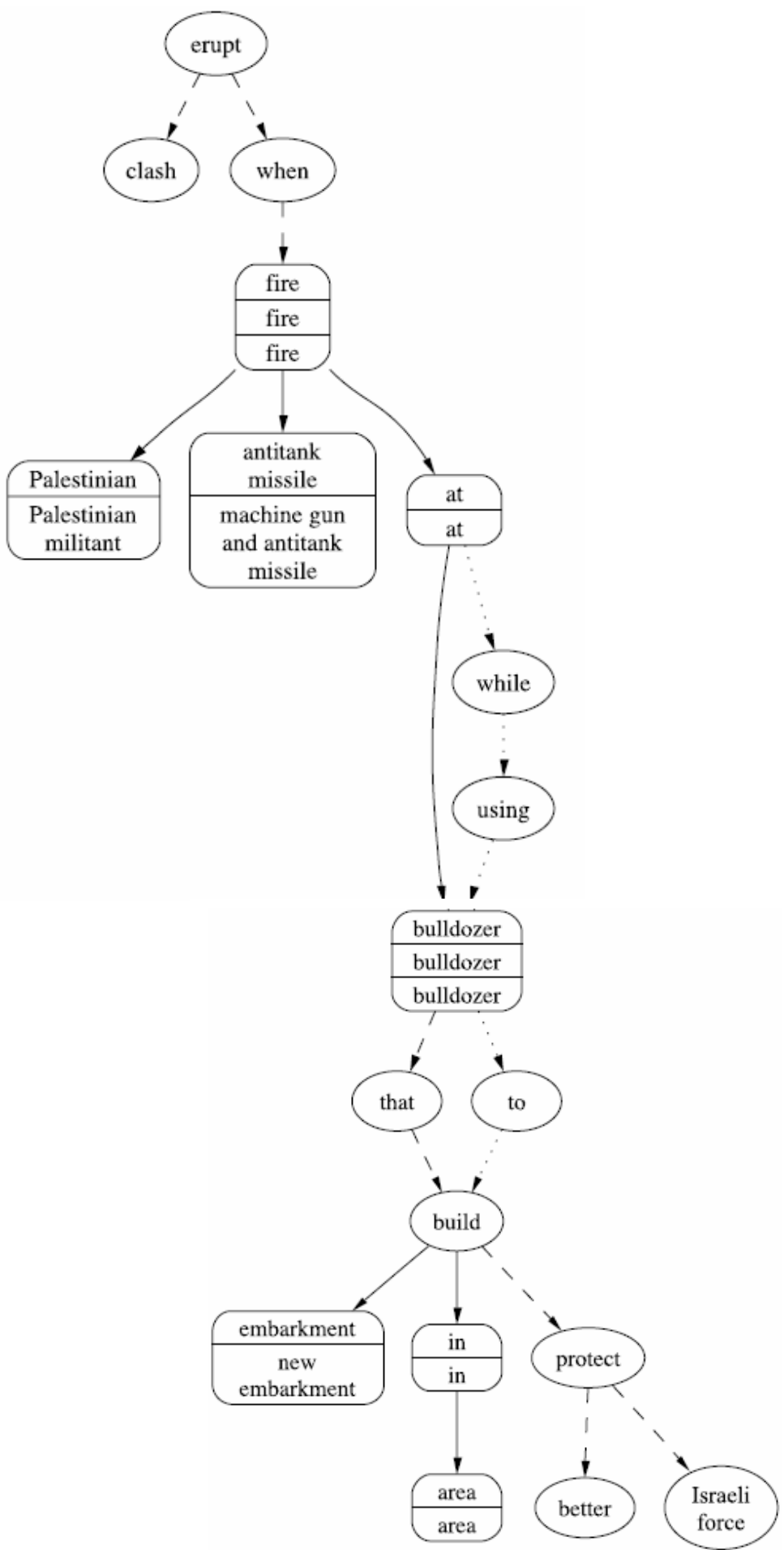

Figura 3: Árvore resultante da fusão das sentenças do Quadro 4 (Barzilay \& Mckeown, 2005; pág. 309) 


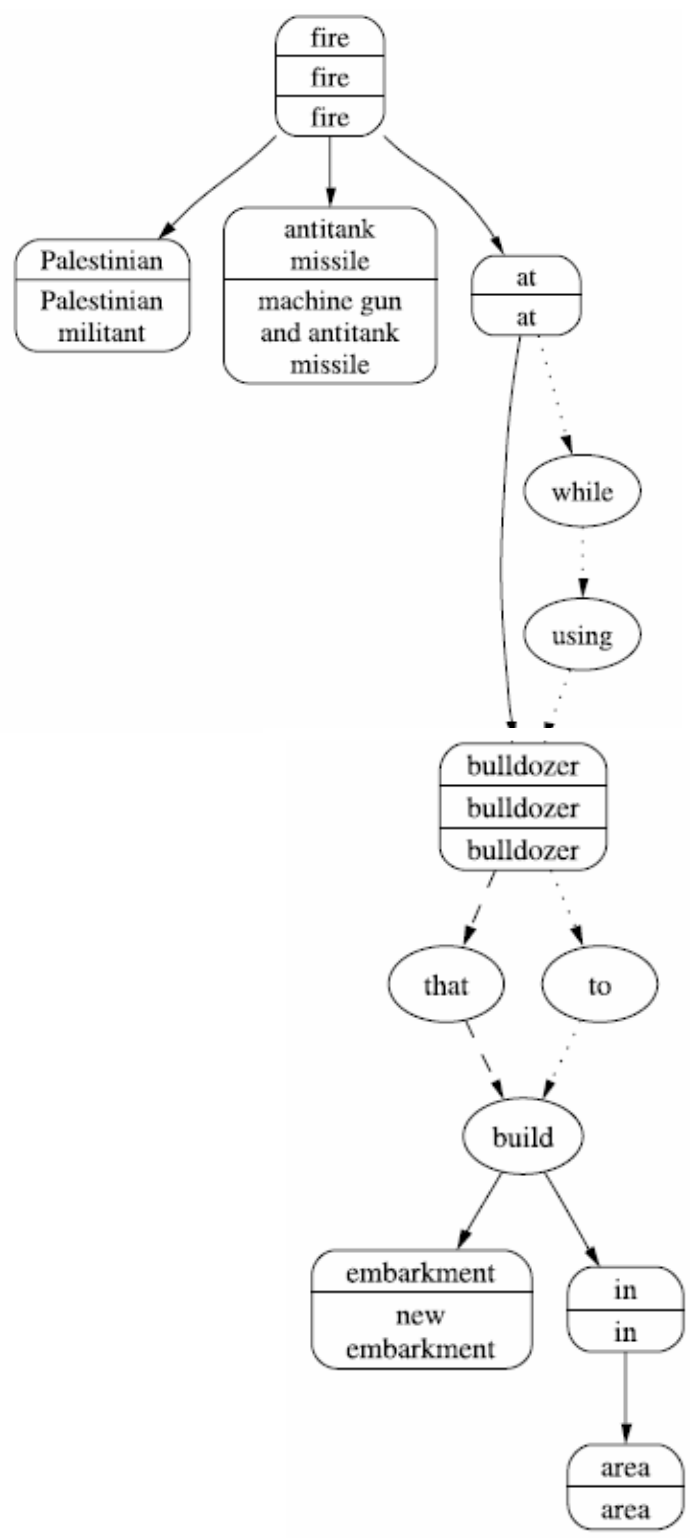

\section{Figura 4: Árvore resultante do processo de poda de subárvores irrelevantes} (Barzilay \& Mckeown, 2005; pág. 311)

A última etapa da fusão de sentenças é a linearização, responsável pela geração da nova sentença. O método adotado por Barzilay (2003) consiste simplesmente em percorrer a árvore resultante do processo de fusão, gerando todas as sentenças válidas possíveis. Os percursos válidos são limitados por restrições de ordem das palavras dadas pela própria árvore resultante da fusão e herdadas da árvore base, a partir da qual se iniciou o processo. Posteriormente, um modelo de língua baseado em trigramas é usado para selecionar a melhor sentença entre todas as sentenças geradas. Nesse modelo, a melhor sentença é calculada com base em estatísticas derivadas de um corpus. O 
modelo foi treinado com um corpus de $60 \mathrm{MB}$ de artigos jornalísticos em inglês, usando a segunda versão do toolkit CMU - Cambridge Statistical Language Modeling (Clarkson \& Rosenfeld, 1997). O Quadro 5 apresenta alguns exemplos de sentenças geradas pelo sistema para o conjunto de sentenças do Quadro 4 (Barzilay \& Mckeown, 2005; pág. 313). As sentenças estão apresentadas seguindo a ordem de importância dada pelo modelo de língua (as mais importantes são apresentadas primeiro).

\section{Quadro 5: Exemplos de sentenças produzidas pelo modelo de Barzilay \& Mckeown(2005; pág. 313)}

\begin{tabular}{|l|}
\hline Palestinians fired antitank missiles at while using a bulldozer. \\
\hline $\begin{array}{l}\text { Palestinian militants fired machine guns and antitank missiles at a } \\
\text { bulldozer that was building an embankment in the area. }\end{array}$ \\
\hline $\begin{array}{l}\text { Palestinian militants fired machine guns and antitank missiles at a } \\
\text { bulldozer. }\end{array}$ \\
\hline $\begin{array}{l}\text { Palestinians fired antitank missile at a bulldozer to build a new } \\
\text { embankment in the area. }\end{array}$ \\
\hline Palestinians fired an antitank missile at a bulldozer. \\
\hline
\end{tabular}

Barzilay \& McKeown (2005) avaliaram seu modelo intrinsecamente, analisando as sentenças geradas em termos de conteúdo e de gramaticalidade. A avaliação de conteúdo foi realizada comparando cada sentença com uma sentença de referência produzida por um humano. O desempenho do sistema foi calculado por meio das medidas de Precisão, Cobertura e Medida-F, conforme definidas no Capítulo 2. Já a gramaticalidade das sentenças foi julgada em três categorias: (a) gramatical, quando a sentença não apresentava qualquer erro de gramática, (b) parcialmente gramatical, quando havia no máximo um erro gramatical e (c) agramatical, para sentenças com mais de um erro. As sentenças classificadas pela categoria (a) receberam peso 1, enquanto que as das categorias (b) e (c) receberam pesos 2 e 3, respectivamente.

Para as avaliações foi utilizado um corpus do gênero jornalístico composto por 100 grupos de sentenças similares, cada um contendo de 3 a 7 sentenças ( 4 sentenças aproximadamente). Os grupos para os quais o humano não foi capaz de fazer a fusão e aqueles que continham sentenças muito parecidas (isto é, com co-seno de similaridade maior que 0.8) não foram considerados na avaliação. Mais especificamente, $34 \%$ das sentenças foram desconsideradas. Para efeitos de comparação, três baselines foram usados. O primeiro deles baseava-se na seleção da menor sentença do conjunto de sentenças similares, que segundo as autoras, era gramatical e tinha grandes chances de 
apresentar conceitos comuns a outras sentenças de entrada. $O$ segundo era uma simplificação do algoritmo de fusão de sentenças que não fazia consultas ao dicionário de paráfrases para o alinhamento das sentenças. O terceiro, por sua vez, baseava-se na sentença mais central do conjunto, a partir da qual se iniciava o processo de fusão. $\mathrm{O}$ segundo e o terceiro baseline tinham como propósito verificar a contribuição do dicionário de paráfrases e do processo de fusão, respectivamente. Em adição, um segundo conjunto de sentenças de referência foi produzido por outro humano (aqui denominado Referência-2). O objetivo, nesse caso, era verificar se as sentenças produzidas pelo segundo humano preservavam o mesmo conteúdo das sentenças produzidas pelo primeiro. Os resultados das avaliações são resumidos na Tabela 1 .

Tabela 1: Resultados da avaliação do modelo de Barzilay \& Mckeown (2005)

\begin{tabular}{|c|c|c|c|c|}
\hline Sistema & Precisão & Cobertura & Medida-F & Gramaticalidade \\
\hline Referência-2 & $98 \%$ & $94 \%$ & $96 \%$ & 2.9 \\
\hline Fusão & $65 \%$ & $72 \%$ & $68 \%$ & 2.3 \\
\hline Baseline-1 & $52 \%$ & $38 \%$ & $44 \%$ & 3.0 \\
\hline Baseline-2 & $41 \%$ & $67 \%$ & $51 \%$ & 3.0 \\
\hline Baseline-3 & $63 \%$ & $64 \%$ & $63 \%$ & 2.4 \\
\hline
\end{tabular}

Conforme a Tabela 1, as sentenças geradas manualmente pelo segundo humano (Referência-2) apresentaram um alto índice de Precisão e Cobertura, indicando, portanto, que, ao contrário dos resultados relatados por Daumé III \& Marcu (2004), de que não há um consenso entre humanos quando se trata de fusão de sentenças não relacionadas, há concordância no que diz respeito à tarefa de fusão de sentenças similares.

Apesar de nenhum dos sistemas terem alcançado o mesmo nível de desempenho do humano, o modelo de fusão obteve os melhores resultados em relação aos três algoritmos baseline. Todavia, seu desempenho não foi tão superior em relação ao Baseline-3, que não incorpora o processo de fusão. Além do mais, tal modelo obteve o pior resultado em relação à gramaticalidade. Barzilay \& Mckeown atribuem esse resultado a erros envolvidos nos processos de alinhamento e linearização e ao modelo de linguagem usado para a escolha das sentenças geradas pelo processo de fusão. 


\subsubsection{Modelo de Marsi \& Krahmer (2005)}

Marsi \& Krahmer (2005) propuseram um modelo de fusão de sentenças para a geração de respostas em um sistema de Perguntas e Respostas do holandês. O modelo contempla as duas formas de fusão, por interseção e por união. Porém, tanto a fusão por interseção, como a fusão por união, ocorre somente entre informações semanticamente relacionadas. Em outras palavras, as sentenças geradas não representam necessariamente a interseção ou a união do conjunto. $\mathrm{O}$ modelo é baseado na arquitetura proposta por Barzilay (2003) (vide Seção 2.1).

O alinhamento de informações comuns é realizado entre pares de árvores de dependências sintáticas de sentenças paralelas. O algoritmo baseia-se em um processo bottom-up e é similar ao usado por Barzilay \& Mckeown (2005). Porém, o alinhamento de dois nós $v$ e $v^{\prime}$, pertencentes a duas árvores de dependências $D$ e $D^{\prime}$, respectivamente, só se realiza se houver uma relação semântica entre a subárvore de $v$ e a subárvore de $v$, denotadas por $\operatorname{STR}(v)$ e STR $\left(v^{\prime}\right)$. Cinco tipos de relação são considerados: (1) EQUALS, se $\operatorname{STR}(v)$ e $\operatorname{STR}(v$ ') são literalmente idênticas (por exemplo, "a small and a large boaconstritor" e "a large and a small boa-constritor"); (2) RESTATES, que se estabelece quando $\operatorname{STR}(v)$ é uma paráfrase de $\operatorname{STR}(v)$ (por exemplo, "a drawing of a boaconstritor snake" e "a drawing of a boa-constritor"); (3) SPECIFIES, se STR(v) é mais específica que $\operatorname{STR}(v$ ') (por exemplo, “the planet B 612" e "the planet"); (4) GENERALIZE, se $\operatorname{STR}(v)$ é mais genérica que $\operatorname{STR}(v$ ') (por exemplo, “the planet" e “the planet B 612") e (5) INTERSECTS, se $\operatorname{STR}(v)$ e $\operatorname{STR}(v$ ') compartilham o mesmo conteúdo, mas cada uma expressa uma informação adicional que não é expressa na outra (por exemplo, "Júpiter and Mars" e "Mars and Venus"). A anotação semântica é feita de forma manual, previamente ao alinhamento.

A similaridade entre dois nós $v$ e $v^{\prime}$, denotada por $\operatorname{Sim}\left(v, v^{\prime}\right)$, depende da similaridade das palavras associadas a esses nós e do alinhamento entre dois nós filhos de $v$ e $v$ ' que maximiza o valor de similaridade calculado entre cada par de descendentes imediatos possíveis desses nós. Assim, como em Barzilay \& Mckeown (2005) (Seção 3.1.1), a função $\operatorname{Sim}\left(v, v^{\prime}\right)$ é dada pela maximização das três expressões: Sim_subárvore $\left(v, v^{\prime}\right), \max _{i}={ }_{1}, \ldots, n S\left(v_{i}, v^{\prime}\right)$ e $\max _{j}={ }_{1}, \ldots, m S\left(v, v_{j}{ }^{\prime}\right)$. A principal diferença do modelo de Marsi \& Krahmer em relação àquele trabalho é a forma como calculam a função Sim_nós $\left(v, v^{\prime}\right)$ na expressão Sim_subárvore $\left(v, v^{\prime}\right)$ (Fórmula 6). Essa função pode assumir quatro possíveis valores, conforme ilustrado na Fórmula 7. 
$\operatorname{Sim\_ subárvore}\left(v, v^{\prime}\right)=\operatorname{Sim\_ nós}\left(v, v^{\prime}\right) \quad+$

$$
\operatorname{Max}_{p \in P\left(v, v^{\prime}\right)}\left(\sum_{(i, j) \in p} \operatorname{Sim} \_\operatorname{dep}\left(\left(v_{i}, v\right),\left(v_{j}, v^{\prime}\right)\right)+\operatorname{Sim}\left(v_{i}, v_{j}\right)\right)
$$

$$
\operatorname{Sim\_ nós}\left(v, v^{\prime}\right)= \begin{cases}10 & \text { se } \operatorname{STR}(v)=\operatorname{STR}\left(v^{\prime}\right) \\ 5 & \text { se relação_semântica }(v)=\text { relação_semântica }\left(v^{\prime}\right) \\ 2 & \text { se vé um sinônimo, hipônimo ou hiperônimo de v } \\ 0 & \text { caso contrário }\end{cases}
$$

A fusão de duas árvores alinhadas tem como base o tipo de relação semântica existente entre seus nós. Por exemplo, se dois nós $v$ e $v^{\prime}$ têm uma relação de RESTATES, ESPECIFIES ou GENERALIZES, então $\operatorname{STR}\left(v^{\prime}\right)$ é adicionada como uma realização alternativa a $\operatorname{STR}(v)$. Esse procedimento é repetido duas vezes com cada par de árvores: uma vez para adicionar as realizações alternativas de cada nó da árvore $D$ em $D^{\prime}$ e outra para incluir as realizações de $D^{\prime}$ em $D$.

Durante a linearização, o algoritmo percorre cada árvore com todas as verbalizações alternativas de cada nó e gera todas as sentenças possíveis sem considerar qualquer informação prévia. As sentenças repetidas e aquelas idênticas às sentenças de entrada são eliminadas. Um modelo de língua baseado em trigramas, treinado com um corpus de $250 \mathrm{MB}$ de palavras pelo toolkit $\mathrm{CMU}$, é responsável pela seleção da sentença mais provável dentre as sentenças restantes. O Quadro 6 apresenta exemplos de sentenças geradas pelo modelo a partir de relações de RESTATES, SPECIFIES e GENERALIZE, extraídos de Marsi \& Krahmer (2005, pág. 114).

\section{Quadro 6: Exemplos de fusão de sentenças (Marsi \& Krahmer, 2005; pág. 114)}

Input 1: Thus have I in the course of my life very many contacts had with very many serious persons.

Input 2: In that way came I in the life with masses-of weighty important people in touch.

Restate: In that way have I in the course of my life very many contacts had with very many serious persons.

Specific: In that way have I in the course of my life with masses-of weighty important people in touch.

General: Thus have I in the life many contacts had with very many serious persons. 
Marsi \& Krahmer (2005) avaliaram a qualidade das sentenças geradas por seu modelo em termos do conteúdo semântico e gramatical. O corpus usado na avaliação consistiu em duas traduções diferentes do Capítulo 1 do livro francês "Le petit prince", para o idioma holandês, o qual compreendia um total de 35 pares de sentenças similares. Um total de 194 relações de RESTATES, 62 de ESPECIFIES e 177 de GENERALIZES foram identificas entre essas sentenças.

A avaliação foi feita por dois humanos que classificaram cada sentença produzida pelo sistema em três categorias: (a) perfeita, ou seja, sem erros de gramática e de semântica, (b) aceitável, isto é, compreensível, mas com pequenos erros gramaticais e semânticos e (c) sem sentido, com sérios erros gramaticais e semânticos. Os resultados obtidos são mostrados na Tabela 2.

Tabela 2: Resultados da avaliação do modelo de Marsi \& Krahmer (2005)

\begin{tabular}{|c|c|c|c|c|c|c|}
\hline \multirow{3}{*}{ Categoria } & \multicolumn{6}{|c|}{ Relação } \\
\hline & \multicolumn{2}{|c|}{ RESTATES } & \multicolumn{2}{|c|}{ SPECIFIES } & \multicolumn{2}{|c|}{ GENERALIZES } \\
\hline & Humano1 & Humano 2 & Humano1 & Humano 2 & Humano1 & Humano 2 \\
\hline Perfeita & 109 & 104 & 28 & 22 & 89 & 86 \\
\hline Aceitável & 44 & 58 & 15 & 16 & 34 & 24 \\
\hline Sem sentido & 41 & 32 & 19 & 24 & 54 & 67 \\
\hline Total & \multicolumn{2}{|c|}{194} & \multicolumn{2}{|c|}{62} & \multicolumn{2}{|c|}{177} \\
\hline
\end{tabular}

Com base nos resultados apresentados na tabela, pode-se notar que aproximadamente metade das sentenças geradas com base nas relações RESTATES e GENERALIZES foram consideradas perfeitas pelos dois humanos, enquanto que para a relação SPECIFIES isso não ocorreu. Segundo os autores, o experimento é, ainda, preliminar e não permite uma explicação plausível para tais resultados.

\subsubsection{Modelo de Fillipova \& Strube (2008)}

O modelo proposto por Filippova \& Strube (2008), para a fusão de sentenças do alemão, baseia-se em um método não supervisionado de compressão de grafo de dependências sintáticas. O modelo foi desenvolvido com base em um corpus de sentenças comparáveis do domínio biográfico e tem como principal foco de aplicação à 
sumarização multidocumento. As sentenças produzidas pelo modelo representam a união das informações mais relevantes das sentenças de entrada. $\mathrm{O}$ modelo também segue a arquitetura proposta por Barzilay (2003), composta por três etapas de alinhamento, fusão e linearização.

Dado um conjunto de sentenças de entrada, o algoritmo constrói um grafo a partir da união de suas correspondentes árvores de dependências sintáticas. Posteriormente, esse grafo é transformado em uma árvore de dependência, por meio de um processo de compressão que abstrai do grafo as informações mais relevantes.

Para facilitar esse processo, cada árvore de dependência passa por uma transformação. Considere a Árvore 1 na Figura 5 subjacente à sentença "Bohr studierte Mathematik und Physik an der Uni in Kopenhagen. (Bohr estudou matemática e física na universidade de Copenhagen.)", extraída de Filippova \& Strube (2008; pág. 180). O processo de transformação dessa árvore na Árvore 2 (Figura 5) consiste em: criar um nó raiz explícito (rotulado como root s); separar os elementos da coordenação, ou seja, "Mathematik und Physik", criando uma dependência direta de cada elemento com seu correspondente núcleo (isto é, o verbo "studierte"); representar as preposições "an" e "in" como arestas na árvore, ao invés de nós; remover as palavras funcionais como determinantes e verbos auxiliares e armazená-los junto ao núcleo, de modo que possam ser recuperados durante a linearização; e substituir todas as ocorrências do nome do biografado "Bohr" pela etiqueta bio (todas as referências alternativas a essa entidade também são mantidas no mesmo nó). Além disso, as palavras de classes abertas são lematizadas e as expressões temporais e os nomes de entidades são agregados em um único nó.

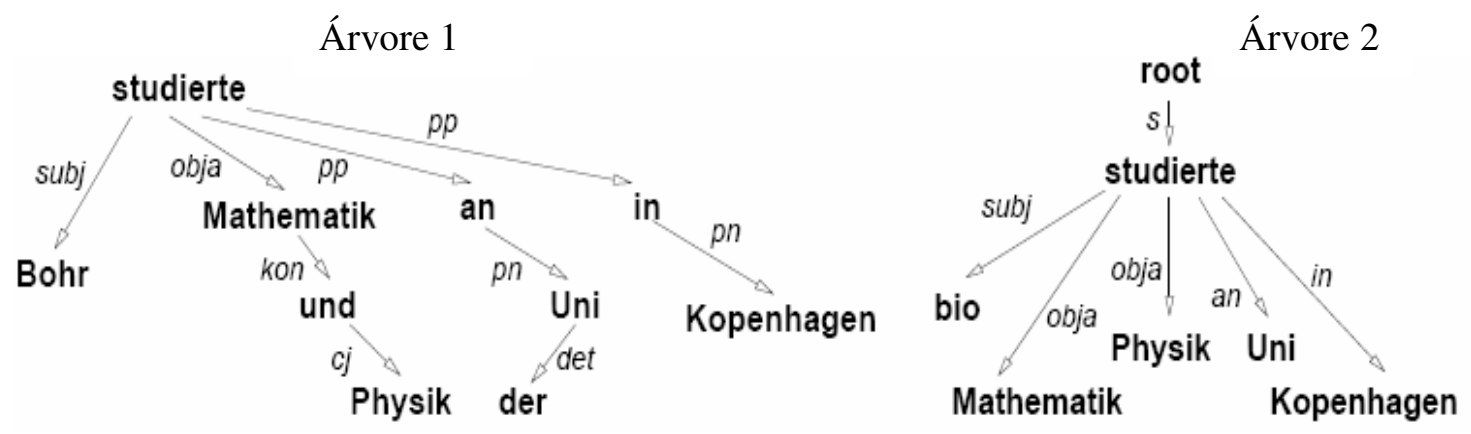

Figura 5: Árvore de dependência sintática antes e após a transformação (Fillipova \& Strube, 2008; pág. 180)

Após a transformação, o alinhamento é aplicado entre todas as combinações de pares de árvores de dependências. Depois, o algoritmo seleciona aleatoriamente uma 
das árvores e a une com todas as outras, obtendo um grafo com a união de todas as sentenças de entrada.

O alinhamento é realizado entre pares de nós cujas palavras associadas possuem o mesmo part-of-speech (POS) e são sinônimas ou têm lemas idênticos. Os traços de dependências sintáticas não são considerados nesse processo. É válido destacar que essa abordagem simples não permite, por exemplo, identificar paráfrases sintáticas como " $a$ capital alemã" e "a capital da Alemanha".

Em seguida, o grafo passa por um processo de compressão, de modo a obter uma nova árvore sintática. A fim de preservar as informações mais importantes das sentenças de entrada e evitar a remoção de constituintes sintáticos relevantes que possam interferir na gramaticalidade da nova sentença, a compressão é baseada em dois fatores: no grau de importância dos constituintes sintáticos e na informatividade das palavras associadas a cada nó.

A importância de cada constituinte sintático, que representa uma aresta no grafo, é calculada com base na probabilidade de ocorrência daquele constituinte (isto é, da aresta) dada a palavra associada ao seu nó de origem. Por exemplo, na Árvore 2 (Figura 5) a probabilidade de ocorrência da aresta "subj" dada a palavra "studieren", denotada por $P($ subj|studieren), é maior do que a probabilidade da aresta "in" dada a palavra "studieren" (P(in|studieren $))$. As probabilidades são estimadas a partir de um corpus de 3000 documentos biográficos coletados da web.

A informatividade de uma palavra $w$ no grafo, denotada por $I(w)$, é calculada pela Fórmula 8.

$$
I(w)=\frac{l}{N} \cdot f_{w} \log \frac{F_{A}}{F_{w}}
$$

$f_{w}$ representa a frequência da palavra $w$ nas sentenças do conjunto de entrada, $F_{w}$ é a frequência de $w$ no corpus todo, $F_{A}$ é a soma das frequências de todas as palavras do grafo no corpus, $N$ é o nível máximo de subordinações existentes na sentença a qual $w$ pertence e $l$ é o número de nós da oração que está em um nível de subordinação acima da oração que contem $w$ na sentença. A intuição subjacente a esse cálculo é que a importância de cada palavra do grafo está associada ao nível de subordinação da oração a qual a palavra pertence na sentença de entrada (Clarke \& Lapata, 2008). 
A compressão do grafo é modelada como um problema de otimização e utiliza a técnica de Programação Linear Inteira (ILP). A fim de decidir quais arestas do grafo serão removidas, para cada aresta que representa uma dependência direta entre um núcleo $h$ e uma palavra $w$, introduz-se uma variável $x_{h, w}^{\mathcal{L}}$, onde $l$ representa o rótulo da aresta, ou seja, o seu POS. Essa variável pode assumir dois valores possíveis: 1, se a aresta deve ser preservada e 0 , caso contrário.

O problema consiste em encontrar uma subárvore do grafo que apresenta o melhor valor para uma função objetivo, que considera o grau de importância sintática, denotado por $P(l \mid h)$, e o grau de informatividade $(I(w))$ (Fórmula 9).

$$
f(X)=\sum_{x} x_{h, w}^{\ell} P(l \mid h) I(w)
$$

A função objetivo está sujeita a quatro tipos de restrições, a saber: i) estrutural, ii) sintática, iii) semântica e iv) metarrestrição. As restrições estruturais são três. A primeira delas estabelece que cada nó tenha somente um nó pai. A segunda restrição estabelece que todo nó tenha pelo menos uma conexão com outro nó na árvore e a terceira restrição, por sua vez, restringe o tamanho da árvore em número de nós, o qual é determinado empiricamente. Em relação à sintaxe, a única restrição é que uma subordinação só deve ser preservada se e somente se ela for uma oração subordinada também na sentença a ser produzida. Já as restrições semânticas visam garantir a compatibilidade dos elementos nas coordenações. Por exemplo, nas sentenças " $E r$ studierte Physik. (Ele estudou Física.)" e "Er studierte Wissenschaft". (Ele estudou Ciências.)", os elementos Physik e Wissenschaft não podem ser agregados em uma coordenação (como na sentença "Er studierte Physik und Wissenschaft."), pois Wissenschaft é uma generalização de Physik. Por fim, a metarrestrição determina que uma restrição semântica só será aplicada entre dois elementos (dois nós) se ambos tiverem que ser preservados (ou seja, se o valor da variável $\left.\mathcal{X}_{h, w}=1,\right)^{5}$. Segundo os autores, a coordenação verbal não é tratada nesse modelo, pois implicaria no uso de relações temporais e/ou discursivas como as relações de precedência e de causa e consequência.

\footnotetext{
${ }^{5}$ Para mais detalhes sobre a formalização dessas restrições no algoritmo, vide Filippova \& Strube (2008).
} 
$\mathrm{Na}$ linearização, a árvore resultante do processo de compressão é percorrida considerando os diferentes caminhos, dadas as verbalizações alternativas de cada nó, de modo a gerar todas as sentenças possíveis. Depois, um método de linearização estatístico desenvolvido especificamente para o alemão (Filippova \& Strube, 2007) é usado para ordenar os constituintes de cada sentença. Com base em diversas informações linguísticas, por exemplo, POS, função sintática (isto é, sujeito, verbo, objeto, etc.), classe semântica (por exemplo, pessoa, lugar e organização), entre outras, o método identifica, para cada verbo finito da sentença, a posição de cada um de seus constituintes dependentes. Entretanto, o método não é capaz de predizer a posição de cada elemento dentro de um constituinte sintático, mas somente a posição do constituinte como um todo. Já a posição dos verbos é fixada pela gramática e é insensível a outros fatores. De acordo com os autores, esse modelo não trata os aspectos de concordância gramatical, pois não há um módulo responsável pela realização superficial apropriada das palavras.

Após a linearização, a melhor sentença gerada é selecionada usando um modelo de trigramas construído a partir de um corpus de 1GB de documentos biográficos pelo tollkit CMU (Clarkson \& Rosenfeld, 1997).

Filippova \& Strube (2008) também avaliaram o seu modelo de forma intrínseca. A avaliação foi feita com 40 sentenças fundidas automaticamente a partir de 40 grupos de sentenças comparáveis do domínio biográfico. As sentenças foram analisadas por 50 falantes nativos do alemão e pontuadas em uma escala de 0 (pior) a 5 (melhor), de acordo com dois critérios: legibilidade e informatividade. Para permitir a avaliação de informatividade, os avaliadores tiveram acesso também às sentenças originais dadas como entrada para o sistema. Para fins de comparação, foi utilizada uma versão adaptada para o alemão do modelo de fusão proposto por Barzilay (2003) (vide Seção 3.1.1). Em adição, cada sentença gerada também foi comparada a uma sentença selecionada aleatoriamente do conjunto de entrada. As sentenças de entrada foram usadas como referência para legibilidade (daqui em diante Max_Legibilidade). As árvores de dependências subjacentes a essas sentenças foram submetidas ao mesmo processo de linearização que as sentenças fundidas automaticamente. Nesse processo não houve nenhuma alteração de conteúdo, mas apenas de forma das sentenças. Os resultados médios obtidos para legibilidade e para informatividade são apresentados na Tabela 3. 
Tabela 3: Resultados médios obtidos para legibilidade e informatividade (Filippova \& Strube, 2008; pág. 183)

\begin{tabular}{|l|c|c|}
\hline \multicolumn{1}{|c|}{ Sistema } & Legibilidade & Informatividade \\
\hline Max_Legibilidade & 4 & 3,5 \\
\hline Filippova \& Strube & 3,7 & 3,1 \\
\hline Barzilay \& Mckeown & 3,1 & 3 \\
\hline
\end{tabular}

Os resultados de um teste de significância estatística, o $t$-teste pareado, realizado por Filippova \& Strube (ou seja, $p=0,01$ ) mostraram que há diferença significativa entre o método proposto pelos autores e o sistema de Barzilay \& Mckeown em termos de legibilidade. Entretanto, não existe diferença em termos de informatividade das sentenças produzidas pelos dois métodos.

\subsection{Modelos de Geração de Paráfrases}

\subsubsection{Modelo de Pang et al. (2003)}

O modelo de Pang et al. (2003) não se trata de um modelo de fusão propriamente dito, mas um modelo de geração de sentenças a partir de sentenças. $\mathrm{O}$ sistema proposto para o inglês recebe como entrada um conjunto de sentenças paralelas monolíngues e produz como saída uma ou mais sentenças que são paráfrases das sentenças de entrada. As sentenças produzidas servem de referência para a avaliação automática de sentenças resultantes de um processo de tradução automática.

$\mathrm{O}$ modelo segue uma arquitetura em pipeline similar à proposta por Barzilay (2003), com exceção de que o alinhamento de informações comuns e a fusão consistem em uma única etapa. Pang et al. alinham árvores sintáticas e não utilizam qualquer tipo de relação semântica ou de dependência sintática. Assim, são alinhadas apenas unidades lexicamente idênticas ou com a mesma categoria sintática. As unidades sintaticamente equivalentes são consideradas paráfrases.

O alinhamento é realizado incrementalmente, ou seja, em um primeiro instante um par de árvores sintáticas é alinhado e as duas árvores são unidas, dando origem a uma floresta sintática. No segundo instante, a próxima árvore é alinhada à floresta e 
unida a ela e, assim, sucessivamente até se obter uma floresta sintática com a fusão de todas as árvores. $\mathrm{O}$ alinhamento procede a partir das raízes das árvores até as suas folhas ou até encontrar dois nós de tipos sintáticos diferentes. A Figura 6 ilustra a floresta sintática resultante do alinhamento das árvores $1 \mathrm{e} 2$, correspondentes às sentenças " 12 persons were killed" e "Twelve people died", respectivamente (Pang et al., 2003; pág. 104). Na floresta sintática, as palavras “12" e "persons" (Árvore 1) estão alinhadas as palavras "twelve" e "people" (Árvore 2), respectivamente, pois apresentam as mesmas características sintáticas (ou seja, CD (cardinal) e NN (nome)).
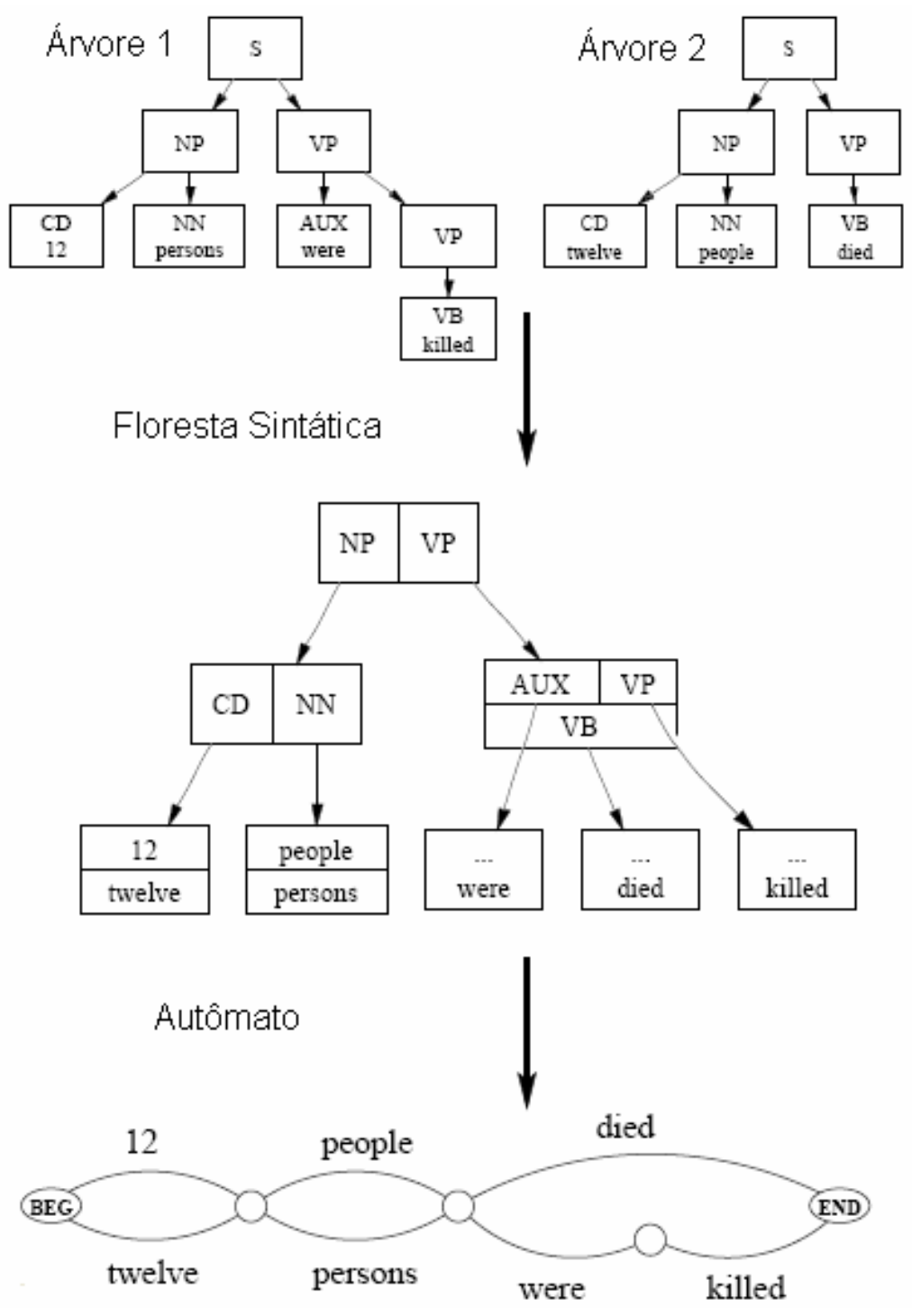

Figura 6: Exemplo de alinhamento e fusão de árvores sintáticas (Pang et al., 2003; pág. 104) 
Após o alinhamento, a floresta é mapeada para um autômato finito (Figura 6). Esse mapeamento é feito percorrendo-se a floresta a partir das raízes até as folhas e criando caminhos alternativos para cada nó com mais de uma verbalização possível. Posteriormente, o autômato passa por um processo de compactação. Durante esse processo, duas arestas rotuladas com a mesma palavra e que tenham um mesmo nó de origem no autômato e um mesmo nó destino são unidas em uma única aresta. Finalizado esse processo, cada caminho no autômato iniciado com o nó $B E G$ e terminado com o nó END representa uma paráfrase ou uma sentença idêntica à alguma sentença de entrada.

A linearização das sentenças, nesse modelo, consiste simplesmente em percorrer o autômato finito, gerando todas as sentenças possíveis. Posteriormente, um modelo de língua construído com o uso do toolkit CMU (Clarkson \& Rosenfeld, 1997) é usado para selecionar as melhores sentenças.

Pang et al. (2003) avaliaram seu modelo intrinsecamente. A avaliação teve como objetivo verificar se as paráfrases produzidas consistiam em diferentes traduções corretas de uma mesma sentença. O corpus utilizado, denominado MTC (Multiple Translation Chinese), era composto por 105 artigos jornalísticos traduzidos do chinês para o inglês por 11 agências de notícias diferentes (totalizando 899 sentenças). Para cada sentença de um artigo em chinês havia, portanto, 11 traduções diferentes em inglês.

A avaliação foi realizada comparando-se pares de sentenças geradas pelo modelo, a fim de verificar se elas constituíam uma paráfrase da outra e, portanto, consistiam em diferentes traduções. Para comparação, usaram um algoritmo de extração de paráfrases (daqui em diante, EP) proposto em Barzilay \& Mckeown (2001). As sentenças foram, então, fornecidas como entrada para esses dois algoritmos e, posteriormente, 600 pares de sentenças foram selecionados aleatoriamente (300 pares de cada um). Os pares de sentenças foram distribuídos entre 4 humanos, sendo que cada um recebeu 150 pares ( 75 de cada algoritmo). Cada par de sentenças foi julgado em três classes: (i) correta, para paráfrases perfeitas em um determinado contexto, (ii) parcialmente correta, para pares de sentenças que apresentavam paráfrases parciais e (iii) incorreta, para pares de sentenças completamente diferentes, isto é, que não constituíam uma paráfrase uma da outra. Os resultados obtidos por cada humano são apresentados na Tabela 4. 
Tabela 4: Resultados da avaliação do modelo de Pang et al. (2003)

\begin{tabular}{|c|c|c|c|c|c|c|}
\hline & \multicolumn{2}{|c|}{ Correta } & \multicolumn{2}{c|}{ Parcial } & \multicolumn{2}{c|}{ Incorreta } \\
\cline { 2 - 7 } & Paráfrase & EP & Paráfrase & EP & Paráfrase & EP \\
\hline Humano-1 & $85 \%$ & $68 \%$ & $12 \%$ & $13 \%$ & $3 \%$ & $19 \%$ \\
\hline Humano-2 & $80 \%$ & $63 \%$ & $13 \%$ & $13 \%$ & $7 \%$ & $24 \%$ \\
\hline Humano-3 & $81 \%$ & $68 \%$ & $5 \%$ & $3 \%$ & $13 \%$ & $29 \%$ \\
\hline Humano-4 & $77 \%$ & $68 \%$ & $17 \%$ & $16 \%$ & $5 \%$ & $16 \%$ \\
\hline Média & $81 \%$ & $66 \%$ & $12 \%$ & $11 \%$ & $7 \%$ & $22 \%$ \\
\hline
\end{tabular}

Embora cada humano tenha avaliado um conjunto diferente de sentenças, todos eles classificaram a maior parte dos pares de sentenças do algoritmo de fusão como corretas (81\% em média conforme Tabela 4), enquanto que 66\% em média das sentenças produzidas pelo algoritmo de paráfrase estavam corretas.

\subsubsection{Modelo de Wan et al. (2005)}

O modelo de Wan et al. (2005) consiste na geração de paráfrases, a partir da recombinação de palavras obtidas de um conjunto de sentenças similares em inglês. As paráfrases produzidas têm como finalidade substituir as sentenças selecionadas para compor um sumário, em uma aplicação de sumarização automática, visando obter sumários mais legíveis e coerentes.

A geração de sentenças é modelada como um problema de busca. Mais especificamente, dado um grafo com as palavras das sentenças de entrada, o algoritmo de Viterbi (Forney 1973) busca pelo melhor caminho no grafo, que representa a sequência de palavras mais provável, com base em informações probabilísticas. Cada vértice corresponde a uma palavra. As arestas, por sua vez, contêm pesos que representam a média de duas probabilidades: a probabilidade de coocorrência do par de palavras associadas a dois vértices (daqui em diante prob_bigrama) e a probabilidade de existir uma relação de dependência entre elas (daqui em diante prob_dependência). Assim, o peso de uma aresta que conecta duas palavras $w_{i+1}$ e $w_{i}$ é definido pela Fórmula 10. 
(10)

$$
\text { p_aresta }\left(w_{i+1}, w_{i}\right)=\text { media }\left(\text { prob_bigrama }\left(w_{i+1} \mid w_{i}\right), p r o b \_d e p e n d e ̂ n c i a\left(w_{i+1} \mid w_{i}\right)\right)
$$

onde prob_bigrama $\left(w_{i+1} \mid w_{i}\right)$ é definida pela Fórmula 11.

$$
\operatorname{prob} \_ \text {bigrama }\left(w_{i+1} \mid w_{i}\right)=\frac{f c o\left(w_{i+1}, w_{i}\right)}{f\left(w_{i}\right)}
$$

$f c o\left(w_{i+1}, w_{i}\right)$ representa o número de coocorrências de $w_{i+1}$ e $w_{i}$, enquanto $f\left(w_{i}\right)$ é a frequência de $w_{i}$. As probabilidades de coocorrência dos bigramas foram calculadas com base em um corpus da Organização das Nações Unidas sobre ajuda humanitária. Durante o percurso no grafo, à medida que uma palavra é adicionada ao caminho, a estrutura de dependência da sentença parcialmente obtida é construída probabilisticamente. Mais especificamente, para cada vértice visitado, o algoritmo calcula o seu dependente mais provável analisando cada uma das palavras já inclusas no caminho. Essas palavras são armazenadas em uma pilha denominada headStack. A probabilidade de dependência entre duas palavras $w_{i+1}$ e $w_{i}$, denotada por prob_dependência $\left(w_{i+1} \mid w_{i}\right)$, é dada pela Fórmula 12.

$$
\begin{aligned}
& \operatorname{prob\_ dependência}\left(w_{i+1} \mid w_{i}\right) \approx \\
& p\left(\operatorname{Dep}_{\text {sym }}\left(w_{i+1}, \text { headStack }\left(w_{i}\right)\right)\right)=\max _{h \in \operatorname{headStack}\left(w_{i}\right)}\left(p\left(\operatorname{Dep}_{\text {sym }}\left(w_{i+1}, h\right)\right)\right.
\end{aligned}
$$

$p\left(\operatorname{Dep}_{s y m}\left(w_{i+1}\right.\right.$, headStack $\left.\left.\left(w_{i}\right)\right)\right)$ é calculada com base na maior probabilidade de dependência entre $w_{i+1}$ e cada palavra $h$ de headStack, que representa um possível núcleo de $w_{i+1}$. Segundo Want et al. (2005), esse cálculo foi inspirado no modelo probabilístico usado pelo parser proposto por Collins (1996). Porém, os autores não apresentam detalhes de como fazem esse cálculo.

A probabilidade de um caminho no grafo é calculada recursivamente conforme a Fórmula 13.

p_caminho $\left(w_{o}, \ldots, w_{i+1}\right)=$ prob_bigrama $\left(w_{i+1}, w_{i}\right) x$ prob_sel $(w) x p \_c a m i n h o\left(w_{o}, \ldots, w_{i}\right)$ 
prob_sel $(w)$ representa a probabilidade de uma palavra $w$ ser escolhida para o sumário. No modelo de Wan et al., todas as palavras são consideradas igualmente importantes, de modo que a probabilidade de cada palavra participar do sumário é sempre igual a 1. O Quadro 7 apresenta vários exemplos de sentenças produzidas por esse modelo, a partir da recombinação de palavras obtidas de três sentenças similares (a, b e c) (Wan et al., 2005; pag. 89). As sentenças geradas automaticamente contêm o número de palavras (entre colchetes) pré-determinado pelo usuário do sistema.

Segundo Want et al., a desvantagem desse modelo é que, por se tratar de um método baseado em recombinação probabilística de palavras, as sentenças resultantes nem sempre refletem a mesma mensagem das sentenças originais.

Quadro 7: Exemplos de sentenças geradas pelo modelo de Wan et al. (2005)

a) A military transporter was scheduled to take off in the afternoon from Yokota air base on the outskirts of Tokyo and fly to Osaka with 37,000 blankets.

b) Mondale said the United States, which has been flying in blankets and is sending a team of quake relief experts, was prepared to do more if Japan requested.

c) United States forces based in Japan will take blankets to help earthquake survivors Thursday, in the U.S. military's first disaster relief operation in Japan since it set up bases here.

Novas sentenças:

[6] united states forces based in blankets

[8] united states which has been flying in blankets

[11] a military transporter was prepared to osaka with 37,000 blankets

[18] mondale said the afternoon from yokota air base on the united states which has been flying in blankets

[20] mondale said the outskirts of tokyo and is sending a military transporter was prepared to osaka with 37,000 blankets

[23] united states forces based in the afternoon from yokota air base on the outskirts of tokyo and fly to osaka with 37,000 blankets

[27] mondale said the afternoon from yokota air base on the outskirts of tokyo and is sending a military transporter was prepared to osaka with 37,000 blankets [29] united states which has been flying in the afternoon from yokota air base on the outskirts of tokyo and is sending a team of quake relief operation in blankets

[31] united states which has been flying in the afternoon from yokota air base on the outskirts of tokyo and is sending a military transporter was prepared to osaka with 37,000 blankets

[34] mondale said the afternoon from yokota air base on the united states which has been flying in the outskirts of tokyo and is sending a military transporter was prepared to osaka with 37,000 blankets

[36] united states which has been flying in japan will take off in the afternoon from yokota air base on the outskirts of tokyo and is sending a military transporter was prepared to osaka with 37,000 blankets 
Wan et al. (2005) avaliaram seu modelo de forma intrínseca. Mais especificamente, os autores mediram o potencial do sistema na preservação dos argumentos dos verbos, que, segundo eles, são fundamentais para predizer a gramaticalidade de uma oração. Assim, eles calcularam a Precisão e a Cobertura dos argumentos de cada verbo de uma sentença gerada em relação aos argumentos do mesmo verbo na sentença de entrada. A Precisão representa o número de argumentos verbais corretos sobre o total de argumentos daquele verbo na sentença gerada pelo sistema. A Cobertura representa o número de argumentos verbais corretos sobre o total de argumentos daquele verbo na sentença de entrada. O corpus de avaliação é composto por 100 grupos de sentenças comparáveis (em média 4 sentenças cada) do domínio jornalístico. Para cada grupo, foram geradas 36 sentenças distintas de tamanhos variando entre 3 e 38 palavras. As Figuras 7 e 8 mostram os resultados médios obtidos para precisão e cobertura (Wan et al., 2005, pág. 93-94). O baseline usado na comparação é uma versão simplificada do modelo, que se baseia somente nas probabilidades dos bigramas, sem fazer uso das probabilidades das dependências.

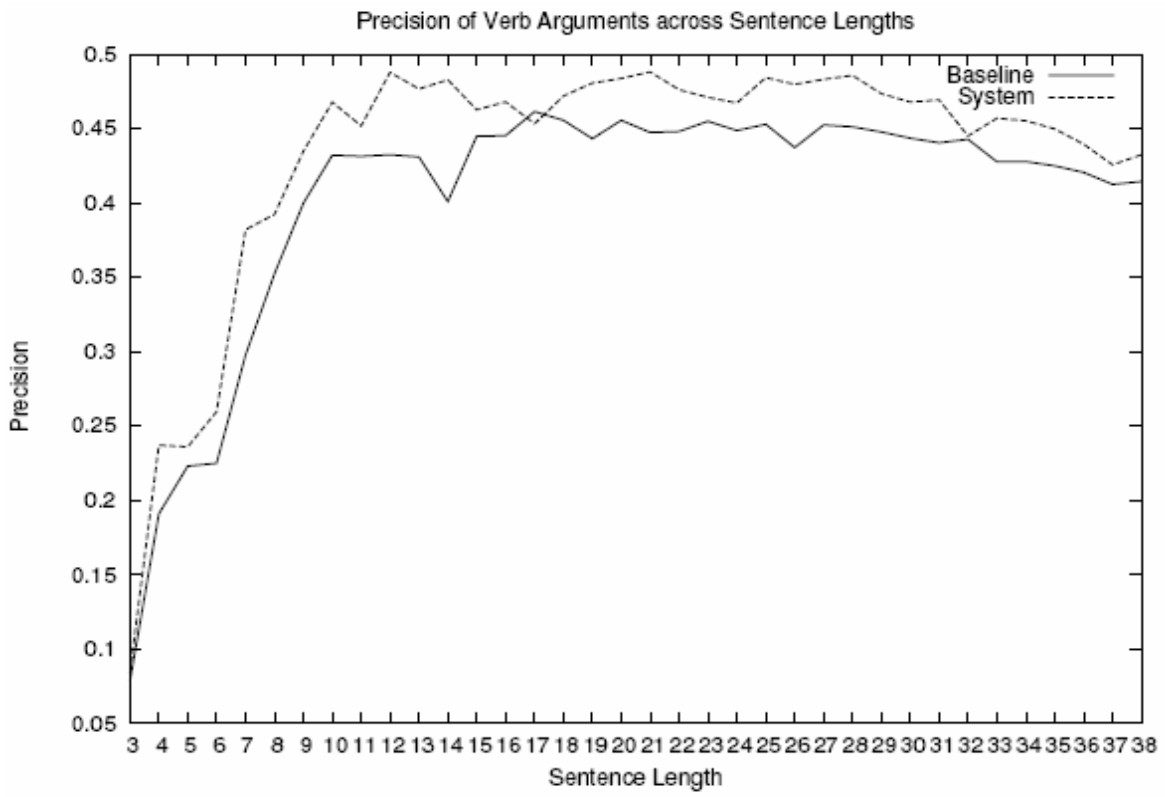

Figura 7: Precisão média da relação verbo-argumento (Wan et al., 2005; pág. 93) 


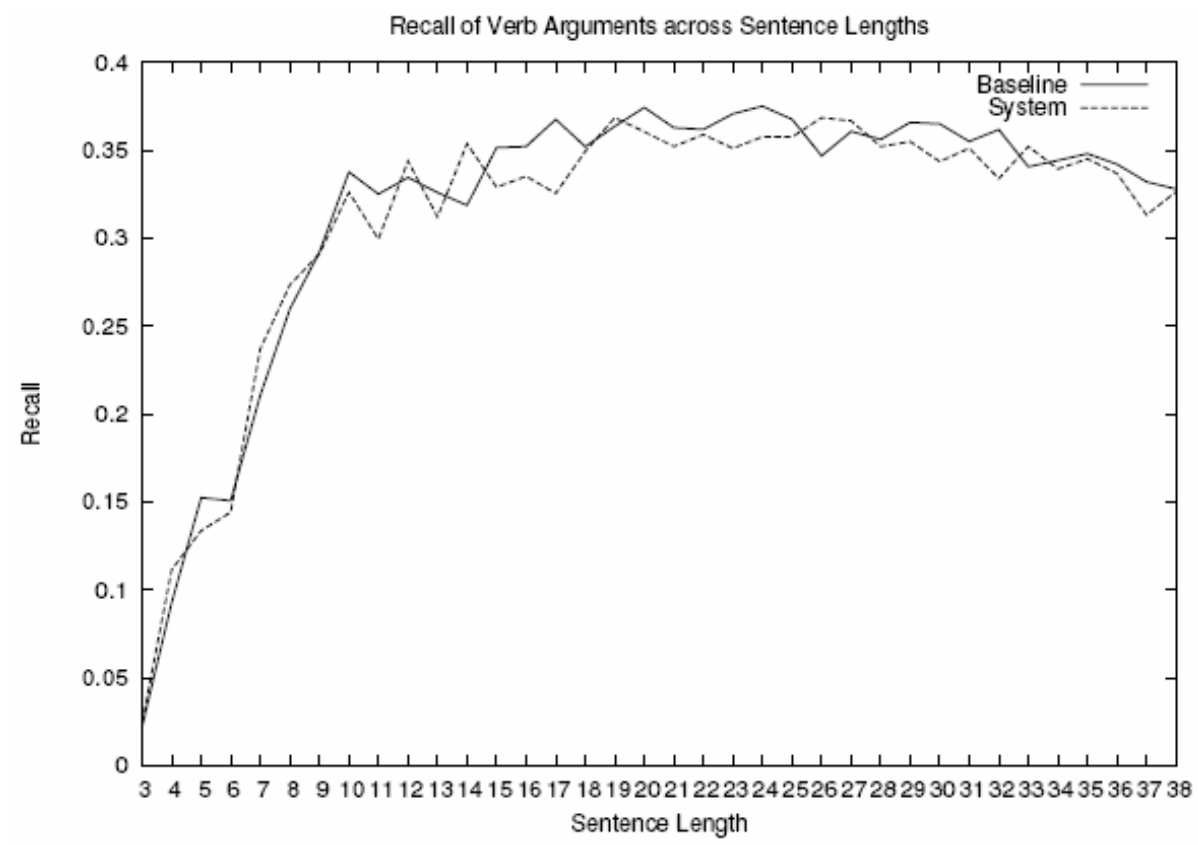

Figura 8: Cobertura média da relação verbo-argumento (Wan et al., 2005; pág. 94)

Segundo Wan et al. (2005), testes estatísticos mostraram que a diferença nos valores de Precisão obtidos pelo modelo, em comparação com o baseline, é significativa na maioria dos casos (exceto para sentenças de comprimento 17 e 32). Esses resultados comprovam, portanto, a contribuição das relações de dependências sintáticas na geração de sentenças gramaticais. Entretanto, as diferenças não são significativas para os valores de cobertura. Isso já era esperado, de acordo com os autores, uma vez que as sentenças mais curtas não preservam necessariamente todos os argumentos de um verbo.

Wan et al. analisaram, ainda, a precisão e a cobertura considerando os argumentos adjacentes aos verbos e os argumentos de longa distância separadamente. Essa análise foi feita de modo similar ao experimento anterior. Porém, os autores não apresentam os resultados obtidos para cobertura, uma vez que eles são insignificantes comparados aos do baseline. Os valores médios obtidos para precisão para os casos de argumentos adjacentes aos verbos e para os argumentos de longa distância são ilustrados nas Figuras 9 e 10, respectivamente (Wan et al., 2005). 


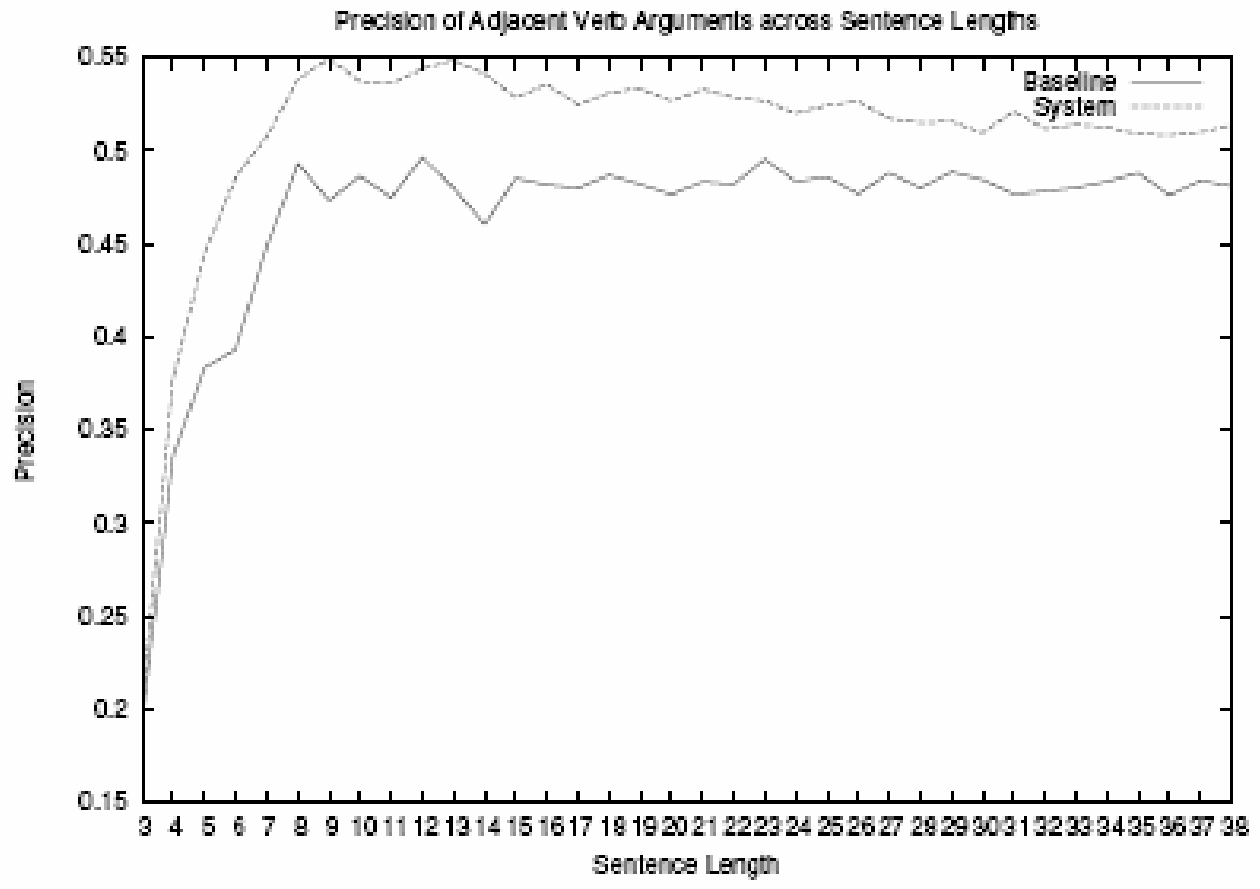

Figura 9: Precisão média dos argumentos adjacentes aos verbos (Wan et al., 2005; pág. 94)

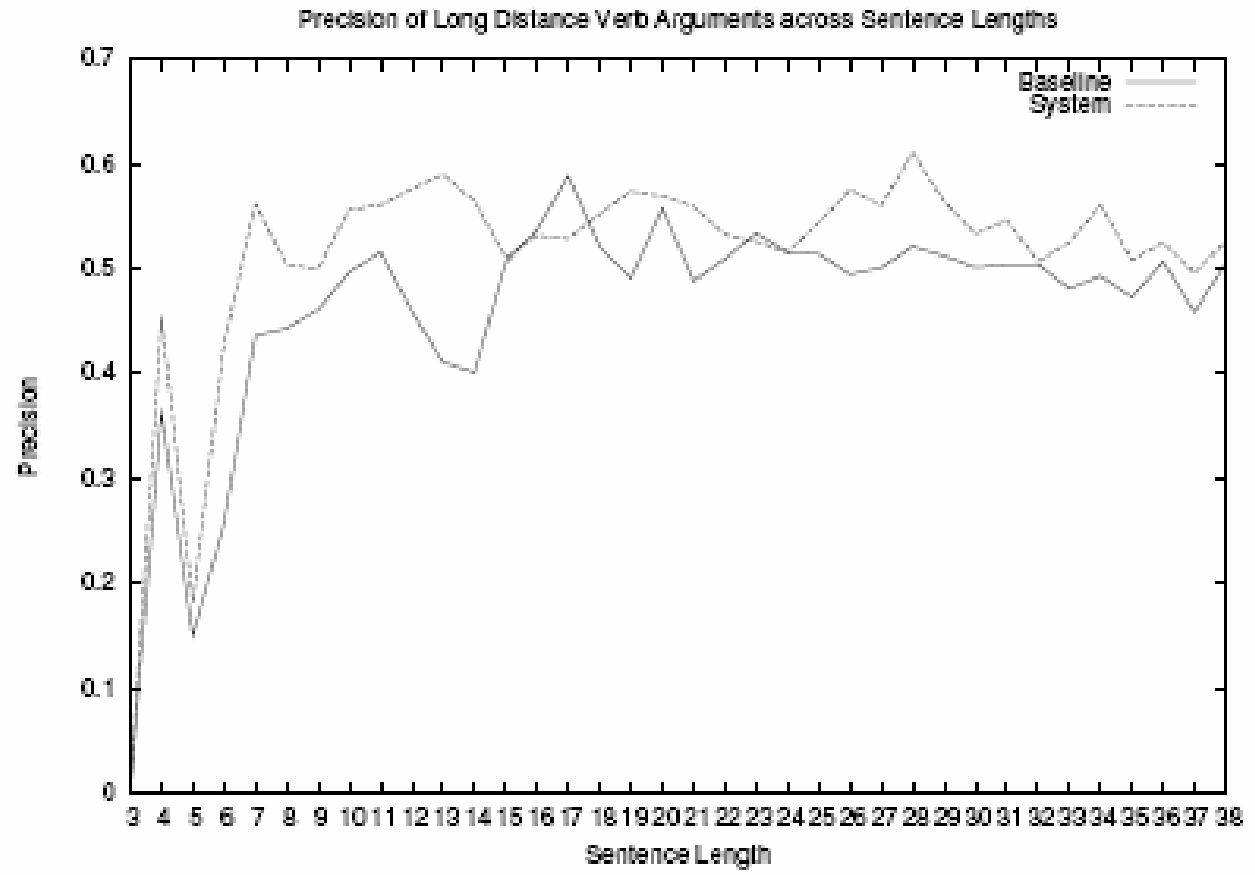

Figura 10: Precisão média dos argumentos verbais de longa distância (Wan et al., 2005; pág. 94) 
De acordo com Wan et al. (2005), os valores de precisão para as dependências adjacentes aos verbos (Figura 10) refletem os resultados obtidos no primeiro experimento (Figura 9). Ou seja, o sistema proposto desempenhou melhor do que o baseline na maioria dos casos e a diferença é estatisticamente significativa. Já no caso das dependências de longa distância, apesar de o gráfico da Figura 10 mostrar um desempenho melhor do sistema na maior parte dos casos, as diferenças não são significativas.

\subsubsection{Modelo de Shen et al. (2006)}

O modelo de Shen et al. (2006) é similar ao proposto por Pang et al. (2003) (Seção 3.2.1) em vários aspectos. Primeiramente, também se trata de um modelo de geração de paráfrases. Em outras palavras, as sentenças produzidas por esse modelo não representam necessariamente a interseção ou a união das sentenças de entrada. Outra semelhança está relacionada aos processos de fusão e linearização, que consistem basicamente na construção de um autômato, a partir do alinhamento de um conjunto de sentenças, e na geração de todas as sentenças possíveis representadas no autômato. $\mathrm{O}$ alinhamento de informações comuns também é puramente baseado em sintaxe. Porém, Shen et al. alinham sentenças, ao invés de árvores sintáticas.

O alinhamento de um conjunto de sentenças similares é construído via programação dinâmica e utiliza a medida de similaridade de Levenshtein, conhecida por edit distance. A edit distance entre duas sentenças é dada pelo número de substituições, inserções ou remoções de palavras necessárias para transformar uma sentença na outra.

Dadas duas sentenças S1 e S2 de tamanhos M e N, respectivamente, o cálculo da edit distance produz uma matriz de distância $\mathrm{D}$ com $\mathrm{M}+1$ linhas por $\mathrm{N}+1$ colunas. $\mathrm{A}$ matriz é construída recursivamente com base na função definida pela Fórmula 14.

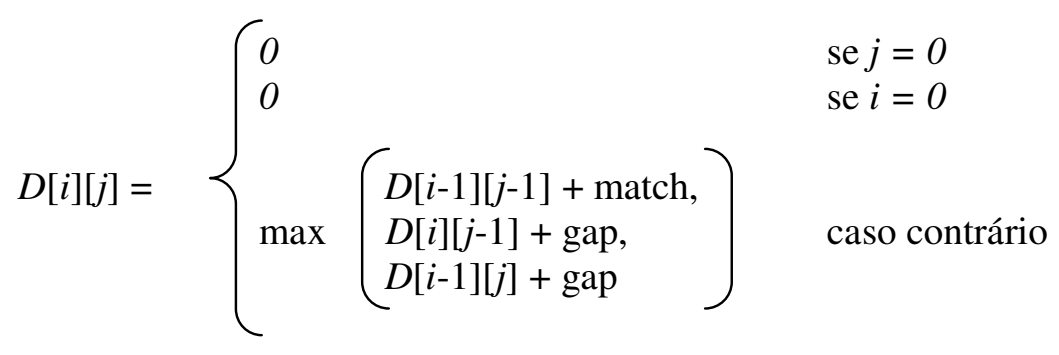


match é igual a 2 se a $i$-ésima palavra de $\mathrm{S} 1$ e a $j$-ésima palavra de $\mathrm{S} 2$ têm as mesmas características sintáticas, e -1 caso contrário. gap é igual a -1 e representa o custo para a inserção de uma palavra vazia (isto é, um gap), ao invés de produzir um alinhamento.

Dada uma entrada $D[i][j]$ na matriz, se o seu valor for derivado de $D[i-1][j-1]+$ match, então a $i$-ésima palavra de $\mathrm{S} 1$ é alinhada com $j$-ésima palavra de $\mathrm{S} 2$, se elas forem sintaticamente similares, ou ambas as palavras são alinhadas a um gap, caso contrário. Se o valor da célula $D[i][j]$ for derivado de $D[i][j-1]+$ gap, então a $i$-ésima palavra de $\mathrm{S} 1$ é alinhada com um gap inserido em $\mathrm{S} 2$ e a j-ésima palavra de $\mathrm{S} 2$ não é consumida. Em caso contrário, a j-ésima palavra de S2 é alinhada com um gap inserido em S1. Palavras lexicamente similares, mas que possuem diferentes $P O S$ não são alinhadas. Nesse caso, match é igual a -1 . O valor de match depende das características sintáticas das duas palavras que estão sendo comparadas. Essas características referemse à posição relativa de cada palavra dentro de um determinado sintagma (se ela pertencer a algum) e ao seu traço de dependência. Assim, cada palavra de uma sentença tem uma etiqueta denominada IOB que indica se a palavra está no início, no meio ou fora de um sintagma. Se duas palavras com o mesmo POS são lexicamente similares e ocupam a mesma posição em um mesmo constituinte sintático, seu valor de IOB é 1 . Se ambas as palavras ocupam diferentes posições em um mesmo constituinte, seu IOB é 0 . Caso contrário, o valor de IOB é -1. A similaridade dos traços de dependência entre duas palavras é calculada pela somatória dos valores de IOB dos dependentes diretos e indiretos de cada palavra nas respectivas sentenças. Se esse resultado somado ao resultado da comparação dos IOBs das duas palavras for menor que 0 , então match é igual a -1. Caso contrário, verifica-se também a posição relativa de cada palavra nas respectivas sentenças. A posição relativa de uma palavra é obtida dividindo-se a sua posição absoluta pelo número de palavras da sentença. Se a diferença entre a posição relativa das duas palavras for menor ou igual 0,4 (definido empiricamente), match será igual a 2 .

O alinhamento de todo o conjunto de sentenças é realizado de forma similar. Após alinhar o primeiro par de sentenças, as sentenças restantes são alinhadas uma a uma com as sentenças previamente alinhadas. Para cada palavra da sentença a ser alinhada, o algoritmo busca pelo melhor alinhamento possível, analisando cada palavra das sentenças já alinhadas. A partir dos alinhamentos identificados, o algoritmo produz um autômato finito e, posteriormente, percorre-o gerando todas as sentenças possíveis. 
Shen et al. (2006) não fornecem mais detalhes sobre o processo de construção do autômato e a geração de sentenças.

Os autores avaliaram intrinsecamente as sentenças produzidas por seu modelo em termos da gramaticalidade e da fidelidade do conteúdo apresentado. $\mathrm{O}$ experimento foi feito com 5 versões distintas do modelo proposto. As três primeiras versões, denotadas por V1, V2 e V3, utilizam uma simplificação do método de alinhamento baseada somente em similaridade lexical. A principal diferença entre elas é que V1 considera o alinhamento de todos os tokens da sentença (e não apenas de palavras), enquanto que V2 alinha tudo, exceto vírgulas. Já V3 é uma modificação de V2 que considera apenas as palavras de classes abertas. As duas últimas versões do algoritmo, V4 e V5, são baseadas em sintaxe. V4 considera somente o alinhamento de palavras de classes abertas, excluindo as vírgulas, enquanto V5 alinha todas as palavras, exceto vírgulas.

O corpus usado nos experimentos é composto por 11 grupos de sentenças comparáveis do domínio jornalístico. Para cada grupo, foram selecionadas aleatoriamente 100 sentenças geradas por cada versão do algoritmo. Essas sentenças foram distribuídas entre 6 humanos e julgadas de forma independente. Os humanos atribuíram nota 4 para sentenças sem erros gramaticais ou cujo conteúdo era fiel ao conteúdo apresentado nas sentenças originais; nota 3 para sentenças com poucos erros de gramática ou cujo conteúdo distorcia um pouco o conteúdo original; nota 2 para sentenças com muitos erros de gramática ou com várias informações distorcidas e nota 1 para sentenças sem sentido. Os resultados médios obtidos para gramaticalidade e fidelidade por cada versão do algoritmo são apresentados na Tabela 5.

Tabela 5: Resultados médios para gramaticalidade e fidelidade (Shen et al., 2006; pág. 752)

\begin{tabular}{|c|c|c|}
\hline Sistema & Gramaticalidade & Fidelidade \\
\hline V1 & 2,89 & 2,98 \\
\hline V2 & 3,00 & 2,95 \\
\hline V3 & 3,15 & 3,22 \\
\hline V4 & 3,68 & 3,59 \\
\hline V5 & 3,47 & 3,30 \\
\hline
\end{tabular}

Conforme mostra a tabela, as versões 4 e 5 do algoritmo, que se baseiam em sintaxe, obtiveram melhor desempenho do que as outras versões que não utilizam 
qualquer informação sintática. Em particular, a versão 4 superou a versão 5 ao desconsiderar os alinhamentos de vírgulas e de palavras de classes fechadas.

\subsection{Considerações Finais}

Os trabalhos descritos neste capítulo diferem em muitos aspectos, por exemplo, em relação ao método utilizado (simbólico ou de busca probabilístico), em relação à entrada (sentenças comparáveis ou paralelas monolíngues), em relação à saída (interseção, união ou paráfrase das sentenças de entrada), em relação aos conhecimentos utilizados (por exemplo, informações de part-of-speech, relações sintáticas de dependência, informações semânticas, etc.), em relação ao foco de aplicação (Sumarização Automática, Perguntas e Respostas ou Tradução Automática), em relação à forma de avaliação, entre outros.

De modo geral, os resultados relatados por esses trabalhos mostram que a área é promissora e que há muito, ainda, a ser feito para melhorar os resultados alcançados até o momento. Além do mais, por se tratar de uma área de pesquisa muito recente, não há um critério de avaliação comum a todos os trabalhos. Portanto, é difícil afirmar qual método representa exatamente o estado atual da arte.

No que diz respeito aos métodos de fusão de sentenças, propriamente ditos, a maioria trata somente um tipo de fusão, ou seja, por interseção ou por união, de modo a atender aos requisitos de alguma aplicação específica, como é o caso dos modelos de Barzilay (2003) e de Fillipova \& Strube (2008). Entretanto, em alguns cenários a escolha por um tipo de fusão ou outro depende das necessidades de cada usuário, conforme observado por Krahmer et al. (2008). Em uma aplicação de perguntas e respostas, por exemplo, um usuário pode desejar uma resposta mais longa e completa (união), enquanto outro pode desejar uma resposta mais curta (interseção). Sistemas de fusão deveriam, assim, permitir a escolha de um tipo ou outro, quer seja pela aplicação ou pelo usuário final.

Nesse sentido, o método proposto por Marsi \& Krahmer (2005) é o único que aborda ambos os tipos de fusão (vide Seção 3.1.2). Porém, no trabalho dos autores, a fusão se dá somente entre informações semanticamente relacionadas. Por exemplo, nos segmentos de texto "the planet B12" e "the planet", que se relacionam por meio da relação SPECIFIES, o mais específico representa a união, isto é, "the planet B12" e o 
mais geral, indicado pela relação GENERALIZE, representa a interseção, ou seja, "the planet". Na fusão por união, por exemplo, esse modelo não considera a agregação de todas as informações apresentadas no conjunto de sentenças. Dessa maneira, não seria possível gerar, por exemplo, a sentença apresentada no Quadro 8, a partir da união das sentenças [1], [2] e [3], já que algumas informações não têm relação com outras (em negrito). A abordagem proposta por Fillipova \& Strube (2008) provavelmente também não conseguiria gerar sentenças similares à apresentada no quadro, pois considera somente a agregação das informações mais importantes do conjunto (vide Seção 3.1.3).

\section{Quadro 8: Exemplo de sentença que não pode ser produzida pelo método proposto} por Marsi \& Krahmer (2005)

[1] O Airbus A320, voo JJ3054, partiu de Porto Alegre, às 17h16 da terça-feira e chegou a São Paulo às 18h45.

[2] A aeronave da TAM Airbus A320, voo JJ3054, partiu de Porto Alegre, às 17h16 com destino a Congonhas.

[3] Um Airbus A320 com capacidade para 170 passageiros partiu de Porto Alegre (RS) às $17 \mathrm{~h} 16$ com destino a Congonhas.

União: A aeronave da TAM Airbus A320, voo JJ3054, com capacidade para 170 passageiros, partiu de Porto Alegre (RS), às $17 \mathrm{~h} 16$ da terça-feira com destino a Congonhas e chegou a São Paulo às $18 \mathrm{~h} 45$.

A fusão por união no método proposto nesta tese aborda a agregação de todas as informações apresentadas no conjunto, e não apenas das informações relacionadas. Além da união, o método contempla também a fusão por interseção, conforme será descrito no Capítulo 5. Antes, porém, o Capítulo 4 descreve sobre a construção e a preparação do corpus usado no desenvolvimento e nas avaliações do método proposto. 


\section{Capítulo 4}

\section{Construção do Corpus de Trabalho}

A metodologia adotada para a proposta e o desenvolvimento do método de fusão de sentenças similares é fundamentalmente baseada na análise de corpora de sentenças em português. Assim, antes de iniciar a construção do método de fusão propriamente dito, é necessário definir um corpus de trabalho. Além disso, os corpora também são um recurso linguístico indispensável na avaliação de um método de fusão.

Conforme apresentado no Capítulo 2, há basicamente dois tipos de corpora que são de interesse para a construção de um sistema de fusão, a saber: os corpora comparáveis monolíngues, formados por conjuntos de sentenças a respeito de um mesmo fato, mas escritos por diferentes autores, e os corpora paralelos monolíngues, formados por conjuntos de sentenças que são diferentes traduções para uma mesma língua de uma mesma sentença em outra língua. Para várias línguas estrangeiras, por exemplo, o inglês e o holandês já existem alguns corpora desses tipos, como citado no Capítulo 3. Contudo, para o português, esses recursos são ainda muito escassos. No que se refere aos corpora comparáveis, mais especificamente, não foi encontrado nenhum para o português. Em relação aos corpora paralelos monolíngues, tem-se conhecimento apenas do corpus CorTrad ${ }^{6}$, que contém a primeira tradução e a segunda versão revisada de 27 contos australianos. Porém, por se tratar de um corpus composto por traduções originais e sua versão revisada, o CorTrad não impõem muitos desafios para a tarefa de fusão, já que muitas sentenças sofreram pouquíssimas ou nenhuma alteração, após a revisão. Além do mais, trata-se de um corpus pequeno e com um vocabulário bastante restrito.

Tendo em vista a escassez de corpora para o português que atenda aos requisitos deste trabalho, quais sejam de um corpus que contemple conjuntos de sentenças similares, foi construído um corpus comparável, para subsidiar a construção do método

\footnotetext{
${ }^{6}$ http://www.fflch.usp.br/dlm/comet/projeto.html\#liter (último acesso em 29/03/10).
} 
de fusão sentencial. Para tanto, foram coletadas manualmente 53 coleções de textos jornalísticos, a partir de diversas agências de notícias brasileiras disponíveis na web (por exemplo, da Folha Online e do JBOnline). A escolha por textos desse gênero se deve a dois fatores principais. O primeiro fator é que, muito comumente, um mesmo fato é publicado por uma infinidade de fontes distintas, de modo que esses textos consistem em uma fonte bastante rica de sentenças similares (isto é, sentenças comparáveis). Outro fator é que os textos jornalísticos apresentam um vocabulário bastante abrangente e de fácil compreensão. O corpus compreende textos dos domínios de ciência, cotidiano, educação, esporte, mundo e política. O número de coleções por cada domínio é apresentado na Tabela 6. Cada coleção é composta por aproximadamente 4 documentos relacionados a um mesmo assunto, totalizando 184 documentos em todo o corpus. É importante observar que todos os documentos de uma mesma coleção foram publicados em uma mesma data, o que assegura uma maior similaridade do conteúdo apresentado nesses documentos.

Tabela 6: Número de coleções de documentos do corpus comparável por cada domínio

\begin{tabular}{|c|c|}
\hline Domínio & \# Coleções \\
\hline Cotidiano & 15 \\
\hline Mundo & 13 \\
\hline Esporte & 10 \\
\hline Política & 10 \\
\hline Ciência & 1 \\
\hline Educação & 1 \\
\hline
\end{tabular}

Com intuito de identificar as sentenças similares de cada coleção do corpus, foi construído um sistema denominado SiSPI - Similar Short-Passages Identiffier (Seno \& Nunes, 2008b; 2008c), que recebe como entrada uma coleção de documentos e produz como saída vários grupos de sentenças similares. A descrição e a avaliação do SiSPI são os temas das Seções 4.1 e 4.2, respectivamente. 


\subsection{SiSPI: Um Sistema para Identificação e Agrupamento de Sentenças Similares}

O SiSPI é composto por dois módulos principais de processamento em pipeline: um módulo de segmentação de sentenças e um módulo de agrupamento de sentenças, conforme ilustrado na arquitetura apresentada na Figura 11. O primeiro módulo é responsável por segmentar cada documento de uma coleção em sentenças. Esse processo é realizado pelo sistema SENTER (Pardo, 2006), um delimitador de sentenças do português. O segundo módulo, por sua vez, é responsável por identificar e agrupar as sentenças similares de uma dada coleção de documentos. Durante esse processo, SiSPI faz uso de um stemmer (Caldas Junior et al., 2001), que permite identificar palavras de uma mesma classe semântica, e de uma lista de palavras de classes fechadas do português (stopwords, em inglês), para a remoção de palavras irrelevantes a esse processo (por exemplo, artigos, preposições e conjunções).

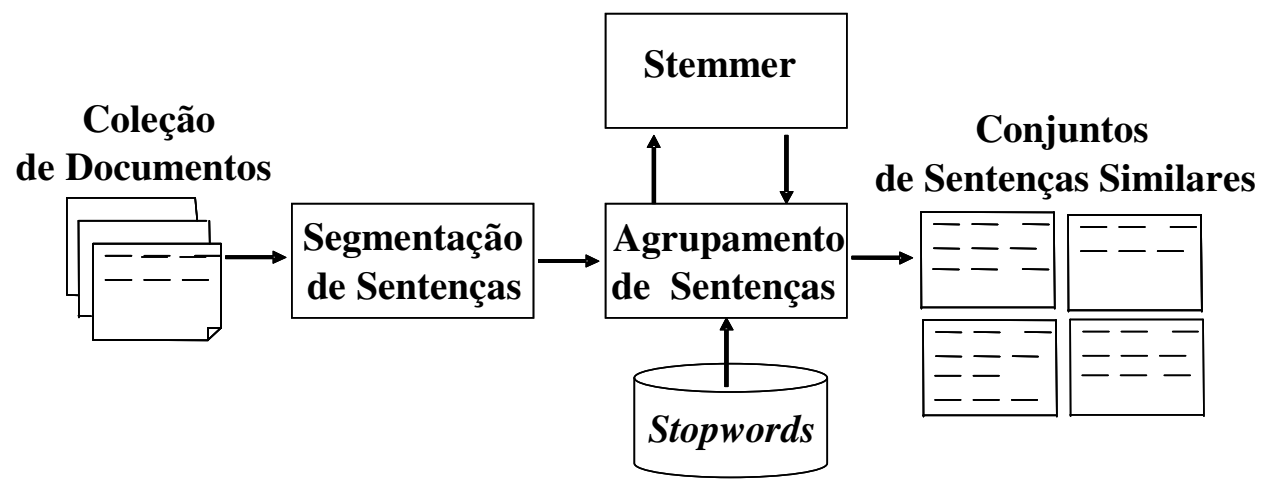

Figura 11: Arquitetura do SiSPI

O agrupamento de sentenças no SiSPI é baseado em um método não supervisionado de clustering conhecido por Single-pass (Van Rijsbergen, 1979). Esse método é bastante simples e eficiente e é um dos mais usados na área de Recuperação de Informação (por exemplo, Klampanos et al., 2006), para o agrupamento de textos. O método baseia-se em uma abordagem incremental, na qual os grupos de sentenças similares são criados incrementalmente a cada iteração do algoritmo. Uma das vantagens desse método é que não é necessário conhecer de antemão o número de grupos, como acontece em outros métodos (por exemplo, K-means (MacQueen, 1967)). Além disso, ele não requer grandes corpora de treinamento. 
O Single-pass, como o próprio nome sugere, requer um único passo sequencial sob todo o conjunto de sentenças a ser agrupado. Dado um conjunto de documentos como entrada, o primeiro grupo é criado selecionando-se a primeira sentença do primeiro documento do conjunto, conforme mostrado no algoritmo do Quadro 9. A cada iteração, o algoritmo verifica se a nova sentença de entrada deve pertencer a algum grupo já existente ou se um novo grupo deve ser criado para aquela sentença. Essa decisão é baseada em uma condição previamente estabelecida para a função de similaridade adotada, ou seja, um limite de similaridade. Duas funções distintas foram implementadas no SiSPI, de forma a calcular a distância semântica entre uma sentença e um grupo. A primeira função é baseada na medida Word-Overlap (WO) (Radev et al., 2008), que calcula o número de palavras em comum entre uma sentença $s$ e um grupo $c_{i}$, normalizado pelo total de palavras de $s$ e $c_{i}$ (Fórmula 15). O valor de similaridade da $W O$ varia de 0 a 0,5 . Quanto mais próximo de 0,5 , maior é a similaridade entre a sentença e aquele grupo.

$$
W O\left(s, c_{i}\right)=\frac{\# \text { PalavrasComuns }\left(s, c_{i}\right)}{\left(|s|+\left|c_{i}\right|\right)}
$$

A segunda função de similaridade baseia-se na distância do co-seno (Salton \& Allan, 1994) aplicada entre o vetor de frequência de termos da sentença $s$ e o vetor que representa os termos mais importantes do grupo $c_{i}$, denominado centroide. $\mathrm{O}$ valor de similaridade dessa função varia de 0 a 1 . Quanto mais próximo de 1 , maior é a similaridade entre a $s$ e $c_{i}$.

O centroide de um grupo de sentenças é determinado a partir de duas medidas estatísticas. A primeira medida é uma adaptação do TF-IDF (Term Frequency Inverse Document Frequency) (Salton \& Allan, 1994). O valor do TF-IDF de uma palavra $w$ pertencente a um grupo $c_{i}$, denotado por $\operatorname{TF}-\operatorname{IDF}\left(w, c_{i}\right)$, é dado pela Fórmula 16, onde $T F\left(w, c_{i}\right)$ representa a frequência da palavra $w$ no grupo $c_{i}$. Quanto maior o valor de $T F$, mais representativa do grupo $c_{i}$ é a palavra $w$. A frequência de documento inversa de $w$, denotada por $\operatorname{IDF}(w)$, é dada pela Fórmula 17, onde $|C|$ representa o total de sentenças de toda a coleção de documentos e $D F(w)$ representa o total de sentenças da coleção que contem $w$. 


\section{Quadro 9: Algoritmo Single-pass}

Entrada: Um conjunto $D=<d_{1}, \ldots, d_{n}>$ com $n$ documentos, onde cada $d_{i}=<s_{1}, \ldots, s_{m}>$ contém $m$ sentenças (para $n$ e $m>0$ ).

Saída: Um conjunto $C=\left\langle c_{1}, \ldots, c_{x}\right\rangle$ com $x$ grupos onde cada grupo $c_{i}=\left\langle s_{1}, \ldots, s_{y}\right\rangle$ contém $y$ sentenças similares (para $y>0$ ).

Passo 1: Inicializa o conjunto $C$

Passo 2: Seleciona uma sentença $s$ de um documento $d_{i}$ (seguindo a ordem de entrada dos documentos)

Se $C$ é igual a vazio

cria o primeiro grupo $c_{i}$ em $C$ e insere $s$

Senão compara $s$ com cada grupo $c_{i}$ de $C$

Se a similaridade entre $s$ e $c_{i}$ for maior que o limite pré-definido adiciona $s$ em $c_{i}$

Senão cria um novo grupo em $C$ e insere $s$

Passo 3: Repita o Passo 2 até que todas as sentenças de todos os documentos tenham sido processadas.

$$
\begin{gathered}
\operatorname{TF}-\operatorname{IDF}\left(w, c_{i}\right)=\operatorname{TF}\left(w, c_{i}\right) * \operatorname{IDF}(w) \\
\operatorname{IDF}(w)=1+\log (|C| / D F(w))
\end{gathered}
$$

A segunda medida usada para calcular o centroide de um grupo é a TF-ISF (Term Frequency Inverse Sentence Frequency) (Larocca Neto et al., 2000). Essa medida é similar ao TF-IDF, exceto que ela calcula a frequência de sentença inversa para um grupo em específico, ao invés de calcular para todos os documentos da coleção. A frequência de sentença inversa de $w$, denotada por $I S F(w)$, é dada pela Fórmula 18, onde $|C|$ representa o total de sentenças do grupo e $S F(w)$ é o total de sentenças do grupo que contêm $w$.

$$
\operatorname{ISF}(w)=1+\log (|C| / S F(w))
$$

Para que uma palavra seja representativa de um determinado grupo, ela deve ter um alto valor de $T F$ e um alto valor de $I S F$ (ou $I D F$ ) e, portanto, um alto valor de $T F$ ISF (ou TF-IDF). 
O número de palavras que devem compor o centroide e o limite mínimo de similaridade, que determina se certa sentença deve ser inserida em um grupo já existente ou se um novo grupo deve ser criado, são parametrizados pelo usuário do sistema. Para a construção do corpus de trabalho, esses parâmetros foram derivados por meio de experimentos, conforme serão descritos na seção a seguir.

\subsection{Avaliação do SiSPI}

A qualidade do resultado de um processo de clustering (ou simplesmente, de uma solução de clustering) pode ser avaliada de duas maneiras: por meio de medidas de qualidade externa ou por meio de medidas de qualidade interna (Steinbach et al., 2000). As medidas de qualidade externa avaliam o quão bom são os grupos produzidos automaticamente comparando-os com grupos de referência (geralmente produzidos por um humano). As medidas de qualidade interna, por sua vez, não usam nenhum tipo de conhecimento externo e avaliam somente a coesão dos grupos, isto é, o quão similar são os elementos de cada grupo. Segundo Steinbach et al. (2000), quando se deseja avaliar a qualidade geral de uma solução ou a eficiência de um método de clustering, as medidas de qualidade externas são mais apropriadas.

Para a avaliação do SiSPI, foram usadas apenas medidas de qualidade externas, conforme será abordado na Subseção 4.2.2. Antes, porém, a Subseção 4.2.1 descreve sobre o corpus de avaliação. Os resultados da avaliação são apresentados na Subseção 4.2.3.

\subsubsection{Corpus de Avaliação}

O corpus de avaliação é composto por 20 coleções de documentos selecionadas aleatoriamente a partir das 53 coleções coletadas da web. Esse subcorpus compreende 71 documentos e 1.153 sentenças no total.

Visando construir o corpus de referência de grupos de sentenças similares, cada sentença de uma coleção foi manualmente classificada, isto é, associada a um nome de grupo (daqui a diante, a classificação manual será referenciada por classes e o agrupamento automático será referenciado por grupos). Nos casos em que havia mais de 
uma classe possível para uma mesma sentença, somente uma foi escolhida, ou seja, a mais similar. É importante observar que no SiSPI cada sentença pertence a um grupo somente.

Para a classificação manual, adotou-se o conceito de similaridade proposto por Hatzivassiloglou et al. (1999; 2001) para a mesma tarefa de identificação de sentenças semanticamente similares. De acordo com esses autores, duas sentenças são semanticamente similares se elas se referem a um mesmo objeto ou evento e i) o objeto realiza a mesma ação em ambas as sentenças, ou ii) é sujeito da mesma descrição. Considere, por exemplo, as sentenças (a), (b) e (c) do Quadro 10, extraídas do corpus. Apesar de todas elas se referirem à explosão de uma bomba caseira, as sentenças (a) e (b) focam na explosão ocorrida no Ministério Público, enquanto que (c) se refere à explosão ocorrida na Secretaria de Estado da Fazenda. Nesse caso, somente (a) e (b) são consideradas similares.

\section{Quadro 10: Exemplo de sentenças similares e não similares}

(a) Uma bomba caseira foi atirada contra a sede do Ministério Público (MP).

(b) Uma bomba caseira foi jogada contra o prédio do Ministério Público, na capital do estado.

(c) Uma bomba caseira atingiu o prédio da Secretaria de Estado da Fazenda, localizado na avenida Rangel Pestana, ao lado do Poupatempo Sé.

\subsubsection{Medidas de Avaliação}

Duas classes de medidas de qualidade externa foram usadas neste trabalho, a saber: i) medidas que avaliam o desempenho do método de clustering e ii) medidas que avaliam a qualidade dos grupos de sentenças similares construídos automaticamente.

Para a avaliação de desempenho, foram usadas as medidas de Precisão, Cobertura e Medida-F, redefinidas no domínio de clustering (Steinbach et al., 2000; Fung et al., 2003).

Seja $N$ o número total de sentenças a serem agrupadas, $K$ o conjunto de classes, $C$ o conjunto de grupos e $n_{i j}$ o número de sentenças da classe $k_{i} \in K$ que estão presentes no grupo $c_{j} \in C$. A Precisão e a Cobertura de $k_{i}$ e $c_{j}$, denotadas por $P\left(k_{i}, c_{j}\right)$ e $C\left(k_{i}, c_{j}\right)$, respectivamente, são definidas pelas Fórmulas 19 e 20 (onde $\left|c_{j}\right|$ e $\left|k_{i}\right|$ denotam o número de sentenças do grupo $c_{j}$ e o número de sentenças da classe $k_{i}$, respectivamente). 
A Precisão representa a fração de sentenças do grupo $c_{j}$ pertencente à classe $k_{i}$ e indica o quão esse grupo é homogêneo em relação àquela classe. A Cobertura, por sua vez, representa o total de sentenças da classe $k_{i}$ presente no grupo $c_{j}$, indicando qual a completude do grupo $c_{j}$ em relação à classe $k_{i}$. Por fim, a Medida-F representa a média harmônica entre a Precisão e a Cobertura (Fórmula 21). Intuitivamente, ela mede a qualidade do grupo $c_{j}$ em descrever a classe $k_{i}$.

$$
\begin{gathered}
P\left(k_{i}, c_{j}\right)=n_{i j} /\left|c_{j}\right| \\
C\left(k_{i}, c_{j}\right)=n_{i j} /\left|k_{i}\right| \\
F\left(k_{i}, c_{j}\right)=\frac{\left(2 * C\left(k_{i}, c_{j}\right) * P\left(k_{i}, c_{j}\right)\right)}{C\left(k_{i}, c_{j}\right)+P\left(k_{i}, c_{j}\right)}
\end{gathered}
$$

A Medida-F de cada classe de todo o conjunto de dados se baseia no grupo que melhor descreve cada classe $k_{i}$, ou seja, no grupo que maximiza o valor de $F\left(k_{i}, c_{j}\right)$ para todo $j$. Assim, o valor de Medida-F global de uma solução de clustering $S$, denotado por $F(S)$, é dado pela Fórmula 22. O valor de $F(S)$ varia de 0 (pior) a 1(melhor).

$$
\begin{aligned}
& F(S)=\sum \quad\left|k_{i}\right| \quad \max c_{j} \in C\left\{F\left(k_{i}, c_{j}\right)\right\} \\
& k_{i} \in K \quad N
\end{aligned}
$$

Para avaliar a qualidade dos grupos de sentenças obtidos automaticamente, foram usadas duas medidas. A primeira é a Entropia (Steinbach et al., 2000), que mede a organização de cada grupo, ou seja, como as várias classes de sentenças estão distribuídas em cada grupo. Uma solução de clustering ideal é aquela na qual todos os grupos contêm sentenças de uma única classe. Nesse caso, o valor de Entropia é zero. O cálculo da Entropia é baseado na distribuição de classes de cada grupo, exatamente como faz a medida de Precisão. Em outras palavras, a Precisão representa a probabilidade de uma sentença escolhida aleatoriamente de um grupo $c_{j}$ pertencer a classe $k_{i}$. A Entropia de um grupo $c_{j}$, denotada por $E\left(c_{j}\right)$, é definida pela Fórmula 23. A Entropia global de uma solução de clustering $S$, denotada por $E(S)$, é dada pela soma 
das entropias de cada grupo $c_{j}$ ponderada pelo tamanho do grupo, conforme mostrado na Fórmula 24. Quanto menor o valor de $E(S)$, melhor é a solução de clustering.

$$
\begin{gathered}
E\left(c_{j}\right)=-\sum P\left(k_{i}, c_{j}\right) \log P\left(k_{i}, c_{j}\right) \\
k_{i} \\
E(S)=\sum_{c_{j}} \frac{\left|c_{j}\right|}{N} E\left(c_{j}\right)
\end{gathered}
$$

A segunda medida é denominada Pureza (Rosell et al., 2004). Como o próprio nome diz, essa medida avalia o quão puro é cada grupo de sentenças. Em outras palavras, a Pureza representa o percentual da classe mais frequente de cada grupo. A Pureza de um grupo $c_{j}$, denotada por $P\left(c_{j}\right)$, é definida pela classe $k_{i}$ que maximiza a Precisão do grupo $c_{j}$ (Fórmula 25). A Pureza global de uma solução de clustering $S$, denotada por $P(S)$, é dada pela soma dos valores de Pureza de cada grupo $c_{j}$ ponderada pelo tamanho do grupo (Fórmula 26). O valor de $P(S)$ varia de 0 (pior) a 1 (melhor).

$$
\begin{gathered}
P\left(c_{j}\right)=\max _{i}\left\{P\left(k_{i}, c_{j}\right)\right\} \\
P(S)=\sum \frac{\left|c_{j}\right|}{N} P\left(c_{j}\right) \\
c_{j} \in C N
\end{gathered}
$$

\subsubsection{Resultados}

Um parâmetro importante a ser definido, quando se aplica um método de clustering, é o limite de similaridade. Conforme descrito na Seção 4.1, esse limite é responsável por determinar quando uma sentença dará origem a um novo grupo. $\mathrm{O}$ limite ideal dependente dos objetivos da aplicação pretendida. Para os modelos TF-IDF e TF-ISF, que se baseiam na função do cosseno, há ainda outro parâmetro relevante: o tamanho do centroide. Esse parâmetro define o número de palavras de um determinado grupo, que será usado para calcular sua similaridade com certa sentença. A configuração adequada desses parâmetros é crucial para se alcançar o resultado almejado. 
Dessa forma, foi realizado um primeiro experimento, para determinar o tamanho ideal do centroide. Quatro configurações distintas foram avaliadas: 5, 10, 15 e 20 palavras. Para esse experimento, foi usado um limite de similaridade de 0,4, definido empiricamente. Os valores obtidos por cada modelo são apresentados na Tabela 7.

Tabela 7: Resultados médios obtidos para os modelos TF-IDF e TF-ISF com centroides de tamanhos variados

\begin{tabular}{|c|c|c|c|c|c|c|}
\hline $\begin{array}{c}\text { Número de Palavras do } \\
\text { Centroide }\end{array}$ & \multicolumn{3}{|c|}{ TF-IDF } & \multicolumn{3}{c|}{ TF-ISF } \\
\cline { 2 - 7 } & Entropia & Medida-F & Pureza & Entropia & Medida-F & Pureza \\
\hline $\mathbf{5}$ & 0,035 & 0,860 & 0,941 & 0,101 & 0,860 & 0,917 \\
\hline $\mathbf{1 0}$ & 0,037 & 0,860 & 0,939 & 0,106 & 0,863 & 0,912 \\
\hline $\mathbf{1 5}$ & 0,036 & 0,862 & 0,940 & 0,101 & 0,864 & 0,913 \\
\hline $\mathbf{2 0}$ & 0,042 & 0,862 & 0,938 & 0,106 & 0,863 & 0,913 \\
\hline
\end{tabular}

De modo geral, os resultados obtidos com cada medida de avaliação não variam muito, na medida em que se aumenta o número de palavras do centroide. Quando se avalia a melhor configuração de centroide para o desempenho global do método (isto é, Medida-F), os centroides de 15 e de 20 palavras superam ligeiramente os demais, no caso do TF-IDF, e o centroide de 15 palavras supera ligeiramente os demais, no caso do TF-ISF. Entretanto, quando se avalia a melhor configuração em termos da qualidade dos grupos (ou seja, em termos de Entropia e Pureza), o centroide de 5 palavras supera ligeiramente os demais em ambos os modelos (exceto para o TF-ISF cujo valor de Entropia é o mesmo com 5 ou 20 palavras). Como a Medida-F é mais completa do que as medidas de Entropia e Pureza, que não avaliam se todos os elementos de uma determinada classe estão presentes em um mesmo grupo, optou-se por usar a configuração com o maior valor de Medida-F, ou seja, 15 palavras.

Após definir o tamanho do centroide, um segundo experimento foi realizado com o objetivo de identificar o limite de similaridade que melhor define o corpus em questão. Cada função de similaridade foi avaliada usando diferentes limites. Para a função do cosseno (isto é, TF-IDF e TF-ISF) os limites variam de 0,1 a 1 , e no caso da função Word Overlap (WO) os limites variam de 0,1 a 0,5 (vide Seção 4.1). A Tabela 8 apresenta os resultados obtidos com cada medida de avaliação. 
Tabela 8: Resultados médios obtidos com cada medida de avaliação para diferentes limites de similaridade

\begin{tabular}{|c|c|c|c|c|c|c|c|c|c|c|c|}
\hline \multicolumn{2}{|l}{ Limite de Similaridade } & $\mathbf{0 , 1}$ & $\mathbf{0 , 2}$ & $\mathbf{0 , 3}$ & $\mathbf{0 , 4}$ & $\mathbf{0 , 5}$ & $\mathbf{0 , 6}$ & $\mathbf{0 , 7}$ & $\mathbf{0 , 8}$ & $\mathbf{0 , 9}$ & $\mathbf{1}$ \\
\hline \multirow{4}{*}{ TF-IDF } & Entropia & 0,843 & 0,287 & 0,096 & 0,037 & 0,016 & 0,005 & 0,004 & 0,003 & 0,002 & 0,001 \\
\cline { 2 - 12 } & Medida-F & 0,603 & 0,814 & 0,886 & 0,860 & 0,841 & 0,828 & 0,812 & 0,799 & 0,775 & 0,736 \\
\cline { 2 - 12 } & Pureza & 0,549 & 0,808 & 0,907 & 0,934 & 0,945 & 0,945 & 0,942 & 0,940 & 0,941 & 0,938 \\
\hline TF-ISF & Entropia & 1,759 & 0,900 & 0,319 & 0,101 & 0,043 & 0,013 & 0,004 & 0,003 & 0,002 & 0,002 \\
\hline \multirow{4}{*}{ WO } & Medida-F & 0,348 & 0,603 & 0,805 & 0,864 & 0,856 & 0,843 & 0,828 & 0,813 & 0,798 & 0,786 \\
\cline { 2 - 12 } & Entropia & 0,572 & 0,079 & 0,010 & 0,000 & 0,001 & - & - & - & - & - \\
\cline { 2 - 11 } & Medida-F & 0,695 & 0,860 & 0,838 & 0,809 & 0,786 & - & - & - & - & - \\
\cline { 2 - 10 } & Pureza & 0,654 & 0,908 & 0,946 & 0,943 & 0,941 & - & - & - & - & - \\
\hline
\end{tabular}

Com relação à Entropia, os valores melhoram consideravelmente, em todas as funções, na medida em que se aumenta o limite de similaridade. O mesmo ocorre para os valores da Medida-F e Pureza, mas até certo ponto. Mais especificamente, a MedidaF alcança o seu valor máximo com um limite de 0,2, para WO, 0,3, para TF-IDF, e 0,4, para TF-ISF. Em relação à Pureza, os valores melhoram até o limite de 0,3, no caso de WO, e até o limite de 0,5 no caso do TF-IDF e TF-ISF.

No que diz respeito aos valores de Entropia e de Pureza, esses são justificados, uma vez que, na proporção em que se aumenta o limite de similaridade, a variedade de classes em cada grupo tende a diminuir. Em outras palavras, há uma tendência dos grupos se tornarem mais homogêneos, ao passo em que o limite de similaridade aumenta. Consequentemente, os valores de Entropia e de Pureza melhoram. Além disso, como há também muitas sentenças não similares no corpus, a tendência é de que esses valores melhorem ainda mais, pois muitos grupos são formados por uma única sentença.

Em relação aos valores da Medida-F, apesar da tendência dos grupos de se tornarem mais homogêneos (aumentando a Precisão), à medida que o limite de similaridade aumenta, torna-se mais difícil identificar sentenças semanticamente equivalentes, porém lexicamente muito distintas. Dessa forma, os valores de Cobertura tendem a diminuir, prejudicando o desempenho global.

Em termos de bom desempenho do método de clustering e qualidade dos grupos de sentenças, o modelo TF-IDF com limite de similaridade 0,4 (daqui em diante TF- 
IDF-0,4) se mostrou mais apropriado para o propósito deste trabalho. Além de obter uma Medida-F de $86 \%$, ele apresentou uma baixa Entropia $(0,037)$ e um alto valor de Pureza $(93,4 \%)$, principalmente quando comparado aos valores obtidos pelo TF-IDF0,3, TF-ISF-0,4 e WO-0,2. Além do mais, o desvio padrão obtido pelo TF-IDF-0,4 (isto é, 0,07 para Medida-F, 0,06 para Pureza e 0,05 para Entropia) foi menor do que o obtido para o TF-IDF-0,3 (0,08 para Medida-F, 0,07 para Pureza e 0,10 para Entropia), TFISF-0,4 (0,09 para Medida-F, 0,08 para Pureza e 0,09 para Entropia) e WO-0,2 (0,08 para Medida-F, 0,06 para Pureza e 0,07 para Entropia). Assim, para construir os grupos de sentenças similares do corpus todo (53 coleções), foi utilizado o modelo TF-IDF-0,4 com um centroide de 15 palavras.

A Tabela 9 mostra o número total de grupos de sentenças identificados a partir das 20 coleções do subcorpus de avaliação e a partir do corpus todo, bem como a média de grupos por coleção. Cada grupo é composto de 2 a 5 sentenças, sendo que em média são aproximadamente 3 sentenças por grupo, tanto no subcorpus como no corpus todo. O total de grupos apresentado não considera os grupos formados por uma única sentença.

Tabela 9: Estatísticas sobre os grupos de sentenças identificados a partir do subcorpus de avaliação e a partir do corpus todo

\begin{tabular}{|c|c|c|}
\hline Corpus & $\begin{array}{c}\text { Número total de } \\
\text { grupos }\end{array}$ & $\begin{array}{c}\text { Número médio de } \\
\text { grupos por coleção }\end{array}$ \\
\hline $\begin{array}{c}\mathbf{2 0} \text { coleções de } \\
\text { avaliação }\end{array}$ & 202 & 10,1 \\
\hline $\mathbf{5 3}$ coleções & 393 & 7,8 \\
\hline
\end{tabular}

Os Quadros 11 e 12 apresentam exemplos de grupos de sentenças bons e ruins construídos pelo SiSPI. 
Quadro 11: Exemplos bons de grupos de sentenças construídos pelo SiSPI

Grupo 1:

[1-1] A polícia informou que o grupo já desviou $\mathrm{R} \$ 70$ milhões, desde 2004.

[1-2] O grupo é acusado de lesar os cofres públicos em cerca de $\mathrm{R} \$ 70$ milhões.

[1-3] Segundo divulgado pela PF, o grupo criminoso desviou desde 2004 cerca de

R \$ 70 milhões dos cofres públicos, por meio do pagamento de serviços, compras e obras superfaturadas.

\section{Grupo 2:}

[2-1] Ao menos 300 policiais de Amapá, Distrito Federal, Mato Grosso, Acre e Rondônia trabalharam na Operação Dominó.

[2-2] A PF divulgou que cerca de 300 policiais federais do Amazonas, Distrito Federal, Mato Grosso, Acre e de Rondônia fazem parte das investigações da "Operação Dominó".

[2-3] As buscas estão sendo feitas nos Estados do Amazonas, Distrito Federal, Mato Grosso, Acre e Rondônia.

[2-4] Mais de 300 policiais federais do Amazonas, Distrito Federal, Mato Grosso, Acre e Rondônia participaram das buscas e prisões.

\section{Grupo 3:}

[3-1] A Agência Americana Antidrogas (DEA) oferecia até US\$ 5 milhões em troca de informações sobre o seu paradeiro.

[3-2] De acordo com o site da DEA, agência do governo americano de combate ao narcotráfico, são oferecidos US\$ 5 milhões para quem forneça informações sobre o paradeiro de Abadia.

\section{Quadro 12: Exemplos ruins de grupos de sentenças construídos pelo SiSPI}

\section{Grupo 1:}

[1-1] Em relação aos primeiros três meses do ano o resultado recorrente da instituição cresceu $0,9 \%$.

[1-2] Na comparação com os primeiros três meses deste ano, a carteira cresceu $3,7 \%$.

\section{Grupo 2:}

[2-1] Com ações em seis Estados --São Paulo, Rio, Minas, Paraná, Santa Catarina e Rio Grande do Sul--, a operação havia capturado 12 suspeitos, até a tarde desta terça-feira.

[2-2] Os agentes da PF cumprem 16 mandados de prisão e 28 de busca e apreensão nos Estados de São Paulo, Rio de Janeiro, Minas Gerais, Paraná, Santa Catarina e Rio Grande do Sul.

\section{Grupo 3:}

[3-1] Há ainda outros feridos graves do prédio da TAM Express, que foram direcionados para hospitais da região.

[3-2] Um dos prédios atingidos era da TAM Express. 


\subsection{Considerações Finais}

Este capítulo apresentou a construção de um corpus composto por 393 conjuntos de sentenças similares do português, para subsidiar na construção e na avaliação do modelo de fusão de sentenças. Para a construção do corpus, foi desenvolvido o sistema SiSPI, que, dado um conjunto de textos em português sobre um mesmo assunto, identifica as sentenças similares e as organiza em grupos. O SiSPI é independente de domínio e pode ser facilmente customizado para outras línguas, uma vez que ele se baseia apenas em informações superficiais (vide Seção 4.1). Outra característica do sistema é que ele permite a identificação de sentenças com diferentes graus de similaridades, definidos pelo próprio usuário. Vários experimentos foram realizados com o SiSPI e os resultados obtidos são bastante satisfatórios (conforme apresentados na Seção 4.2.3).

O capítulo a seguir apresenta o método de fusão de sentenças para o português. 


\section{Um Método para a Fusão Automática de Sentenças em Português}

Após apresentar o levantamento bibliográfico no Capítulo 3 e a construção do corpus de trabalho no Capítulo 4, apresenta-se, neste capítulo, o método proposto para a fusão automática de sentenças similares do português. Esse método contempla, em um mesmo modelo, os dois tipos de fusão citados no Capítulo 2 - fusão por interseção e fusão por união de informações. A fusão por união segue uma estrátegia não abordada, até o momento, na literatura - a agregação de todas as informações apresentadas em um conjunto de sentenças, por meio de regras. Como visto no Capítulo 3, as abordagens existentes consideram somente a agregação das informações mais importantes de um conjunto (vide Fillipova \& Strube, 2008) e a união de informações semanticamente relacionadas (vide Marsi \& Krahmer, 2005). Tais abordagens não preservam, portanto, todas as informações de um conjunto.

O método de fusão proposto é baseado em uma abordagem simbólica. Nesta abordagem, todo o conhecimento necessário ao processo de fusão deve ser explicitado e formalizado para que a tarefa em questão possa ser automatizada. O conhecimento visado, nesse caso, é aquele que auxiliará no planejamento do conteúdo a ser veiculado pela nova sentença, bem como o conhecimento linguístico necessário para a estruturação e a realização superficial da sentença (por exemplo, informações morfológicas e sintáticas). Todo esse conhecimento é extraído diretamente das próprias sentenças do conjunto a ser fundido e por meio do alinhamento de conceitos comuns apresentados nessas sentenças (Seções 5.2 e 5.3). Mais especificamente, o alinhamento é responsável por auxiliar na seleção do conteúdo relevante, assim como na identificação do conteúdo redundante que precisa ser descartado. Além disso, ele auxilia no processo de união de informações na fusão por união (Seção 5.2.2). 
O método segue as três etapas básicas de um modelo de fusão propostas por Barzilay (2003) - (1) alinhamento de informações comuns, (2) fusão e (3) linearização, conforme ilustrado na Figura 12. Primeiramente, as sentenças do conjunto a ser fundido (no mínimo duas sentenças) são analisadas por um parser, que constrói, para cada sentença, a árvore de dependência sintática. Após o parsing, as sentenças são alinhadas, identificando-se os conceitos equivalentes entre elas. O alinhamento é baseado nos traços de dependências sintáticas de cada sentença (conforme será abordado na Seção 5.1). Durante o alinhamento, o método faz uso de um thesaurus, de uma lista de stopwords (por exemplo, artigos, preposições e conjunções), para a remoção de palavras irrelevantes a esse processo, e de um conjunto de regras que permitem o reconhecimento de paráfrases (Seção 5.1.1). Os alinhamentos identificados nesta etapa são responsáveis por guiar o processo de fusão, propriamente dito, na identificação dos conceitos a serem veiculados nas novas sentenças. A fusão pode ser de duas formas: por interseção de informações ou por união de informações (Figura 12). A última etapa, por sua vez, é a linearização, que consiste na realização linguistica das sentenças obtidas a partir da etapa anterior, selecionando as estruturas morfológicas e sintáticas apropriadamente. Durante esse processo, o método faz uso de um gerador de formas superficiais do português, que permite a realização superficial das sentenças (como será descrito na Seção 5.3). É importante observar que nenhum dos métodos encontrados na literatura contempla um módulo de linearização propriamente dito, que permita tratar os aspectos de concordância gramatical e a realização superficial apropriada das palavras (vide Capítulo 3). O método apresentado aqui é o primeiro que trata desses aspectos. Entretanto, é importante dizer desde já que esta tese não pretende propor soluções completas para o processo de realização linguística, uma vez que ele consite em uma tarefa suficientemente complexa para merecer um trabalho independente. Em outras palavras, não é o objetivo deste trabalho desenvolver um realizador linguístico completo para o português.

Conforme visto no Capítulo 1, várias aplicações do PLN podem ser beneficiadas por um sistema de fusão sentencial, especialmente os sistemas de sumarização de textos e de perguntas e respostas. Visando permitir a aplicação automática do método proposto em várias tarefas que envolvem o processamento do português, foi construído um protótipo de sistema denominado Zíper. O Zíper é independente de aplicação, podendo, portanto, ser usado no contexto de qualquer aplicação em que esse processo se faz 
necessário. A concepção desse protótipo, por outro lado, é imprescindível para a realização de testes e validação do método de fusão de sentenças aqui proposto.

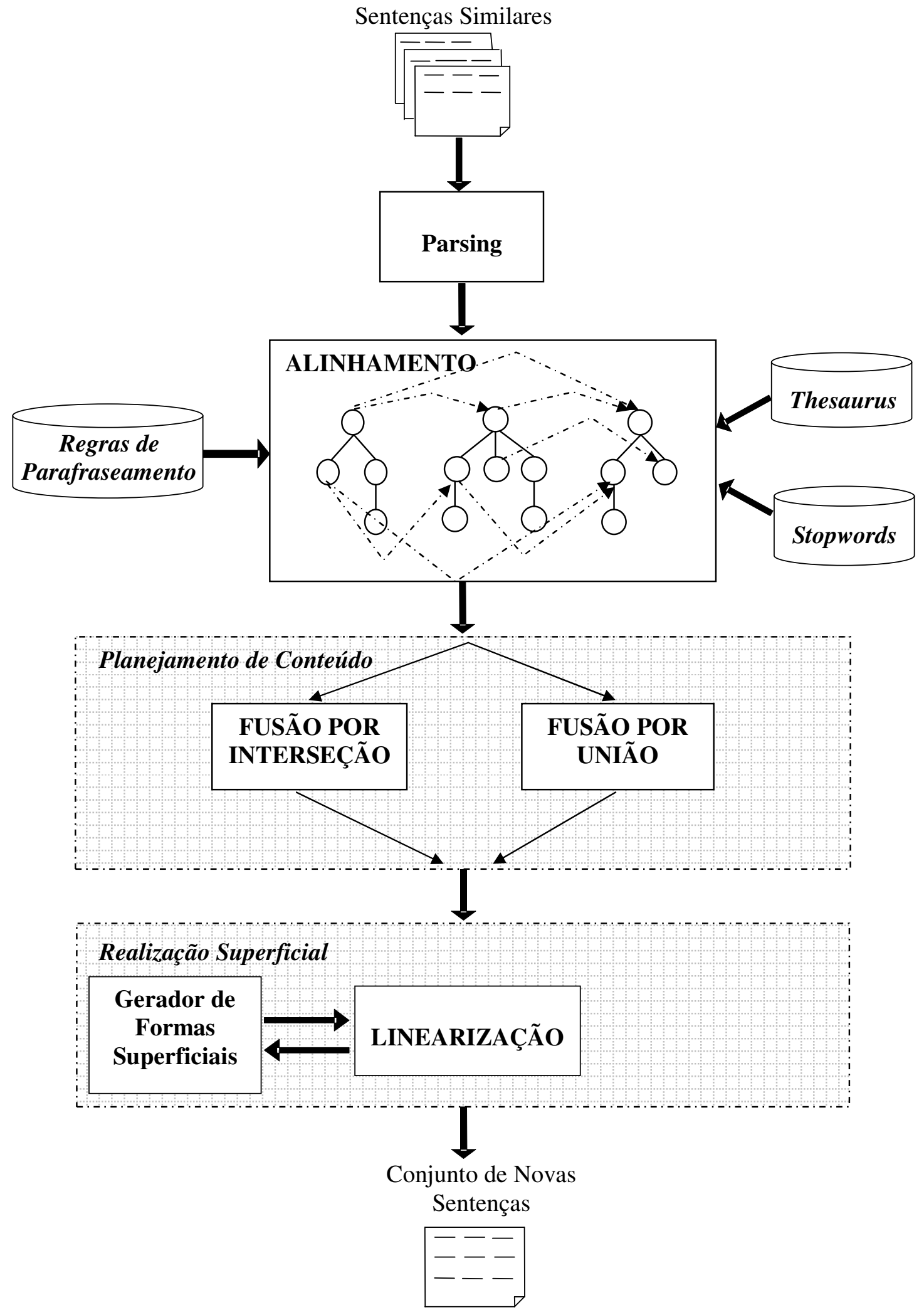

Figura 12: Principais etapas do método de fusão de sentenças 
Este capítulo está organizado da seguinte maneira: a Seção 5.1 apresenta a metodologia adotada no alinhamento de informações comuns no Zíper, bem como a formulação das regras de parafraseamento e a avaliação do método de alinhamento; a Seção 5.2 descreve os processos de fusão por interseção e fusão por união de informações; a Seção 5.3 é dedicada ao processo de linearização de sentenças e a Seção 5.4 apresenta as considerações finais.

\subsection{O Alinhamento}

O alinhamento de informações comuns consiste na identificação de palavras e de segmentos multipalavras semanticamente similares entre as sentenças de um mesmo conjunto. Estabelecer a correspondência entre dois ou mais conceitos não é uma tarefa trivial. A língua natural é tão poderosa que permite que um mesmo significado seja expresso de muitas maneiras distintas. Por exemplo, nas sentenças apresentadas no Quadro 13, extraídas do corpus de trabalho (Capítulo 4), é possível observar vários conceitos com sentido aproximado (no contexto apresentado) expressos de formas bem distintas: "deputados e parlamentares", "máfia dos sanguessugas e esquema de superfaturamento das ambulâncias ", "segunda-feira e segunda-feira, dia 21" e “cassação e julgamento". Apesar das variações lexicais e estruturais, os falantes da língua são capazes de reconhecer que, nesse contexto, esses conceitos têm um significado aproximado.

As diferentes formas de se comunicar uma mesma informação são conhecidas como paráfrases. A capacidade de parafrasear é parte da competência linguística. Segundo Milićević (2007a), falar uma língua consiste, principalmente, em saber parafrasear nessa língua.

\section{Quadro 13: Sentenças similares 1}

[1] Os deputados acusados de envolvimento na máfia dos sanguessugas têm até a meia-noite desta segunda-feira para renunciar aos mandatos se quiserem escapar da cassação.

[2] Os parlamentares acusados de envolvimento com o esquema de superfaturamento das ambulâncias têm até a meia-noite desta segunda-feira, dia 21, para renunciar ao mandato, caso queiram escapar do julgamento por quebra de decoro. 
Há muito tempo as paráfrases têm sido foco de estudos linguísticos, dada sua importância para a compreensão e a modelagem das línguas naturais. Como exemplos podem-se citar os trabalhos de Chomsky (1957) e de Harris (1957) que tratam a modelagem de paráfrases sob o ponto de vista da gramática - a Gramática Transformacional. As paráfrases abordadas nesses trabalhos apresentam variações estruturais e são denominadas paráfrases sintáticas. O fenômeno das paráfrases também foi foco de várias pesquisas na linguística sistêmica funcional (por exemplo, Halliday, 1985; Hassan, 1987 e Cross, 1992) e na semântica generativa (McCawley, 1976) ${ }^{7}$. Milićević (2007b) apresenta uma visão geral das principais abordagens linguísticas sobre o tema, desde Harris até as mais recentes, com respostas para várias questões interessantes sobre a modelagem das paráfrases.

$\mathrm{Na}$ literatura há muitas definições distintas sobre o termo paráfrase. Uma definição bastante representativa é a de Hoey (1991): "duas sequências distintas de palavras são paráfrases se uma puder ser substituída pela outra, em um dado contexto, sem alterar significativamente o sentido”. Segundo essa definição, as paráfrases não necessariamente preservam o mesmo significado. Embora muitos linguistas concordem que as paráfrases têm uma equivalência conceitual aproximada (por exemplo, Harris, 1957; Halliday, 1985 e Sant'Anna, 2004), o relacionamento entre os elementos que constituem uma paráfrase é, ainda, uma questão aberta (Dras, 1999).

$\mathrm{Na}$ última década muitas abordagens têm sido propostas para o reconhecimento automático de paráfrases. Em Barzilay \& Mckeown (2001), por exemplo, é proposto um método não supervisionado que extrai paráfrases de textos paralelos monolíngues, que são traduções distintas de um romance em francês para o inglês. A identificação de paráfrases é baseada no alinhamento de sentenças. Mais especificamente, esse método considera que palavras e segmentos multipalavras que ocorrem em contextos similares entre duas sentenças alinhadas são paráfrases. Shyniama \& Sekine (2003) e Sekine (2005) utilizam entidades nomeadas como âncoras para a extração de paráfrases em textos comparáveis. Métodos probabilísticos também têm sido foco de muitas pesquisas na área. Quirck et al. (2004), por exemplo, usam técnicas de tradução automática estatística (Statistical Machine Translation, no inglês) para extrair paráfrases de corpus comparável monolíngue. Bannard \& Callison-Burch (2005) e Callison-Burch (2007; 2008) também usam um método estatístico de tradução automática para identificar

\footnotetext{
${ }^{7}$ A descrição detalhada desses trabalhos não faz parte dos objetivos desta tese.
} 
paráfrases. Porém, ao invés de corpus comparável, eles usam corpus paralelo bilíngue. A desvantagem das abordagens estatísticas é que elas requerem grandes corpora de treinamento com frequências expressivas de paráfrases, um recurso praticamente inexistente para a maioria das línguas, inclusive para o português.

Apesar de ser um fenômeno bastante comum em qualquer língua natural, a maioria dos métodos de fusão de sentenças propostos na literatura (vide Capítulo 3) trata somente o reconhecimento de palavras sinônimas, consideradas em muitos trabalhos como paráfrase lexical (por exemplo, Barzilay, 2003). As paráfrases mais complexas, com variações lexicais e estruturais (por exemplo, "capital paulista e capital de São Paulo", "dar apoio e apoiar" e "máfia dos sanguessugas e esquema de superfaturamento das ambulâncias"), têm recebido pouca atenção nesses trabalhos devido a sua complexidade e à indisponibilidade de recursos como corpora e analisadores semânticos, para muitas línguas, que são de fundamental importância para o tratamento computacional.

O alinhamento de informações comuns no Zíper faz uso de um conjunto de sinônimos que permite a identificação de palavras similares. Para a identificação de paráfrases com variações estruturais, é proposta uma abordagem baseada em um conjunto de regras, elaboradas a partir de exemplos extraídos do corpus de trabalho. A formulação dessas regras é o tema da próxima seção.

\subsubsection{Formulação de Regras de Parafraseamento}

Vários linguistas sugerem que o número de regras que cobrem todos os casos de paráfrases com variações sintáticas é limitado. De acordo com Mel'čuk (1988), por exemplo, 60 regras são suficientes para cobrir todos os casos em qualquer língua natural. Para Harris (1957), esse número seria ainda menor: 20 regras apenas. Estudos baseados em corpora de textos em inglês também sugerem que há um número pequeno de regras que cobrem a maioria dos casos (Barzilay, 2003).

Tendo em vista esses trabalhos, foi feita uma análise de corpus, visando à formulação de regras para identificar os casos de paráfrases mais comuns em português. Embora a análise manual limite significativamente o tamanho do corpus analisado, ela permite investigar com precisão o modo como o fenômeno se manifesta na língua. 
Na literatura, as paráfrases são comumente classificadas em dois tipos: lexical e sintático. O exemplo (1) do Quadro 14 constitui uma paráfrase lexical, enquanto que o exemplo (2), com uma sentença na voz ativa e outra na passiva, constitui uma paráfrase sintática. Algumas paráfrases, entretanto, podem pertencer a essas duas categorias, como é o caso dos exemplos (3), (4) e (5). A distinção entre paráfrases lexicais e sintáticas é bastante controversa na literatura e, por essa razão, esse esquema de classificação não foi adotado neste trabalho.

\section{Quadro 14: Exemplos de paráfrases lexicais e sintáticas}

\begin{tabular}{l}
\hline 1. acre-doce ; agridoce \\
2. Bandidos incendiaram uma agência do Itaú. ; Uma agência do Itaú foi \\
incendiada por bandidos. \\
\hline 3. aviação brasileira ; Força Aérea do Brasil \\
\hline 4. cidade de Campinas ; Campinas (SP) \\
\hline 5. Paulo comprou o carro de Pedro. ; Pedro vendeu o carro para Paulo. \\
\hline
\end{tabular}

De forma análoga à realizada por Barzilay (2003), as paráfrases são classificadas aqui apenas em termos de granularidade. As paráfrases em nível de palavras, ou formadas por um conjunto de palavras (daqui em diante, multipalavras) que isoladamente não constituem uma paráfrase da outra, são denominadas atômicas. É o caso dos exemplos (1) e (4) (Quadro 14). As paráfrases formadas por uma combinação de paráfrases atômicas e que podem ser decompostas em outras paráfrases menores são denominadas compostas. Esse é o caso dos exemplos (2), (3) e (5). Por exemplo, a paráfrase (3) é composta de duas paráfrases atômicas: "aviação e Força Aérea" e "brasileira e do Brasil". As paráfrases multipalavras correspondem aos sintagmas nominais e verbais, sendo que os sintagmas nominais podem conter até dois sintagmas preposicionados. A definição de paráfrase adotada neste trabalho segue aquela proposta por Hoey (1991), em que duas sequências distintas de palavras são ditas paráfrases se uma delas puder ser substituída pela outra, em um dado contexto, sem que haja distorção significativa do significado original.

Para identificar os principais padrões de paráfrases, foram selecionados aleatoriamente 30 pares de sentenças comparáveis do corpus descrito no Capítulo 4. Assim, para cada um dos 393 grupos construídos pelo SiSPI, foram obtidas todas as possíveis combinações de pares de sentenças comparáveis, resultando aproximadamente em 670 pares em todo corpus. Um total de 81 paráfrases foi identificado, sendo $52 \%$ 
delas atômicas e 48\% compostas. Os Quadros 15 e 16 apresentam alguns exemplos de paráfrases atômicas e compostas, respectivamente.

Aproximadamente 33,3\% das paráfrases atômicas são do tipo um-para-um, isto é, ocorrem em nível de palavras, por exemplo, (a), (b), (c), (d) e (e) (Quadro 15). Dessas, 8 ocorrem entre verbos (por exemplo, (a) e (b)) e 4 aparecem entre substantivos comuns ou próprios (por exemplo, (c), (d) e (e)). 21,4\% são do tipo um-para-dois, por exemplo, (f), (g), (h), (i) e (j), sendo que os padrões mais comuns são substantivo e substantivo seguido por adjetivo ((f) e (g)), verbo e verbo seguido por substantivo ((h) e (i)) e substantivo próprio e substantivo próprio seguido de um aposto contendo outro substantivo próprio ((j)). 40,5\% são do tipo um-para-muitos, isto é, ocorrem entre uma palavra e uma multipalavras (maior que duas palavras), por exemplo, (l) e (m). Apenas 4,8\% das paráfrases atômicas (isto é, duas ocorrências) são formadas por um par de multipalavras (vide exemplos (n) e (o)).

Quadro 15: Exemplos de paráfrases atômicas

\begin{tabular}{|l|}
\hline a. arrasou ; venceu \\
\hline b. informar ; publicar \\
\hline c. colisão ; choque \\
\hline d. membro ; integrante \\
\hline e. Liga Mundial ; Liga Mundial-06 \\
\hline f. acordo ; acordo financeiro \\
\hline g. grupo ; grupo criminoso \\
\hline h. trabalham ; fazem parte \\
\hline i. pontuou ; recebeu indicação \\
\hline j. PCC ; PCC (Primeiro Comando da Capital) \\
\hline l. Brasil ; seleção brasileira masculina de vôlei \\
\hline m. incêndio ; incêndio de grandes proporções \\
\hline n. máfia dos sanguessugas ; esquema de superfaturamento das ambulâncias \\
\hline o. cidade de Tampere ; Tampere (FIN) \\
\hline
\end{tabular}

Quadro 16: Exemplos de paráfrases compostas

\begin{tabular}{|l|}
\hline a. Guarda Civil Metropolitana (GCM ) ; GCM (Guarda Civil Metropolitana) \\
\hline b. candidato tucano Geraldo Alckmin ; tucano Geraldo Alckmin \\
\hline c. $44 \%$ das intenções de voto ; 44\% dos votos \\
\hline d. José Maria Eymael do PSDC ; José Maria Eymael (PSDC) \\
\hline e. liderança do Grupo B da Liga ; liderança do Grupo B \\
\hline f. parte traseira da outra locomotiva ; parte traseira de outro trem) \\
\hline g. capital russa ; capital da Rússia \\
\hline h. bujão de gás ; botijão de gás \\
\hline i. direção da Câmara ; Mesa Diretora da Câmara \\
\hline j. mercado moscovita ; mercado Cherskisov de Moscou \\
\hline l. cerca de 300 policiais federais ; ao menos 300 policiais \\
\hline m. cidade de Tampere, na Finlândia ; Tampere (FIN) \\
\hline
\end{tabular}


As paráfrases composicionais foram analisadas em termos das transformações realizadas em uma das partes que constituem as paráfrases, em relação à outra parte. Quatro tipos de transformações foram identificados, a saber:

i) permutação na ordem dos elementos, como é o caso do exemplo (a) do Quadro 16;

ii) remoção de elementos como substantivos (exemplos (b) e (c)), preposições ((d)), sintagmas preposicionados ((e)) e a exclusão de elementos devido a construções elípticas ((f));

iii) alteração lexical, por exemplo, em (g), (h) e (i);

iv) e alteração lexical com remoção de elementos, por exemplo, em (j), (1) $\mathrm{e}(\mathrm{m})$.

A permutação de elementos foi observada em 2,6\% dos casos (ou seja, 1 ocorrência apenas) e não houve alteração em termos estruturais. A remoção ocorreu em cerca de 38,5\% das paráfrases composicionais. Nesse caso, sempre há transformação na estrutura sintática. A alteração lexical, por sua vez, é a mais frequente de todas, representando $48,7 \%$ dos casos. Como a estruturação sintática é frequentemente regida pelas escolhas lexicais (Mel'čuk, 1988) (por exemplo, na paráfrase (g), Quadro 15, o uso do nome próprio Rússia requer o uso da preposição de e do artigo definido $a$, enquanto que o uso do adjetivo russa não necessita da preposição e do artigo), em muitos casos ocorreram transformações estruturais, como em $(\mathrm{g})$. Porém, em vários casos a alteração lexical não causou mudanças estruturais, como pode ser visto nos exemplos (h) e (i). Somente 4,9\% dos casos apresentaram alteração lexical com remoção de algum elemento, por exemplo, em (j), (l) e (m).

Com exceção das paráfrases atômicas do tipo um-para-um, de modo geral as paráfrases identificadas apresentam muitas variações de padrões sintáticos, sendo que na maioria dos casos cada padrão ocorre somente uma vez. Esse fato é corroborado por outros estudos da literatura. Barzilay (2003), por exemplo, observa que os padrões de paráfrases seguem a distribuição de Zipf, ou seja, há poucos padrões que cobrem grande parte dos casos.

Com base nessa análise, foram identificadas 21 regras de parafraseamento, cobrindo tanto os casos de paráfrases atômicas (com exceção das paráfrases um-para- 
um), como os casos de paráfrases compostas ${ }^{8}$. Essas regras estão respresentadas por meio de expressões regulares conforme a sintaxe da linguagem Perl, na qual o sistema de fusão foi implementado. O Quadro 17 apresenta dois exemplos de regras, juntamente com exemplos extraídos do corpus de análise (onde ADJ: adjetivo; DET: determinante; N: substantivo; PRP: preposição; PROP: nome próprio; ?: indica zero ou uma ocorrência e I: indica alternativa (operador $o u$ )). O conjunto completo de regras é apresentado no Apêndice I. Todas as regras prevêem ao menos uma ocorrência de palavras similares entre as partes que compõem a paráfrase, podendo ser palavras idênticas, sinônimas ou cognatas (vide Seção 5.1.2). Os números nas regras indicam quais devem ser as unidades similares. Por exemplo, a regra R1 prevê a ocorrência de um substantivo comum às duas partes (ou seja, N1). Em R2 deve haver pelo menos um substantivo (N1) ou nome próprio (PROP1) em comum entre elas.

Quadro 17: Exemplos de regras de parafraseamento

\begin{tabular}{|l|l|}
\hline R1. DET? N1 ADJ ; DET? N1 PROP? & $\begin{array}{l}\text { a capital russa ; a capital da Rússia } \\
\text { o mercado moscovita ; o mercado Cherkisov de } \\
\text { Moscou } \\
\text { a parte dianteira ; a parte da frente }\end{array}$ \\
\hline $\begin{array}{l}\text { R2. DET? (N1IPROP1) ; DET? N1 } \\
\text { PRP? DET? ADJ? (NIPROP1) }\end{array}$ & $\begin{array}{l}\text { um incêndio ; um incêndio de grandes proporções } \\
17 \text { h16 ; } 17 \mathrm{~h} 16 \text { da terça-feira } \\
\text { prioridade ; prioridade do governo } \\
\text { a avenida ; a avenida Washington Luiz } \\
\text { segunda-feira ; manhã desta segunda-feira } \\
\text { Lula ; presidente Lula }\end{array}$ \\
\hline
\end{tabular}

De acordo com R1, duas sequências distintas de palavras S1 e S2 são paráfrases se S1 iniciar com um substantivo (N1), precedido ou não por um determinante (DET?) e seguido de um adjetivo (ADJ) e S2 iniciar com um substantivo (similar ao de S1), precedido ou não por um determinante (DET?) e seguido ou não por um nome próprio (PROP?), acompanhado por uma preposição (PRP) que, por sua vez, pode ou não ser acompanhada por um determinante (DET?), e finalizada com um nome próprio ou um substantivo (PROPIN). No caso de R2, dois segmentos distintos S1 e S2 são paráfrases se S1 iniciar com um substantivo ou um nome próprio (N1|PROP1), precedido ou não por um determinante (DET?), e S2 iniciar com um substantivo (N1), precedido ou não por um determinante (DET?), e finalizado por outro substantivo ou nome próprio

\footnotetext{
${ }^{8}$ Inicialmente, 27 regras haviam sido identificadas, conforme descrito em Seno \& Nunes (2008a; 2009a). Durante a fase de testes do algoritmo de alinhamento, essas regras foram refinadas, visando torná-las mais genéricas. Esse processo resultou em 21 regras apenas.
} 
(NIPROP1) que, por sua vez, pode ser precedido ou não por uma preposição (PRP?), um determinante (DET?) e um adjetivo (ADJ?). Algumas regras são mais gerais, permitindo maior variabilidade dos padrões de paráfrases, por exemplo, as regras R2, R3, R4, R8 e R9 (Apêndice I), enquanto outras são mais específicas com estruturas bem fixadas como R10, R12, R14, R15, R16, entre outras. Embora as regras mais genéricas permitam maior robustez, elas são mais sujeitas a erros.

É importante ressaltar que não há regras para as paráfrases atômicas em nível de palavras (essas representam 17,3\% de todas as paráfrases). Esses casos são resolvidos por meio de consultas ao thesaurus e por meio de medidas de similaridade estatística (Seção 5.1.2). Além dessas, algumas paráfrases não têm um padrão bem definido, podendo variar muito. Esse é o caso, por exemplo, das paráfrases explicativas (por exemplo, "Agência Americana Antidrogas (DEA) ; DEA, agência do governo americano de combate ao narcotráfico"). Outras paráfrases são ainda mais complexas e requerem inferência e conhecimento de mundo para serem compreendidas como tal, por exemplo, "o Brasil ; a seleção brasileira masculina de vôlei”, “os vários altos funcionários egípcios ; as autoridades", "1\% das intenções de voto ; percentual”, "o julgamento ; a cassação" e "a máfia das sanguessugas ; o esquema de superfaturamento das ambulâncias". Para esses casos não foi possível construir nenhuma regra.

\subsubsection{Estratégia de Alinhamento}

De modo similar ao realizado em vários métodos da literatura (vide Capítulo 3), o alinhamento de informações comuns no Zíper é baseado em árvores de dependências sintáticas. Porém, o mesmo foi implementado seguindo uma metodologia não encontrada, até o momento, em outros trabalhos. Mais especificamente, ao invés do alinhamento local de subárvores (vide, por exemplo, Barzilay, 2003 e Marsi \& Krahmer, 2005), a abordagem proposta aqui segue um processo de alinhamento global que identifica, para cada segmento (palavra ou sintagma) de uma sentença, todos os possíveis candidatos ao alinhamento na outra sentença por meio de heurísticas, e calcula qual é o candidato mais provável ${ }^{9}$. Diferentemente do alinhamento local, essa abordagem garante que, se houver um segmento similar entre duas sentenças, passível de ser identificado por meio de regras de parafraseamento, de relações de sinonímia ou

\footnotetext{
${ }^{9}$ Versões preliminares do método descrito aqui foram publicadas em Seno \& Nunes (2008b; 2009a).
} 
de medidas de similaridade estatística (conforme descritas a seguir nesta seção), eles serão alinhados. No alinhamento local, o alinhamento de dois segmentos depende do alinhamento de seus descendentes nas subárvores que têm esses segmentos como raíz. Essa abordagem pode forçar o alinhamento de segmentos não relacionados, nos casos em que os seus descendentes estiverem alinhados, deixando de alinhar segmentos altamente similares que se encontram em subárvores distintas (muito comum em sentenças semanticamente similares, mas com estruturas bem distintas).

As árvores de dependências sintáticas são fornecidas pelo parser Palavras (Bick, 2000), considerado um dos melhores parsers do português. O Palavras é um parser simbólico, baseado em regras, e apresenta uma precisão de $99 \%$ em termos de análise morfológica (classificação de palavras e flexão) e uma precisão de cerca de $98 \%$ em termos de análise sintática (Bick, 2005). Esse parser fornece a anotação de dependência entre palavras, por exemplo, a dependência entre um núcleo e seu modificador. Porém, conforme visto na Seção 5.1.1, a análise manual mostrou que as paráfrases mais comuns ocorrem entre sintagmas nominais (por exemplo, direção da Câmara e Mesa Diretora da Câmara) e entre sintagmas verbais (por exemplo, chegaram a obter e alcançaram). Além disso, muitas dessas paráfrases não podem ser decompostas em palavras (por exemplo, cidade de Tampere e Tampere (FIN)), formando paráfrases do tipo uma-paramuitas ou muitas-para-muitas. Visando tratar corretamente esses casos, na representação de árvores adotada, os nós correspondem aos sintagmas nominais e verbais. Para obter a dependência entre sintagmas, as subárvores de cada árvore de dependências representando sintagmas nominais e sintagmas verbais foram unificadas em um único nó ${ }^{10}$. Para facilitar o alinhamento, as palavras foram reduzidas a sua forma canônica e as palavras de classes fechadas (por exemplo, as preposições e as conjunções) foram eliminadas. Porém, as preposições e os artigos contidos nos sintagmas foram preservados, de modo a permitir o alinhamento de paráfrases como $a$ capital russa e a capital da Rússia. A lematização também foi realizada pelo Palavras.

A Figura 13 ilustra dois exemplos de árvores de dependências sintáticas correspondentes às sentenças "O Airbus A320, voo JJ3054, partiu de Porto Alegre, às 17 16 da terça-feira e chegou a São Paulo às 18h45." e "A aeronave da TAM Airbus A320, voo JJ3054, partiu de Porto Alegre, às 17 h16 com destino a Congonhas." (sentenças [1] e [2] do Quadro 3, Capítulo 2). As setas indicam as dependências entre

\footnotetext{
${ }^{10}$ Para uma descrição detalhada da construção das árvores de dependências a partir da saída do Palavras, vide Seno \& Nunes (2009a).
} 
cada nó terminal e seu nó pai. Por exemplo, o nó terminal o Airbus A320, voo JJ3054, na Árvore 1, é dependente do nó raiz partir, configurando a relação de dependência entre sujeito (suj) e verbo (ver). De modo similar, o nó terminal o aeronave de o TAM Airbus A320, voo JJ3054, na Árvore 2, e o nó raiz partir também configuram a relação de dependência entre sujeito e verbo. O nó terminal Porto Alegre (Árvores 1 e 2 ), por sua vez, é dependente do nó raiz partir, estabelecendo a relação de dependência entre objeto (obj) e verbo. Outro exemplo de dependência entre verbo e objeto pode ser visto na Árvore 1 entre os nós não terminais chegar e São Paulo.

\section{ÁRVORE 1}
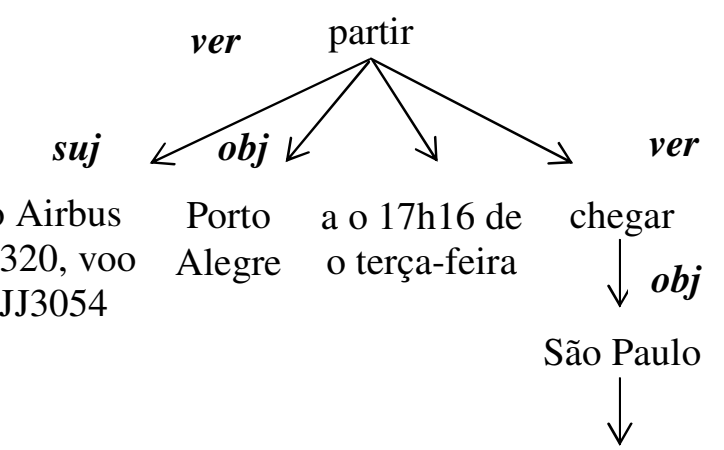

a o $18 \mathrm{~h} 45$

\section{ÁRVORE 2}

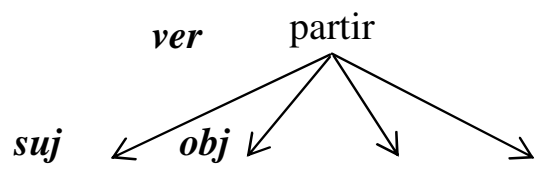

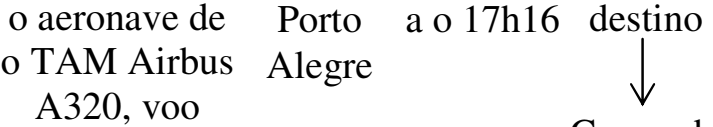

a Congonhas

Figura 13: Árvores de dependências sintáticas

A seguir, apresenta-se o algoritmo de alinhamento de informações comuns.

\subsubsection{Algoritmo de Alinhamento}

O alinhamento de informações comuns é realizado entre pares de árvores de dependências sintáticas. Dadas duas árvores $T_{S 1}$ e $T_{S 2}$, o algoritmo busca pelo melhor alinhamento entre cada nó $v$ de $T_{S 1}$ e cada nó $v^{\prime}$ de $T_{S 2}$. $\mathrm{O}$ alinhamento é do tipo um-paraum, ou seja, cada nó de $T_{S 1}$ é alinhado com no máximo um nó de $T_{S 2}$. Além disso, alguns conceitos podem não ter correspondentes na outra sentença e, portanto, alguns nós podem não ser alinhados.

Ao invés de analisar exaustivamente o espaço de busca de todos os alinhamentos possíveis entre $T_{S 1}$ e $T_{S 2}$, o algoritmo faz uso de três heurísticas, na tentativa de encontrar segmentos que compartilham informação semanticamente equivalente entre as duas árvores. São elas: casamento idêntico, isto é, palavras com o mesmo lema, sinônimos e 
cognatos. Os sinônimos são identificados por meio de consultas a um thesaurus, o TeP ${ }^{11}$ - Thesaurus Eletrônico para o Português do Brasil (Maziero et al., 2008), desenvolvido no contexto do projeto Wordnet-BR (Dias-da Silva et al., 2006; 2008). O TeP contempla conjuntos de sinônimos para verbos, substantivos, adjetivos e advérbios. As palavras cognatas, que tem grafias semelhantes, são identificadas por meio da medida de similaridade LCSR - Longest Common Subsequence Ratio (Melamed, 1995). O LCSR de duas palavras é calculado dividindo-se o comprimento da maior subsequência de caracteres em comum entre elas (não necessariamente contíguos) pelo comprimento da maior palavra. Por exemplo, o LCSR das palavras Hezbolla e Hisbolla é 0,75 (isto é, 6/8), uma vez que a subsequência de caracteres em comum entre elas é $h-b-o-l-l-a$. Essa medida é útil principalmente quando as palavras não estão representadas no thesaurus. Esse é o caso, por exemplo, dos nomes próprios que não são contemplados no TeP e frequentemente apresentam variações (por exemplo, Rui Pimenta e Rui Costa Pimenta). $\mathrm{O}$ valor de similaridade mínimo estabelecido entre duas palavras é 0,65. Esse valor foi determinado empiricamente com base em exemplos positivos e negativos de palavras cognatas no corpus de desenvolvimento. A LCSR só não é usada para verbos, a fim de evitar casos como correr e morrer que, apesar da alta similaridade (isto é, LCSR = $0,84)$, têm significados completamente distintos.

Como as árvores de dependências representam as relações entre sintagmas (vide Figura 13), para a aplicação das heurísticas o algoritmo usa um conjunto de palavras de conteúdo de cada sentença, como mostra o pseudocódigo da função de alinhamento de árvores de dependências no Quadro 18. As palavras de conteúdo, também conhecidas por palavras de classes abertas, incluem os substantivos, os verbos, os advérbios e os adjetivos.

Assim, para cada palavra $s$, pertencente ao conjunto de palavras de conteúdo da sentença correspondente à árvore $T_{S I}$ (denotada por $S 1$ ), o algoritmo identifica todas as palavras da sentença $S 2$, correspondente à $T_{S 2}$, que satisfazem uma das três condições (casamento idêntico, sinônimo ou cognato), criando um conjunto $C$ de candidatas ao alinhamento (linha 5 do pseudocódigo). As palavras candidatas devem possuir o mesmo part-of-speech (POS) da palavra $s$, de modo a garantir um alinhamento mais confiável.

\footnotetext{
${ }^{11}$ Disponível em: http://www.nilc.icmc.usp.br/tep2/download.htm (último acesso em 2/02/2010).
} 
Quadro 18: Algoritmo de alinhamento de árvores de dependências sintáticas

Função: alinhar_arvores_dependencias

Entrada: Uma sentença $S 1=\left\{s_{1}, \ldots, s_{n}\right\}$ com $n$ palavras de conteúdo e sua respectiva árvore $T_{S l}=\left\{v_{1}, \ldots, v_{x}\right\}$ com $x$ nós. Uma sentença $S 2=\left\{w_{1}, \ldots, w_{m}\right\}$ com $m$ palavras de conteúdo e sua respectiva árvore $T_{S 2}=\left\{v_{1}^{\prime}, \ldots, v_{y}^{\prime}\right\}$ com $y$ nós.

Saída: um conjunto $A$ de alinhamentos entre os nós de $T_{S 1}$ e $T_{S 2}$.

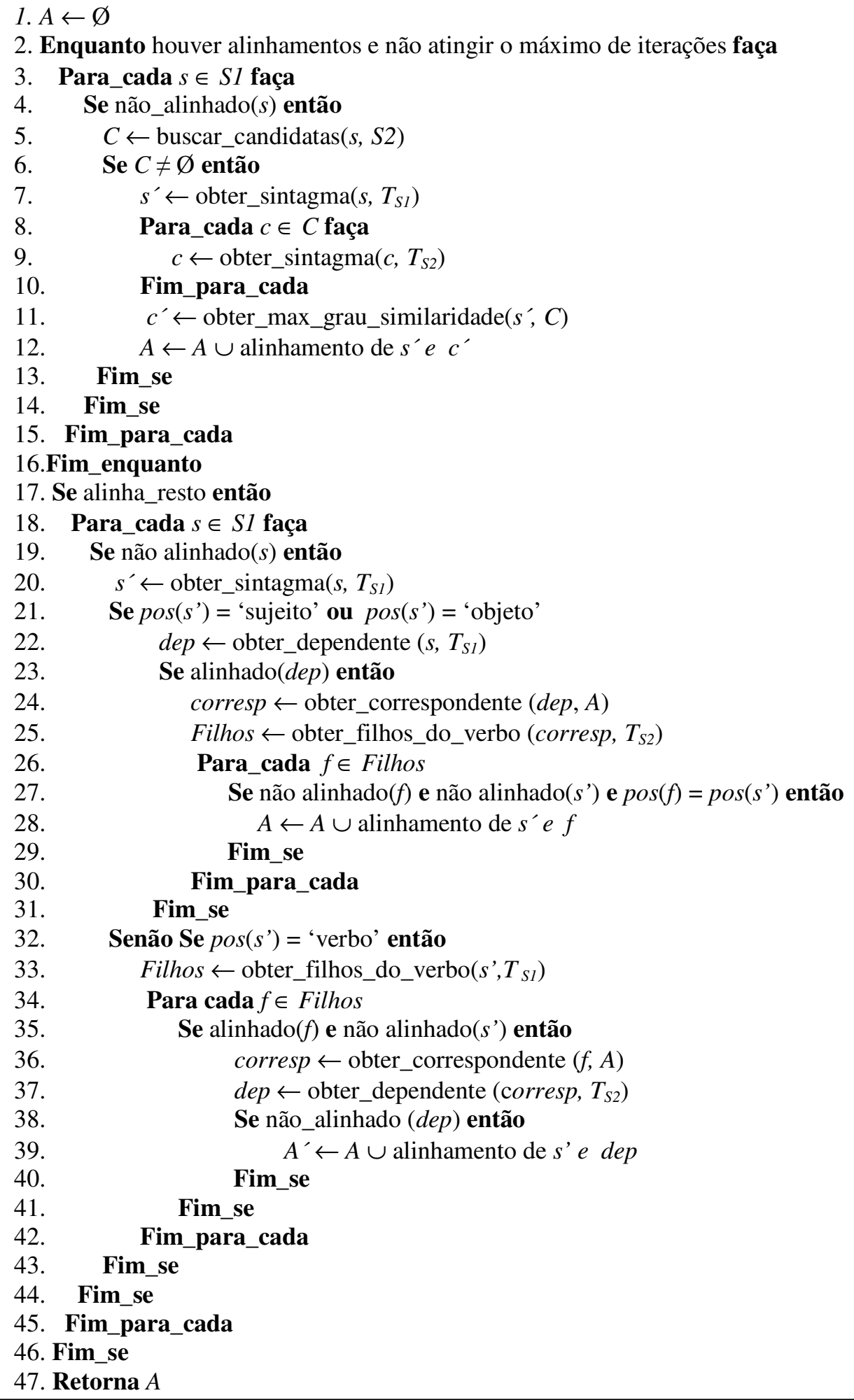


Supondo que $C$ é um conjunto não vazio, o algoritmo recupera os sintagmas correspondentes da palavra $s$ (linha 7) e de cada candidata $c$ pertencente a $C$ (linhas $8 \mathrm{e}$ 9), caso elas pertençam a algum sintagma na árvore (por exemplo, na Árvore 1 (Figura 13), Airbus A320 é um nome pertencente ao sintagma nominal o Airbus A320, voo JJ 3054). O alinhamento de $s$ (daqui em diante $s^{\prime}$ ), denotado por $A\left(s^{\prime}\right)$, é dado pelo segmento $c^{\prime}$ que maxima o grau de similaridade de cada candidato $c$ em relação à $s^{\prime}$, denotado por $G S\left(s^{\prime}, c\right)$ (linhas 11 e 12). Formalmente, $A\left(s^{\prime}\right)$ é definida pela Fórmula 27. A função $G S\left(s^{\prime}, c\right)$, por sua vez, é calculada pela Fórmula 28.

$$
A\left(s^{\prime}\right)=\max c \in C\left\{G S\left(s^{\prime}, c\right)\right\}
$$

$$
G S\left(s^{\prime}, c\right)=\operatorname{Sim}\left(s^{\prime}, c\right)+\operatorname{Sim} \_f u n \_\sin \left(s^{\prime}, c\right)+\operatorname{Sim} \_d e p\left(s^{\prime}, c\right)
$$

$\operatorname{Sim}\left(s^{\prime}, c\right)$ representa a similaridade entre as palavras associadas a $s^{\prime}$ e $c$, podendo assumir três valores: 1, em casos de casamento idêntico ou de paráfrases; 0,5, em casos de sinônimos ou de cognatos; 0, caso contrário. As regras de parafraseamento são aplicadas quando não há casamento idêntico entre $s^{\prime}$ e $c$ e pelo menos uma das partes é um segmento multipalavras. Se nenhuma regra se aplicar, então $\operatorname{Sim}\left(s^{\prime}, c\right)$ será igual a zero. Esses valores foram determinados empiricamente com base no corpus de desenvolvimento, assim como os valores das demais funções descritas a seguir.

Sim_fun_sin $\left(s^{\prime}, c\right)$ representa a similaridade da função sintática desempenhada por $s^{\prime}$ e por $c$, nas respectivas sentenças (por exemplo, sujeito, objeto direto e objeto indireto). É pouco provável que um segmento que tenha função de sujeito em uma sentença corresponda a um segmento que tenha função adverbial na outra sentença. Assim, o objetivo dessa função é favorecer os segmentos que têm o mesmo papel sintático. Quando ambos desempenham o mesmo papel, ela assume o valor 0,03, caso contrário Sim_fun_sin $\left(s^{\prime}, c\right)$ é igual a zero.

Sim_dep $\left(s^{\prime}, c\right)$, por sua vez, representa a similaridade dos pais de $s^{\prime}$ e de $c$ (isto é, os segmentos dos quais $s^{\prime}$ e $c$ dependem) ou a similaridade dos filhos de $s^{\prime}$ e de $c$ (ou seja, os segmentos que dependem de $s^{\prime}$ e de $c$ ). Essa função assume o valor 0,03, quando os pais ou os filhos são similares, e 0 caso contrário. A similaridade dos pais é calculada para os casos em que $s^{\prime}$ e $c$ têm função de sujeito ou de objeto. Nesses casos, o algoritmo verifica se há similaridade entre os respectivos verbos. A similaridade dos 
filhos é calculada somente nos casos em que $s^{\prime}$ e $c$ são predicados verbais. Nesses casos, o algoritmo verifica se algum dos filhos de $s^{\prime}$ e $c$ (por exemplo, o sujeito ou o objeto) foram previamente alinhados. Para tanto, nas primeiras iterações, o algoritmo prioriza o alinhamento de substantivos próprios e comuns, visando encontrar as correspondências entre os sujeitos e os objetos. Só então, após alinhar os substantivos, ele alinha os verbos. Porém, como os verbos são alinhados por último, ao encontrar um sujeito ou objeto, o algoritmo verifica se os verbos correspondentes são sinônimos ou paráfrases.

Por fim, ele tenta alinhar as palavras e sintagmas restantes sem alinhamento, para os quais nenhuma regra de parafraseamento pode ser aplicada. Esses alinhamentos são opcionais (vide linha 17) e são realizados somente para verbos, sujeitos e objetos (linhas 21 e 32), com base nos seus traços de dependência sintática. Ou seja, nos casos em que dois verbos principais foram previamente alinhados e os sujeitos ou objetos correspondentes nas sentenças estão sem alinhamento, eles são alinhados, assumindo-se que eles são equivalentes (linhas 21-31). De maneira similar, se dois sujeitos ou objetos foram alinhados previamente e os verbos correspondentes nas sentenças não foram, então eles também são alinhados (linhas 32-43). Embora essa função possa parecer audaciosa, ela auxilia na identificação de paráfrases mais complexas que necessitam de inferência e de conhecimento de mundo para serem resolvidas. Exemplos desses casos podem ser vistos nas sentenças do Quadro 19 (extraídas do corpus). Nas sentenças [1-a] e [1-b], por exemplo, o alinhamento dos verbos principais, venceu, permitiu o alinhamento dos respectivos sujeitos "O Brasil e a seleção brasileira masculina de vôlei" (em negrito). De forma análoga, o alinhamento dos sintagmas verbais "vai instaurar e vai instaurar", nas sentenças [2-a] e [2-b], possibilitou o alinhamento entre "Ele e o presidente do Conselho de Ética, deputado Ricardo Izar (PTB-SP)". Entretanto, o alinhamento dos sujeitos "o grupo e o grupo criminoso", nas sentenças [3a] e [3-b], resultou no alinhamento incorreto entre "é acusado e desviou". O intercâmbio entre eles prejudicaria a gramaticalidade e a semântica das sentenças.

Uma vez que todos os segmentos similares entre $T_{S I}$ e $T_{S 2}$ foram identificados, o algoritmo adiciona em $T_{S 1}$ todas as suas interseções com $T_{S 2}$ e, da mesma maneira, ele adiciona em $T_{S 2}$ todas as interseções com $T_{S 1}$. Como ilustração, a Figura 14 apresenta as árvores de dependências ilustradas na Figura 13 depois de serem alinhadas. As caixas de textos e as setas não tracejadas representam os nós alinhados, bem como o seu correspondente na outra sentença, enquanto que as setas tracejadas indicam os nós sem alinhamento. 


\section{Quadro 19: Exemplos de alinhamentos identificados pela função alinha_resto}

[1-a] O Brasil venceu a Finlândia no primeiro confronto entre as seleções, nesta sexta-feira, na cidade de Tampere, pela Liga Mundial de vôlei 2006, por 3 sets a 0, com parciais de 25/17, 25/22 e 25/21.

[1-b] A seleção brasileira masculina de vôlei, que é treinada por Bernardinho, venceu a Finlândia por 3 sets a 0 , parciais de 25/17, 25/22 e 25/21, nesta sextafeira, em Tampere (FIN), e manteve sua invencibilidade na Liga Mundial-06.

[2-a] Ele vai instaurar o processo contra os deputados envolvidos com a máfia dos sanguessugas amanhã, às $10 \mathrm{~h} 30$.

[2-b] As renúncias têm que ser publicadas até terça-feira, quando o presidente do Conselho de Ética, deputado Ricardo Izar (PTB-SP), vai instaurar os processos de perda de mandato contra os 69 deputados acusados pela CPI dos Sanguessugas de envolvimento com a máfia das ambulâncias.

[3-a] O grupo é acusado de lesar os cofres públicos em cerca de R\$ 70 milhões, desde 2004 .

[3-b] Segundo divulgada pela PF, o grupo criminoso desviou desde 2004 cerca de $\mathrm{R} \$ 70$ milhões dos cofres públicos, por meio do pagamento de serviços, compras e obras superfaturadas.

Após alinhar as duas primeiras árvores das sentenças do conjunto de entrada, o algoritmo tenta alinhar a próxima árvore $\left(T_{S 3}\right) \operatorname{com} T_{S 1}$ e com $T_{S 2}$ (caso o número de árvores de entrada seja $>2$ ). $\mathrm{O}$ alinhamento entre os nós de $T_{S 3}$ e de $T_{S 1}$ procede de modo similar ao alinhamento de $T_{S 1}$ e $T_{S 2}$, conforme descrito anteriormente. Porém, o alinhamento entre um nó $v$ '” pertencente a $T_{S 3}$ e um nó $v$ pertencente a $T_{S l}$, que possui interseção com um nó $v^{\prime}$ de $T_{S 2}$, indica que há também uma interseção entre $v^{\prime}$ ' e $v$ '. Dessa forma, ao encontrar um nó $v$ em $T_{S 1}$ equivalente ao nó $v$ '” de $T_{S 3}$, o algoritmo adiciona $v$ em $T_{S 3}$ como uma verbalização alternativa de $v$ "' e também a interseção de $v$ com o nó $v^{\prime}$ de $T_{S 2}$ (se houver), terminando a busca por correspondentes de $v^{\prime}$. Do mesmo modo, $v$ ' é adicionado como uma alternativa ao nó $v$ em $T_{S 1}$ (e de $v$ ' em $T_{S 2}$, se houver). Caso não encontre nenhum correspondente de $v$ ' em $T_{S l}$, a busca continua em $T_{S 2}$. Esse processo segue até que todas as árvores do conjunto tenham sido analisadas. 

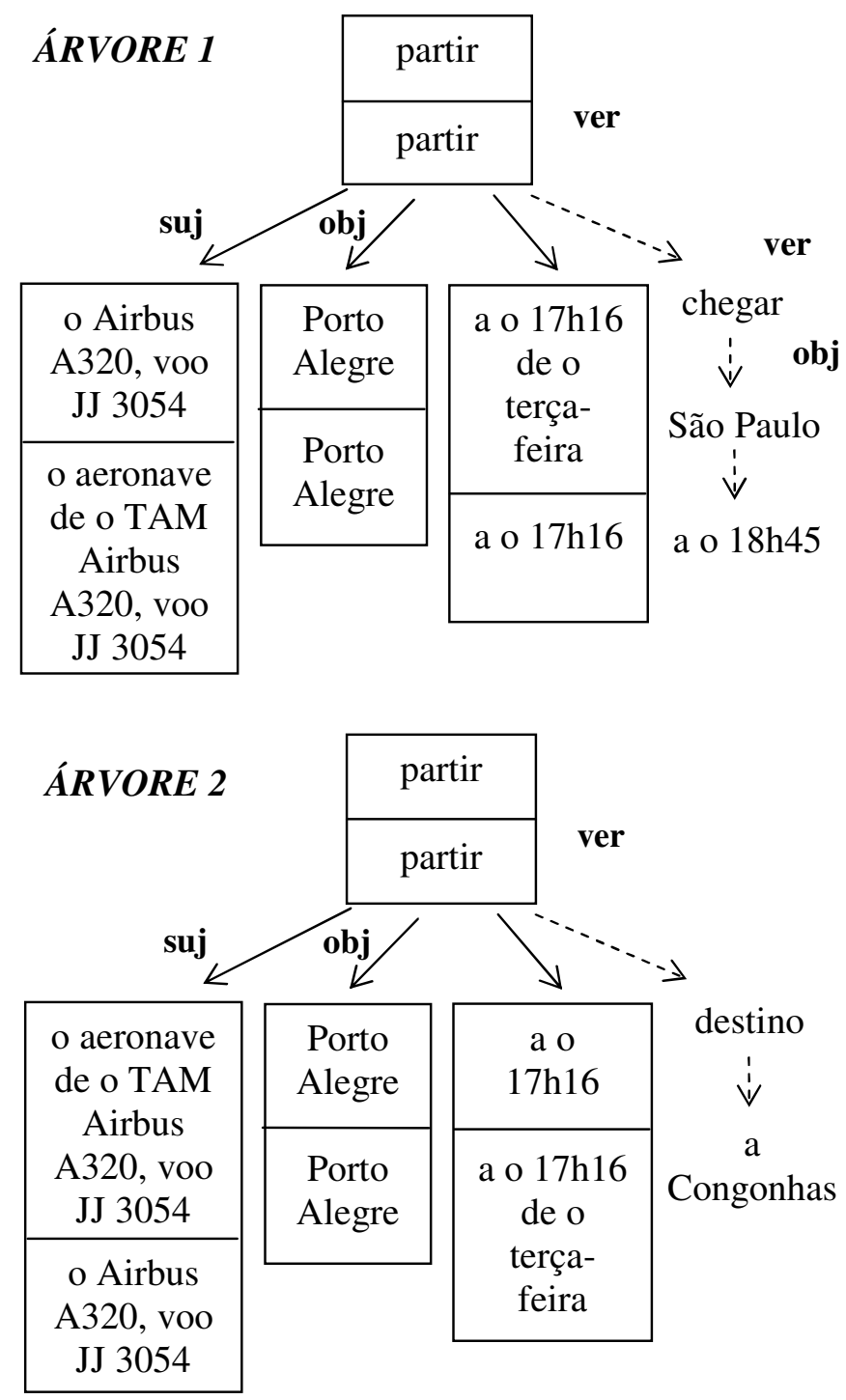

Figura 14: Ilustração das árvores de dependências sintáticas da Figura 13 após o alinhamento de informações comuns

\subsubsection{Avaliação}

A qualidade dos alinhamentos produzidos automaticamente foi avaliada com base em um corpus de referência composto por 20 pares de sentenças, extraídos aleatoriamente dos 670 pares gerados a partir dos 393 grupos de sentenças que compõem o corpus de trabalho (conforme descrito na subseção 5.1.1). É relevante dizer que os conjuntos de sentenças desse subcorpus diferem daqueles usados na formulação das regras de parafraseamento. Como o algoritmo de alinhamento trabalha sempre com 
pares de sentenças, acredita-se que o seu desempenho ao alinhar duas sentenças de entrada seria equivalente ao alinhar um conjunto de sentenças.

Para a construção do corpus de referência, os 20 pares de sentenças foram manualmente alinhados por dois linguistas computacionais. Posteriormente, a concordância entre eles foi calculada com base no total de alinhamentos em comum dividido pelo total de alinhamentos produzidos pelos dois anotadores. Uma taxa de concordância de $87 \%$ foi obtida, indicando que os alinhamentos de referência são bastante confiáveis.

O desempenho do alinhador foi avaliado usando as medidas de Precisão, Cobertura e Medida-F. Seja R o conjunto de alinhamentos de referência, A o conjunto de alinhamentos produzidos automaticamente e $|\mathrm{A} \cap \mathrm{R}|$ o conjunto de alinhamentos automáticos corretamente produzidos. A Precisão representa a fração dos alinhamentos automáticos identificados corretamente, em relação a todos os alinhamentos automáticos produzidos (Fórmula 29). A Cobertura representa a fração dos alinhamentos automáticos identificados corretamente, em relação a todos os alinhamentos previstos no conjunto de referência (Fórmula 30). A Medida-F, por sua vez, representa a média harmônica entre a Precisão e a Cobertura (Fórmula 31) .

$$
\begin{gathered}
\text { Precisão }=\frac{|A \cap R|}{|A|} \\
\text { Cobertura }=\frac{|A \cap R|}{|R|}
\end{gathered}
$$

$$
\text { Medida-F }=\frac{2 * \text { Precisão } * \text { Cobertura }}{\text { Precisão }+ \text { Cobertura }}
$$

Para fins de comparação, foram usados dois algoritmos baseline. O primeiro baseline (daqui em diante Baseline-1) é baseado somente no casamento de segmentos idênticos, nos sinônimos e nos cognatos, sem fazer uso das regras de parafraseamento e das relações sintáticas de dependências. O segundo baseline (Baseline-2) é uma extensão do Baseline-1 que inclui também os traços de dependências sintáticas. O Baseline-1 tem como propósito avaliar a contribuição das regras de parafraseamento e 
das dependências sintáticas no alinhamento de informações comuns, enquanto que o Baseline-2 visa apenas verificar a contribuição das regras de parafraseamento.

Os resultados médios obtidos pelo alinhador proposto e por cada baseline para Precisão, Cobertura e Medida-F são apresentados na Tabela 10.

Tabela 10: Resultados médios obtidos para Precisão, Cobertura e Medida-F no alinhamento de informações comuns

\begin{tabular}{|c|c|c|c|}
\hline Sistema & Precisão & Cobertura & Medida-F \\
\hline Alinhador Proposto & 0,87 & 0,83 & 0,85 \\
\hline Baseline -1 & 0,81 & 0,76 & 0,78 \\
\hline Baseline-2 & 0,81 & 0,75 & 0,78 \\
\hline
\end{tabular}

Conforme mostrado na tabela, o alinhador proposto obteve um ganho de Precisão de 7,4\% em relação aos dois algoritmos baseline e um ganho de aproximadamente 9\% de Cobertura e de Medida-F. O bom desempenho dos sistemas baseline já era esperado devido às características do próprio corpus. Aproximadamente $72 \%$ dos alinhamentos identificados (149 alinhamentos no total) ocorreram entre segmentos literalmente idênticos.

É interessante observar que, ao incluir as relações de dependências sintáticas no Baseline-2, não houve ganho de desempenho, comparado ao Baseline-1. A diferença de desempenho só foi verificada ao adicionar as regras de parafraseamento no algoritmo proposto (vide Tabela 10).

Com o propósito de verificar a contribuição do método proposto no alinhamento de sinônimos, cognatos e paráfrases apenas (excluindo-se os casamentos idênticos), a Precisão, a Cobertura e a Medida-f foram novamente calculadas considerando-se somente esses casos. Os resultados médios obtidos são apresentados na Tabela 11.

Tabela 11: Resultados médios obtidos para Precisão, Cobertura e Medida-F no alinhamento de sinônimos, cognatos e paráfrases

\begin{tabular}{|c|c|c|c|}
\hline Sistema & Precisão & Cobertura & Medida-F \\
\hline Alinhador Proposto & 0,69 & 0,60 & 0,64 \\
\hline Baseline-1 & 0,55 & 0,14 & 0,23 \\
\hline Baseline-2 & 0,53 & 0,24 & 0,33 \\
\hline
\end{tabular}


Ao desconsiderar os alinhamentos de segmentos literalmente idênticos, o alinhador proposto apresentou uma melhora substancial de desempenho em relação aos dois baselines, tanto no que se refere à Precisão, como no que se refere à Cobertura e à Medida-F. Em relação à Precisão houve uma melhora de até 30,2\%, enquanto que para Cobertura o ganho foi de $328,5 \%$ comparado ao Baseline-1 e de $150 \%$ comparado ao Baseline-2. Já no que diz respeito ao desempenho global (Medida-F), o modelo proposto apresentou um aumento de 178,2\% na comparação com o Baseline-1 e um aumento de $94 \%$ na comparação com o Baseline-2.

Como se pode observar na Tabela 11 , o uso das relações de dependências sintáticas no Baseline-2 contribuiu para uma pequena melhora de 3,8\% em termos de Precisão, em relação ao Baseline-1. Porém, em termos de Cobertura e de Medida-F houve uma melhora de $71,4 \%$ e de $43 \%$, respectivamente, sobre o Baseline-1. Esses resultados comprovam que o uso do thesaurus, da medida de cognatos LCSR e das relações sintáticas de dependência auxiliam no alinhamento de segmentos semanticamente similares, porém não são suficientes para identificar os casos mais complexos de segmentos com variações lexicais e sintáticas, como é o caso das paráfrases parcialmente tratadas pelas regras de parafraseamento.

O Quadro 20 mostra alguns exemplos de alinhamentos produzidos pelo algoritmo, no corpus em questão.

\section{Quadro 20: Exemplos de alinhamento automático}

\begin{tabular}{|c|}
\hline a. a aviação israelense ; a aviação de Israel \\
\hline b. Lula ; o presidente Luiz Inácio Lula da Silva \\
\hline $\begin{array}{l}\text { c. o chefe de polícia do campus ; o chefe de } \\
\text { polícia da universidade }\end{array}$ \\
\hline $\begin{array}{l}\text { d. a máfia dos sanguessugas ; a máfia das } \\
\text { ambulâncias }\end{array}$ \\
\hline $\begin{array}{l}\text { e. o presidente do TJ ; o presidente do Tribunal } \\
\text { de Justiça do Estado }\end{array}$ \\
\hline $\begin{array}{l}\text { f. a Secretaria de Estado da Fazenda ; a Secretaria } \\
\text { da Fazenda }\end{array}$ \\
\hline $\begin{array}{l}\text { g. os processos de perda de mandato contra os } 69 \\
\text { deputados ; o processo contra os deputados } \\
\text { envolvidos }\end{array}$ \\
\hline $\begin{array}{l}\text { h. uma quadrilha de altos funcionários públicos ; } \\
\text { a quadrilha }\end{array}$ \\
\hline i. voltou ; recomeçou \\
\hline j. enchentes ; inundações \\
\hline 1. bateu ; chocou \\
\hline
\end{tabular}




\subsection{A Fusão}

Sob a perspectiva da geração de língua natural, a fusão de informações consiste no planejamento do conteúdo das sentenças a serem geradas. Esse processo envolve a seleção dos conceitos a serem transmitidos e a escolha das unidades lexicais apropriadas para comunicar cada conceito.

A seleção de conteúdo no Zíper é guiada pelo alinhamento de informações comuns, realizado na etapa anterior (vide Seção 5.1). Mais especificamente, o alinhamento indica quais conceitos são redundantes e que, portanto, precisam ser sintetizados e aqueles que aparecem em somente uma sentença, devendo ser descartados, no caso da fusão por interseção, e preservados, no caso da fusão por união.

Ao invés de construir uma nova árvore de dependências sintáticas, a partir da união de todas as árvores do conjunto de entrada, e, posteriormente, comprimir essa árvore (como fazem, por exemplo, Barzilay \& Mckeown (2005) e Fillipova \& Strube 2008), o planejamento de conteúdo no método proposto é baseado em transformações realizadas nas próprias árvores das sentenças originais, que guardam todas as verbalizações alternativas de cada nó. A união de todas as árvores em uma única árvore é um processo não trivial que envolve uma série de decisões, por exemplo, a escolha de uma árvore base para agregar todas as demais árvores, a posição de inserção de subárvores na árvore base, bem como a reconstrução das relações de dependências, entre outras, estando mais propensa a produzir sentenças agramaticais. Com a construção de sentenças a partir de transformações aplicadas nas árvores das sentenças originais, acredita-se que esses erros gramaticais possam ser minimizados.

Assim, o planejamento de conteúdo é aplicado a todas as árvores de dependências do conjunto de entrada, que darão origem à geração de várias sentenças, conforme será descrito na Seção 5.3. Antes, porém, as Subseções 5.2.1 e 5.2.2 descrevem a fusão por interseção e a fusão por união, respectivamente.

\subsubsection{Fusão por Interseção}

A fusão por interseção consiste em preservar, nas sentenças de saída, somente as informações similares das sentenças de entrada, ou seja, a interseção entre elas. Desse modo, as informações que não têm qualquer interseção com outras informações 
apresentadas no conjunto de sentenças devem ser descartadas. Considere, por exemplo, as Árvores 1 e 2 apresentadas na Figura 14 (Seção 5.1.2) e reproduzidas na Figura 15, por conveniência. Na Árvore 1, a subárvore mais a direita não tem interseção com nenhuma subárvore da Árvore 2 e, portanto, deveria ser descartada. De modo similar, na Árvore 2, a subárvore não alinhada (mais a direita) também deveria ser excluída. Assim, o planejamento de conteúdo na fusão por interseção se resume em um processo de remoção de subárvores não intersectadas e seleção de unidades lexicais.

Dessa maneira, cada árvore de dependências sintáticas passa por um processo de poda, no qual as subárvores não alinhadas são descartadas (vide o pseudocódigo apresentado no Quadro 21). Entretanto, a remoção de todos os elementos não alinhados pode prejudicar a gramaticalidade e a semanticidade das sentenças a serem produzidas como, por exemplo, a remoção do sujeito e do verbo da sentença. Para evitar que constituintes sintáticos relevantes sejam excluídos, somente elementos autocontidos que não interferem no sentido e na gramaticalidade são removidos. Seguindo outros trabalhos da literatura (por exemplo, Jing \& Mckeown, 2000 e Barzilay \& Mckeown, 2005), esses elementos incluem as orações relativas (rel), as orações coordenadas (co) e os adjuntos adverbiais (fA - função advervial) ${ }^{12}$ (linhas 3 e 4 do pseudocódigo). Um exemplo de sentença em que esses elementos ocorrem pode ser visto no Quadro 22. Na sentença [1], por exemplo, há uma oração relativa, um adjunto adverbial de tempo e uma oração coordenada aditiva (em negrito) que não aparecem na sentença [2]. Esses elementos podem ser descartados, portanto, já que a sua remoção não prejudica a gramaticalidade e a compreensão da mensagem principal da sentença. Apesar de a sentença [2] também apresentar uma informação não compartilhada com a sentença [1] (em itálico e negrito), essa informação não pode ser descartada, pois exerce a função de objeto direto. A remoção desse objeto exigiria uma reestruturação em termos gramaticais. Contudo, o método de fusão não dispõe de uma gramática que possa auxiliar nesse processo.

Como o alinhamento é realizado em nível de palavras e sintagmas (e não em nível de orações), em muitos casos uma subárvore representando uma oração relativa, uma coordenada ou um adjunto adverbial contém apenas um ou dois nós alinhados. Em alguns casos, esses alinhamentos representam uma fração muito grande da subárvore, indicando que ela não deve ser descartada, enquanto em outros não. Para tratar

\footnotetext{
${ }^{12}$ Neste documento, o adjunto adverbial se refere tanto aos sintagmas adverbiais como as orações subordinadas adverbiais.
} 
adequadamente cada caso, optou-se pela exclusão somente das subárvores que estiverem menos de $30 \%$ alinhadas (linhas 5 e 6). Essa porcentagem foi determinada empiricamente com base no corpus de desenvolvimento.

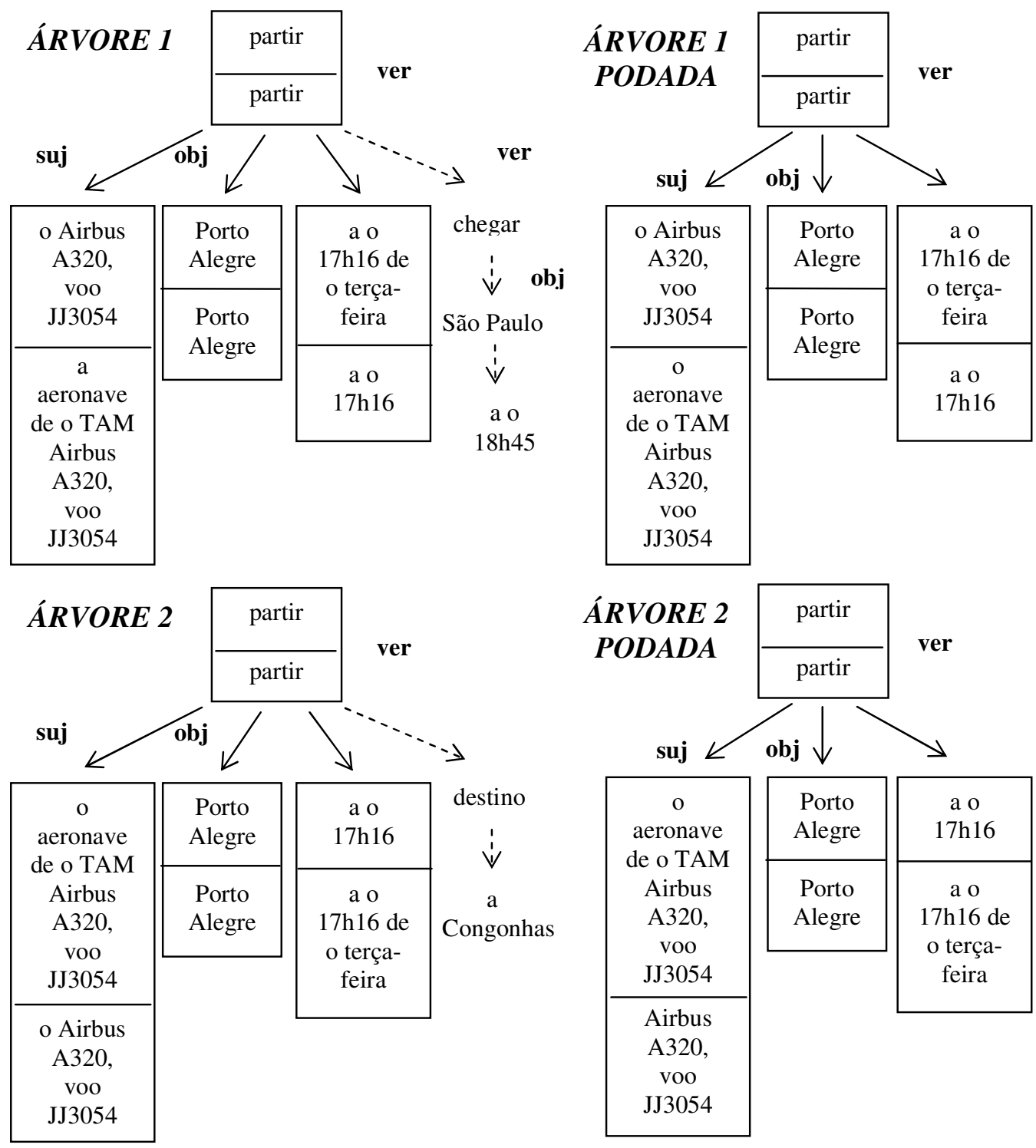

Figura 15: Exemplo de poda de subárvores não intersectadas

A Figura 15 ilustra as Árvores 1 e 2 após a poda de subárvores não intersectadas. $\mathrm{Na}$ Árvore 1, a subárvore removida refere-se a uma oração coordenada aditiva, enquanto que, na Árvore 2, a subárvore removida refere-se a um adjunto adverbial. 


\section{Quadro 21: Algoritmo da função que poda subárvores não intersectadas}

Função: podar_subárvores

Entrada: Um conjunto $C=\left\{T_{1}, \ldots, T_{n}\right\}$ com $n$ árvores de dependências sintáticas, onde cada $T_{i}=\left\{v_{1}, \ldots, v_{m}\right\}$ com $m$ nós. Para um nó $v_{i}$, a subárvore de $T_{i}$ que tem $v_{i}$ como seu nó raiz é denotada por $T_{i}\left(v_{i}\right)$.

Saída: Um conjunto $C^{\prime}=\left\{T_{1}^{\prime}, \ldots, T_{n}{ }^{\prime}\right\}$ com $n$ árvores de dependências sintáticas, no qual cada $T_{i}{ }^{\prime}$ representa sua respectiva árvore $T_{i} \in C$ após a poda de subárvores.

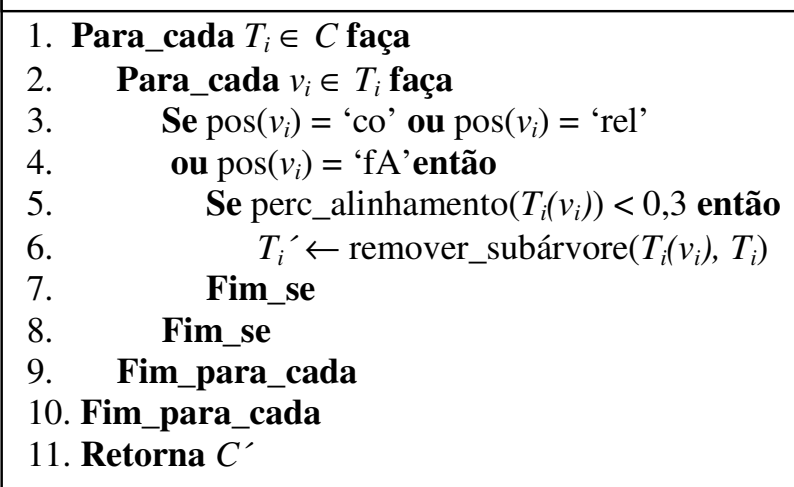

Quadro 22: Exemplo de elementos sem interseção que são excluídos das sentenças

[1] A seleção brasileira masculina de vôlei, que é treinada por Bernardinho, venceu a Finlândia por 3 sets a 0, parciais de 25/17, 25/22 e 25/21, nesta sextafeira, em Tampere (FIN), e manteve sua invencibilidade na Liga Mundial-06.

[2] A seleção brasileira masculina de vôlei conseguiu a sétima vitória consecutiva na Liga Mundial ao derrotar a Finlândia por 3 sets a 0 - parciais de 25/17, 25/22 e 25/21 -, em jogo realizado na cidade de Tampere, na Finlândia.

Após a seleção dos conceitos a serem preservados na construção de novas sentenças, o próximo passo do planejamento de conteúdo é determinar quais unidades lexicais serão usadas para representar cada conceito. As verbalizações possíveis são aquelas identificadas durante o alinhamento e armazenadas em cada árvore (vide Figura 15). Como não há informações semânticas suficientes para auxiliar na decisão de qual das alternativas melhor expressa um determinado conceito (por exemplo, que possam informar qual a mais geral e a mais específica), duas estratégias distintas foram adotadas. A primeira estratégia constrói todas as sentenças válidas possíveis a partir de cada árvore de dependência sintática, de forma análoga a realizada por vários métodos da literatura (vide Capítulo 3). A segunda estratégia faz uso de duas heurísticas para determinar qual a melhor opção dentre as alternativas disponíveis. A primeira heurística prioriza a seleção da menor verbalização disponível, ou seja, aquela que apresentar o menor número de palavras de conteúdo (isto é, substantivos, adjetivos, verbos e advérbios). A menor verbalização tem grandes chances de 
representar a interseção de todas as alternativas disponíveis como, por exemplo, em "o Airbus A320, voo JJ3054 $\Leftrightarrow$ o aeronove de o TAM Airbus A320, voo JJ3054" e " a o 17h16 $\Leftrightarrow$ a o $17 h 16$ de o terça-feira" (Figura 15). Nos casos em que todas as alternativas têm o mesmo número de palavras, o algoritmo considera todas as possibilidades. A segunda heurística, por sua vez, prioriza a seleção de verbalizações que contêm nomes próprios, visando resolver anáforas. Por exemplo, quando uma das alternativas contém um sintagma nominal e as demais são expressões anafóricas como em "Véron $\Leftrightarrow$ o meio campista", "o Japão $\Leftrightarrow$ o país" e “ACM $\Leftrightarrow$ o parlamentar $\Leftrightarrow$ o político baiano". A substituição da expressão anafórica pelo nome aumenta a clareza das sentenças a serem produzidas. Nos casos em que duas ou mais alternativas contêm nomes próprios, por exemplo, em "o Airbus A320, voo JJ3054 $\Leftrightarrow$ o aeronove de o TAM Airbus A320, voo JJ3054" (Figura 15), ele seleciona a menor delas (ou seja, “o Airbus A320, voo JJ3054"). A Figura 16 ilustra as Árvores 1 e 2 (Figura 15) após a aplicação das heurísticas de seleção de unidades lexicais. Coincidentemente, nesse exemplo, as árvores resultantes são iguais. Portanto, elas darão origem a duas sentenças idênticas, conforme será descrito na Seção 5.3. Antes, porém, a subseção a seguir descreve a fusão por união de informações.

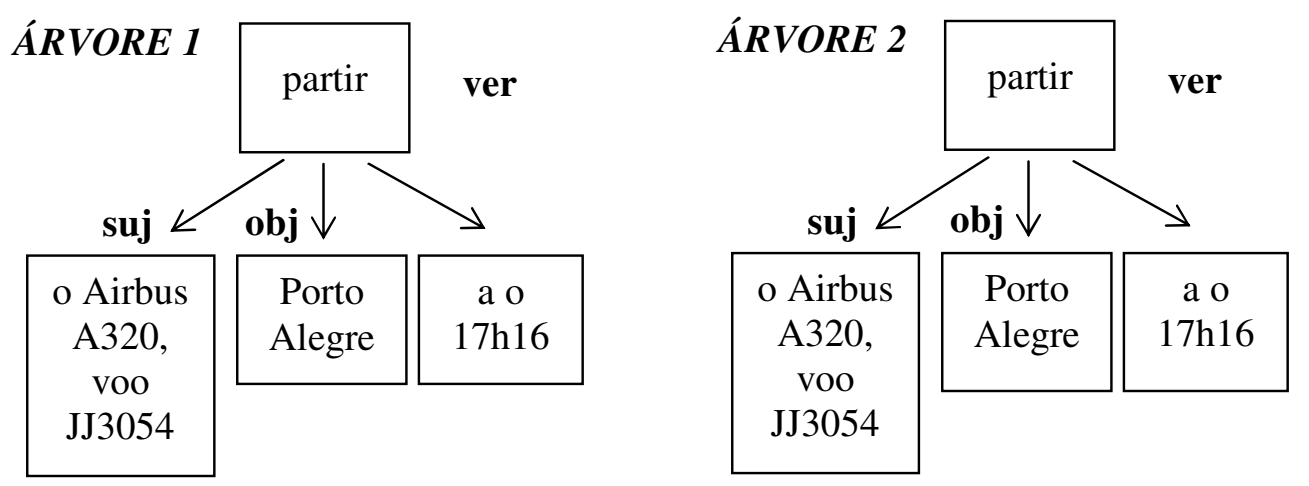

Figura 16: Árvores 1 e 2 após a seleção de unidades lexicais na fusão por interseção

\subsubsection{Fusão por União}

A fusão por união consiste em produzir sentenças que preservam todas as informações veiculadas pelas sentenças de entrada, sem redundâncias. Assim, ao contrário da fusão por interseção, que remove de cada árvore as subárvores sem alinhamento, na fusão por união a árvore toda deve ser preservada. Além do mais, cada árvore deve agregar todas as subárvores do conjunto não contempladas por ela, a fim de 
produzir sentenças representando a união do conjunto de entrada. Considere, por exemplo, as Árvores 1 e 2 ilustradas na Figura 15 (antes da poda). Para garantir que todas as informações apresentadas nelas sejam consideradas na construção de novas sentenças, a Árvore 1 precisaria agregar também a subárvore da Árvore 2 não contemplada por ela. De maneira similar, a subárvore da Árvore 1 não apresentada na Árvore 2, deveria ser agregada a ela.

Assim, o planejamento de conteúdo na fusão por união consiste em identificar, dada uma árvore de dependências, as subárvores do conjunto de entrada não contempladas por aquela árvore, de forma que possam ser agregadas a ela. $\mathrm{O}$ alinhamento de informações comuns é essencial para esse processo, permitindo identificar as subárvores que não têm interseção com determinada árvore.

Dado um conjunto $C=\left\{T_{1}, \ldots, T_{n}\right\}$ com $n$ árvores de dependências sintáticas, o Zíper busca, para cada árvore $T_{i}$ pertencente a $C$, as subárvores das demais sentenças de entrada que não estão alinhadas a ela, criando um conjunto $U$ de subárvores candidatas a união, conforme mostrado no pseudocódigo do Quadro 23 (linha 2). Todavia, a união indiscriminada de todas as subárvores sem alinhamentos pode resultar na produção de sentenças agramaticais, com excesso de elementos ou com elementos conflitantes. Considere, por exemplo, as sentenças apresentadas no Quadro 22. Ao unir o objeto direto da sentença [2] (em itálico e negrito) na árvore da sentença [1], o algoritmo poderia produzir sentenças agramaticais e com distorção de significado, como a sentença "A seleção brasileira masculina de vôlei, que é treinada por Bernardinho, venceu a sétima vitória consecutiva na Liga Mundial a Finlândia por 3 sets a 0 , parciais de 25/17, 25/22 e 25/21, nesta sexta-feira, na cidade de Tampere, na Finlândia, e manteve sua invencibilidade na Liga Mundial-06." A fim de evitar esses problemas, somente os elementos sintáticos autocontidos são considerados na união. Conforme visto na Seção 5.2.1, esses elementos se referem às orações relativas, às orações coordenadas e aos adjuntos adverbiais. O pseudocódigo da função que identifica as subárvores para união (função obter_subárvores_para_união) é apresentado no Quadro 24. As orações relativas, as coordenadas e os adjuntos adverbiais são indicados por rel, co e fA (função adverbial), respectivamente (linha 5). É válido dizer que uma subárvore que não tem interseção com $T_{i}$ pode ter interseção com as demais árvores do conjunto $C$. Dessa maneira, para impedir a união de subárvores redundantes, uma subárvore candidata ao conjunto $U$ não deve apresentar interseção com nenhuma das subárvores já pertencentes a esse conjunto (linha 7 do pseudocódigo). 


\section{Quadro 23: Algoritmo da função que une subárvores}

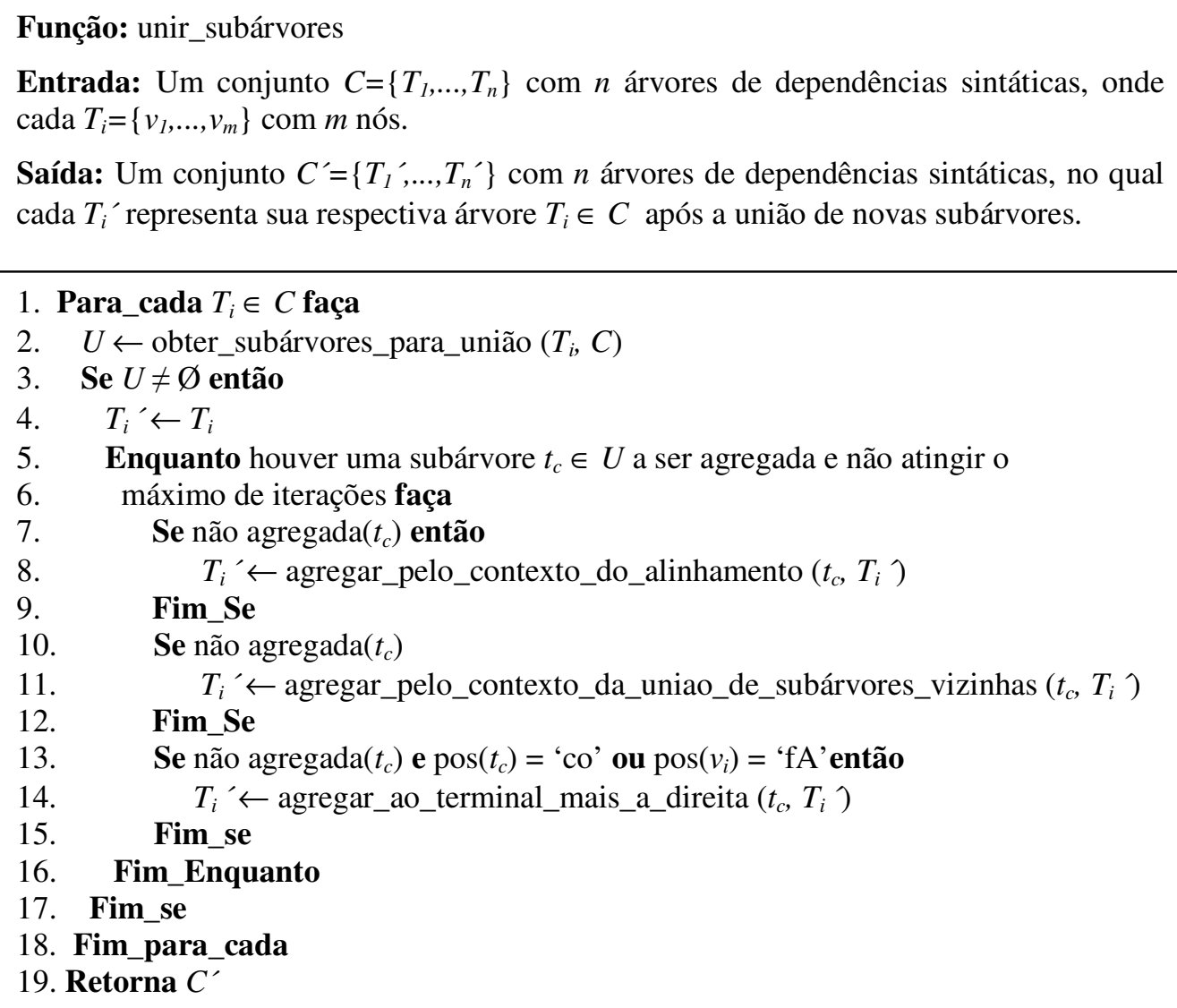

Saída: Um conjunto $C^{\prime}=\left\{T_{1}^{\prime}, \ldots, T_{n}{ }^{\prime}\right\}$ com $n$ árvores de dependências sintáticas, no qual cada $T_{i}$ 'representa sua respectiva árvore $T_{i} \in C$ após a união de novas subárvores.

Supondo que $U$ seja um conjunto não vazio (linha 3 do Quadro 23), o algoritmo tenta agregar cada subárvore $t_{c} \in U$ na árvore $T_{i}$. Entretanto, estabelecer a posição de inserção de cada $t_{c}$ em $T_{i}$ consiste em um dos maiores desafios desse processo. Para que uma sentença seja bem-formada, há uma enormidade de regras gramaticais que devem ser obedecidas. Porém, como o método de fusão não dispõe de uma gramática que possa auxiliar nesse processo, ele se baseia em duas heurísticas. A primeira heurística baseiase em informações de contexto obtidas a partir do alinhamento de conceitos comuns entre $T_{i}$ e a árvore de origem de $t_{c}$, se existir algum (linha 8). Por exemplo, considere que $t_{c}$ representa a subárvore sem alinhamento na Árvore 2 da Figura 17 (representadas por caixas tracejadas) e $T_{i}$ representa a Árvore 1. Para obter a posição de inserção de $t_{c}$ em $T_{i}$, o algoritmo verifica se o segmento na sentença correspondente à árvore que contém $t_{c}$ (Árvore 2), adjacente ao segmento apresentado na raiz de $t_{c}$ (ou seja, "a as 17h16" (em negrito na figura)), está alinhado a algum nó $v_{i}$ de $T_{i}$. Se estiver, como é o caso desse exemplo (vide nó em negrito na Árvore 1), $t_{c}$ é inserida como descendente de 
$v_{i}$ (vide Figura 17). É importante dizer, no entanto, que essa descendência não implica em uma relação de dependência sintática entre $t_{c}$ e $v_{i}$. Ao inserir $t_{c}$ em $T_{i}$, seu traço de dependência precisaria ser reconstruído em função dos elementos que compõem a árvore $T_{i}$. Porém, para que isso seja possível, faz-se necessário o uso de um parser durante esse processo. Como essa informação não é fundamental para a fusão e nem para a linearização (vide Seção 5.3), a reconstrução da análise de dependência não é necessária. De modo similar, a subárvore sem alinhamento na Árvore 1 da Figura 17 (sem caixa de texto) é agregada na Árvore 2. A árvore resultante desse processo é ilustrada na Figura 18.

\section{Quadro 24: Algoritmo da função que obtém subárvores para união}

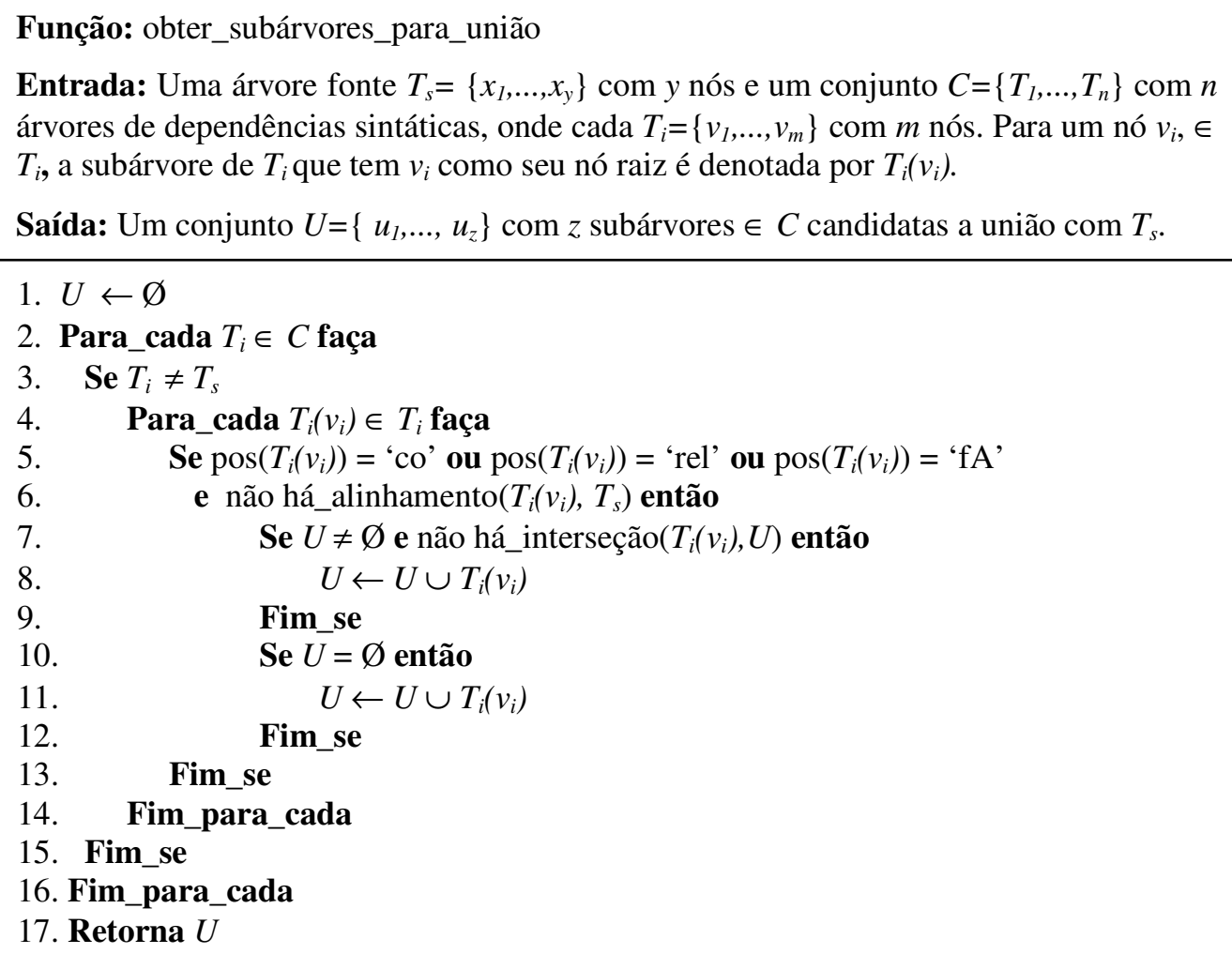

Caso o segmento adjacente àquele representado na raiz da subárvore $t_{c}$ não estiver alinhado a um nó $v_{i} \in T_{i}$, o algoritmo tentará obter a posição de inserção de $t_{c}$ a partir do alinhamento entre o segmento que segue aquele representado no nó terminal de $t_{c}$ (se existisse algum) e algum nó $v_{i} \in T_{i}$. Supondo que haja algum alinhamento, $t_{c}$ será inserida em $T_{i}$ como descendente do nó que contém o segmento adjacente ao segmento representado pelo nó $v_{i}$. 

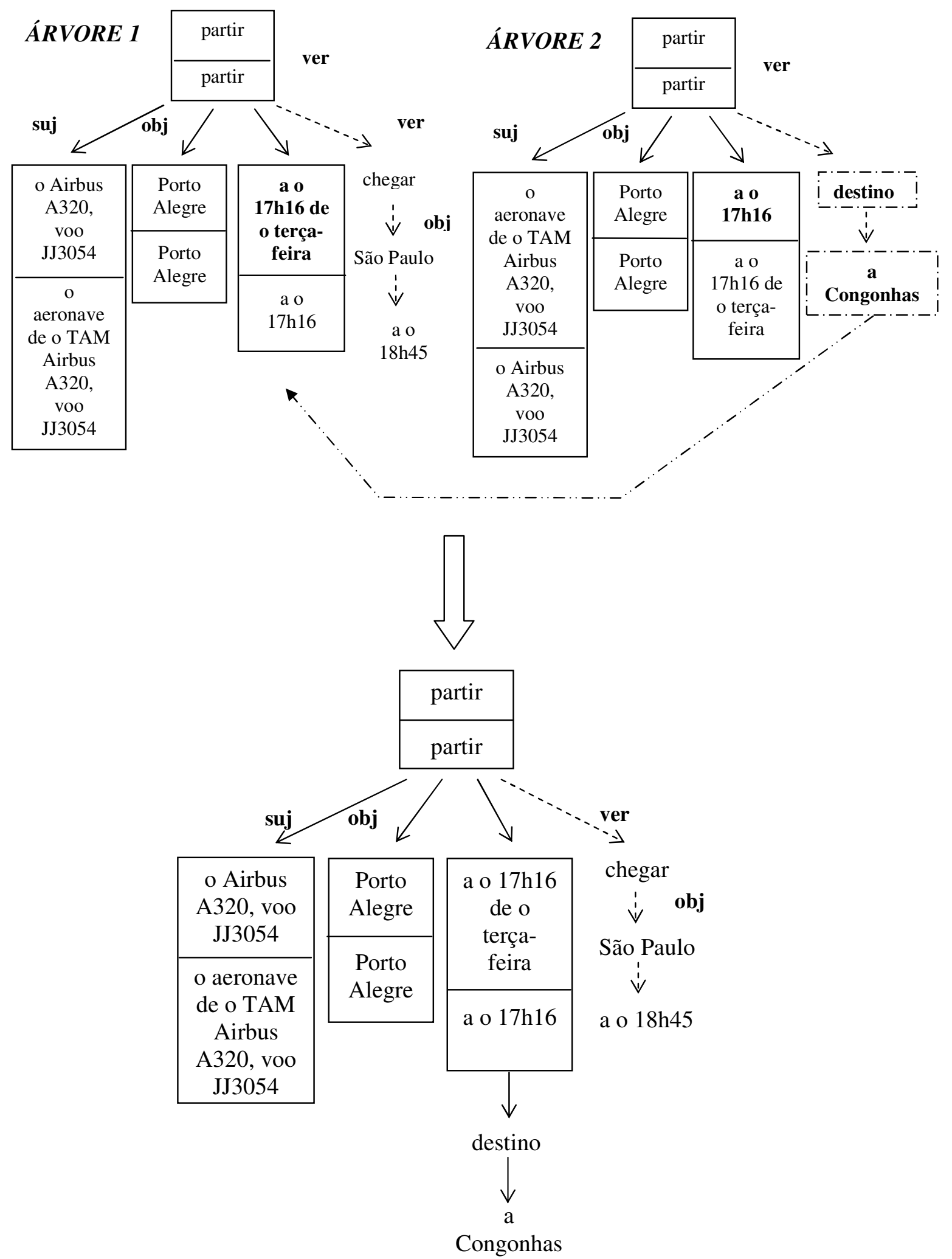

Figura 17: Exemplo de união de subárvores 


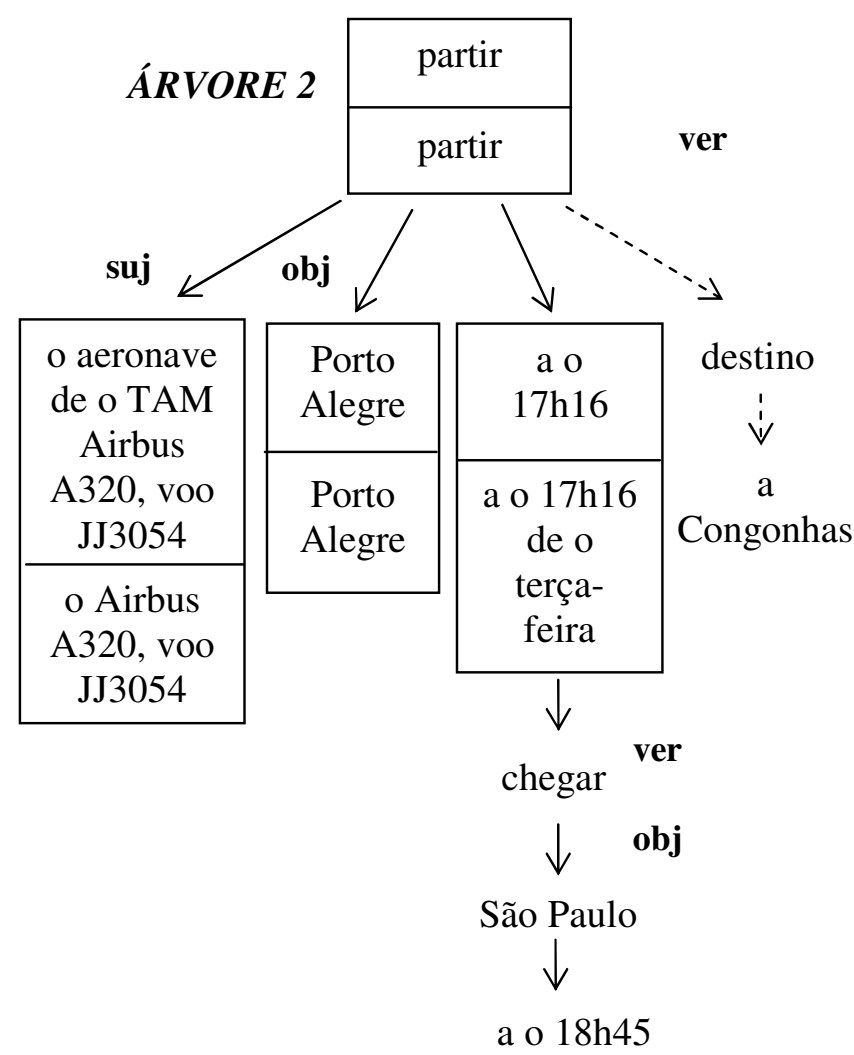

Figura 18: Árvore 2 após a união da subárvore da Árvore 1

Em alguns casos, entretanto, a inserção pelo contexto do alinhamento pode falhar. Por exemplo, considere as sentenças [1] e [2] do Quadro 25. Ao incluir a oração coordenada apresentada na sentença [1] (em negrito e itálico) pelo contexto do alinhamento entre Katowice (Polônia) e Katowice, na Polônia (em negrito), o algoritmo pode gerar sentenças sem sentido, como a sentença [3] apresentada naquele quadro.

Quadro 25: Contra-exemplo de agregação de informações por meio do contexto dado pelo alinhamento

[1] O time de Bernardinho derrotou a Rússia por 3 sets a 1, parciais de 18/25, 25/23, 28/26 e 25/22, em Katowice (Polônia), e alcançou seu sétimo título da Liga Mundial.

[2] Neste domingo, em Katowice, na Polônia, a seleção brasileira venceu a Rússia por 3 sets a 1, com parcias de 18/25, 25/23, 28/26 e 25/22.

[3] Neste domingo, em Katowice, na Polônia, e alcançou seu sétimo título da Liga Mundial a seleção brasileira venceu a Rússia por 3 sets a 1, com parcias de $18 / 25,25 / 23,28 / 26$ e $25 / 22$. 
A segunda heurística, por sua vez, tenta agregar $t_{c}$ em $T_{i}$ com base em informações de contextos obtidas a partir de outras subárvores vizinhas de $t_{c}$ já agregadas a $T_{i}$, caso haja alguma (linha 11 do Quadro 23). Assim como na primeira heurística, o contexto é dado pelo segmento adjacente ao segmento contido na raiz de $t_{c}$ (contexto esquerdo) ou pelo segmento que segue aquele contido no nó terminal de $t_{c}$ (contexto direito), na sentença correspondente à árvore que contém $t_{c}$. Supondo que o vizinho da esquerda tenha sido agregado a $T_{i}$, $t_{c}$ é inserida como descendente de seu vizinho em $T_{i}$. Caso apenas o vizinho direito tenha sido agregado a $T_{i}$, então $t_{c}$ é inserida como ascendente de seu vizinho em $T_{i}$. A intuição por trás desta heurística é que, se um segmento $s$ é vizinho do segmento representado pela subárvore $t_{c}$ na sentença de origem, então há uma chance de eles serem vizinhos também na sentença de destino. Essa heurística só é aplicada quando a tentativa de inserir $t_{c}$ pelo contexto do alinhamento (primeira heurística) falhar.

Por fim, se a subárvore $t_{c}$ não puder ser agregada por nenhuma das heurísticas, ela é inserida como descendente do nó terminal mais a direita de $T_{i}$, ou seja, no final da sentença (linhas 13 e 14). Entretanto, apenas as orações coordenadas e os adjuntos adverbiais podem ser inseridos dessa forma. As orações relativas são agregadas somente pelo contexto, pois se referem a um termo ou nome específico.

A seleção de unidades lexicais na fusão por união é realizada por meio de duas heurísticas, similares àquelas aplicadas na fusão por interseção (Seção 5.2.1). Porém, enquanto na interseção há uma heurística que prioriza a seleção da menor verbalização disponível em cada nó, na união essa heurística seleciona a maior de todas as verbalizações (em número de palavras de conteúdo). Em geral, a maior verbalização representa a união de todas as verbalizações disponíveis como, por exemplo, em "o Airbus A320, voo JJ3054 $\Leftrightarrow a$ aeronove da TAM Airbus A320, voo JJ3054" e "às $17 h 16 \Leftrightarrow$ às 17 h16 da terça-feira". A segunda heurística, por sua vez, é equivalente àquela da fusão por interseção que prioriza a seleção de verbalizações contendo nomes próprios (por exemplo, em "Ele $\Leftrightarrow$ o presidente do Conselho de Ética, deputado Ricardo Izar (PTB-SP)"). Nos casos em que duas ou mais verbalizações contêm nomes próprios, por exemplo, em "o Airbus A320, voo JJ3054 $\Leftrightarrow a$ aeronove da TAM Airbus A320, voo JJ3054", o algoritmo seleciona a maior delas (isto é, "a aeronove da TAM Airbus A320, voo JJ3054”). A Figura 19 ilustra as Árvores 1 e 2 apresentadas nas Figuras 17 e 18 após a aplicação das heurísticas de seleção de unidades lexicais. 


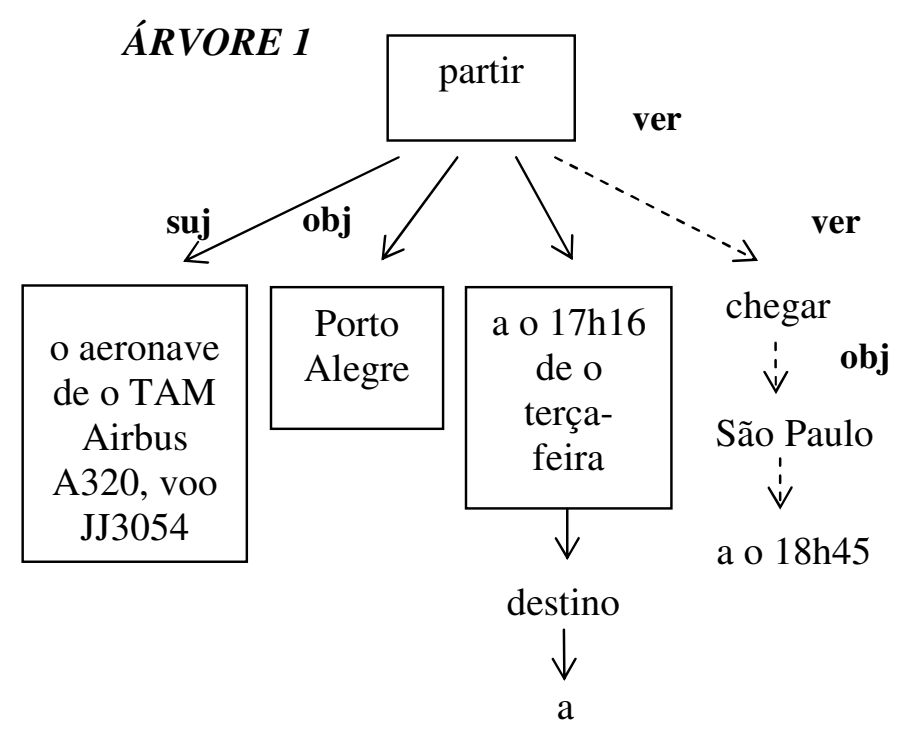

Congonhas

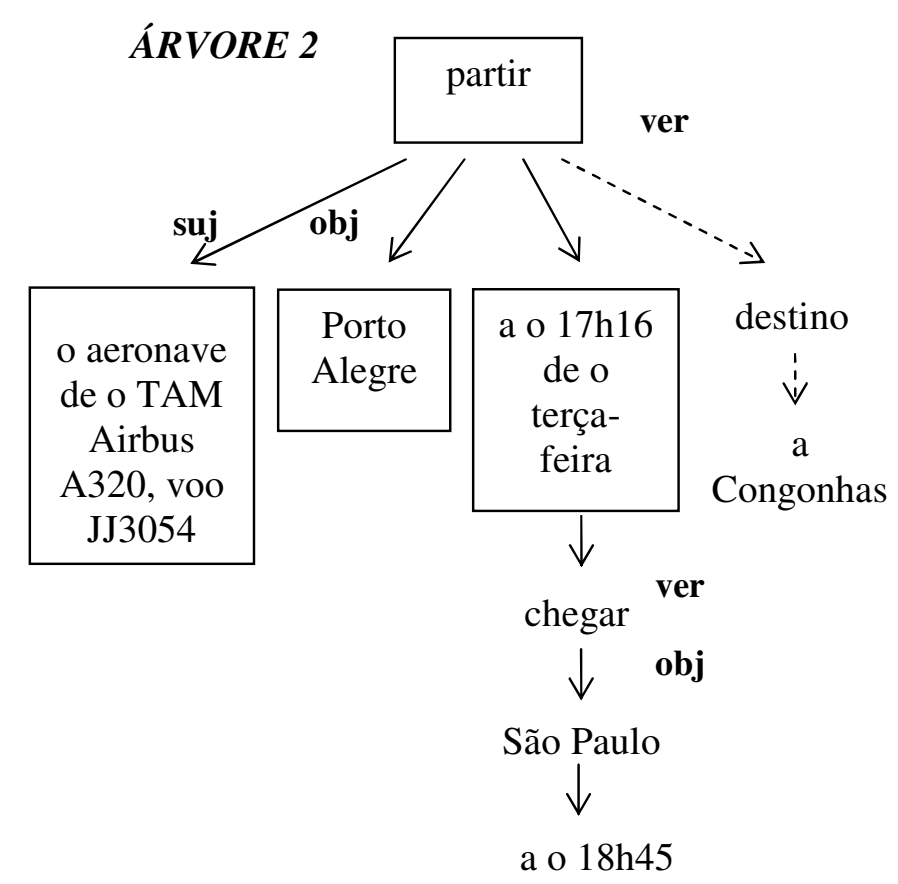

Figura 19: Árvores 1 e 2 após a seleção de unidades lexicais na fusão por união

\subsection{A Linearização}

A última etapa da fusão sentencial é a linearização, que consiste na realização superficial das sentenças. É senso comum que uma sentença não é uma simples sequência de palavras justapostas. Toda língua natural é definida por um conjunto de 
regras (gramática) que especificam o que é uma sentença bem-formada naquela língua. As regras gramaticais regem tanto as estruturas morfológicas, que determinam como as palavras são formadas, como as estruturas sintáticas, que especificam como as sentenças são formadas. Assim, a linearização pode ser resumida como um processo que consiste em aplicar essas regras à representação abstrata de sentenças obtidas durante a etapa de fusão, a fim de produzir sentenças morfologicamente e sintaticamente corretas. Entretanto, como a entrada do método de fusão é um conjunto de sentenças supostamente bem-formadas, parte do conhecimento necessário para a linearização é extraída dessas sentenças, dispensando o uso de uma gramática.

Dessa maneira, para cada sentença de entrada é mantido um vetor associativo (hash) com informações de todos os seus tokens (palavras, símbolos e caracteres de pontuação). As chaves no vetor correspondem à posição de cada token na sentença e possuem até 5 tipos de informações, armazenadas nos seguintes campos:

- sup: contém a forma superficial de uma palavra, um número, um símbolo ou um caractere de pontuação (por exemplo, partiu, parlamentares, \%, etc.).

- base: contém o lema de uma palavra, um número ou um símbolo (por exemplo, partir, parlamentar, \%, etc.). Caracteres de pontuação não têm essa informação.

- pos: contém o part-of-speech (POS) do item lexical, símbolo ou caractere de pontuação, conforme a anotação do parser. Por exemplo, $\mathrm{n}$ (substantivo), v-pcp (verbo do particípio) e pu (pontuação).

- morf: contém as características morfológicas de uma palavra como gênero, número, tempo, modo, etc. Por exemplo, M S (masculino, singular) e PR 3P IND VFIN (presente, terceira pessoa, plural, indicativo, verbo finito). A quantidade desses atributos varia de acordo com o POS da palavra. Os símbolos e os caracteres de pontuação não possuem esse tipo de informação.

- dep: contém a chave do dependente de uma palavra no mesmo vetor de tokens. Os símbolos e os caracteres de pontuação não possuem dependente.

Cada nó em uma árvore de dependência é formado, assim, por um conjunto de chaves que especificam quais palavras de um vetor de tokens compõem aquele nó. Além disso, cada nó guarda também o identificador da sentença de origem dessas palavras, 
uma vez que, após a fusão de informações, uma árvore pode conter segmentos de várias sentenças do conjunto de entrada.

Como as saídas do processo de fusão de informações são as estruturas sintáticas das sentenças a serem geradas (árvores de dependências), a linearização consiste basicamente em a) determinar os traços morfológicos de cada item lexical, a fim de obter sua forma superficial adequada e b) gerar todas as sentenças possíveis a partir de todos os percursos válidos de cada árvore. Os percursos válidos em uma árvore são determinados por restrições de ordem das palavras herdadas das sentenças de entrada. Os caracteres de pontuação, as preposições e outros tokens não representados nas árvores também são recuperados do vetor de tokens das respectivas sentenças de entrada.

Não muito raro, dois ou mais segmentos alinhados apresentam atributos morfológicos distintos. Assim, dependendo do segmento selecionado para compor a nova sentença, pode ser necessário alterar a sua forma superficial, de modo a preservar a gramaticalidade. Considere as árvores A1 e A2 da Figura 20, referentes às sentenças [1] e [2] do Quadro 26 (extraídas do corpus), após serem alinhadas. Os segmentos em itálico em A1 correspondem aos segmentos originados de A2 e vice-versa. Como se pode observar nessas árvores, há vários alinhamentos entre segmentos morfologicamente distintos (em negrito). Os traços morfológicos são apresentados entre parênteses, onde F: feminino, M: masculino, S: singular, P: plural, 3: terceira pessoa, DET: determinante, FUT: futuro, IND: indicativo, VFIN: verbo finito e SUBJ: subjuntivo $^{13}$. Suponha que, após um processo de fusão por interseção, A1 resultasse na árvore ilustrada na Figura 21. As sentenças produzidas a partir de A1 seriam agramaticais, pois não há concordância de gênero entre o sujeito do verbo ser, o trecho $(\mathrm{M})$, e o predicativo do sujeito reaberto $(\mathrm{F})$. Além do mais, ao considerar em um percurso o sujeito "o reforma" e o predicado "passar a ser fazer", haverá discordância em número, já que o sujeito encontra-se no plural $(\mathrm{P})$ e o predicado no singular (S).

\section{Quadro 26: Sentenças similares 2}

[1] Na segunda etapa, a parte concluída será reaberta e a obra passará a ser feita na outra cabeceira.

[2] Quando for concluída esta fase, o trecho será reaberto e as reformas passarão a ser feitas na outra cabeceira.

\footnotetext{
${ }^{13}$ Para os sintagmas nos quais todas as palavras contêm os mesmos traços, a etiqueta morfológica é mostrada apenas uma vez, como é o caso de o segundo etapa. Para o verbo ser na locução verbal passar a ser fazer, não há traços morfológicos, pois ele está no infinitivo.
} 
A1

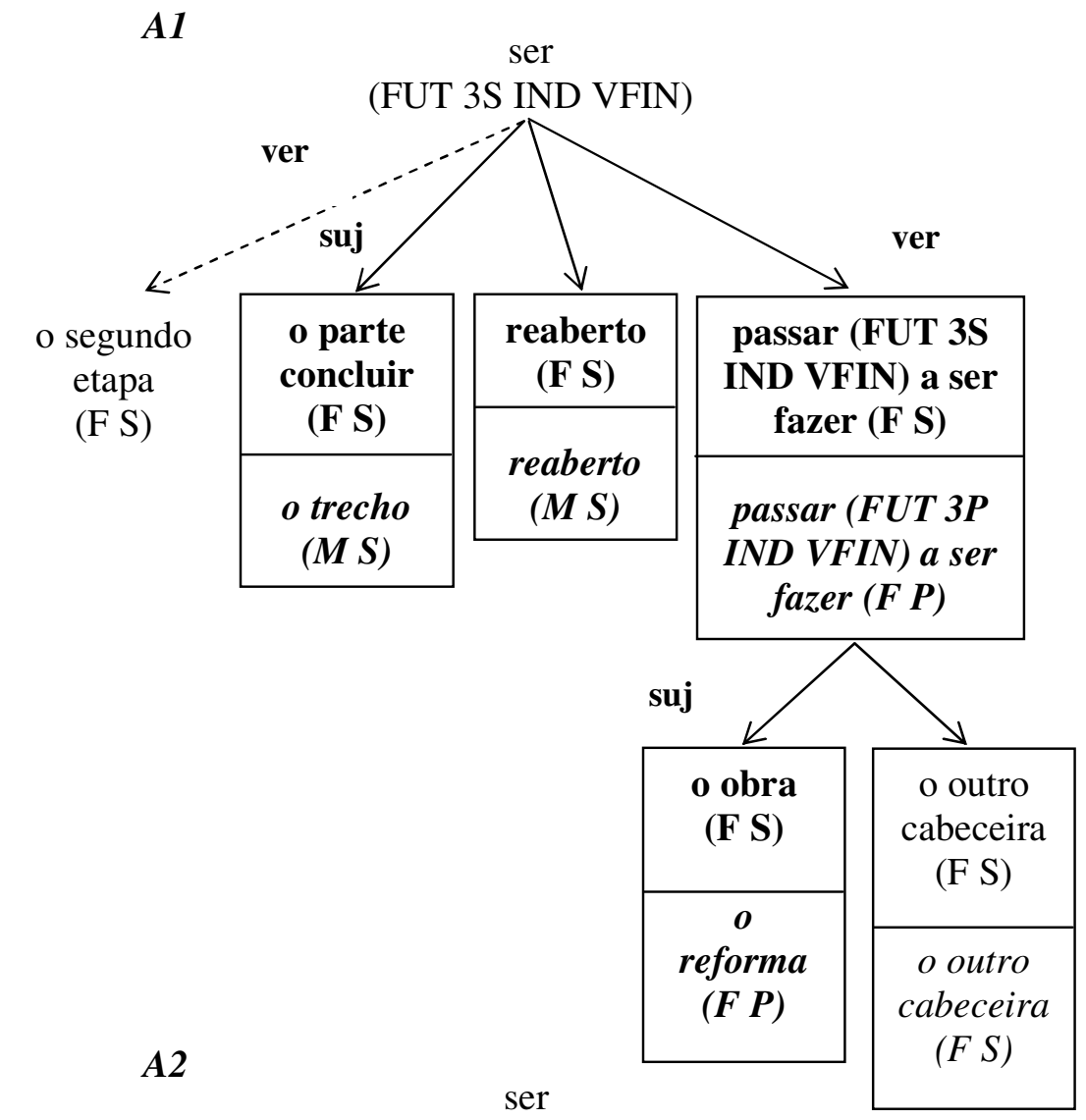

(FUT 3S IND VFIN)

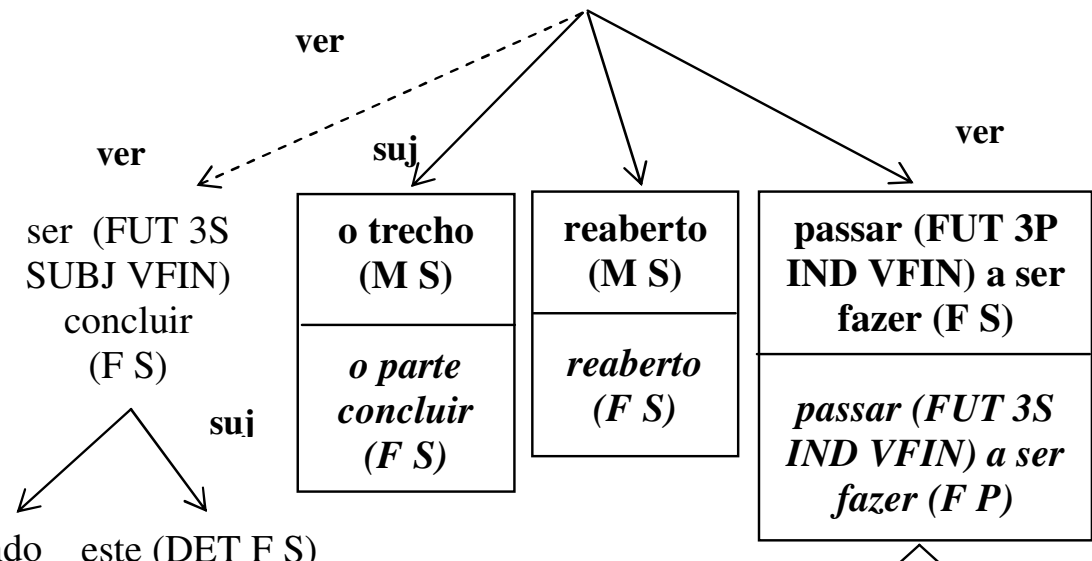

quando este (DET F S)

(F S) fase (F S)

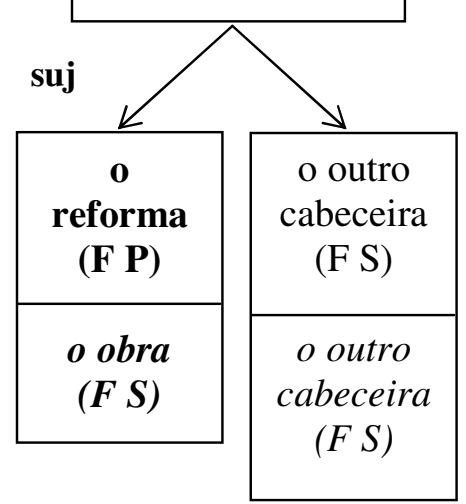

Figura 20: Exemplo de segmentos alinhados com características morfológicas distintas 


\section{A1 PODADA}

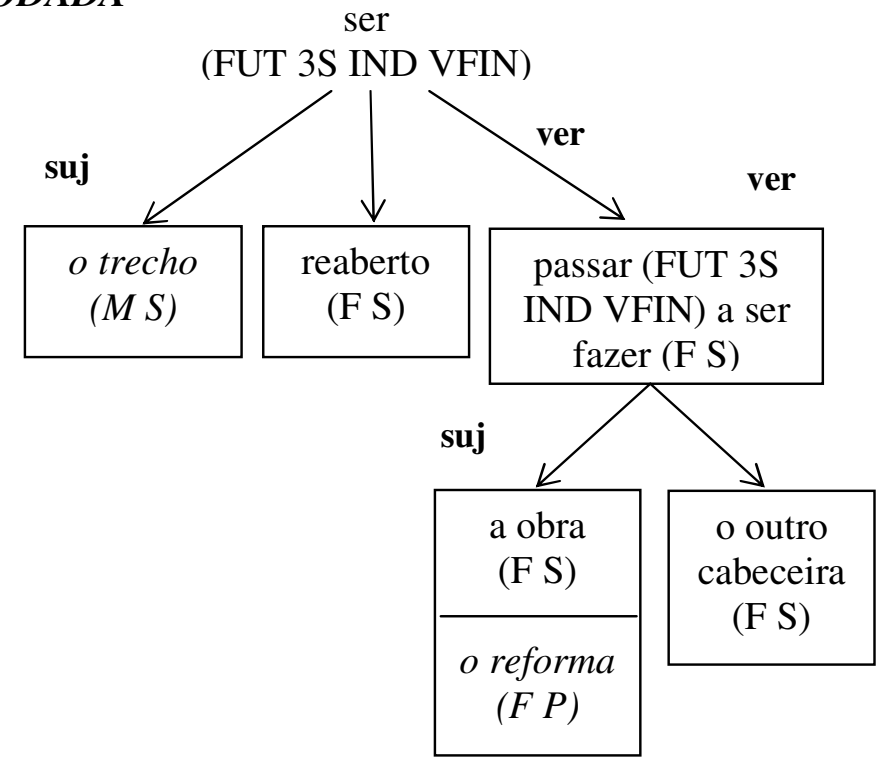

\section{Figura 21: Árvore A1 da Figura 20 após o processo de fusão por interseção}

Para evitar a produção de sentenças agramaticais, Zíper verifica, para cada percurso válido em uma árvore, se há concordância nominal e verbal. Havendo concordância entre todos os elementos sintáticos, o algoritmo recupera a forma superficial de cada item lexical no respectivo vetor de tokens. Caso haja alguma discordância entre dois elementos, ele tenta determinar os traços morfológicos apropriados de cada elemento envolvido, a partir dos seus traços de dependência sintática. Posteriormente, o algoritmo faz uso de um gerador de formas superficiais do português, desenvolvido no contexto do projeto de doutorado de Caseli (2007), que recebe como entrada o lema de uma palavra, o POS e os traços morfológicos e retorna a forma superficial correspondente. Por exemplo, para lema $=$ casa $P O S=\mathrm{n}$ (substantivo) e morfologia = F P (feminino, plural), o gerador retorna a forma superficial casas .

A concordância nominal diz respeito à concordância entre um substantivo e seus modificadores (artigo, pronome, numeral e adjetivo) quanto ao gênero (masculino ou feminino) e ao número (singular ou plural). Contudo, como a árvore de dependência no Zíper é formada por sintagmas, geralmente o núcleo (substantivo) e o modificador não são separados (como em "o trecho", "a segunda etapa") e, portanto, a concordância entre eles é preservada. Em alguns casos, porém, um substantivo precedido por um determinante pode ter sido alinhado a outro não precedido por um determinante, por exemplo, as garotas e menina. Ao substituir as garotas na sua árvore de origem por 
menina, o determinante deverá ser preservado, para não prejudicar a gramaticalidade. Nesse caso, o substantivo herda os mesmos traços morfológicos (gênero e número) daquele artigo, de modo a assumir a forma superficial meninas. Nos casos em que um adjetivo, pronome ou numeral tem função de predicativo do sujeito, também é necessário fazer a concordância entre o sujeito e o predicativo, pois, devido ao alinhamento, eles podem apresentar características morfológicas distintas. Um exemplo disso pode ser visto na árvore da Figura 21, em que o adjetivo reaberto possui gênero feminino, enquanto que o sujeito o trecho possui gênero masculino. Nesses casos, o predicativo deve assumir os mesmos traços morfológicos do núcleo do sujeito. Esses traços podem ser recuperados a partir da relação de dependência entre o predicativo e o verbo e entre o sujeito e o verbo. Para tanto, Zíper recupera o verbo correspondente ao predicativo e, então, recupera o sujeito correspondente ao verbo. Caso o predicativo não concorde com o núcleo do sujeito em gênero e/ou número, os traços morfológicos daquele sujeito são atribuídos ao predicativo e, em seguida, são passados ao gerador de formas superficiais para a realização linguística. Por exemplo, no caso do adjetivo reaberto (Figura 21), o algoritmo identifica o verbo correspondente (ser) e, a partir desse verbo, ele identifica o núcleo do sujeito daquele verbo, isto é, trecho. Como não há concordância de gênero entre o núcleo e o adjetivo, ele atribui ao adjetivo os mesmos traços morfológicos daquele núcleo (isto é, M S).

A concordância verbal diz respeito ao verbo em relação ao sujeito. De acordo com Faraco \& Moura (1994), a regra geral no português, em caso de sujeito simples, é o verbo concordar com o núcleo do sujeito em número e em pessoa $\left(1^{\mathrm{a}}, 2^{\mathrm{a}}\right.$ e $\left.3^{\mathrm{a}}\right)$. Em caso de sujeito composto, o verbo vai para o plural ou concorda com o núcleo mais próximo. Se o sujeito for composto por elementos de pessoas gramaticais diferentes (por exemplo, "A professora e eu tomaremos providências."), a concordância em relação à pessoa deve obedecer uma série de restrições, que dizem respeito à prevalência da pessoa gramatical. Por exemplo, se um sujeito estiver na $3^{\text {a }}$ pessoa (por exemplo, professora) e o outro estiver na $1^{\mathrm{a}}$ pessoa (por exemplo, eu), o verbo concorda na $1^{\mathrm{a}}$ pessoa (isto é, tomaremos). Contudo, no Zíper, a concordância verbal é feita somente em relação ao núcleo do primeiro sujeito e, portanto, não segue necessariamente essas restrições. Essa limitação se deve ao fato de que, no parser Palavras, o verbo se relaciona somente com o primeiro núcleo do sujeito, não havendo, assim, dependência entre os demais nomes e o verbo. Dessa maneira, ao encontrar um problema de 
concordância entre um verbo e o núcleo de um sujeito, Zíper atribui os traços morfológicos (número e/ou pessoa) daquele núcleo ao verbo.

Em casos de locuções verbais formadas por um verbo auxiliar e um verbo do partícipio (por exemplo, “A explosão foi registrada às 10h.”), o algoritmo faz a concordância em número e pessoa entre o auxiliar e o núcleo do sujeito e a concordância em gênero e número entre o verbo do partícipio e o núcleo do sujeito. Em locuções verbais mais complexas, por exemplo, aquelas formadas por um verbo no finito, um verbo de ligação e um verbo do particípio (como em “...a obra passará a ser feita..." (sentença [1] do Quadro 26)), o verbo finito concorda com o núcleo do sujeito em número e pessoa e o verbo do particípio concorda em gênero e número. Por exemplo, para um dado percurso na árvore da Figura 21, contendo o sujeito "o reforma (F P)" e a locução verbal "passar (FUT 3S IND VFIN) a ser fazer (F S)", o Zíper atribui os traços morfológicos apropriados aos verbos passar e fazer (isto é, passar (FUT 3P IND VFIN), fazer (F P)), a partir da dependência com o núcleo do sujeito (isto é, reforma), estabelecendo a concordância entre eles. É importante dizer que há vários casos especiais de concordância verbal que não seguem essas regras gerais. Um exemplo é o caso do verbo ser, que ora concorda com o sujeito (por exemplo, "A garota é inteligente"), ora concorda com o predicativo (por exemplo, "Nem tudo são flores.”). Contudo, esses casos não são tratados de forma diferenciada pelo Zíper.

Por fim, Zíper faz as contrações entre preposição e artigo (por exemplo, de + $\mathrm{o}(\mathrm{s})=\mathrm{do}(\mathrm{s}), \mathrm{a}+\mathrm{as}=$ às, em $+\mathrm{o}(\mathrm{s})=\mathrm{no}(\mathrm{s}))$, entre a preposição $a$ e os demostrativos iniciados por $a$ (por exemplo, a + aquele(s) = àquele(s)), entre outros.

O Quadro 27 ilustra as sentenças produzidas a partir dos percursos válidos na árvore da Figura 21. As sentenças geradas a partir das árvores da Figura 16 (Seção 5.2.1), construídas por meio da fusão por interseção, e as sentenças geradas a partir das árvores da Figura 19 (Seção 5.2.2), construídas pelo processo de fusão por união, são mostradas no Quadro 28.

\section{Quadro 27: Sentenças geradas a partir da árvore apresentada na Figura 21}

(a) O trecho será reaberto e a obra passará a ser feita na outra cabeceira.

(b) O trecho será reaberto e as reformas passarão a ser feitas na outra cabeceira. 


\section{Quadro 28: Sentenças geradas a partir da fusão por interserção e a partir da fusão} por união

Interseção:

(1-a) O Airbus A320, voo JJ3054 partiu de Porto Alegre às 17h16.

(1-b) O Airbus A320, voo JJ3054 partiu de Porto Alegre às $17 \mathrm{~h} 16$.

União:

(2-a) A aeronave da TAM Airbus A320, voo JJ3054 partiu de Porto Alegre às 17h16 da terça-feira com destino à Congonhas e chegou em São Paulo às 18h45.

(2-b) A aeronave da TAM Airbus A320, voo JJ3054 partiu de Porto Alegre às 17h16 da terça-feira e chegou em São Paulo às $18 \mathrm{~h} 45$ com destino à Congonhas.

Após gerar todas as sentenças a partir de cada árvore, a melhor sentença é selecionada com o auxílio de um modelo de língua baseado em bigramas. Esse modelo calcula a probabilidade de cada sentença ocorrer na língua por meio de estatísticas derivadas de um corpus. O modelo de língua foi treinado com o Corpus NILC ${ }^{14}$, composto por $160 \mathrm{MB}$ de textos jornalísticos do português do Brasil, usando o toolkit jNina (Pereira \& Paraboni, 2007). Nesse modelo, a probabilidade de cada sentença é calculada com base na medida de entropia da informação, que mede o grau de incerteza de uma sentença. Quanto menor o valor de entropia, maior a chance da sentença ocorrer naquela língua. Por exemplo, as sentenças (2-a) e (2-b) do Quadro 28 apresentam uma entropia de 10,5 e 10,7, respectivamente, indicando, portanto, que a sentença (2-a) é a mais provável.

\subsection{Considerações Finais}

Este capítulo apresentou um método para a fusão automática de sentenças similares do português. O método é baseado em uma abordagem simbólica e permite tanto a fusão de sentenças por interseção de informações, como a fusão de sentenças por união de informações. Embora tenha sido concebido a partir de corpora de sentenças comparáveis, esse método também pode ser aplicado a corpora de sentenças paralelas monolíngues. Os Capítulos 6 e 7 apresentam as avaliações intrínsecas e extrínsecas do método.

\footnotetext{
${ }^{14}$ Disponível em: http://www.nilc.icmc.usp.br/ rh/corpus/ (último acesso em: 21/05/2009).
} 


\section{Avaliação Intrínseca}

O Zíper foi avaliado intrinsecamente de três formas: i) em termos da seleção de conteúdo (informatividade), ii) em termos da gramaticalidade e semanticidade e iii) em termos da representatividade das sentenças produzidas. Este capítulo descreve sobre a metodologia adotada em cada uma das avaliações e apresenta os resultados obtidos para a fusão por interseção (daqui em diante, Zíper-Interseção) e para a fusão por união (daqui em diante, Zíper-União).

Este capítulo está organizado da seguinte maneira: a Seção 6.1 descreve sobre os corpora usados nos experimentos; a Seção 6.2 apresenta a metodologia empregada na análise de conteúdo, bem como os resultados obtidos para o Zíper-Interseção e para o Zíper-União; as Seções 6.3 e 6.4 apresentam, respectivamente, a análise de gramaticalidade e semanticidade e a análise de representatividade das sentenças, juntamente com os resultados obtidos com cada tipo de fusão; por fim, a Seção 6.5 apresenta a discussão dos resultados.

\subsection{Sobre os Corpora de Avaliação}

As avaliações foram realizadas com dois corpora distintos, ambos do gênero jornalístico. O primeiro corpus é composto por 58 conjuntos de sentenças similares, extraídos do corpus de 393 conjuntos de sentenças identificados pelo SiSPI (vide Capítulo 4). Para a construção desse corpus (daqui em diante, SubCorpus_SiSPI), inicialmente foram selecionados, de forma aleatória, 100 conjuntos de sentenças não utilizados no desenvolvimento do método de fusão. Como o SiSPI não apresentou um desempenho ótimo em todos os casos (o sistema alcançou 86\% de Medida-F no melhor caso (Capítulo 4)), os conjuntos que não continham sentenças semanticamente similares (9\%) foram excluídos. Além desses, os conjuntos com sentenças idênticas ou quase 
idênticas, isto é, com cosseno de similaridade maior do que 0,8 (33\% dos casos) também foram eliminados.

O segundo corpus é composto por 20 conjuntos de sentenças similares selecionados aleatoriamente do corpus CSTNews (Aleixo \& Pardo, 2008). O CSTNews consiste de 50 coleções de documentos comparáveis anotados em nível de sentenças com relações da teoria discursiva CST - Cross Document Structure Theory (Radev, 2000). É valido dizer que as 50 coleções que compõem esse corpus também fazem parte do corpus de 53 coleções de documentos descrito no Capítulo 4. Dessa maneira, os conjuntos de sentenças do SubCorpus_SiSPI pertencentes também ao corpus CSTNews foram removidos antes da seleção dos 20 conjuntos a serem analisados (daqui em diante denominado SubCorpus_CSTNews).

As relações CST se estabelecem entre sentenças de textos pertencentes a uma mesma coleção e exploram as similaridades e diferenças do conteúdo expresso nesses textos. O conjunto original proposto por Radev (2000) é composto por 24 relações, sendo que várias delas ocorrem entre sentenças de conteúdo comparável, tais como as relações Equivalence, Identity, Subsumption e Overlap. A relação Overlap é particularmente interessante para a fusão, pois ocorre entre sentenças que contêm informações em comum, mas que apresentam também informações adicionais distintas entre si. Por essa razão, para compor o SubCorpus_CSTNews, foram selecionados 20 conjuntos contendo somente sentenças relacionadas por meio da relação Overlap. Cada conjunto é composto de 2 a 3 três sentenças aproximadamente.

Os dois corpora foram processados pelo Zíper-Interseção e pelo Zíper-União e as interseções e as uniões de sentenças foram produzidas para cada conjunto de sentenças similares. Do SubCorpus_SiSPI, foram selecionadas para análise as três sentenças mais bem pontuadas pelo modelo de língua (jNina) de cada conjunto. É importante dizer que, nos experimentos realizados com esse corpus, analisou-se uma versão preliminar do método de fusão por interseção (Seção 5.2.1), baseada em um processo de geração de todas as sentenças válidas possíveis a partir de cada árvore de dependência sintática (ou seja, sem fazer uso das heurísticas de seleção de unidades lexicais ${ }^{15}$. Em outras palavras, esse método não contemplava a interseção de informações alinhadas, gerando todas as alternativas possíveis de um mesmo conceito identificadas na fase de alinhamento. Por consequência, frequentemente ele gerava

\footnotetext{
${ }^{15}$ Esse método foi publicado em Seno \& Nunes (2009b).
} 
muitas sentenças idênticas às sentenças de entrada. A fim de evitar a seleção dessas sentenças pelo jNina, elas foram previamente descartadas, de forma análoga a realizada nos trabalhos de Barzilay \& Mckeown (2005) e de Marsi \& Krahmer (2005). A versão do método que faz uso das heurísticas de seleção de unidades lexicais foi avaliada apenas com o SubCorpus_CSTNews.

Para o SubCorpus_CSTNews, foram analisadas, para cada conjunto de sentenças similares, duas sentenças produzidas por cada método de fusão, a saber: a melhor sentença segundo o jNina e a melhor sentença selecionada manualmente. A seleção manual teve como objetivo analisar o potencial do modelo de língua na identificação da melhor sentença gerada, tanto no que diz respeito a gramaticalidade e semanticidade, como no que diz respeito ao conteúdo e a representatividade das sentenças.

\subsection{Análise de Seleção de Conteúdo}

A seleção de conteúdo no Zíper-Interseção e no Zíper-União foi avaliada manualmente comparando-se o conteúdo de cada sentença gerada automaticamente (daqui em diante, sentenças automáticas) com as sentenças de referências produzidas manualmente para um mesmo conjunto de sentenças similares. Essa comparação teve como objetivo avaliar o quanto do conteúdo das sentenças de referências foi preservado nas sentenças automáticas.

A seleção de conteúdo foi avaliada em termos de Precisão, Cobertura e MedidaF, conforme definidas pelas Fórmulas 1, 2 e 3 (Capítulo 2). Como baseline de comparação do Zíper-Interseção foi utilizada a menor sentença (em número de palavras) de cada conjunto de sentenças similares. De maneira análoga, na avaliação do ZíperUnião adotou-se como baseline a maior sentença de cada conjunto. Apesar da simplicidade desses baselines, eles são bastante poderosos, pois, por se tratar de sentenças comparáveis, tanto a menor como a maior sentença contêm muitas informações comuns às demais sentenças do conjunto e, não muito raro, elas representam bem a interseção e a união de todas as sentenças, respectivamente.

A Subseção 6.2.1 descreve a construção dos corpora de referências utilizados na análise de seleção de conteúdo. Em seguida, as Subseções 6.2.2 e 6.2.3 apresentam os resultados obtidos pelo Zíper-Interseção e pelo Zíper-União, respectivamente. 


\subsubsection{Construção dos Corpora de Referência}

Dois corpora de referência foram construídos para cada método de fusão, sendo um de referência do SubCorpus_SiSPI e outro de referência do SubCorpus_CSTNews. Cada corpus foi construído manualmente por dois linguistas computacionais e, posteriormente, a concordância entre eles foi calculada.

Para a construção dos corpora de referência do Zíper-Interseção, os linguistas foram instruídos a produzir, para cada conjunto de sentenças similares, uma única sentença, preservando apenas as informações comuns expressas no respectivo conjunto. Apenas para um conjunto do SubCorpus_SiSPI não foi possível fazer a fusão, pois, de acordo com os linguistas, as sentenças não tinham interseção. De maneira similar, na construção dos corpora de referência do Zíper-União, os linguistas foram instruídos a produzir uma única sentença para cada conjunto, combinando todas as informações expressas no conjunto, sem redundâncias. Não houve casos em que não foi possível fazer a fusão.

A concordância entre os linguistas foi verificada calculando a Precisão, a Cobertura e a Medida-F de cada sentença do linguista 1 (daqui em diante Ref1) em relação à sentença do linguista 2 (Ref2), conforme definidas no Capítulo 2. Como ilustração considere as sentenças [a] e [b] no Quadro 29 produzidas por Ref1 e Ref2, respectivamente, a partir da interseção das sentenças similares [1], [2] e [3], extraídas do SubCorpus_SiSPI. Em [a] há três unidades de informação: a primeira delas refere-se aos R \$ 106 bilhões que serão aplicados em habitação; a segunda informação refere-se aos R \$ 40 bilhões que serão aplicados em saneamento básico e a terceira informação referese ao fato de que essas informações foram dadas pelo presidente. Todas essas informações estão expressas também em [b] por meio de paráfrases. Além dessas, há ainda outra informação em [b] não expressa em [a], relacionada ao fato de que serão investidos R $\$ 504$ bilhões no PAC. A Precisão nesse caso é igual a 100\%, isto é, três informações de Ref1 preservadas em Ref2 sobre três informações de Ref1, enquanto que a Cobertura é de 75\%, ou seja, três informações de Ref1 preservadas em Ref2 sobre quatro informações de Ref2. O valor de Medida-F é igual a 85,7\%. 


\section{Quadro 29: Exemplo de fusões de sentenças produzidas manualmente}

\section{Sentenças similares:}

[1] Segundo o presidente, serão investidos R\$ 504 bilhões no PAC - R\$ 106 bilhões em habitação e R $\$ 40$ bilhões em saneamento - até 2010.

[2] "Vamos investir R \$ 504 bilhões, dos quais R\$ 106 bilhões serão aplicados em habitação e R $\$ 40$ bilhões em saneamento básico", estimou.

[3] Segundo o presidente, R $\$ 106$ bilhões serão destinados ao setor de habitação e outros R $\$ 40$ bilhões serão investidos em saneamento básico.

\section{Fusão por interseção (manual):}

[a] $\mathrm{R} \$ 106$ bilhões serão aplicados em habitação e $\mathrm{R} \$ 40$ bilhões em saneamento básico, segundo o presidente.

[b] Lula estimou que serão investidos $\mathrm{R} \$ 504$ bilhões no PAC, sendo R $\$ 106$ bilhões para habitação e $\mathrm{R} \$ 40$ bilhões para saneamento.

A Tabela 12 apresenta a concordância média obtida entre os linguistas na construção de cada corpus de referência.

Tabela 12: Concordância média obtida em termos de Precisão, Cobertura e Medida-F na construção dos corpora de referência

\begin{tabular}{|c|c|c|c|c|}
\hline \multirow{2}{*}{} & \multicolumn{2}{|c|}{ SubCorpus_SiSPI } & \multicolumn{2}{c|}{ SubCorpus_CSTNews } \\
\cline { 2 - 5 } & Interseção & União & Interseção & União \\
\hline Precisão & $97 \%$ & $92 \%$ & $96 \%$ & $99 \%$ \\
\hline Cobertura & $89 \%$ & $96 \%$ & $95 \%$ & $97 \%$ \\
\hline Medida-F & $91 \%$ & $94 \%$ & $94 \%$ & $98 \%$ \\
\hline
\end{tabular}

É importante observar que para ambos os corpora houve maior concordância na fusão por união do que na fusão por interseção. Uma possível explicação é que a fusão por interseção envolve mais subjetividade no que diz respeito às informações que devem ser eliminadas da sentença resultante, pois nem sempre é possível remover informações, ainda que irrelevantes, sem alterar o significado original. Outra observação interessante é que para ambos os tipos de fusão houve maior concordância na fusão das sentenças do SubCorpus_CSTNews do que do SubCorpus_SiSPI. Entretanto, é válido ressaltar que o corpus de referência do SubCorpus_SiSPI foi construído por linguistas computacionais com formação em Ciências da Computação, enquanto que o corpus de referência do SubCorpus_CSTNews foi construído por linguistas computacionais com formação em Letras. Por se tratar de especialistas diferentes, não é possível comparar os valores obtidos pelos dois corpora. 
Esses resultados sugerem que a avaliação de conteúdo com base na comparação com sentenças de referência faz sentido na tarefa de fusão, pois, para um mesmo conjunto de sentenças comparáveis, diferentes humanos produzem sentenças muitos similares em termos de conteúdo.

\subsubsection{Resultados da Análise de Seleção de Conteúdo na Fusão por Interseção}

A Tabela 13 apresenta os resultados médios para Precisão, Cobertura e MedidaF obtidos na avaliação do Zíper-Interseção com os 58 conjuntos de sentenças do SubCorpus_SiSPI.

Tabela 13: Resultados da análise de seleção de conteúdo obtidos na fusão por interseção com o SubCorpus_SiSPI

\begin{tabular}{|c|c|c|c|c|c|c|}
\hline & \multicolumn{3}{|c|}{ Ref1 } & \multicolumn{3}{c|}{ Ref2 } \\
\hline & Precisão & Cobertura & Medida-F & Precisão & Cobertura & Medida-F \\
\hline Baseline & 0,79 & 0,88 & 0,79 & 0,80 & 0,97 & 0,85 \\
\hline Top1_jNina & 0,85 & 0,88 & 0,84 & 0,81 & 0,91 & 0,84 \\
\hline Top2_jNina & 0,84 & 0,94 & 0,87 & 0,81 & 0,97 & 0,86 \\
\hline Top3_jNina & 0,83 & 0,85 & 0,89 & 0,80 & 0,87 & 0,89 \\
\hline
\end{tabular}

Considerando Ref1, apesar de a Top1_jNina apresentar um ganho de desempenho de 7,5\% e de 6,3\% para Precisão e Medida-F, respectivamente, em relação ao baseline (menor sentença), análises estatísticas realizadas com o t-teste, com um fator de confiança de 95\% ( $p$-value < 0,05), mostraram que esses ganhos não são significativos. Resultados similares também foram observados com Ref2, exceto para Cobertura, na qual o baseline apresentou um ganho significativo de 6,6\% sobre a Top1_jNina.

Na comparação entre o baseline e a Top2_jNina, a sentença automática obteve uma melhora de 6,3\% de Precisão, 6,8\% de Cobertura e 10,1\% de Medida-F, de acordo com Ref1. Essas diferenças foram estatisticamente comprovadas pelo t-teste. Porém, de acordo com Ref2, não existe diferença estatística entre o baseline e a Top2_jNina em nenhum dos casos.

Ao comparar o baseline e a Top3_jNina, considerando apenas Ref1, a sentença automática apresentou uma melhora estatisticamente significativa de 5\% de Precisão e 
12,6\% de Medida-F. Porém, em termos de Cobertura ambos são estatisticamente equivalentes. Considerando Ref2, o t-teste mostrou que não há diferença estatística entre o baseline e a Top3_jNina, tanto no que se refere à Precisão, como no que se refere à Cobertura e à Medida-F.

Uma possível explicação para os resultados obtidos é que a natureza do corpus possa ter favorecido o baseline de menor sentença. O SubCorpus_SiSPI é formado por conjuntos de sentenças que são em grande parte paráfrases completas umas das outras, ou seja, há menos sentenças com informações adicionais não expressas em outras sentenças. Desse modo, há grande chance de a menor sentença corresponder à interseção do conjunto, o que justificaria o bom desempenho do baseline. Diferentemente, no SubCorpus_CSTNews cada conjunto é formado por sentenças que contêm informações em comum, mas que também apresentam informações adicionais distintas entre si. Nesse caso, a hipótese é que o método baseline obteria um pior desempenho, principalmente em relação à Precisão, pois a menor sentença poderia incluir também informações não comuns a outras sentenças do conjunto. Essa hipótese foi verificada por meio de experimentos descritos mais adiante nesta seção.

Na comparação do desempenho entre Top1_jNina, Top2_jNina e Top3_jNina, análises estatísticas realizadas com o teste Anova (Analysis of Variance) ${ }^{16}$, com fator de confiança de 95\%, mostraram que não existe diferença entre elas, tanto em termos Precisão como em termos de Cobertura e Medida-F.

A Tabela 14 apresenta os resultados médios para Precisão, Cobertura e MedidaF obtidos na avaliação com os 20 conjuntos de sentenças do SubCorpus_CSTNews. Devido ao alto custo da avaliação manual e a boa concordância obtida entre os linguistas computacionais na construção do corpus de referência do SubCorpus_CSTNews (isto é, 94\% de Medida-F (vide Seção 6.2.1)), o desempenho de cada sentença automática foi calculado somente em relação a uma referência.

No que se refere à Precisão, a Top1_jNina apresentou um ganho de 42,8\% em relação ao baseline, enquanto que a Top1_SM obteve uma melhora de 55,1\% comparada ao baseline. De acordo com o t-teste, esses ganhos de desempenho são estatisticamente significativos ( $p$-value < 0,05). Esses resultados comprovam que, quando as sentenças de entrada são paráfrases parciais uma das outras (isto é, cada

\footnotetext{
${ }^{16}$ Segundo Wainer (2007), o teste Anova é o mais apropriado quando se deseja comparar mais do que duas amostras. Esse teste pode ser encontrado no Microsoft Office Excel 2003 ou versão superior.
} 
sentença apresenta também informações adicionais não apresentadas em outras sentenças), a Precisão, no que diz respeito ao baseline de menor sentença, reduz significativamente, prejudicando o desempenho global. Em termos de Cobertura, os testes estatísticos mostraram que não existe diferença significativa entre o baseline e a Top1_jNina e nem entre o baseline e a Top1_SM. Esses resultados já eram esperados uma vez que a menor sentença de cada conjunto contém muitas informações similares às demais sentenças do conjunto.

Tabela 14: Resultados da análise de seleção de conteúdo obtidos na fusão por interseção com o SubCorpus_CSTNews

\begin{tabular}{|c|c|c|c|}
\hline & Precisão & Cobertura & Medida-F \\
\hline Baseline & 0,49 & 0,95 & 0,63 \\
\hline Top1_jNina & 0,70 & 0,91 & 0,75 \\
\hline Top1_SM & 0,76 & 1,00 & 0,84 \\
\hline
\end{tabular}

Analisando o desempenho global, a Top1_jNina apresentou uma melhora de 19\% comparada ao baseline, enquanto que a Top1_SM obteve um ganho de 33,3\% sobre o baseline. Novamente, o t-teste mostrou que essas diferenças são estatisticamente relevantes.

$\mathrm{Na}$ comparação entre a melhor sentença selecionada automaticamente (Top1_jNina) e a melhor sentença selecionada manualmente (Top1_SM), os testes estatísticos mostraram que a Top1_SM alcançou uma melhora de 7,1\%, 9,9\% e $12 \%$ para Precisão, Cobertura e Medida-F, respectivamente. Esses resultados sugerem que o modelo estatístico de língua tem baixo potencial no que diz respeito à identificação da melhor sentença em termos de conteúdo.

\subsubsection{Resultados da Análise de Seleção de Conteúdo na Fusão por União}

A Tabela 15 apresenta os resultados médios obtidos para Precisão, Cobertura e Medida-F na avaliação do Zíper-União usando o SubCorpus_SiSPI. 
Tabela 15: Resultados da análise de seleção de conteúdo obtidos na fusão por união com o SubCorpus_SiSPI

\begin{tabular}{|c|c|c|c|c|c|c|}
\hline & \multicolumn{3}{|c|}{ Ref1 } & \multicolumn{3}{c|}{ Ref2 } \\
\cline { 2 - 7 } & Precisão & Cobertura & Medida-F & Precisão & Cobertura & Medida-F \\
\hline Baseline & 0,96 & 0,91 & 0,93 & 0,96 & 0,87 & 0,90 \\
\hline Top1_jNina & 0,84 & 0,83 & 0,82 & 0,88 & 0,83 & 0,84 \\
\hline Top2_jNina & 0,83 & 0,88 & 0,84 & 0,87 & 0,87 & 0,86 \\
\hline Top3_jNina & 0,84 & 0,87 & 0,84 & 0,88 & 0,88 & 0,87 \\
\hline
\end{tabular}

De modo similar ao observado na avaliação do Zíper-Interseção (Seção 6.2.2), o teste Anova mostrou que, de acordo com ambas as referências, não existe diferença significativa em termos de Precisão, Cobertura e F-measure entre as sentenças Top1_jNina, Top2_jNina e Top3_jNina, no que se refere ao conteúdo. Na comparação de cada uma dessas sentenças com o baseline (maior sentença), este obteve o melhor desempenho em termos de Precisão e Medida-F, tanto para Ref1 como para Ref2. Uma possível explicação para a queda na Precisão no modelo proposto está relacionada à baixa Cobertura do alinhador, no que diz respeito ao alinhamento de paráfrases (vide Seção 5.1). Quando o alinhador não identifica as paráfrases entre as sentenças de um conjunto, o módulo de fusão, que toma decisões com base nos alinhamentos previamente identificados, tende a considerar essa redundância de informações na geração de novas sentenças, o que provoca uma redução na Precisão. Um exemplo de sentença em que esse problema ocorreu pode ser visto no Quadro 30. Nesse caso, o alinhador não foi capaz de identificar a correspondência entre "duas pessoas que estavam em uma moto" (sentença [1]) e "motoqueiros" (sentença [2]), fazendo com que ambas as informações fossem incluídas na nova sentença. A precisão no Zíper-União pode ser melhorada com a criação de novas regras permitindo a identificação de paráfrases sintáticas pelo alinhador e com a inclusão de um dicionário de paráfrases, induzido a partir de corpora (vide, por exemplo, Barzilay \& Mckeown, 2001; Barzilay \& Lee, 2003; Bannard \& Callison-Burch, 2005 e Callison-Burch, 2008). 
Quadro 30: Exemplo de sentença automática com redundância de informações, causadas por falha no processo de alinhamento

\section{Sentenças similares:}

[1] O apresentador foi roubado por duas pessoas que estavam em uma moto logo após sair de um restaurante do bairro.

[2] O apresentador foi roubado num semáforo da Rua Doutor Renato Paes de Barros, no Itaim Bibi, por motoqueiros.

\section{União:}

O apresentador foi roubado em um semáforo da Rua Doutor Renato Paes de Barros, no Itaim Bibi, por motoqueiros por duas pessoas que estavam em uma moto logo após sair de um restaurante do bairro.

No que diz respeito à Cobertura, com exceção da Top1_jNina (Ref1), não existe diferença, em termos estatísticos, quando se compara o baseline e as sentenças automáticas. Assim como ocorreu na fusão por interseção, esses resultados já eram esperados, pois a maior sentença de cada conjunto contém muitas informações em comum com as demais sentenças do conjunto.

Como consequência do bom desempenho em termos de Precisão e Cobertura, analisando o desempenho global, o baseline obteve uma melhora estatisticamente significativa de 13,4\%, comparado a Top1_jNina, e de 10,7\%, comparado a Top2_jNina e a Top3_jNina, de acordo com Ref1. Já de acordo com Ref2, houve uma melhora de 7,1\% e 4,6\% comparado a Top1_jNina e a Top2_jNina, respectivamente. Porém, o tteste mostrou que não há diferença entre o baseline e a Top3_jNina.

A Tabela 16 apresenta os resultados médios obtidos para Precisão, Cobertura e Medida-F na avaliação do modelo de fusão por união usando o SubCorpus_CSTNews. De modo similar ao realizado na avaliação do Zíper-Interseção com o SubCorpus_CSTNews, o desempenho de cada sentença automática foi verificado somente em relação a uma referência.

Tabela 16: Resultados da análise de seleção de conteúdo obtidos na fusão por união com o SubCorpus_CSTNews

\begin{tabular}{|c|c|c|c|}
\hline & Precisão & Cobertura & Medida-F \\
\hline Baseline & 0,99 & 0,76 & 0,85 \\
\hline Top1_jNina & 0,91 & 0,83 & 0,81 \\
\hline Top1_SM & 0,97 & 0,94 & 0,95 \\
\hline
\end{tabular}

No que se refere à Precisão, a Top1_jNina obteve um queda no desempenho de 8\% comparado ao baseline, enquanto que a Top1_SM apresentou um desempenho 
similar ao baseline, conforme comprovado pelo t-teste. Já em relação à Cobertura, a Top1_jNina e o baseline obtiveram o mesmo desempenho em termos estatísticos, enquanto que a Top1_SM superou o baseline em 23,6\%. É válido dizer que o modelo estatístico de língua, como é o caso do jNina, tende a privilegiar as menores sentenças, que em geral apresentam uma menor entropia. Isso pode explicar o pior desempenho da Top1_jNina em termos de Cobertura.

Analisando o desempenho global (Medida-F), também não há diferença estatística entre o baseline e a Top1_jNina. Porém, quando se compara a Top1_SM e o baseline, a Top1_SM obteve uma melhora de desempenho de 11,7\%, comprovada pelo t-teste. Os testes estatísticos também comprovaram que a Top1_SM é melhor do que a Top1_jNina em todos os aspectos. O ganho foi de 6,6\% para Precisão, 13,2\% para Cobertura e 17,2\% para Medida-F. Mais uma vez, os resultados sugerem que o modelo estatístico de língua é pouco robusto no que diz respeito à seleção da melhor sentença em termos de conteúdo.

\subsection{Análise de Gramaticalidade e Semanticidade}

A gramaticalidade e a semanticidade das sentenças automáticas foram julgadas por dois linguistas computacionais falantes nativos do português. Cada avaliador foi instruído a atribuir, para cada sentença automática, uma nota de 1 a 3 , sendo 1 para as sentenças sem sentido ou com sérios erros gramaticais; 2 para as sentenças compreensíveis, mas com pequenos erros gramaticais ou semânticos, e 3 para as sentenças perfeitas, ou seja, sem erros gramaticais ou semânticos. Durante essa análise, os avaliadores foram orientados a ignorar problemas relacionados à pontuação. $\mathrm{O}$ uso inadequado e a ausência de vírgulas e ponto e vírgulas são limitações do Zíper. A pontuação é determinada por uma série de fatores gramaticais e o desenvolvimento de regras prevendo o tratamento de cada caso foge do escopo desta tese.

A concordância entre os avaliadores foi verificada usando a medida Kappa (Carletta, 1996). Os valores do Kappa obtidos para o SubCorpus_SiSPI e para o SubCorpus_CSTNews são apresentados na Tabela 17. Não é possível fazer uma comparação da concordância obtida em cada corpus, pois os linguistas que avaliaram o SubCorpus_SiSPI não são os mesmos que avaliaram o SubCorpus_CSTNews. Contudo, acredita-se que o fato de o SubCorpus_CSTNews ser quase três vezes menor do que o 
SubCorpus_SiSPI possa ter contribuído para que houvesse maior concordância naquele caso.

Tabela 17: Concordância obtida em termos da medida Kappa na análise de gramaticalidade e semanticidade

\begin{tabular}{|c|c|c|c|c|}
\hline \multirow{2}{*}{} & \multicolumn{2}{|c|}{ SubCorpus_SiSPI } & \multicolumn{2}{c|}{ SubCorpus_CSTNews } \\
\cline { 2 - 5 } & Zíper-Interseção & Zíper-União & Zíper-Interseção & Zíper-União \\
\hline Top1_jNina & 0,55 & 0,51 & 0,83 & 0,89 \\
\hline Top2_jNina & 0,44 & 0,62 & - & - \\
\hline Top3_jNina & 0,58 & 0,47 & - & - \\
\hline Top1_SM & - & - & 0,72 & 0,60 \\
\hline
\end{tabular}

Segundo Carletta (1996), valores acima de 0,8 indicam que essa análise tem uma boa replicabilidade e valores entre 0,67 e 0,8 permitem que conclusões sejam obtidas. No entanto, de acordo com Craggs \& Wood (2005) é um erro assumir esses valores indiscriminadamente para qualquer tarefa, pois, dada à diversidade de fenômenos analisados e de suas diferentes aplicações, não é possível estabelecer os limites nos quais todos os fenômenos devem ser julgados. Portanto, segundo os autores, é necessário analisar, com base na aplicação pretendida, se a concordância observada é suficiente. É importante dizer que não foram encontrados na literatura valores de referência para esse tipo de análise em específico.

Embora os critérios de avaliação tenham sido estabelecidos aos avaliadores, há uma subjetividade inerente à avaliação humana. Por exemplo, para a sentença do Quadro 31, produzida pelo Zíper-União a partir do conjunto de sentenças ilustrado na figura (extraído do SubCorpus_SiSPI), um dos avaliadores atribuiu nota 2 para gramaticalidade e semanticidade, apesar da alteração ocorrida no sujeito da sentença (isto é, "o senador Antonio Carlos Magalhães" foi substituído por "a morte") que prejudicou o sentido da mesma. O outro avaliador, por sua vez, atribuiu nota 1 para essa sentença.

Apesar da subjetividade inerente à análise manual, acredita-se que pode ter havido maior concordância entre os avaliadores no que diz respeito à identificação das sentenças perfeitas e das sentenças com sérios erros de gramática e/ou semântica, do que no julgamento das sentenças que não eram nem perfeitas nem tão ruins. Para verificar essa hipótese, o Kappa foi novamente calculado considerando somente duas 
classes de sentenças, ou seja, sentenças sem nenhum erro gramatical ou semântico (isto é, que receberam nota 3) e sentenças com poucos ou muitos erros gramaticais e semânticos (ou seja, que receberam notas 1 e 2). Os resultados obtidos são apresentados na Tabela 18.

Quadro 31: Exemplo de análise de gramaticalidade e semanticidade realizada por humanos

\section{Conjunto de Sentenças:}

[1] O senador Antonio Carlos Magalhães (DEM-BA) morreu às 11h40 de hoje, aos 79 anos, em São Paulo, em decorrência de falência de múltiplos órgãos secundária à insuficiência cardíaca.

[2] Segundo comunicado do Instituto do Coração (Incor), em São Paulo, a morte foi "decorrência de falência de múltiplos órgãos secundária à insuficiência cardíaca".

\section{União:}

Segundo comunicado do Instituto do Coração (Incor), aos 79 anos, em São Paulo, a morte morreu às $11 \mathrm{~h} 40$ de hoje, em "decorrência de falência de múltiplos órgãos secundária à insuficiência cardíaca".

Tabela 18: Concordância obtida em termos da medida Kappa na análise de gramaticalidade e semanticidade, considerando apenas duas classes de sentenças

\begin{tabular}{|c|c|c|c|c|}
\hline \multirow{2}{*}{} & \multicolumn{2}{|c|}{ SubCorpus_SiSPI } & \multicolumn{2}{c|}{ SubCorpus_CSTNews } \\
\cline { 2 - 5 } & Zíper-Interseção & Zíper-União & Zíper-Interseção & Zíper-União \\
\hline Top1_jNina & 0,58 & 0,62 & 0,90 & 1,00 \\
\hline Top2_jNina & 0,47 & 0,72 & - & - \\
\hline Top3_jNina & 0,75 & 0,70 & - & - \\
\hline Top1_SM & - & - & 0,86 & 0,68 \\
\hline
\end{tabular}

No que se refere à avaliação com o SubCorpus_SiSPI, os resultados apresentados na tabela mostram que há maior concordância entre os avaliadores, para ambos os métodos de fusão, quando se trata somente de classificar as sentenças em perfeitas e sentenças com erros. De modo geral, a discordância no julgamento das sentenças que não eram nem tão boas nem tão ruins foi maior na união do que na interseção. Ao considerar somente duas classes de sentença, a concordância na união melhorou 21,5\%, 16,1\% e 49\% em relação à Top1_jNina, Top2_jNina e Top3_jNina, respectivamente. Na interseção, a melhora foi de 5,5\%, 6,8\% e 29,3\% para Top1_jNina, Top2_jNina e Top3_jNina, respectivamente. Em relação ao SubCorpus_CSTNews, também houve maior concordância ao se considerar apenas duas classes de sentenças. Na interseção, houve um aumento de 8,4\% e de 19,4\% para Top1_jNina e Top1_SM, 
respectivamente, enquanto que na união a melhora foi de 12,3\% para Top1_jNina e 13,3\% para Top1_SM.

As Subseções 6.3.1 e 6.3.2 apresentam os resultados obtidos para gramaticalidade e semanticidade pelo Zíper-Interseção e pelo Zíper-União, respectivamente.

\subsubsection{Resultados da Análise de Gramaticalidade e Semanticidade na Fusão por Interseção}

A Tabela 19 apresenta as médias das notas obtida na avaliação de gramaticalidade e semanticidade do Zíper-Interseção usando o SubCorpus_SiSPI.

Tabela 19: Resultados da análise de gramaticalidade e semanticidade obtidos na fusão por interseção com o SubCorpus_SiSPI

\begin{tabular}{|c|c|c|}
\hline & Avaliador1 & Avaliador2 \\
\hline Top1_jNina & 2,4 & 2,6 \\
\hline Top2_jNina & 2,3 & 2,6 \\
\hline Top3_jNina & 2,2 & 2,4 \\
\hline
\end{tabular}

Apesar de a Top1_jNina apresentar um ganho de 4,3\% e de 9\% sobre a Top2_jNina e a Top3_jNina, respectivamente, de acordo com o Avaliador1, análises estatísticas realizadas com o teste Anova, com fator de confiança de 95\%, mostraram que, em termos de gramaticalidade e semanticidade, não há distinção entre elas. Esses resultados também foram confirmados na análise do Avaliador2. De modo geral, os resultados mostram que as sentenças geradas pelo método de interseção são bem formadas.

Os resultados médios obtidos na avaliação com o SubCorpus_CSTNews são apresentados na Tabela 20. Como se pode observar, ambos os avaliadores concordaram que as sentenças selecionadas manualmente (Top1_SM) são melhores do que as sentenças selecionadas pelo modelo de língua (Top1_jNina), em termos de gramaticalidade e semântica. A Top1_SM apresentou um ganho de 16,6\% em relação à Top1_jNina, comprovado estatisticamente pelo t-teste $(p$-value $<0,05)$. Esses resultados mostram a fragilidade do modelo estatístico de língua em distinguir sentenças bemformadas de sentenças mal-formadas. Acredita-se que os resultados para a seleção 
automática possam ser melhorados com o uso de modelos de língua mais robustos, por exemplo, os baseados em sintaxe. Segundo experimentos realizados por Daumé III et al. (2002), os modelos baseados em sintaxe são mais apropriados em aplicações que envolvem geração de língua natural (por exemplo, a Sumarização Automática e a Tradução Automática) do que os modelos baseados em n-grama.

Tabela 20: Resultados da análise de gramaticalidade e semanticidade obtidos na fusão por interseção com o SubCorpus_CSTNews

\begin{tabular}{|c|c|c|}
\hline \multirow{2}{*}{} & \multicolumn{2}{|c|}{ Gramaticalidade e Semanticidade } \\
\cline { 2 - 3 } & Avaliador1 & Avaliador2 \\
\hline Top1_jNina & 2,4 & 2,4 \\
\hline Top1_SM & 2,8 & 2,8 \\
\hline
\end{tabular}

No que diz respeito aos problemas gramaticais e semânticos identificados nas análises, os mais comuns foram erros de conjugação verbal, o uso incorreto de preposições e seleção lexical inadequada, devido a erros no processo de alinhamento, que alteraram o sentido das sentenças. O Quadro 32 apresenta alguns exemplos de sentenças automáticas com erros. Na sentença [1], por exemplo, há um erro de conjugação do verbo "puxar". Esse erro se deve ao fato de que, na árvore de dependência sintática que originou essa sentença, o verbo "puxar", no particípio do passado (i.e. "puxado"), estava alinhado ao verbo "puxar" no passado simples (i.e. "puxou”). Ao realizar a sentença selecionando esse segundo caso, não foi possível recuperar as características morfossintáticas apropriadas para a realização superficial do verbo, em razão de diferenças estruturais das sentenças originais em que esses verbos ocorreram. A sentença [2] exemplifica um erro causado pelo uso inadequado da preposição "na" antes de "bola na trave". Isso ocorreu porque ao substituir, na sentença original, "a trave" por "a bola na trave" foi mantida a preposição "em" que precedia o segmento "a trave". No Zíper não há regras para tratar esses casos. Outro exemplo do uso impróprio de preposição pode ser visto na sentença [3], antes de "6h30 desta terçafeira”. Já na sentença [4] da figura, um erro no alinhamento entre dois advérbios nas sentenças originais, isto é, os advérbios "não" e "também" alterou completamente o significado da sentença, quando o advérbio "não" foi escolhido para formar a nova sentença. O correto, nesse caso, seria “Também é frequente a sonegação de despesas médicas e de omissão de renda de aluguel.". 
Quadro 32: Exemplos de sentenças com erros geradas pelo Zíper-Interseção

[1] Em mais um contra-ataque, desta vez puxou por Vágner Love, Daniel Alves foi lançado, entrou na área e bateu cruzado para ampliar.

[2] O meio-campista ajeitou de cabeça e Riquelme, de primeira, mandou na bola na trave.

[3] O colombiano Juan Carlos Ramirez Abadia, o Chupeta, um dos traficantes de drogas mais procurados do mundo, foi preso nas $6 \mathrm{~h} 30$ desta terça-feira (7), na Grande São Paulo.

[4] Não é frequente a sonegação de despesas médicas e de omissão de renda de aluguel.

Os Quadros 33 e 34 apresentam bons exemplos de sentenças produzidas pelo modelo de fusão por interseção extraídos do SubCorpus_SiSPI e do SubCorpus_CSTNews, respectivamente.

\section{Quadro 33: Bons exemplos de sentenças geradas pelo Zíper-Interseção para o} SubCorpus_SiSPI

\section{Grupo 1:}

[1] ACM estava internado no InCor-SP (Instituto do Coração), do Hospital das Clínicas, desde o dia 13 de junho, quando deu entrada para tratar de complicações renais e cardíacas.

[2] O parlamentar estava internado no Instituto do Coração, do Hospital das Clínicas, desde o dia 13 de junho, quando passou mal no plenário e foi transferido para a capital paulista.

[3] O político baiano estava internado desde o dia 13 de junho.

Interseção: ACM estava internado no Instituto do Coração, do Hospital das Clínicas, desde o dia 13 de junho.

\section{Grupo 2:}

[1] Fabiana Murer, 26, conquistou ontem, no estádio João Havelange, a primeira medalha de ouro do atletismo nacional no Pan do Rio.

[2] RIO - Como esperado, a atleta Fabiana Murer conquistou a medalha de ouro - a $29^{\mathrm{a}}$.

Interseção: Fabiana Murer, 26, conquistou ontem a medalha de ouro.

\section{Grupo 3:}

[1] O bispo de Barra (BA), dom Luiz Flávio Cappio, 61, já deixou a UTI (Unidade de Terapia Intensiva) do hospital Memorial de Petrolina (PE).

[2] O bispo de Barra (BA), d. Luiz Flávio Cappio, de 61 anos, deixou na manhã desta quinta (20) a UTI do Hospital Memorial de Petrolina (PE) e foi transferido para um apartamento do mesmo hospital.

[3] PETROLINA (PE) - O bispo de Barra (BA), d. Luiz Flávio Cappio, 61, deixou a UTI do Hospital Memorial de Petrolina (PE) por volta das 7h30 desta quinta-feira, 20, e foi transferido para um apartamento do mesmo local.

[4] O bispo de Barra (BA), d. Luiz Flávio Cappio, deixou a Unidade de Terapia Intensiva (UTI) do hospital Memorial de Petrolina (PE), onde está internado desde ontem.

Interseção: O bispo de Barra (BA), dom Luiz Flávio Cappio, de 61 anos, já deixou a UTI do hospital Memorial de Petrolina (PE). 


\section{Quadro 34: Bons exemplos de sentenças geradas pelo Zíper-Interseção para o SubCorpus_CSTNews}

\section{Grupo 1:}

[1] Enquanto durarem as obras, os vôos serão transferidos para o Aeroporto de Viracopos, em Campinas, a $95 \mathrm{~km}$ da Capital, segundo informa o ministério de Nelson Jobim por meio de nota.

[2] Quando isso ocorrer, a pista deverá ser fechada, e os vôos que a utilizariam serão transferidos para o Aeroporto de Viracopos (Campinas).

Interseção: Os vôos serão transferidos para o Aeroporto de Viracopos (Campinas).

\section{Grupo 2:}

[1] Heloísa Helena, candidata à presidência pelo PSOL, aparece em terceiro, com 11\% das intenções de voto, seguida por Cristovam Buarque (PDT) e Luciano Bivar (PSL), ambos com $1 \%$.

[2] O senador Cristovam Buarque (PDT) e Luciano Bivar (PSL) ficaram cada um com $1 \%$ das intenções de voto, enquanto José Maria Eymael (PDC) e Rui Costa Pimenta (PCO) não receberam indicação.

Interseção: Cristovam Buarque (PDT) e Luciano Bivar (PSL) ficaram cada um com $1 \%$.

\section{Grupo 3:}

[1] A cidade tinha oito pontos de alagamento, sendo dois intransitáveis, e a Marginal do Pinheiros registrava o pior ponto de lentidão da capital, com 9,4 km da Rodovia Castelo Branco até a Ponte Cidade Jardim, no sentido Interlagos.

[2] Até $9 \mathrm{~h} 30 \mathrm{~m}$ foram registrados oito pontos de alagamento, dois deles intransitáveis na Marginal Pinheiros, na altura da Ponte João Dias, e na Marginal Tietê, no acesso à Rodovia dos Bandeirantes.

Interseção: A cidade tinha oito pontos de alagamento, era dois intransitáveis, e a Marginal do Pinheiros registrava o pior ponto de lentidão da capital.

\subsubsection{Resultados da Análise de Gramaticalidade e Semanticidade na Fusão por União}

A Tabela 21 apresenta as médias das notas obtidas na análise de gramaticalidade e semanticidade do modelo de fusão por união usando o SubCorpus_SiSPI. Assim como observado na análise de gramaticalidade e semanticidade do Zíper-Interseção, na seção anterior, o teste Anova comprovou que não existe diferença estatística entre a primeira, a segunda e a terceira sentença mais bem pontuada pelo jNina, de acordo com ambos os avaliadores. Esses resultados são comparáveis àqueles obtidos na fusão por interseção. 
Tabela 21: Resultados da análise de gramaticalidade e semanticidade obtidos na fusão por união com o SubCorpus_SiSPI

\begin{tabular}{|c|c|c|}
\hline \multirow{2}{*}{} & \multicolumn{2}{|c|}{ Gramaticalidade e Semanticidade } \\
\cline { 2 - 3 } & Avaliador1 & Avaliador2 \\
\hline Top1_jNina & 2,3 & 2,4 \\
\hline Top2_jNina & 2,3 & 2,4 \\
\hline Top3_jNina & 2,1 & 2,2 \\
\hline
\end{tabular}

A Tabela 22 apresenta os resultados médios obtidos na avaliação com o SubCorpus_CSTNews.

Tabela 22: Resultados da análise de gramaticalidade e semanticidade obtidos na fusão por união com SubCorpus_CSTNews

\begin{tabular}{|c|c|c|}
\hline & Avaliador1 & Avaliador2 \\
\hline Top1_jNina & 2,2 & 2,2 \\
\hline Top1_SM & 2,3 & 2,5 \\
\hline
\end{tabular}

De acordo com o Avaliador1, a Top1_SM obteve um ganho de 4,5\% sobre a Top1_jNina, mas essa diferença não é estatisticamente relevante ( $p$-value $>0,05)$. Porém, de acordo com o Avaliador2, a Top1_SM superou a Top1_jNina em 13,6\% e essa diferença foi estatisticamente comprovada pelo t-teste.

De modo geral, os problemas encontrados nessas análises são os mesmos identificados na interseção, por exemplo, erros de conjugação verbal, seleção lexical inadequada e uso inapropriado e/ou a ausência de preposições (vide exemplos na Seção 6.3.1).

Os Quadros 35 e 36 apresentam bons exemplos de sentenças produzidas pelo modelo de fusão por união extraídos do SubCorpus_SiSPI e do SubCorpus_CSTNews, respectivamente. 


\section{Quadro 35: Bons exemplos de sentenças geradas pelo Zíper-União para o SubCorpus_SiSPI}

\section{Grupo 1:}

[1] ACM estava internado no InCor-SP (Instituto do Coração), do Hospital das Clínicas, desde o dia 13 de junho, quando deu entrada para tratar de complicações renais e cardíacas.

[2] O parlamentar estava internado no Instituto do Coração, do Hospital das Clínicas, desde o dia 13 de junho, quando passou mal no plenário e foi transferido para a capital paulista.

[3] O político baiano estava internado desde o dia 13 de junho.

União: ACM estava internado no Instituto do Coração, do Hospital das Clínicas, desde o dia 13 de junho, quando passou mal no plenário e foi transferido para a capital paulista para tratar de complicações renais e cardíacas.

\section{Grupo 2:}

[1] Fabiana Murer, 26, conquistou ontem, no estádio João Havelange, a primeira medalha de ouro do atletismo nacional no Pan do Rio.

[2] RIO - Como esperado, a atleta Fabiana Murer conquistou a medalha de ouro - a $29^{\mathrm{a}}$.

União: RIO - Como esperado, a atleta Fabiana Murer conquistou, no estádio João Havelange, a primeira medalha de ouro do atletismo nacional no Pan do Rio - a 29a

\section{Grupo 3:}

[1] O bispo de Barra (BA), dom Luiz Flávio Cappio, 61, já deixou a UTI (Unidade de Terapia Intensiva) do hospital Memorial de Petrolina (PE).

[2] O bispo de Barra (BA), d. Luiz Flávio Cappio, de 61 anos, deixou na manhã desta quinta (20) a UTI do Hospital Memorial de Petrolina (PE) e foi transferido para um apartamento do mesmo hospital.

[3] PETROLiNA (PE) - O bispo de Barra (BA), d. Luiz Flávio Cappio, 61, deixou a UTI do Hospital Memorial de Petrolina (PE) por volta das 7h30 desta quinta-feira, 20, e foi transferido para um apartamento do mesmo local.

[4] O bispo de Barra (BA), d. Luiz Flávio Cappio, deixou a Unidade de Terapia Intensiva (UTI) do hospital Memorial de Petrolina (PE), onde está internado desde ontem.

União: O bispo de Barra (BA), dom Luiz Flávio Cappio, 61, deixou a UTI (Unidade de Terapia Intensiva) do hospital Memorial de Petrolina (PE), onde está internado desde ontem por volta das 7 h30 desta quinta-feira, 20, e foi transferido para um apartamento do mesmo local. 
Quadro 36: Bons exemplos de sentenças geradas pelo Zíper-União para o SubCorpus_CSTNews

\section{Grupo 1:}

[1] Enquanto durarem as obras, os vôos serão transferidos para o Aeroporto de Viracopos, em Campinas, a $95 \mathrm{~km}$ da Capital, segundo informa o ministério de Nelson Jobim por meio de nota.

[2] Quando isso ocorrer, a pista deverá ser fechada, e os vôos que a utilizariam serão transferidos para o Aeroporto de Viracopos (Campinas).

União: Quando isso ocorrer, a pista deverá ser fechada, e enquanto durarem as obras os vôos que a utilizariam serão transferidos para o Aeroporto de Viracopos (Campinas), a $95 \mathrm{~km}$ da Capital, segundo informa o ministério de Nelson Jobim por meio de nota.

\section{Grupo 2:}

[1] Heloísa Helena, candidata à presidência pelo PSOL, aparece em terceiro, com $11 \%$ das intenções de voto, seguida por Cristovam Buarque (PDT) e Luciano Bivar (PSL), ambos com $1 \%$.

[2] O senador Cristovam Buarque (PDT) e Luciano Bivar (PSL) ficaram cada um com 1\% das intenções de voto, enquanto José Maria Eymael (PDC) e Rui Costa Pimenta (PCO) não receberam indicação.

União: O senador Cristovam Buarque (PDT) e Luciano Bivar (PSL) ficaram cada um com 1\% das intenções de voto, enquanto José Maria Eymael (PDC) e Rui Costa Pimenta $(\mathrm{PCO})$ não receberam indicação e Heloísa Helena, candidata à presidência pelo PSOL, aparece em terceiro, com $11 \%$ das intenções de voto.

\section{Grupo 3:}

[1] A cidade tinha oito pontos de alagamento, sendo dois intransitáveis, e a Marginal do Pinheiros registrava o pior ponto de lentidão da capital, com 9,4 km da Rodovia Castelo Branco até a Ponte Cidade Jardim, no sentido Interlagos.

[2] Até $9 \mathrm{~h} 30 \mathrm{~m}$ foram registrados oito pontos de alagamento, dois deles intransitáveis - na Marginal Pinheiros, na altura da Ponte João Dias, e na Marginal Tietê, no acesso à Rodovia dos Bandeirantes.

União: Até 9h30m foram registrados o pior ponto de lentidão da capital, com 9,4 $\mathrm{km}$ da Rodovia Castelo Branco até a Ponte Cidade Jardim, no sentido Interlagos e oito pontos de alagamento, dois deles intransitáveis - na Marginal Pinheiros, na altura da Ponte João Dias, e na Marginal Tietê, no acesso à Rodovia dos Bandeirantes.

\subsection{Análise de Representatividade}

A análise de representatividade teve como objetivo verificar o quão bem cada sentença automática representa o conjunto a partir do qual ela foi gerada, de modo que possa substituí-lo em um dado contexto, sem que haja perda significativa da mensagem comunicada no conjunto. No caso da interseção, uma sentença representa bem o seu conjunto se ela reproduz a mensagem comum a todas as sentenças do conjunto (isto é, a 
zona de interseção). No caso da união, uma sentença representa bem o seu conjunto se ela reproduz todas as informações nele expressas (isto é, a mensagem do conjunto união), eliminando-se apenas as redundâncias.

A representatividade das sentenças produzidas pelo Zíper também foi julgada por dois linguistas computacionais. Os avaliadores foram instruídos a atribuir nota 1 para as sentenças que distorceram a mensagem comunicada no conjunto, nota 2 para as sentenças que preservaram parcialmente a mensagem do conjunto e nota 3 para as sentenças que preservaram exatamente a mesma mensagem do conjunto (somente a mensagem comum à maioria das sentenças, na interseção, e a mensagem toda na união). A concordância entre os linguistas também foi analisada aplicando-se a medida Kappa, cujos valores obtidos pelos dois modelos com cada corpus encontram-se na Tabela 23. Não se pode comparar a concordância obtida em cada corpus, pois os avaliadores não foram os mesmos em ambos os corpora.

Tabela 23: Concordância obtida em termos da medida Kappa na análise de representatividade

\begin{tabular}{|c|c|c|c|c|}
\hline \multirow{2}{*}{} & \multicolumn{2}{|c|}{ SubCorpus_SiSPI } & \multicolumn{2}{c|}{ SubCorpus_CSTNews } \\
\cline { 2 - 5 } & Zíper-Interseção & Zíper-União & Zíper-Interseção & Zíper-União \\
\hline Top1_jNina & 0,34 & 0,25 & 0,72 & 0,55 \\
\hline Top2_jNina & 0,32 & 0,46 & - & - \\
\hline Top3_jNina & 0,30 & 0,47 & - & - \\
\hline Top1_SM & - & - & 0,63 & 0,50 \\
\hline
\end{tabular}

Com o intuito de verificar se houve maior concordância entre os avaliadores ao separar as sentenças com boa representatividade (isto é, com nota 3) das sentenças pouco ou nada representativas (ou seja, com notas 1 e 2), o Kappa foi novamente calculado considerando somente essas duas classes de sentenças. Os resultados obtidos apresentam-se na Tabela 24.

Conforme se pode ver na tabela, a concordância na avaliação de ambos os tipos de fusão é maior quando se trata apenas de identificar as sentenças com boa representatividade e as sentenças menos representativas, tanto no que se refere ao SubCorpus_SiSPI, como no que se refere ao SubCorpus_CSTNews. Considerando apenas o SubCorpus_SiSPI, a concordância na fusão por interseção melhorou $115 \%$, $40,6 \%$ e 83,3\% em relação à Top1_jNina, Top2_jNina e Top3_jNina, respectivamente, 
ao se considerar somente duas classes de sentenças. Na união, houve uma melhora de 60\%, 21,7\% e de 14,9\% para Top1_jNina, Top2_jNina e Top3_jNina, respectivamente. Já em relação ao SubCorpus_CSTNews, a concordância na fusão por interseção aumentou 23,6\% e 15,9\%, respectivamente, para Top1_jNina e Top1_SM, enquanto que na união houve uma melhora na concordância de 5,4\% para Top1_jNina e de 28,9\% para Top1_SM.

Tabela 24: Concordância obtida em termos da medida Kappa na análise de representatividade, considerando apenas duas classes de sentenças

\begin{tabular}{|c|c|c|c|c|}
\hline & \multicolumn{2}{|c|}{ SubCorpus_SiSPI } & \multicolumn{2}{c|}{ SubCorpus_CSTNews } \\
\cline { 2 - 5 } & Zíper-Interseção & Zíper-União & Zíper-Interseção & Zíper-União \\
\hline Top1_jNina & 0,73 & 0,40 & 0,89 & 0,58 \\
\hline Top2_jNina & 0,45 & 0,56 & - & - \\
\hline Top3_jNina & 0,55 & 0,54 & - & - \\
\hline Top1_SM & - & - & 0,73 & 0,58 \\
\hline
\end{tabular}

As Subseções 6.4.1 e 6.4.2 apresentam os resultados obtidos na análise de representatividade do Zíper-Interseção e do Zíper-União, respectivamente.

\subsubsection{Resultados da Análise de Representatividade na Fusão por Interseção}

As médias das notas obtidas na avaliação de representatividade das três melhores sentenças produzidas pelo Zíper-Interseção com o SubCorpus_SiSPI estão resumidas na Tabela 25. Esses resultados mostram que, tanto na análise do Avaliador1 como na análise do Avaliador2, as três sentenças representam igualmente bem o seu conjunto. É válido observar que, apesar da baixa concordância entre os avaliadores nessa tarefa (vide Tabela 25), os resultados médios obtidos por cada sentença são similares na análise dos dois avaliadores. 
Tabela 25: Resultados da análise de representatividade obtidos na fusão por interseção com o SubCorpus_SiSPI

\begin{tabular}{|c|c|c|}
\hline & Avaliador1 & Avaliador2 \\
\hline Top1_jNina & 2,7 & 2,6 \\
\hline Top2_jNina & 2,7 & 2,6 \\
\hline Top3_jNina & 2,6 & 2,6 \\
\hline
\end{tabular}

A Tabela 26 apresenta os resultados médios obtidos na avaliação de representatividade com o SubCorpus_CSTNews. Como se pode observar na tabela, ambos avaliadores concordaram que as sentenças selecionadas manualmente (Top1_SM) são aproximadamente $8 \%$ mais representativas do que as sentenças selecionadas automaticamente (Top1_jNina). Com 95\% de confiança, o t-teste comprovou que essa diferença é estatisticamente relevante.

Tabela 26: Resultados da análise de representatividade obtidos na fusão por interseção com o SubCorpus_CSTNews

\begin{tabular}{|c|c|c|}
\hline \multirow{2}{*}{} & \multicolumn{2}{|c|}{ Representatividade } \\
\cline { 2 - 3 } & Avaliador1 & Avaliador2 \\
\hline Top1_jNina & 2,5 & 2,4 \\
\hline Top1_SM & 2,7 & 2,6 \\
\hline
\end{tabular}

\subsubsection{Resultados da Análise de Representatividade na Fusão por União}

A Tabela 27 apresenta as médias das notas obtidas na avaliação de representatividade das três melhores sentenças produzidas pelo Zíper-União com o SubCorpus_SiSPI. Tanto na análise do Avaliador1 como na análise do Avaliador2, o teste Anova mostrou que não existe diferença entre as três sentenças, de modo que ambas representam igualmente bem o seu conjunto. 
Tabela 27: Resultados da análise de representatividade obtidos na fusão por união com o SubCorpus_SiSPI

\begin{tabular}{|l|c|c|}
\hline \multirow{2}{*}{} & \multicolumn{2}{|c|}{ Representatividade } \\
\cline { 2 - 3 } & Avaliador1 & Avaliador2 \\
\hline Top1_jNina & 2,7 & 2,5 \\
\hline Top2_jNina & 2,7 & 2,6 \\
\hline Top3_jNina & 2,6 & 2,5 \\
\hline
\end{tabular}

Os resultados médios obtidos na avaliação com o SubCorpus_CSTNews são apresentados na Tabela 28. Considerando a análise do Avaliador1, a Top1_SM obteve uma melhora de 13\%, em termos de representatividade, em relação à Top1_jNina. Já de acordo com o Avaliador2, o ganho foi de 8,33\%. Com $95 \%$ de confiança, o t-teste provou que em ambos os casos a diferença entre as duas sentenças é estatisticamente significativa.

Tabela 28: Resultados da análise de representatividade obtidos na fusão por união com o SubCorpus_CSTNews

\begin{tabular}{|c|c|c|}
\hline \multirow{2}{*}{} & \multicolumn{2}{|c|}{ Representatividade } \\
\cline { 2 - 3 } & Avaliador1 & Avaliador2 \\
\hline Top1_jNina & 2,3 & 2,4 \\
\hline Top1_SM & 2,6 & 2,6 \\
\hline
\end{tabular}

\subsection{Discussão dos Resultados}

Os experimentos apresentados neste capítulo mostraram que o desempenho do método de fusão proposto, tanto no que se refere ao conteúdo como no que se refere à gramaticalidade e semanticidade e à representatividade das sentenças, está relacionado a uma série de fatores. As avaliações de conteúdo, por exemplo, mostraram que a natureza do corpus é um fator que influencia no desempenho em termos de conteúdo. Quando as sentenças de entrada são paráfrases parciais uma das outras (ou seja, cada sentença apresenta informações comuns a outras sentenças do conjunto, mas também adiciona informações distintas entre si), o Zíper-Interseção e o Zíper-União superam os baselines de menor sentença e de maior sentença do conjunto, respectivamente. $\mathrm{O}$ 
Zíper-Interseção obteve uma melhora no desempenho de até 33\% (para a seleção manual de sentenças automáticas), enquanto que o Zíper-União obteve uma melhora de até $11 \%$ (vide Seções 6.2.2 e 6.2.3). Em contrapartida, quando as sentenças de entrada são, em sua maioria, paráfrases completas umas das outras (isto é, não apresentam informações novas distintas entre si), o Zíper-Interseção tem um desempenho similar ao seu baseline e o Zíper-União é ainda pior que o seu baseline. É válido dizer, entretanto, que a natureza das sentenças de entrada não influenciou na gramaticalidade e semanticidade e nem na representatividade das sentenças produzidas. De modo geral, as sentenças geradas por ambos os tipos de fusão são bem formadas e representam bem o seu conjunto.

Outro fator de influência é o modelo de língua. Em termos de conteúdo, na fusão por interseção as sentenças selecionadas manualmente são $12 \%$ melhores do que as sentenças selecionadas com o jNina, enquanto que, na fusão por união, as sentenças manualmente selecionadas são 17,2 \% melhores do que as selecionadas pelo modelo de língua (vide Seções 6.2.2 e 6.2.3). As avaliações de gramaticalidade e semanticidade e de representatividade também mostraram melhoras significativas no desempenho, quando as sentenças automáticas foram selecionadas manualmente. Na fusão por interseção, houve uma melhora de 16,6\% para gramaticalidade e semanticidade e de $8 \%$ para representatividade (vide Seções 6.3.1 e 6.4.1). Na fusão por união, o ganho para gramaticalidade e semanticidade e para representatividade foi de aproximadamente $13 \%$ (vide Seções 6.3.2 e 6.4.2). Os resultados da seleção automática podem ser melhorados, por exemplo, com o uso de modelos de língua baseados em sintaxe. Contudo, até o momento presente não se tem conhecimento de nenhum modelo que possa ser treinado com corpora em português.

O bom desempenho do alinhador de informações comuns também é crucial para o bom desempenho do método de fusão. A baixa cobertura no alinhamento de paráfrases, por exemplo, pode resultar em um pior desempenho em termos de precisão, principalmente na fusão por união (conforme visto na Seção 6.2.3). Todavia, o bom funcionamento do alinhador depende em grande parte do desempenho do parser. Em vários casos, observou-se que erros cometidos pelo parser resultaram em erros no processo de alinhamento, desencadeando problemas na fusão. Por exemplo, para a sentença [1] do conjunto de sentenças do Quadro 37 (extraído do SubCorpus_SiSPI), o parser anotou "Cândido Portinari do Museu de Arte" como um único nome próprio, sendo que "Cândido Portinari do Museu de Arte de São Paulo (Masp)" compõe um 
único sintagma nominal (vide análises produzidas pelo parser no Anexo B). Esse erro provocou o alinhamento do sintagma da sentença [1] com o sintagma nominal "o Masp (Museu de Arte de São Paulo)", da sentença [2], e com o nome "São Paulo", da sentença [3]. Em consequência disso, a qualidade das sentenças produzidas pelos dois modelos de fusão foi bastante prejudicada. Um exemplo de sentença produzida por cada modelo pode ser visto no Quadro 37.

\section{Quadro 37: Sentenças com erros produzidas pelo Zíper-Interseção e pelo Zíper- União, devido à erros do parser}

\section{Conjunto de sentenças similares:}

[1] Ladrões levaram duas obras de Pablo Picasso e Cândido Portinari do Museu de Arte de São Paulo (Masp).

[2] SÃO PAULO - Ladrões invadiram o Masp (Museu de Arte de São Paulo), na madrugada desta quinta-feira, e levaram do acervo os quadros "O Lavrador de Café" (1939), de Portinari, e "O Retrato de Suzanne Bloch" (1904), de Picasso.

[3] SÃO PAULO (Reuters) - Um quadro do pintor espanhol Pablo Picasso e outro do brasileiro Cândido Portinari foram roubados na madrugada desta quinta-feira do Museu de Arte de São Paulo, informou a assessoria de imprensa do Masp, que citou as obras como duas das principais do acervo.

Interseção: O Masp (Museu de Arte de São Paulo) - ladrões invadiram Cândido Portinari do Museu de Arte de São Paulo (Masp), na madrugada desta quinta-feira, e levaram do acervo os quadros " O Lavrador de Café " (1939), de Portinari, e "O Retrato de Suzanne Bloch" (1904), de Picasso.

União: Cândido Portinari do Museu de Arte de São Paulo (Masp) - quadros do espanhol Pablo Picasso e outro do brasileiro Cândido Portinari foram roubados na madrugada desta quinta-feira do Museu de Arte de São Paulo, Cândido Portinari do Museu de Arte de São Paulo (Masp), na madrugada desta quinta-feira, e levaram de acervo os quadros " O Lavrador de Café " (1939), de Portinari, e "O Retrato de Suzanne Bloch de Pablo Picasso" (1904), de Picasso, informou. 


\section{Avaliação Extrínseca}

O Zíper-Interseção e o Zíper-União foram avaliados extrinsecamente no contexto de uma aplicação de sumarização automática. O objetivo dessa avaliação foi verificar qual a contribuição de cada método para essa tarefa específica.

Os experimentos foram realizados com um sistema de sumarização multidocumento do português, proposto por Jorge \& Pardo (2009). A sumarização multidocumento consiste em produzir, a partir de um conjunto de textos relacionados a um mesmo assunto (textos comparáveis), um único sumário. Um sumário multidocumento deve conter no mínimo as informações mais relevantes do conjunto, ao mesmo tempo em que trata a redundância e as contradições de informações que são muito comuns nesses textos.

O sumarizador desenvolvido por Jorge \& Pardo é baseado na teoria discursiva CST - Cross Document Structure Theory (Radev, 2000). Essa teoria explora as similaridades e diferenças entre o conteúdo de textos comparáveis, estabelecendo relações entre suas partes (por exemplo, entre parágrafos e sentenças). As relações CST auxiliam no processo de seleção do conteúdo mais relevante de um conjunto de textos para a produção do sumário, além de permitir a identificação de informações redundantes e contraditórias. Dois métodos de seleção de conteúdo são descritos no trabalho dos autores. O primeiro método extrai as sentenças que mais se relacionam com outras sentenças do conjunto, assumindo que essas sentenças têm mais chances de apresentar informações relevantes (daqui em diante, método Geral). O segundo método é uma variação do primeiro que propõe tratar a redundância de informações (daqui em diante, método da Redundância). Por exemplo, se duas sentenças relevantes estão relacionadas por uma relação de identidade (Identity) ou de equivalência (Equivalence), que indicam que as duas sentenças expressam a mesma informação, somente uma delas é selecionada para compor o sumário. Caso duas sentenças estejam relacionadas por 
uma relação de subsunção (Subsumption), que expressa que uma sentença está contida na outra, somente a maior sentença é selecionada para o sumário ${ }^{17}$. Os autores ressaltam, entretanto, a importância de se ter um mecanismo de fusão sentencial para tratar os casos em que duas ou mais sentenças apresentam informações em comum, mas também expressam informações adicionais distintas entre sí. Essas sentenças são relacionadas pela relação Overlap. A fusão por união, nesse caso, garantiria a preservação de todo o conteúdo expresso nas sentenças relacionadas, sem redundâncias. A fusão por interseção, por sua vez, agiria sintetizando o conteúdo mais importante dessas sentenças em uma única sentença.

A relação Overlap é uma das mais frequentes em textos comparáveis e, apesar disso, nenhum tratamento especial é dado a ela nos métodos de sumarização propostos por Jorge \& Pardo (2009). Por consequência, a redundância nos sumários é bastante frequente, comprometendo seriamente sua qualidade. Uma análise feita com 50 sumários produzidos pelo método Geral, para 50 coleções de textos do corpus CSTNews (Aleixo \& Pardo, 2008), mostrou que 28 sumários (56\%) continham em média 4 sentenças redundantes, relacionadas pela relação Overlap. A mesma análise foi realizada com os sumários produzidos pelo método da Redundância e mostrou que 30 (60\%) apresentavam em média 3 sentenças redundantes. Um exemplo de sumário contendo várias sentenças com informações sobrepostas pode ser visto no Quadro 38. Esse sumário foi construído pelo método Geral, para um conjunto de 4 textos extraídos do corpus CSTNews. As sentenças relacionadas pela relação Overlap estão destacadas em negrito na figura e os relacionamentos entre as sentenças estão apresentados em itálico. Por exemplo, a segunda sentença do sumário, referenciada por [S6_D3] (isto é, sexta sentença do documento 3 do conjunto), tem uma relação de Overlap com a terceira e a quinta sentença do sumário (ou seja, [S2_D4] e [S2_D2], respectivamente) e uma relação de Attribution com a última sentença (isto é, [S19_D4]) ${ }^{18}$.

\footnotetext{
${ }^{17}$ Para obter mais informações sobre esses métodos, vide Jorge \& Pardo (2009).

${ }^{18}$ Para detalhes sobre a definição das relações CST, vide Radev (2000).
} 
Quadro 38: Exemplo de sumário multidocumento produzido pelo método Geral de sumarização proposto por Jorge \& Pardo (2009)

[S16_D2]:S9_D4(Elaboration):S18_D3(Subsumption):S17_D3(Elaboration)

Niigata foi atingida em outubro de 2004 por um tremor também de magnitude 6,8 , que deixou mais de 3 mil feridos.

[S6_D3]:S2_D4(Overlap):S2_D2(Overlap):S19_D4(Attribution)

A Tepco inicialmente declarou que o tremor não havia causado vazamentos, mas, mais tarde, revelou que 1.200 litros de água com materiais radioativos da usina haviam vazado para o mar.

[S2_D4]:S6_D3(Overlap):S2_D2(Elaboration)

Os abalos provocaram vazamento de material radioativo na maior usina nuclear do mundo.

[S9_D4]:S16_D2(Elaboration):S18_D3(Historical-background):

S17_D3(Elaboration)

No caso do Japão, a magnitude apontada de 6,8 é considerada "forte".

[S2_D2]:S6_D3(Overlap):S2_D4(Elaboration):S19_D4(Overlap)

Além do vazamento de água contendo material radioativo, gases radioativos também escaparam da usina nuclear de Kashiwazaki, segundo informou a BBC.

[S18_D3]:S16_D2(Subsumption):S9_D4(Historical-background)

Em Niigata, um terremoto em outubro de 2004, também de magnitude 6,8, matou 65 pessoas e deixou mais de 3.000 feridos.

[S17_D3]:S16_D2(Elaboration):S9_D4(Elaboration)

O Japão é um dos países mais atingidos por terremotos no mundo, com um tremor a cada pelo menos cinco minutos.

[S19_D4]:S6_D3(Attribution):S2_D2(Overlap)

Um incêndio afetou a central nuclear de Kashiwazaki-Kariwa, situada próxima do epicentro do tremor, causando o vazamento de água com restos de material radioativo, segundo a companhia elétrica.

Tendo em vista a importância de se ter um tratamento específico para as sentenças relacionadas por meio de Overlap, foram realizados experimentos com o intuito de verificar se o Zíper (vide Capítulo 5) pode contribuir de alguma forma para melhorar a qualidade dos sumários.

A Seção 7.1 descreve sobre a metodologia de avaliação adotada e, em seguida, a Seção 7.2 apresenta os resultados obtidos pelo Zíper-Interseção e pelo Zíper-União. Por fim, a Seção 7.3 apresenta as considerações finais deste capítulo.

\subsection{Metodologia de Avaliação}

As avaliações foram realizadas com o método Geral de sumarização proposto por Jorge \& Pardo (2009). Esse método foi escolhido devido à grande frequência de 
sentenças com sobreposição de informações (Overlap) presentes nos seus sumários (ou seja, 4 sentenças em média, conforme visto na seção anterior). O corpus usado nas análises foi o CSTNews (Aleixo \& Pardo, 2008), que compreende 50 coleções de textos comparáveis anotados com relações da CST. Cada coleção acompanha também um sumário construído manualmente, por um linguista, com base em uma taxa de compressão de $70 \%$ (em nível de palavras) em relação ao maior texto da coleção.

A fim de não influenciar no processo de sumarização do modelo de Jorge \& Pardo, a fusão sentencial consistiu em um processo de pós-edição dos sumários. Para tanto, os 28 sumários com redundância de informações provocadas pela inserção de sentenças relacionadas por meio de Overlap, dos 50 sumários produzidos para o corpus CSTNews (70\% de compressão), passaram por um pré-processamento que consistiu em duas etapas: i) identificação dos conjuntos de sentenças para fusão e ii) construção das árvores de dependência sintática com o parser Palavras. A identificação dos grupos de sentenças para fusão baseou-se nas relações CST presentes nos sumários produzidos automaticamente (vide Quadro 38), mais especificamente, nas relações de Overlap $^{19}$. No sumário do Quadro 38, por exemplo, há somente um grupo composto pelas sentenças S6_D3, S2_D4, S2_D2 e S19_D4 (em negrito). Apesar de não existir um relacionamento de Overlap explícito entre as sentenças S6_D3 e S19_D4, bem como entre S2_D4 e S19_D4, optou-se, nesse caso, por mantê-las em um mesmo conjunto, uma vez que há uma relação de Overlap entre S6_D3 e S2_D2 (assim como entre S6_D3 e S2_D4) e S2_D2, por sua vez, se relaciona com S19_D4 também por meio de Overlap. Assim, cada sentença foi incluída em apenas um conjunto. A inclusão de uma mesma sentença em vários conjuntos distintos provocaria, ainda, uma redundância de informações nos sumários, especialmente no que diz respeito à fusão por união.

Após o pré-processamento, os conjuntos de sentenças foram submetidos ao Zíper, para a geração das respectivas interseções e uniões de sentenças. Posteriormente, duas sentenças de cada método foram selecionadas para cada conjunto de entrada, sendo uma delas a sentença mais bem pontuada pelo jNina e a outra selecionada aleatóriamente. A seleção aleatória teve como objetivo apenas avaliar a contribuição do modelo de língua. Cada sentença automática foi, então, inserida no sumário (na posiçao

\footnotetext{
${ }^{19}$ As relações CST dos textos originais foram reproduzidas nos sumários apenas para os experimentos descritos neste capítulo. Os sumários produzidos pelo sistema de Jorge \& Pardo (2009) não incluem essas relações.
} 
em que ocorreu a primeira sentença com Overlap do conjunto) ${ }^{20}$, substituindo o seu respectivo conjunto. Para cada um dos 28 sumários, foram produzidos, portanto, quatro novos sumários: dois sumários para o Zíper-Interseção, sendo um com as sentenças selecionadas pelo jNina (daqui em diante, Interseção_Top1_jNina) e outro com as sentenças selecionadas aleatoriamente (Interseção_SA), e dois sumários para o ZíperUnião, sendo um com as sentenças selecionadas pelo jNina (União_Top1_jNina) e outro com as sentenças selecionadas de forma aleatória (União_SA).

Para efeito de ilustração, os Quadro 39 e 40 apresentam o sumário do Quadro 38 depois da fusão por interseção e da fusão por união de sentenças com sobreposição de informações, respectivamente. No sumário do Quadro 39, a sentença resultante da fusão (segunda sentença) foi selecionada pelo modelo de língua, enquanto que no sumário do Quadro 40 a seleção da sentença automática (segunda sentença) foi feita de forma aleatória.

\section{Quadro 39: Sumário após a fusão por interseção de sentenças relacionadas por meio de Overlap}

Niigata foi atingida em outubro de 2004 por um tremor também de magnitude 6,8 , que deixou mais de 3 mil feridos.

Um incêndio afetou a central nuclear de Kashiwazaki-Kariwa, situada próxima do epicentro do tremor e provocou o vazamento de água com restos de material radioativo.

No caso do Japão, a magnitude apontada de 6,8 é considerada "forte".

Em Niigata, um terremoto em outubro de 2004, também de magnitude 6,8, matou 65 pessoas e deixou mais de 3.000 feridos.

O Japão é um dos países mais atingidos por terremotos no mundo, com um tremor a cada pelo menos cinco minutos.

\section{Quadro 40: Sumário após a fusão por união de sentenças relacionadas por meio de Overlap}

Niigata foi atingida em outubro de 2004 por um tremor também de magnitude 6,8 , que deixou mais de 3 mil feridos.

Além do vazamento de água contendo material radioativo, gases radioativos, segundo a companhia elétrica também escaparam da usina nuclear de Kashiwazaki, segundo informou a BBC mais tarde e revelou que 1.200 litros de água com materiais radioativos da usina haviam vazado para o mar.

No caso do Japão, a magnitude apontada de 6,8 é considerada "forte".

Em Niigata, um terremoto em outubro de 2004, também de magnitude 6,8, matou 65 pessoas e deixou mais de 3.000 feridos.

O Japão é um dos países mais atingidos por terremotos no mundo, com um tremor a cada pelo menos cinco minutos.

${ }^{20}$ A posição de inserção das sentenças automáticas nos sumários não é relevante para os experimentos descritos neste capítulo. Além do mais, o método proposto por Jorge \& Pardo (2009) não trata a ordenação das sentenças dos sumários. 
A contribuição de cada método de fusão para a sumarização foi analisada automaticamente com o uso da ferramenta ROUGE versão 1.5.5 (Lin, 2004a; Lin, 2004b). A ROUGE fornece várias medidas que calculam o grau de informatividade dos sumários produzidos automaticamente (daqui em diante, sumários automáticos). A informatividade é calculada em termos de Precisão, Cobertura e Medida-F e se baseia na coocorrência de n-gramas entre os sumários automáticos e os sumários construídos por humanos (daqui em diante, sumários de referência). A Precisão do sumário automático é dada pelo número de n-gramas do sumário de referência que coocorrem no sumário automático dividido pelo total de n-gramas do sumário automático. A Cobertura é calculada dividindo-se o total de n-gramas do sumário de referência que coocorrem no sumário automático pelo total de n-gramas do sumário de referência. A Medida-F, por sua vez, representa a média harmônica entre a Precisão e a Cobertura. Embora a ROUGE permita calcular a Precisão e a Cobertura considerando-se n-gramas de vários tamanhos (o "n” pode variar de 1 a 9) ${ }^{21}$, de acordo com o autor a comparação de unigramas (daqui em diante, ROUGE-1) é suficiente para medir a informatividade dos sumários. O número de sumários de referência também pode variar. Porém, não há recomendação sobre o número de sumários ideal. Segundo Lin (2004a, 2004b), independente do número de sumários de referência usados na comparação, a ROUGE é capaz de distinguir um sumário bom de um sumário ruim tão bem quanto um humano.

Nos experimentos apresentados neste capítulo utilizou-se somente um sumário de referência para cada sumário automático e a medida baseada em unigramas (ROUGE-1). Os resultados obtidos por cada modelo de fusão sentencial são apresentados na seção a seguir.

\subsection{Resultados da Avaliação Extrínseca}

A Tabela 29 apresenta os resultados médios obtidos com a ROUGE-1 para os sumários antes da fusão e após a fusão por interseção e por união de sentenças relacionadas pela relação Overlap.

${ }^{21}$ Para mais detalhes sobre essas e outras medidas, vide (Lin, 2004a; Lin, 2004b). 
Tabela 29: Resultados médios obtidos para Precisão, Cobertura e Medida-F antes e depois da fusão por interseção e por união de sentenças relacionadas por meio de Overlap

\begin{tabular}{|c|c|c|c|}
\hline Sumários & Precisão & Cobertura & Medida-F \\
\hline Antes da fusão & 0,52501 & 0,57389 & 0,54547 \\
\hline União_SA & 0,55585 & 0,52985 & 0,53504 \\
\hline União_Top1_jNina & 0,55529 & 0,52157 & 0,53010 \\
\hline Interseção_Top1_jNina & 0,57272 & 0,46464 & 0,49314 \\
\hline Interseção_SA & 0,55684 & 0,46579 & 0,49263 \\
\hline
\end{tabular}

Quando se compara os sumários antes e depois da fusão de sentenças com sobreposição de informações, observa-se uma melhora em termos de Precisão, tanto no que diz respeito à fusão por união, como no que diz respeito à fusão por interseção. $\mathrm{Na}$ união, a melhora foi de aproximadamente 6\% (tanto para a seleção aleatória (União_SA) como para a seleção com o jNina (União_Top1_jNina)), enquanto que na interseção houve uma melhora de até 9\% (isto é, para Interseção_Top1_jNina). Testes estatísticos realizados com o t-teste, com um fator de $95 \%$ de confiança, mostraram que esses ganhos são estatisticamente significativos. Em contrapartida, na comparação de desempenho em termos de Cobertura, observa-se uma perda de desempenho de até $8,3 \%$ após a fusão por união e uma perda de até $23,5 \%$ após a fusão por interseção (nos piores casos). Uma explicação possível é que as sentenças resultantes da fusão não seguem tão estritamente as palavras do sumário de referência, mas somente o sentido, dificultando assim a identificação dos conceitos correspondentes pela ROUGE. Isso é admissível uma vez que a ROUGE não faz uso de recursos linguísticos como a Wordnet e nem de stemmers e lematizadores, que auxiliariam na identificação de palavras de uma mesma classe semântica ${ }^{22}$. Outra possível explicação é que, ao comprimir os sumários eliminando-se as informações redundantes, informações relevantes também tenham sido eliminadas. Isso pode acontecer principalmente na fusão por interseção, em que somente as informações comuns entre as sentenças de um mesmo conjunto são preservadas. No entanto, é importante dizer que, por se tratar de um processo de pósedição de sumários, já era esperado que houvesse uma redução maior de Cobertura na interseção, uma vez que a seleção do conteúdo mais relevante dos textos-fonte havia sido realizada previamente. Dessa forma, acredita-se que a fusão de sentenças, quer seja

\footnotetext{
${ }^{22}$ Para a língua inglesa, a ROUGE utiliza a Wordnet e um stemmer.
} 
por interseção quer seja por união, convencionada ao processo de seleção de conteúdo poderá trazer mais benefícios para os sumários. A síntese de várias sentenças em uma única sentença durante esse processo permitiria, por exemplo, a seleção de outras sentenças também relevantes, até que a taxa de compressão fosse atingida.

Em consequência da queda nos valores de Cobertura, houve também uma redução em termos do desempenho global (Medida-F), como mostrado na Tabela 29. Porém, o t-teste mostrou que para a fusão por união as diferenças no desempenho não são estatisticamente significativas (ou seja, p-value > 0,05). Por outro lado, as análises mostraram que na fusão por interseção houve uma perda estatisticamente significativa de até $10,7 \%$, no pior caso.

$\mathrm{Na}$ comparação entre os sumários cujas sentenças fundidas automaticamente foram selecionadas de forma aleatória e os sumários cujas sentenças foram selecionadas pelo modelo de língua, tanto na interseção como na união, o t-teste mostrou que a diferença entre eles não tem significância estatística. Portanto, pode-se concluir que, em termos de informatividade, a seleção de sentenças com o modelo estatístico de língua não oferece nenhum ganho de desempenho, quando comparada à seleção aleatória.

\subsection{Considerações Finais}

As avaliações descritas neste capítulo mostraram que o Zíper pode contribuir para reduzir a redundância de informações nos sumários produzidos automaticamente. No Zíper-Interseção, houve uma melhora em termos de Precisão de até 9\%, em comparação com os sumários antes da fusão de sentenças redundantes, enquanto que o Zíper-União apresentou um ganho de Precisão de cerca de 6\%. Todavia, os experimentos mostraram que houve perda significativa de informatividade (isto é, Cobertura), especialmente após a fusão por interseção (vide Seção 7.2). Acredita-se que a Cobertura dos sumários pode ser melhorada com a aplicação da fusão durante o processo de seleção de conteúdo mais importante dos textos-fonte, possibilitando, assim, a inclusão de outras sentenças relevantes no sumário, após a síntese de um conjunto de sentenças redundantes.

O próximo capítulo apresenta as conclusões deste trabalho, descrevendo as principais contribuições e apontando algumas possibilidades de trabalhos futuros. 


\section{Conclusões}

Nesta tese, investigou-se um método para a fusão automática de sentenças similares em português. A proposta prevê a geração de sentenças sem redundâncias ou contradições, a partir de um conjunto de sentenças similares, por meio do alinhamento de palavras e segmentos multipalavras que expressam um mesmo conceito no conjunto, e ainda de um linearizador sentencial, que faz uso de conhecimento linguístico extraído das sentenças de entrada e de um gerador de formas superficiais do português. Como resultado prático desta pesquisa, foi desenvolvido o primeiro sistema de fusão sentencial para a língua portuguesa, o Zíper, o qual se baseia em uma abordagem simbólica e independente de domínio.

Zíper permite dois tipos de fusão distintos (Capítulo 5) - fusão por interseção (Zíper-Interseção), que produz sentenças que capturam somente as informações mais relevantes das sentenças de entrada (ou seja, a interseção das sentenças) e fusão por união (Zíper-União), que produz sentenças que capturam todas as informações da entrada (ou seja, a união das sentenças). Esse é o primeiro sistema a contemplar a geração de sentenças representando a união do conjunto de sentenças.

O sistema foi avaliado intrinsecamente em relação a vários aspectos: i) conteúdo (informatividade), ii) gramaticalidade e semanticidade e iii) representatividade das sentenças produzidas (vide Capítulo 6). As avaliações foram realizadas com dois corpora distintos, a saber: um corpus de conjuntos de sentenças altamente similares e um corpus de conjuntos de sentenças que são paráfrases parciais uma das outras (vide Seção 6.1). No que diz respeito ao conteúdo das sentenças, os experimentos mostraram que a natureza do corpus é um fator de influência no desempenho do Zíper. Com o corpus de paráfrases parciais, o Zíper-Interseção e o Zíper-União superaram o baseline de menor sentença e o baseline de maior sentença do conjunto em até $33 \%$ e $11 \%$, respectivamente (vide Seções 6.2.2 e 6.2.3). Porém, com o corpus de sentenças 
altamente similares, o Zíper-Interseção apresentou um desempenho similar ao baseline (em média 86\% de Medida-F) e o Zíper-União não superou o baseline (ou seja, obteve em média $85 \%$ de Medida-F contra $90 \%$ do baseline). Embora não seja possível fazer uma comparação direta com outros métodos da literatura, devido às diferenças das línguas (entre outros fatores), é válido dizer que em um experimento similar o método de fusão por interseção proposto por Barzilay \& Mckeown (2005), para a língua inglesa, alcançou $68 \%$ de Medida-F.

A natureza do corpus não influenciou, entretanto, nos aspectos de gramaticalidade, semanticidade e representatividade das sentenças geradas pelos dois tipos de fusão. De modo geral, os experimentos mostraram que as sentenças produzidas pelo Zíper-Interseção e o Zíper-União são bem formadas e representam bem seu respectivo conjunto (vide Seções 6.3 e 6.4), comprovando, assim, a hipótese da tese, segundo a qual é possível produzir sentenças com qualidade satisfatória, a partir da fusão de sentenças similares em português, usando para tanto várias ferramentas e recursos linguísticos disponíveis para essa língua.

A fim de analisar a contribuição da tarefa de fusão sentencial para as aplicações que processam múltiplos textos, Zíper também foi avaliado extrinsecamente no contexto de um sumarizador multidocumento do português (Capítulo 7). Os resultados obtidos sugerem que o método proposto pode contribuir para reduzir a redundância de informações nos sumários. Em particular, a fusão por interseção de sentenças redundantes melhorou a Precisão dos sumários em até $9 \%$, enquanto que a fusão por união de sentenças redundantes apresentou um ganho de Precisão de aproximadamente $6 \%$. Contudo, para ambos os casos houve perda significativa de Cobertura (isto é, até $8,3 \%$ na fusão por união e até $23,5 \%$ na fusão por interseção (nos piores casos)). É válido dizer, entretanto, que essa perda de Cobertura já era esperada, uma vez que a fusão de sentenças foi aplicada como um processo de pós-edição de sumários, e, portanto, depois da seleção de conteúdo relevante. Acredita-se que a fusão sentencial poderá trazer mais benefícios para a sumarização se aplicada durante o processo de seleção de conteúdo.

As Seções 8.1 e 8.2 descrevem, respectivamente, as principais contribuições obtidas nesta tese e algumas possibilidades de trabalhos futuros. 


\subsection{Principais Contribuições}

Neste trabalho é possível identificar contribuições de várias naturezas para o processamento automático da língua portuguesa, tais como métodos, sistemas, recursos e conhecimento linguístico formalizado. Destacam-se, aqui, algumas contribuições principais.

Com relação aos métodos, destaca-se o desenvolvimento de um método simbólico e independente de domínio para a fusão automática de sentenças similares em português, que contempla tanto a fusão por interseção de informações, como a fusão por união de informações. Visando possibilitar a aplicação automática do método proposto em várias tarefas do PLN envolvendo o português, foi construído um protótipo de sistema, o Zíper. Esse sistema é imprescindível para a avaliação e validação do método de fusão sentencial. É importante dizer aqui que, em um futuro próximo, Zíper poderá ser acoplado ao sumarizador multidocumento proposto por Jorge \& Pardo $(2009 ; 2010)$.

Dado que a fusão de sentenças no método proposto é fortemente baseada no alinhamento de informações comuns, propôs-se também um método para o alinhamento automático de palavras e segmentos multipalavras que expressam conceitos similares em sentenças do português. Esse método foi implementado e consiste em um dos módulos principais do Zíper (vide Capítulo 5). Por ser um módulo independente, ele pode ser aplicado a outras tarefas em que esse processo seja útil, por exemplo, em sistemas de resolução de anáforas. De fato, o alinhamento de conceitos similares consiste em um passo importante rumo à detecção automática de paráfrases. A partir do alinhamento de grandes corpora, seria possível treinar sistemas de reconhecimento de paráfrases. Um léxico de paráfrases, por sua vez, é útil em praticamente toda grande aplicação de PLN, seja na interpretação ou na geração de textos.

Como a metodologia de desenvolvimento deste trabalho é baseada em corpus, propôs-se, ainda, um método de clustering, para a construção automática de corpus de sentenças similares a partir de uma coleção de textos. Tal método resultou na construção do protótipo SiSPI, que recebe como entrada uma coleção de textos e produz como saída vários grupos de sentenças similares. Um ponto favorável do SiSPI é que não é necessário conhecer de antemão o número de grupos de sentenças. Um sistema desse tipo pode ser útil também em várias outras aplicações do PLN que necessitam de um 
processo de reconhecimento de paráfrases em nível sentenças, tais como a sumarização multidocumento e os sistemas de perguntas e respostas.

No que diz respeito à construção de recursos, pode-se citar a construção de um corpus composto por 53 coleções de textos comparáveis monolíngues, do domínio jornalístico, contendo aproximadamente 4 textos por coleção (vide Capítulo 4). A partir desse corpus, construiu-se, por meio do SiSPI, um corpus de 393 conjuntos de sentenças similares, consistindo de 3 sentenças em média por conjunto. $\mathrm{O}$ uso desse corpus no desenvolvimento e na avaliação do método de fusão sentencial resultou em outras versões desse corpus, a saber:

i) corpus alinhado em nível de sentenças, contendo aproximadamente 670 pares de sentenças similares. Esse corpus foi obtido a partir de todas as combinações possíveis de pares de sentenças similares de cada um dos 393 conjuntos identificados pelo SiSPI;

ii) corpus alinhado em nível de conceitos, resultante do processo de alinhamento de informações comuns (por exemplo, sinônimos e paráfrases) entre sentenças similares;

iii) corpus de sentenças anotadas sintaticamente pelo parser Palavras (Bick, 2000).

Finalmente, com relação a conhecimento linguístico-computacional formalizado, destaca-se a especificação de um conjunto composto por 21 regras que permitem a identificação de paráfrases com variações sintáticas em textos do português do Brasil.

\subsection{Trabalhos Futuros}

Apresentam-se, nesta seção, várias possibilidades de extensão deste trabalho, relacionadas ao aprimoramento de vários processos envolvidos na fusão automática de sentenças, desde o alinhamento até a seleção de sentenças geradas automaticamente.

O alinhamento de informações comuns é crucial para o processo de fusão sentencial, quer seja fusão por interseção ou fusão por união. Contudo, esse é também um dos maiores desafios na construção de métodos de fusão. Conforme visto nos experimentos apresentados na Seção 5.1.3, o método proposto para a identificação de conceitos similares ainda pode ser melhorado, principalmente no que se refere à identificação de paráfrases mais complexas, com variações lexicais e estruturais. Uma 
possibilidade de melhorar esse processo é fazer uso de conhecimento de senso comum. Informações de senso comum podem ser úteis para explicitar conceitos comuns implícitos nas sentenças. Dekker (2006), por exemplo, faz uso desse tipo de conhecimento para identificar palavras similares em um modelo de inferência textual. Nesse sentido, uma possibilidade é usar a base de senso comum desenvolvida no contexto do projeto Open Mind Common Sense no Brasil (OMCS-Br) ${ }^{23}$, pelo Laboratório de Interação Avançada (LIA) - UFSCar, em parceria com o Media Lab do Massachusetts Institute of Technology (MIT). O uso de conhecimento semântico também pode ser útil nesse processo, tais como informações sobre entidades mencionadas e papel semântico. Esse tipo de conhecimento pode ser obtido, por exemplo, com o parser Palavras (Bick, 2006) e com o sistema REMBRANDT (Cardoso, 2008), um reconhecedor de entidades mencionadas do português. Relações de hiperonímia e hiponímia também podem contribuir para a identificação de palavras distintas, mas com equivalência conceitual aproximada. Conforme mencionado no Capítulo 5, o alinhador proposto faz uso apenas da relação de sinonímia. É válido dizer que a Wordnet-BR (Di Felippo \& Dias-da-Silva, 2007) já contempla as relações de hiperonímia e hiponímia entre verbos, sendo que os relacionamentos entre substantivos se encontram em fase de desenvolvimento (Scarton \& Aluísio, 2009). Outra possibilidade é a construção de um léxico de paráfrases do português. Esse recurso pode ser construído automaticamente a partir de corpora comparável monolíngue (Shinyama \& Sekine, 2003, 2005; Sekine, 2005), paralelo monolíngue (Barzilay \& Mckeown, 2001) ou multilíngue (Callison-Burch, 2007; 2008). O pacote NATools ${ }^{24}$, que fornece um conjunto de ferramentas para a indução automática de léxicos bilíngues a partir de corpora paralelos multilíngue, também pode ser usado para este propósito. Por fim, pode-se ainda formular novas regras de parafraseamento com base em análise de corpora em português.

Com relação ao processo de fusão, propriamente dito, mais especificamente no que se refere à fusão por união, uma possibilidade de trabalho futuro é investigar técnicas para o aprimoramento do método de agregação de informações obtidas de várias sentenças em uma única sentença. Como visto na Seção 5.2.2, ao unir informações de várias sentenças, o Zíper-União utiliza heurísticas baseadas em contexto

\footnotetext{
${ }^{23} \mathrm{http}: / /$ www.sensocomum.ufscar.br (último acesso em 29/01/2010).

${ }^{24}$ NATools está disponível livremente em: http://natura.di.uminho.pt/natura/natura/ (último acesso em 29/01/2010).
} 
para determinar a ordem de apresentação das informações na sentença. Entretanto, esse método não leva em consideração uma série de fatores que podem ser determinantes para a ordenação dos eventos na sentença, tais como relações temporais, de causa e efeito, entre outras. Acredita-se que modelos discursivos, por exemplo, a teoria RST Rhetorical Structure Theory (Mann \& Thompson, 1987) podem contribuir para esse processo, uma vez que permitem estabelecer relações retóricas intra-sentenciais. Nesse sentido, uma possibilidade é utilizar o analisador discursivo do português do Brasil, o DiZer (Pardo \& Nunes, 2006), baseado na teoria RST.

Outra possibilidade de trabalho futuro refere-se ao aprimoramento do processo de seleção de sentenças geradas pelo Zíper. Conforme descrito no Capítulo 6, a seleção manual de sentenças geradas automaticamente apresentou uma melhora de 16,6\% em termos de gramaticalidade e semanticidade e de $8 \%$ em termos de representatividade (vide Seções 6.3.1 e 6.4.1), na fusão por interseção, comparada à seleção pelo modelo estatístico de língua. Na fusão por união, houve um ganho de $13 \%$ tanto para gramaticalidade e semanticidade, como para representatividade. Acredita-se que a qualidade das sentenças selecionadas automaticamente pode ser melhorada com o desenvolvimento de um modelo de língua guiado pela sintaxe, como proposto por Daumé III et al. (2002).

Por fim, visando tornar o método de fusão sentencial mais robusto, novos experimentos devem ser realizados para verificar o seu desempenho com corpora de outros gêneros ou domínios como, por exemplo, literários e científicos. Nesse caso, os mesmos critérios analisados nos experimentos descritos nesta tese podem ser considerados, ou seja, gramaticalidade e semanticidade, representatividade e conteúdo (vide Capítulo 6). 


\section{Capítulo 9}

\section{Referências Bibliográficas}

Aleixo, P. \& Pardo, T.A.S. (2008). CSTNews: Um Corpus de Textos Jornalísticos Anotados Segundo a Teoria Discursiva Multidocumento CST (Cross-document Structure Theory). Série de Relatórios Técnicos do Instituto de Ciências Matemáticas e de Computação, Universidade de São Paulo, nº 326, 12 p.

Bannard, C. \& Callison-Burch, C. (2005). Paraphrasing with Bilingual Parallel Corpora. In: Proceeding of Association for Computational Linguistics - ACL, pp. 597-604.

Barzilay, R. (2003). Information Fusion for Multidocument Summarization: Paraphrasing and Generation. Phd. Thesis, Columbia University, New York, $221 \mathrm{p}$.

Barzilay, B. \& Mckeown, K. (2001). Extracting Paraphrases from a Parallel Corpus. In: Proceedings of Association for Computational Linguistics - ACL, pp. 50-57.

Barzilay, R. \& Lee, L. (2003). Learning to Paraphrase: An Unsupervised Approach Using Multiple-Sequence Alignment. In: Proceedings of the Human Language Technology Conference of the North American Chapter of the ACL HLT/NAACL, pp. 16-23.

Barzilay, R. \& McKeown, K. (2005). Sentence Fusion for Multi-document News Summarization. Computational Linguistics, Vol. 31, nº 3, pp. 297-327.

Bick, E. (2000). The Parsing System "Palavras" - Automatic Grammatical Analysis of Portuguese in a Constraint Grammar Framework. Aarhus University Press.

Bick, E. (2005). Gramática Constritiva na Análise Automática de Sintaxe Portuguesa. A Língua Portuguesa no Computador. Campinas: Mercado de Letras, São Paulo: FAPESP. ISBN: 85-7591-044-2, pp. 1-17.

Bick, E. (2006). Functional Aspects in Portuguese NER. In: Proceedings of the $7^{\text {th }}$ International Workshop on Computational Processing of the Portuguese Language - PROPOR (Lecture Notes in Computer Science, 3960), pp. 80-89. 
Branco, A.; Rodrigues, L.; Silva, J.; Silveira, S. (2008). Real-time Open-Domain QA in the Portuguese Web. In: Proceedings of the $11^{\text {th }}$ Ibero-American Conference on Artificial Inteligence - IBERAMIA (Lecture Notes in Computer Science, 5290), pp. 322-331.

Caldas Junior, J.; Imamura, C.Y.M.; Rezende, S.O. (2001). Avaliação de um Algoritmo de Stemming para a Língua Portuguesa. In: Proceedings of the $2^{\text {nd }}$ Congress of Logic Applied to Technology, Vol. 2, pp. 267-274.

Callison-Burch, C. (2008). Syntactic Constraints on Paraphrases Extracted from Parallel Corpora. In: Proceedings of the Conference on Empirical Methods in Natural Language Processing - EMNLP, pp. 196-205.

Callison-Burch, C. (2007). Paraphrasing and Translation. Phd. Thesis, University of Edinburgh, Scotland, 206 p.

Cardoso, N. (2008). REMBRANDT - Reconhecimento de Entidades Mencionadas Baseado em Relações e Análise Detalhada do Texto. Desafios na Avaliação Conjunta do Reconhecimento de Entidades Mencionadas: O Segundo HAREM, ISBN: 978-989-20-1656-6, pp. 195-211.

Carletta, J. (1996). Assessing Agreement on Classification Tasks: The Kappa Statistics. Computational Linguistics, Vol. 22, nº 2, pp. 249-254.

Caseli, H.M. (2007). Indução de Léxicos Bilíngües e Regras para a Tradução Automática. Tese de Doutorado. ICMC-USP, São Carlos, 158 p.

Clarke, J. \& Lapata, M. (2008). Global Inference for Sentence Compression: An Integer Linear Programming Approach. Journal of Artificial Intelligence Research, Vol. 31, pp. 399-429.

Clarkson, P. \& Rosenfeld, R. (1997). Statistical Language Modeling Using the CMUCambridge Toolkit. In: Proceedings of ESCA Eurospeech, Vol. 5, pp. 27072710.

Chomsky, N. (1957). Syntactic Structures. The Hague: Mouton Publishers, Paris.

Costa, L.F. \& Cabral, L.M. (2008). Answering Portuguese Questions. In: Proceedings of the International Conference on Computational Processing of Portuguese Language - PROPOR (Lecture Notes in Artificial Intelligence, 5190), pp. 228231.

Craggs, R. \& Wood, M.M. (2005). Evaluating Discourse and Dialogue Coding Schemes. Computational Linguistics, Vol. 31, pp. 289-295. 
Cross, M. (1992). Choice in Lexis: Computer Generation of Lexis as Most Delicate Grammar. Language Sciences 14.4, pp. 579-607.

Collins, M. (1996). A New Statistical Parser Based on Bigram Lexical Dependencies. In: Proceedings of the $34^{\text {th }}$ Annual Meeting of the Association for Computational Linguistics - ACL, pp. 184-191.

Dalmas, T. \& Webber, B. (2007). Answer Comparison in Automated Question Answering. Journal of Applied Logic, Vol. 5, n 1, pp. 104-120.

Daumé III, H.; Knight, K.; Langkilde-Geary, I.; Marcu, D.; Yamada, K. (2002). The Importance of Lexicalized Syntax Models for Natural Language Generation Tasks. In: Proceedings of the Second International Conference on Natural Language Generation - IGNL, 8p.

Daumé III, H. \& Marcu, D. (2004). Generic Sentence Fusion is an Ill-Defined Summarization Task. In: Proceedings of the Workshop on Text Summarization Branches Out at ACL, pp. 96-103.

Dekker, M. C. (2006). Recognizing Textual Entailment. Thesis (Master's degree) Faculty of Arts, Utrecht University, Utrecht, Netherlands.

Dias-da-Silva, B.C.; Di Felippo, A.; Hasegawa, R. (2006). Methods and Tools for Encoding the WordNet.Br Sentences, Concept Glosses, and ConceptualSemantic Relations. In: Proceedings of the $7^{\text {th }}$ International Workshop on Computational Processing of the Portuguese Language - PROPOR (Lecture Notes in Computer Science, 3960), pp. 120-130.

Dias-da-Silva, B.C.; Di Felippo, A.; Nunes, M.G.V. (2008). The Automatic Mapping of Princeton Wordnet Lexical-Conceptual Relations Onto the Brazilian Portuguese Wordnet Database. In: Proceedings of the Sixth International Language Resources and Evaluation - LREC (European Language Resources Association - ELRA, ISBN 2-9517408-4-0), pp. 1535-1541.

Di Felippo, A. \& Dias-da Silva, B. C. (2007). Towards an Automatic Strategy for Acquiring the Wordnert.Br Hierarchical Relations. In: Anais do V Workshop em Tecnologia da Informação e da Linguagem Humana - TIL, pp. 1717-1720.

Dras, M. (1999). Tree Adjoining Grammar and the Reluctant Paraphrasing of Text. Phd. Thesis, Macquarie University, Australia, 282 p.

Faraco, C.E. \& Moura, F.M. (1994). Gramática. São Paulo: Ática, 13a edição, ISBN: 85-08-03654. 
Filippova, R. \& Strube, M. (2007). Generating Constituent Order in German Clauses. In: Proceedings of the $45^{\text {th }}$ Annual Meeting of the Association for Computational Linguistics, pp. 320-327.

Filippova, R. \& Strube, M. (2008). Sentence Fusion via Dependency Graph Compression. In: Proceedings of the Conference on Empirical Methods in Natural Language Processing - EMNLP, pp. 177-185.

Forney, G. D. (1973). The Viterbi Algorithm. In: Proceedings of the IEEE, Vol. 61, $\mathrm{n}^{\circ}$ 3, pp. 268-278.

Fung, B.C.M.; Wang, K.; Ester, M. (2003). Hierarchical Document Clustering using Frequent Itemsets. In: Proceedings of the $3^{\text {rd }}$ SIAM International Conference on Data Mining, pp. 59-70.

Halliday, M.A.K. (1985). Systemic Background. Systemic Perspectives on Discourse. Norwood, N.J.: Ablex.

Harris, Z.S. (1957). Co-occurrence and Transformation in Linguistic Structure. Language, Vol. 33, n 3, pp. 283-340.

Hasan, R. (1987). The Grammarian's Dream: Lexis as Most Delicate Grammar. New Developments in Systemic Linguistics: Theory and Description. London: Pinter.

Hatzivassiloglou, V.; Klavans, J. L.; Eskin, E. (1999). Detecting Text Similarity over Short Passages: Exploring Linguistic Feature Combinations via Machine Learning. In: Proceedings of the Conference on Empirical Methods in Natural Language Processing and Very Large Corpora - EMNLP, pp. 203-212.

Hatzivassiloglou, V.; Klavans, J.L.; Holcombe, M.L.; Barzilay, R.; Kan, M.; McKeown, K.R. (2001). SimFinder: A Flexible Clustering Tool for Summarization. In Proceedings of the Workshop on Automatic Summarization at NAACL, pp. 4149.

Hoey, M. (1991). Patterns of Lexis in Text. Oxford: Oxford University Press.

Jing, H. \& Mckeown, K. (2000). Cut and Paste Based Summarization. In: Proceedings of the First Conference of the North American Chapter of the Association of Computational Linguistics - NAACL, pp. 178-185.

Jorge, M.L.C. \& Pardo, T.A.S. (2009). Content Selection Operators for Multidocument Summarization based on Cross-document Structure Theory. In: Anais do VII Simpósio Brasileiro em Tecnologia da Informação e da Linguagem Humana STIL, 8p. 
Jorge, M.L.C. \& Pardo, T.A.S. (2010). Formalizing CST-based Content Selection Operations. In: Proceedings of the International Conference on Computational Processing of Portuguese Language - PROPOR (Lecture Notes in Artificial Intelligence, 6001), pp. 25-29.

Klampanos, I.A.; Jose, J.M.; van Rijsbergen, C.J.K. (2006). Single-pass Clustering for Peer-to-Peer Information Retrieval: The Effect of Document Ordering. In: Proceedings of First International Conference on Scalable Information Systems - INFOSCALE, Vol. 152, pp. 36-43.

Krahmer, E.; Marsi, E.; van Pelt, P. (2008). Query-based Sentence Fusion Is Better Defined and Leads to More Preferred Results than Generic Sentence Fusion. In: Proceedings of the Human Language Technology Conference - HLT/ACL, pp. 193-196.

Larocca Neto, J.; Santos, A.D.; Kaestner, C.A.A.; Freitas, A.A. (2000). Document Clustering and Text Summarization. In: Proceedings of the $4^{\text {th }}$ International Conference on Practical Applications of Knowledge Discovery and Data Mining - PAAD, pp. 41-55.

Lin, C. (2004a). ROUGE: a Package for Automatic Evaluation of Summaries. In: Proceedings of the Workshop on Text Summarization Branches Out, pp. 74-81.

Lin, C. (2004b). Looking for a Few Good Metrics: Automatic Summarization Evaluation - How Many Samples Are Enough?. In: Proceedings of the Fourth NTCIR Workshop, pp. 1-8.

MacQueen, J. B. (1967). Some Methods for Classification and Analysis of Multivariate Observations. In: Proceedings of the $5^{\text {th }}$ Berkeley Symposium on Mathematical Statistics and Probability. Berkeley, University of California Press, Vol. 1, pp. 281-297.

Mann, W.C. \& Thompson, S.A. (1987). Rhetorical Structure Theory: A Theory of Text Organization. Technical Report ISI/RS-87-190.

Marsi, E. \& Krahmer, E. (2005). Explorations in Sentence Fusion. In: Proceedings of the $10^{\text {th }}$ European Workshop on Natural Language Generation - ENLG, pp. 109-117.

Maziero, E.G.; Pardo, T.A.S.; Di Felippo, A.; Dias-da-Silva, B.C. (2008). A Base de Dados Lexical e a Interface Web do TeP 2.0 - Thesaurus Eletrônico para o Português do Brasil. In: Anais do VI Workshop em Tecnologia da Informação e da Linguagem Humana - TIL, pp. 390-392. 
McCawley, J.D. (1976). Syntax and Semantics, 7: Notes from the Linguistic Underground. New York: Academic Press.

Melamed, I. D. (1995). Automatic Evaluation and Uniform Filter Cascades for Inducing N-Best Translation Lexicons. In: Proceedings of $3^{\text {rd }}$ Annual Workshop on Very Large Corpora - WVLC, pp. 184-198.

Mel'čuk, I. (1988). Dependency Syntax: Theory and Practice. Albany: State University of New York Press.

Milićević, J. (2007a). Semantic Equivalence Rules in Meaning-Text Paraphrasing. Selected Lexical and Grammatical Issues in Meaning-Text Theory. Amsterdam/Philadelphia: Benjamins, pp. 267-297.

Milićević, J. (2007b). La Paraphrase. Modélisation de la Paraphrase Langagière. Bern: Peter Lang, ISBN: 978-3-03911-197-8, 400p.

Miller, G.A.; Beckwith, R.; Fellbaum, C.; Gross, D.; Miller, K. (1993). Introduction to Wordnet: An Online Lexical Database. Technical Report, Princeton University.

Pang, B.; Knight, K.; Marcu, D. (2003). Syntax-based Alignment of Multiple Translations: Extracting Paraphrases and Generating New Sentences. In: Proceedings of the Human Language Technology Conference - HLT/NAACL, pp. 102-109.

Pardo, T.A.S.; Rino, L.H.M.; Nunes, M.G.V. (2003). GistSumm: A Summarization Tool Based on a New Extractive Method. In Proceedings of the $6^{\text {th }}$ Workshop on Computational Processing of the Portuguese Language - Written and Spoken, (Lecture Notes in Artificial Intelligence, 2721), pp. 210-218.

Pardo, T.A.S. (2005). GistSumm - GIST SUMMarizer: Extensões e Novas Funcionalidades. Série de Relatórios do NILC, NILC-TR-05-05, Universidade de São Paulo, 8p.

Pardo, T.A.S. (2006). SENTER: Um Segmentador Sentencial Automático para o Português do Brasil. Série de Relatórios Técnicos do NILC, NILC-TR-06-01, Universidade de São Paulo, 6p.

Pardo, T.A.S. \& Nunes, M.G.V. (2006). DiZer: An Automatic Discourse Analyzer for Brazilian Portuguese. In: Proceedings of the V Best MSc Dissertation/PhD Thesis Contest-CTDIA, 10p.

Pereira, D.B. \& Paraboni, I. (2007). A Language Modelling Tool for Statistical NLP. In: Anais do V Workshop em Tecnologia da Informação e da Linguagem HumanaTIL, pp. 1679-1688. 
Quirck, C.; Brockett, C.; Dolan, W. (2004). Monolingual Machine Translation for Paraphrase Generation. In: Proceedings of the Conference on Empirical Methods in Natural Language Processing - EMNLP, pp. 142-149.

Radev, D. \& Mckewon, K. (1998). Generating Natural Language Summaries from Multiple On-line Sources. Computational Linguistics, Vol 24, nº 3, pp. 469-500.

Radev, D.R. (2000). A Common Theory of Information Fusion from Multiple Text Sources, Step One: Cross-document Structure. In: Proceedings of the $1^{\text {st }}$ ACL Workshop on Discourse and Dialogue - SIGDIAL, pp. 74-83.

Radev, D.R.; Jing, H.; Stys, M.; Tam, D. (2004). Centroid-based Summarization of Multiple Documents. Information Processing and Management, Vol. 40, pp. 919-938.

Radev, D., Otterbacher, J., Zhang, Zhu. (2008). Cross-document Relationship Classification for Text Summarization.

Reiter, E. \& Dale, R. (2000). Building Natural Language Generation Systems. Cambridge University Press, Cambridge.

Salton, G. \& Allan, J. (1994). Text Retrieval Using the Vector Processing Model. In: Proceedings of the $3^{\text {rd }}$ Symposium on Document Analysis and Information Retrieval, pp. 9-22.

Sant'Anna, A.R. (2004). Paródia, Paráfrase \& CIA. Editora Ática, $7^{\mathrm{a}}$ edição, São Paulo-SP.

Scarton, C.E. \& Aluísio, S.M. (2009). Herança Automática das Relações de Hiperonímia para a Wordnet.Br. Série de Relatórios do NILC, NILC-TR-09-10, $47 \mathrm{p}$.

Sekine, S. (2005). Automatic Paraphrase Discovery Based on Context and Keywords between NE Pairs. In: Proceedings of the International Workshop on Paraphrasing - IWP, pp. 80-87.

Seno, E.R.M. \& Nunes, M.G.V. (2008a). Automatic Alignment of Common Information in Comparable Sentences of Portuguese. In: Anais do VI Workshop em Tecnologia da Informação e da Linguagem Humana - TIL, pp. 331-335.

Seno, E.R.M. \& Nunes, M.G.V. (2008b). Some Experiments on Clustering Similar Sentences of Texts in Brazilian Portuguese. In: Proceedings of the International Conference on Computational Processing of Portuguese Language - PROPOR (Lecture Notes in Artificial Intelligence, 5190), pp. 133-144. 
Seno, E.R.M. and Nunes, M.G.V. (2008c). SiSPI: A Short-Passage Clustering System. Série de Relatórios Técnicos do NILC, NILC-TR-08-01, Universidade de São Paulo, 17p.

Seno, E.R.M. \& Nunes, M.G.V. (2009a). Reconhecimento de Informações Comuns para a Fusão de Sentenças Comparáveis do Português. In: Revista Linguamática, $\mathrm{n}^{\circ}$ 1, pp.71-87.

Seno, E.R.M. \& Nunes, M.G.V. (2009b). Fusão Automática de Sentenças Similares em Português. In: Anais do VII Simpósio Brasileiro em Tecnologia da Informação e da Linguagem Humana - STIL, 8p.

Shen, S.; Radev, D. R.; Patel, A.; Erkan, G. (2006). Adding Syntax to Dynamic Programming for Aligning Comparable Texts for the Generation of Paraphrases. In: Proceedings of the International Conference on Computational Linguistics COLING, pp. 747-754.

Shinyama, Y. \& Sekine S. (2003). Paraphrase Acquisition for Information Extraction. In: Proceedings of the International Workshop on Paraphrasing: Paraphrase Aquisition and Applications - IWP at ACL, pp. 65-71.

Sparck-Jones, K. \& Galliers, J.R. (1998). Evaluating Natural Language Processing Systems: an Analysis and Review. Computational Linguistics, Vol 2, no 4, pp. 336-338.

Steinbach, M., Karypis, G., Kumar, V. (2000). A Comparison of Document Clustering Techniques. In: Proceedings of the International Conference on Knowledge Discovery \& Data Mining - KDD, pp. 1-2.

Van Rijsbergen, C.J. (1979). Information Retrieval. Butterworths, Massachusetts, $2^{\text {nd }}$ ed.

Wan, S.; Dras, M.; Dale, R.; Paris, C. (2005). Towards Statistical Paraphrase Generation: Preliminary Evaluations of Grammaticality. In: Proceedings of the $3^{\text {rd }}$ International Workshop on Paraphrasing - IWP, pp. 88-95.

Wainer, J. (2007). Métodos de Pesquisa Quantitativa e Qualitativa para a Ciência da Computação. Jornada de Atualização em Informática - JAI (XXVII Congresso da Sociedade Brasileira de Computação). Editora PUC-Rio, pp. 221-262. 


\section{Apêndice I - Regras de Parafraseamento}

O Quadro I-1 apresenta as regras de parafraseamento, juntamente com alguns exemplos extraídos do corpus de análise ${ }^{25}$ (onde ADJ: adjetivo; ADV: advérbio; DET: determinante; N: substantivo; NUM: numeral; PRP: preposição; PROP: nome próprio; PRON: pronome; REL: pronome relativo; V: verbo; ?: indica zero ou uma ocorrência; I: indica alternativa (operador $\mathrm{ou}$ ) e os números indicam as unidades similares).

Quadro I-1: Regras de parafraseamento

\begin{tabular}{|c|c|}
\hline REGRA & EXEMPLOS \\
\hline $\begin{array}{l}\text { R1. DET? N1 ADJ ; DET? N1 PROP? } \\
\text { PRP DET? (PROPIN) }\end{array}$ & $\begin{array}{l}\text { a capital russa ; a capital da Rússia } \\
\text { o mercado moscovita ; o mercado Cherkisov de } \\
\text { Moscou } \\
\text { a parte dianteira ; a parte da frente }\end{array}$ \\
\hline $\begin{array}{l}\text { R2. DET? (N1IPROP1) ; DET? N1 } \\
\text { PRP? DET? ADJ? (NIPROP1) }\end{array}$ & $\begin{array}{l}\text { um incêndio ; um incêndio de grandes proporções } \\
17 \mathrm{~h} 16 ; 17 \mathrm{~h} 16 \text { da terça-feira } \\
\text { prioridade ; prioridade do governo } \\
\text { a avenida ; a avenida Washington Luiz } \\
\text { segunda-feira ; manhã desta segunda-feira } \\
\text { Lula ; presidente Lula }\end{array}$ \\
\hline 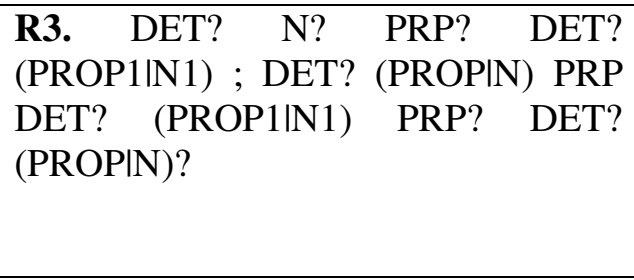 & $\begin{array}{l}\text { a direção da Câmara ; a Mesa Diretora da Câmara } \\
\text { a liderança do Grupo B ; a liderança do Grupo B } \\
\text { da Liga } \\
\text { a Airbus A320 ; a aeronave da TAM Airbus } \\
\text { A320 } \\
\text { a margem de erro ; a margem de erro da pesquisa }\end{array}$ \\
\hline $\begin{array}{l}\text { R4. DET? (PROPIN) ADJ? ADJ? } \\
\text { (PROP1) ; DET? (PROPIN) ADJ? } \\
\text { ADJ? (PROP1) }\end{array}$ & $\begin{array}{l}\text { o candidato Geraldo Alckmin ; o candidato } \\
\text { tucano Geraldo Alckmin } \\
\text { a agência oficial russa Intar-Tass ; a agência } \\
\text { Intar-Tass }\end{array}$ \\
\hline $\begin{array}{l}\text { R5. DET? PROP1 PRP N NUM? ; } \\
\text { DET? PROP1 }\end{array}$ & $\begin{array}{l}\text { a Liga Mundial de vôlei } 2006 \text {; a Liga Mundial- } \\
06\end{array}$ \\
\hline $\begin{array}{l}\text { R6. DET? N1 PRP (DETIN)? PROP1 } \\
\text {; DET? N1? PROP1 }\end{array}$ & $\begin{array}{l}\text { o programa de rádio "Café com o Presidente" ; } \\
\text { programa Café com o Presidente } \\
\text { as investigações da Operação Dominó ; a } \\
\text { Operação Dominó }\end{array}$ \\
\hline $\begin{array}{l}\text { R7. DET? ADJ? N1 PRP DET? N2 ; } \\
\text { DET? N1 PRP DET? N2; }\end{array}$ & $\begin{array}{l}\text { o bujão de gás ; o botijão de gás } \\
\text { um "verdadeiro canteiro de obras" ; um canteiro } \\
\text { de obras }\end{array}$ \\
\hline
\end{tabular}

\footnotetext{
${ }^{25}$ Algumas regras ocorreram apenas uma vez no corpus e, portanto, são ilustradas com um único exemplo.
} 
Quadro I-1: Regras de parafraseamento (continuação)

\begin{tabular}{|c|c|}
\hline $\begin{array}{l}\text { R8. ADV NUM1 N1? (ADJIV)?; } \\
\text { ADV? NUM1 N1? ADJ? }\end{array}$ & $\begin{array}{l}\text { cerca de } 500 \text { pessoas ; } 510 \text { pessoas } \\
\text { ao menos } 300 \text { policiais federais ; cerca de } 300 \\
\text { policiais } \\
\text { pelo menos sete ; sete } \\
\text { ao menos } 30 \text { parlamentares acusados ; } 30 \\
\text { acusados }\end{array}$ \\
\hline $\begin{array}{l}\text { R9. DET? PROP1 PROP? ; DET? } \\
\text { N? PRP? DET? PROP1 PRP? DET? } \\
\text { PROP }\end{array}$ & $\begin{array}{l}\text { Ray Jayawardhana ; Ray Jayawardhana, da } \\
\text { Universidade de Toronto } \\
\text { Blacksburg, Estados Unidos ; Blacksburg } \\
\text { (Virginia) } \\
\text { Valentin D. Ivanov ; Valentin Ivanov, do } \\
\text { Observatório Europeu Austral } \\
\text { PCC; PCC (Primeiro Comando da Capital) } \\
\text { a Tampere (FIN) ; a cidade de Tampere, na } \\
\text { Finlândia }\end{array}$ \\
\hline R10. DET? N1 ; DET? N1 ADJ & $\begin{array}{l}\text { o grupo ; o grupo criminoso } \\
\text { acordo ; acordo financeiro }\end{array}$ \\
\hline $\begin{array}{l}\text { R11. DET? N1 ADJ1 PRP DET? } \\
\text { PRON N? ; DET? N1 ADJ1 PRP } \\
\text { DET? PRON N }\end{array}$ & $\begin{array}{l}\text { a parte traseira de outro ; parte traseira da outra } \\
\text { locomotiva }\end{array}$ \\
\hline $\begin{array}{l}\text { R12. PRON N1 ; N1 PRP DET? } \\
\text { PROP }\end{array}$ & seu paradeiro ; paradeiro de Abadia \\
\hline $\begin{array}{l}\text { R13. NUM1 N PRP DET? N1 ; } \\
\text { NUM1 N PRP DET? N PRP DET? } \\
\text { N1 }\end{array}$ & $44 \%$ dos votos ; $44 \%$ das intenções de voto \\
\hline R14. NUM1 N1 ; NUM1 ADV N1 & IS Gincicintes ing \\
\hline R15. V1 PRP V; V1 & ram a obter ; alcançaram \\
\hline R16. V1 V; V1 & istrada ; aconteceu \\
\hline R17. ADJ N1 ; N1 ADV ADJ & or campanha; \\
\hline $\begin{array}{l}\text { R18. ADV? NUM? N REL PRON } \\
\text { V N? ; ADV? NUM? N REL V V V } \\
\text { N? }\end{array}$ & $\begin{array}{l}\text { mais de } 500 \text { pessoas que se dizem vitimas ; mais } \\
\text { de } 500 \text { pessoas que alegam ter sido vitimas }\end{array}$ \\
\hline $\begin{array}{l}\text { R19. N1 ADJ? REL V V V PRP } \\
\text { DET N2 ; N1 ADJ? PRP DET N1 }\end{array}$ & $\begin{array}{l}\text { estudos finais que estão sendo realizados pela } \\
\text { Infraero ; estudos finais da Infraero }\end{array}$ \\
\hline $\begin{array}{l}\text { R20. DET N1 DET DET N ; DET } \\
\text { N1 REL ADV? PRON? V PRP } \\
\text { DET N PRP? DET? N? }\end{array}$ & $\begin{array}{l}\text { vários cadáveres dentro dos trens ; vários } \\
\text { cadáveres que ainda se encontram no interior }\end{array}$ \\
\hline $\begin{array}{l}\text { R21. N ADJ PROP1 ; PROP1 N } \\
\text { PRP DET? N? PROP }\end{array}$ & $\begin{array}{l}\text { serviço online Science Express } ; \text { Science } \\
\text { Express, site da revista Science }\end{array}$ \\
\hline
\end{tabular}




\section{Anexo A - Coleção de Textos Comparáveis}

Os Quadros A1-A4 apresentam quatros textos sobre a explosão de uma bomba em um mercado de Moscou. Esses textos compõem uma das 53 coleções de textos comparáveis do corpus descrito no Capítulo 4.

\section{A1: Texto 1}

Nove pessoas morreram, três delas crianças, e outras 25 ficaram feridas nesta segunda-feira em uma explosão ocorrida em um mercado de Moscou, informou a polícia.

A explosão, supostamente causada por vazamento de um botijão de gás, foi registrada por volta das $10 \mathrm{~h} 40$ ( $3 \mathrm{~h} 40$ de Brasília) no setor denominado Evrazia do mercado Cherkizov, um dos maiores shoppings da capital da Rússia.

A maioria dos feridos, entre os quais há quatro com menos de 18 anos, foi hospitalizada.

Cerca de dez de carros de bombeiros e mais de uma dezena de ambulâncias foram enviadas ao local, que foi isolado pela polícia.

A procuradoria de Moscou anunciou a criação de um grupo especial para investigar o acidente.

Fontes do Ministério do Interior da Rússia citadas pela agência Interfax descartaram a possibilidade de a explosão em Cherkizov ter sido um ataque terrorista.

\section{A2: Texto 2}

MOSCOU (Rússia) - Nove pessoas morreram, sendo três crianças, e outras 25 ficaram feridas nesta segunda-feira em uma explosão registrada em um mercado moscovita, informou a Polícia de Moscou. A explosão, cujas causas ainda são desconhecidas, aconteceu às 10h40 (3h40 em Brasília) no mercado Cherkizov, localizado no nordeste da capital russa. A maioria dos feridos, entre os quais há quatro menores, foi hospitalizada.

A explosão - supostamente de um bujão de gás, segundo versões policiais preliminares aconteceu no setor denominado "Evrazia" do mercado Cherkizov, um dos maiores shoppings da capital russa. Cerca de dez carros de bombeiros e mais de uma dezena de ambulâncias foram enviadas ao local, que foi isolado pela Polícia.

A procuradoria de Moscou anunciou a criação de um grupo especial para investigar o acidente. Fontes do Ministério do Interior da Rússia citadas pela agência "Interfax" descartaram a possibilidade de a explosão em Cherkizov ter sido um ataque terrorista. 
A3: Texto 3

Dez pessoas morreram, duas delas crianças, e outras 39 ficaram feridas nesta segunda-feira em uma explosão de uma bomba no mercado de Cherkizov, um dos maiores de Moscou, em um ataque que as autoridades dizem acreditar ser um acerto de contas.

Nos últimos sete anos, quase cem pessoas morreram em oito ataques com explosivos em mercados russos, envolvendo atentados terroristas e ajustes de contas entre criminosos. $\mathrm{O}$ mais sangrento aconteceu em 19 de março de 1999, quando terroristas detonaram uma bomba no mercado Central de Vladikavkaz, capital da república russa da Ossétia do Norte, vizinha da Tchetchênia. $\mathrm{O}$ ataque deixou 52 mortos e cerca de 200 feridos.

"Concorrência comercial", estas foram as palavras usadas pelo promotor de Moscou, Yuri Siomin, para destacar a provável causa da explosão que provocou morte e destruição em um dos mercados populares mais movimentados da cidade.

A bomba, com uma carga de entre $1 \mathrm{~kg}$ e 1,5 kg de dinamite, explodiu às $10 \mathrm{~h} 40$ (3h40 de Brasília) e destruiu mais de 200 metros quadrados de construções leves em Evrazia, um dos setores no qual é dividido o mercado de Cherkizov, no nordeste de Moscou.

Siomin declarou à agência oficial Itar-Tass que a bomba explodiu entre dois contêineres, perto de um botijão de gás, em um pavilhão comercial fechado.

Em um primeiro momento, fontes policiais disseram que a explosão tinha ocorrido no interior de uma cafeteria e testemunhas disseram que viram quanto dois desconhecidos deixaram uma bolsa e saíram correndo do estabelecimento.

"Não vemos nada que permita dizer que um atentado terrorista foi cometido no mercado de Izmailovo (região onde fica o centro comercial)", disse Siomin à Interfax.

A Promotoria de Moscou abriu um processo por assassinato, embora tenha comunicado que todas as possíveis causas da explosão serão investigadas, incluindo um ataque terrorista.

"Estamos diante de um choque de grandes interesses comerciais ou perante um acerto de contas banal entre criminosos", afirmou Siomin.

Segundo o centro de emergências médicas da capital russa, oito pessoas, entre elas duas crianças, morreram na hora e dois adultos que foram levados ao hospital número 36 de Moscou não resistiram.

Outras 39 pessoas feridas foram atendidas em quatro centros médicos da capital russa.

Inicialmente, a polícia divulgou a versão de que foi um acidente causado pela explosão de um bujão de gás. No entanto, pouco depois, o primeiro vice-prefeito de Moscou, Vladimir Resin, descartou essa hipótese. "Isto não foi um acidente, foi proposital", disse Resin à agência Itar-Tass.

A tragédia em Evrazia não impediu que outros setores do mercado de Cherkizov continuassem funcionando. 


\section{A4: Texto 4}

MOSCOU (Rússia) - Uma explosão causou nesta segunda-feira a morte de dez pessoas e deixou cerca de 30 feridas no mercado Cherkizov de Moscou. De acordo com a polícia da capital russa, uma bomba causou o incidente. As autoridades policiais de Moscou assinalaram que no recinto do mercado, situado no Nordeste da cidade, foi detonada uma carga explosiva.

- Por causa da explosão, morreram dez pessoas e 31 foram hospitalizadas - declarou à agência "Interfax" o alto funcionário de Moscou, Vladimir Resin. Anteriormente, a Polícia havia informado sobre nove mortos, sendo três deles crianças, e 25 feridos. Pouco depois da detonação, ocorrida às $10 \mathrm{~h} 40$ ( $3 \mathrm{~h} 40 \mathrm{em}$ Brasília), fontes da polícia moscovita adiantaram que ela teria acontecido provavelmente por causa da explosão acidental de um bujão de gás.

- Isto não foi um acidente, foi proposital - disse Resin, citado pela agência oficial russa "Itar-Tass".

A Promotoria de Moscou começou um processo penal por assassinato, não por terrorismo, o que indica que as autoridades têm uma tendência a acreditar que a explosão possa ter sido um acerto de contas entre delinqüentes.

- No curso da investigação, serão examinadas todas as versões, incluindo a de um ataque terrorista - informou o centro de imprensa da Promotoria de Moscou.

A bomba detonou no interior de uma cafeteria localizada no setor denominado "Evrazia" do mercado Cherkizov. 


\section{Anexo B - Exemplo de Análise Produzida pelo Parser Palavras}

Os Quadros B.1 e B.2 apresentam, respectivamente, a análise sintática e a análise de dependência produzida pelo parser PALAVRAS para a sentença "Ladrões levaram duas obras de Pablo Picasso e Cândido Portinari do Museu de Arte de São Paulo (MASP)." (extraídas do corpus de trabalho). As árvores de dependência no Ziper são construídas a partir dos formatos de saída TigerXML (Quadro B.1) e Visl (Quadro B.2), conforme descrito em Seno \& Nunes (2009a).

\section{Quadro B.1: Análise sintática obtida com o parser Palavras no formato TigerXML}

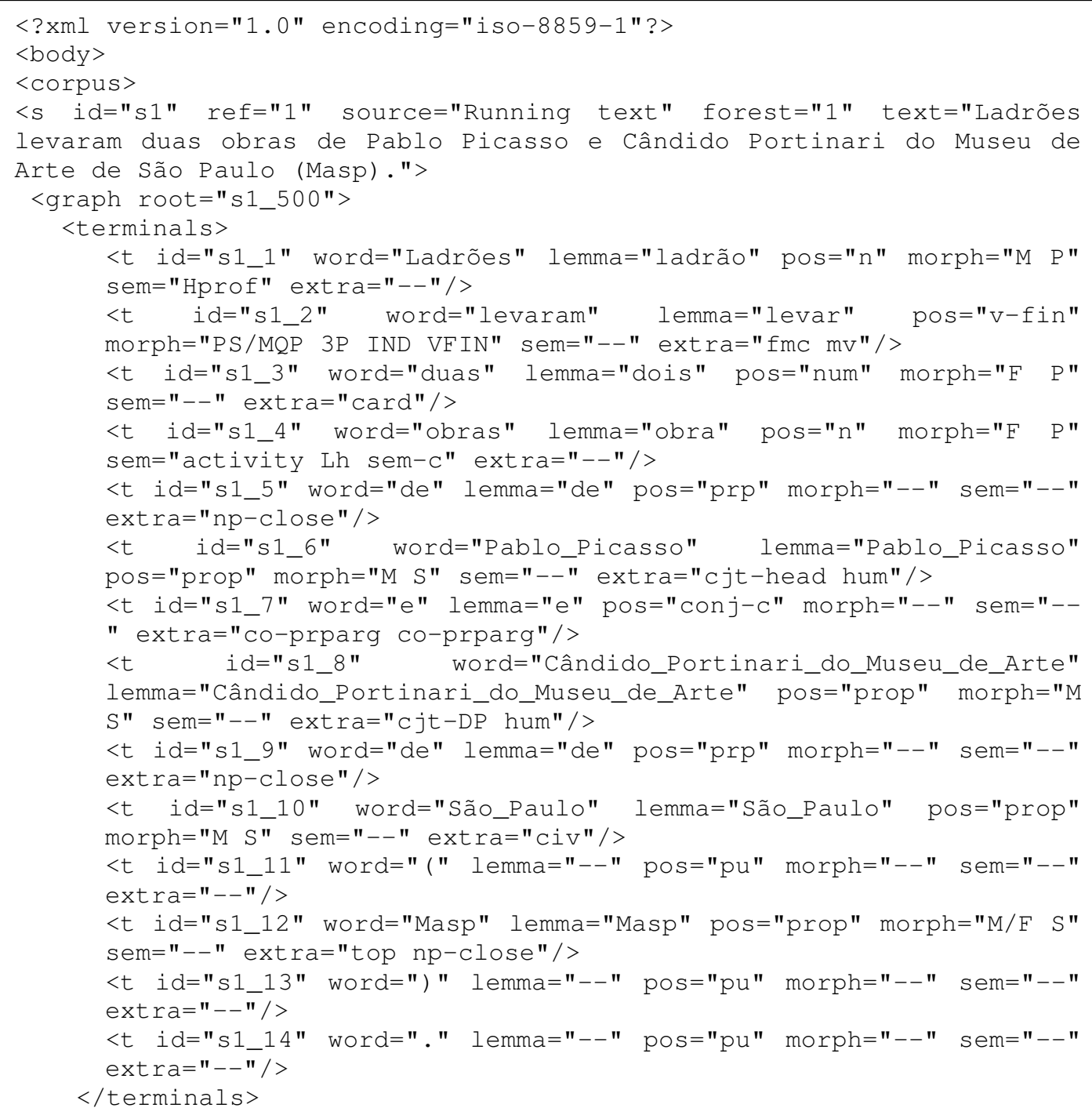


Quadro B.1: Análise sintática obtida com o parser Palavras no formato TigerXML(continuação)

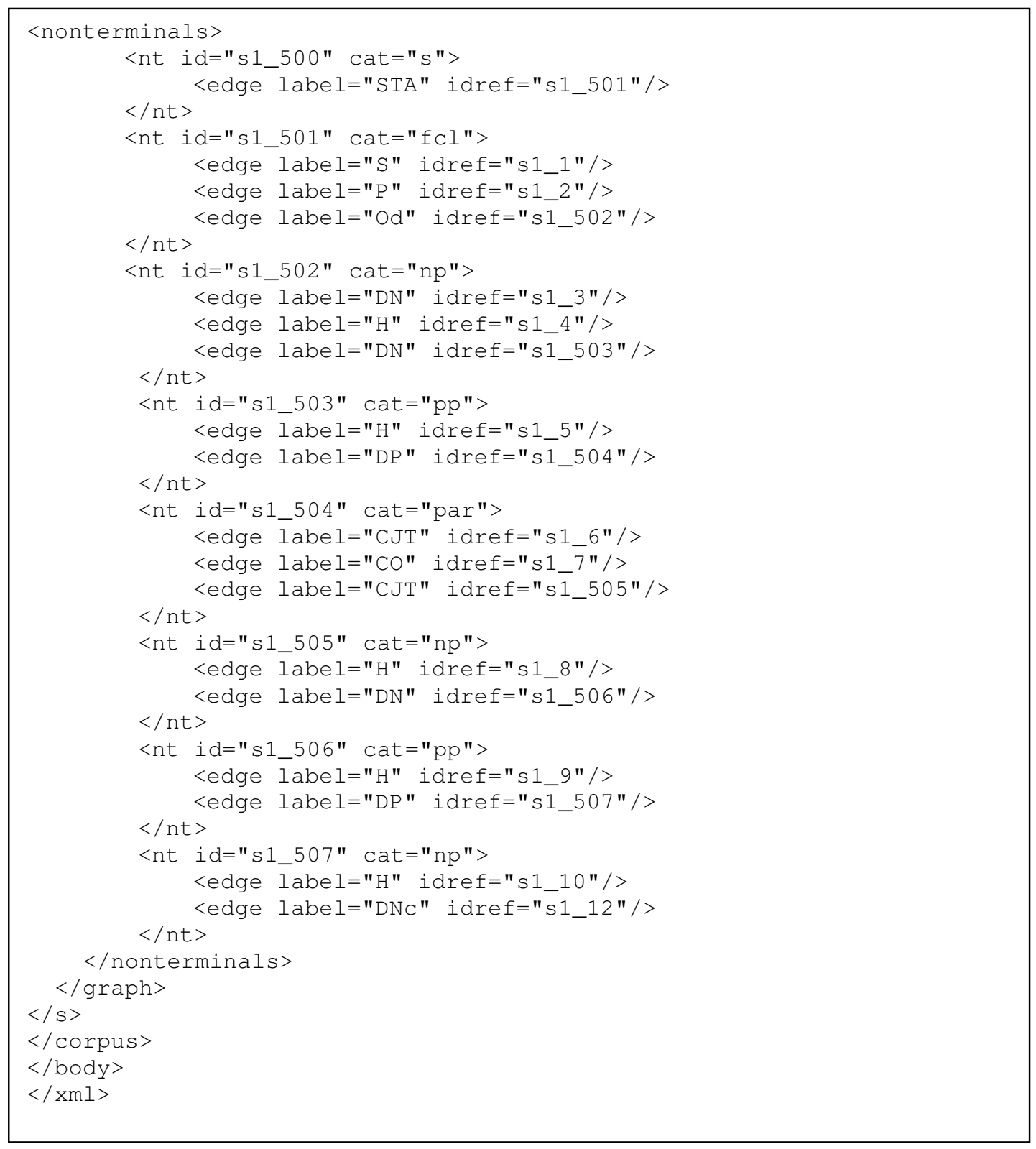


Quadro B.2: Análise de dependência sintática obtida com o parser Palavras no formato Visl

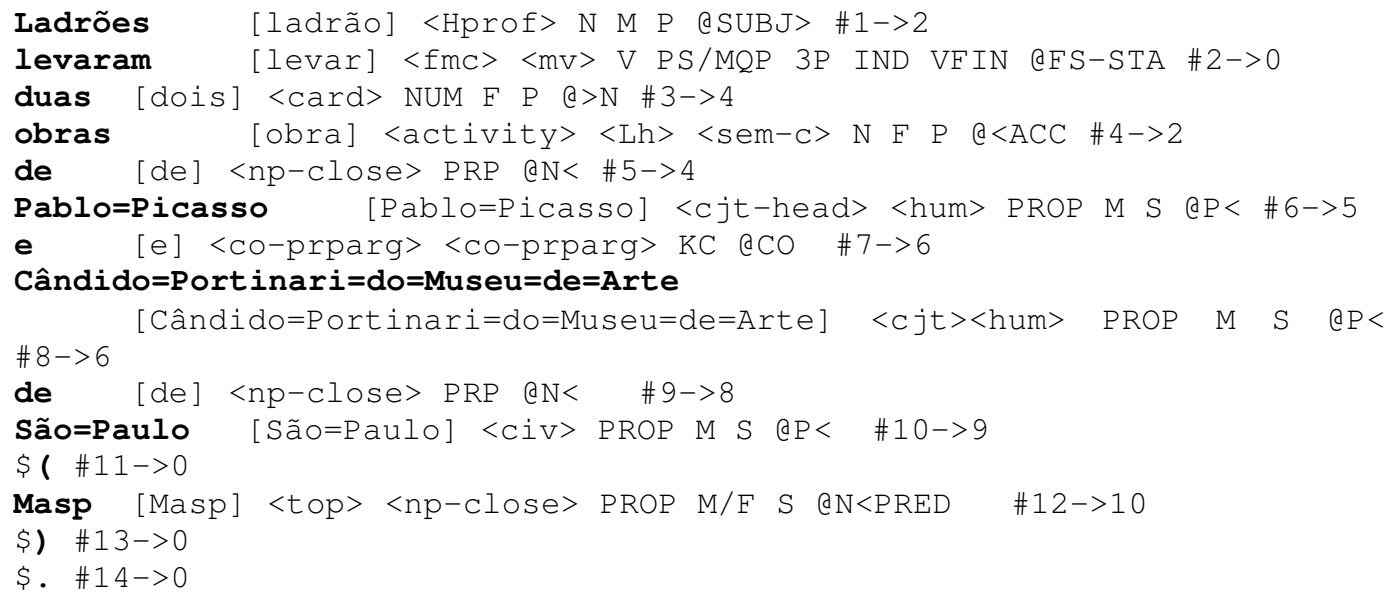

